Water Resources Infrastructure

\title{
Literature Review - Vegetation on Levees
}

Maureen K. Corcoran, Donald H. Gray, David S. Biedenharn, Charlie D. Little, James R. Leech, Freddie Pinkard, Pamela Bailey, and Landris T. Lee

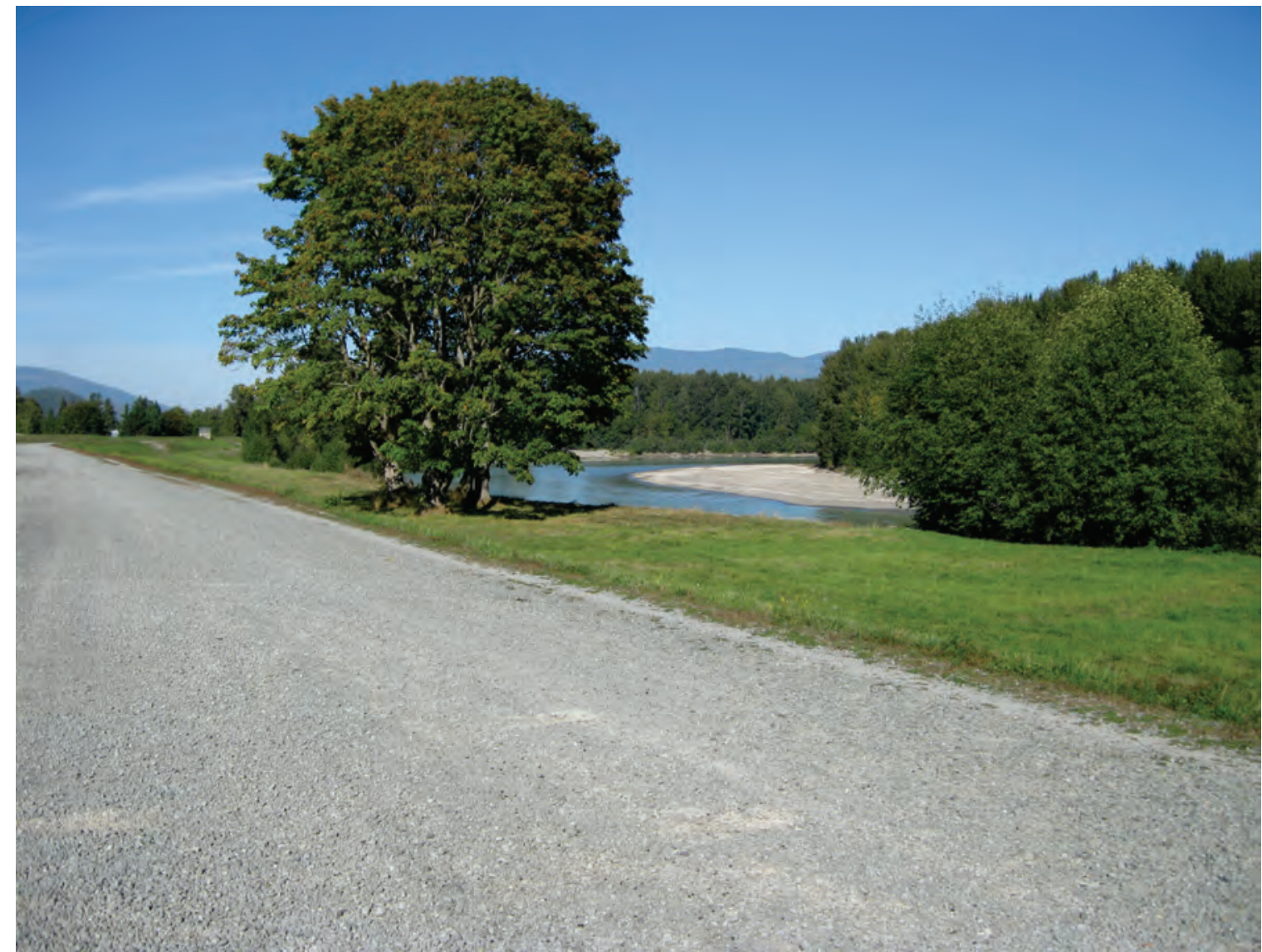




\section{Literature Review - Vegetation on Levees}

Maureen K. Corcoran and Landris T. Lee

Geotechnical and Structures Laboratory

U.S. Army Engineer Research and Development Center 3909 Halls Ferry Road

Vicksburg, MS 39180-6199

James R. Leech and Charles D. Little

Coastal and Hydraulics Laboratory

U.S. Army Engineer Research and Development Center 3909 Halls Ferry Road

Vicksburg, MS 39180-6199

Pamela Bailey

Environmental Laboratory

U.S. Army Engineer Research and Development Center 3909 Halls Ferry Road

Vicksburg, MS 39180-6199

Freddie Pinkard

U.S. Army Engineer District, Vicksburg

4155 Clay Street

Vicksburg, MS 39183

Donald H. Gray

University of Michigan

306 South State Street

Ann Arbor, MI 48104

David S. Biedenharn

Biedenharn Group, LLC

3303 Woodland Place

Vicksburg, MS 39180

Final report

Approved for public release; distribution is unlimited.

Prepared for U.S. Army Corps of Engineers

Washington, DC 20314-1000 


\begin{abstract}
The U.S. Army Engineer Research and Development Center conducted an extensive literature review of topics related to vegetation on levees. An objective of this compilation was to better assess if woody vegetation compromises levee integrity. Other objectives were to identify data gaps within the compiled documents on the subject of studying the effects of woody vegetation on levees and to use this information as a foundation for future research.
\end{abstract}

In this literature review, vegetation types were identified as woody (i.e., trees, bushes, and shrubbery) and non-woody (brush, shrubs, herbs, and grasses). Vegetation species differ in root system, trunk diameter, and growth pattern. Therefore, the vegetation species documented in the research publications were identified in this literature review.

Understanding these differences and the interaction of each vegetation species with the levee soil structure is necessary for interpreting the effects of levee vegetation.

More than 200 documents were reviewed under the following categories: journal articles, federal and state government documents, books, newspaper/Internet articles, proceedings/ briefings, reviews/ annual reports/ workshops, dissertations/theses, and international guidance. Of these, 61 addressed some aspect of woody vegetation on levees. However, this number includes guidance documents and conference briefings. There are very few research publications that focus specifically on the complex interaction of woody vegetation and a soil matrix within an engineered levee.

DISCLAIMER: The contents of this report are not to be used for advertising, publication, or promotional purposes. Citation of trade names does not constitute an official endorsement or approval of the use of such commercial products. All product names and trademarks cited are the property of their respective owners. The findings of this report are not to be construed as an official Department of the Army position unless so designated by other authorized documents. 


\section{Contents}

Preface

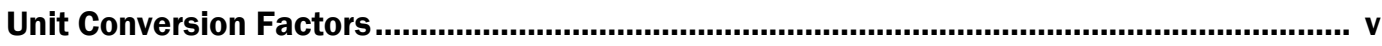

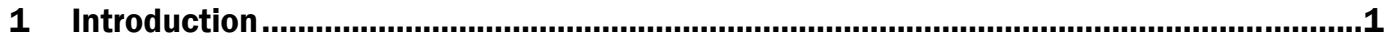

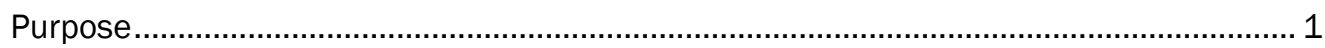

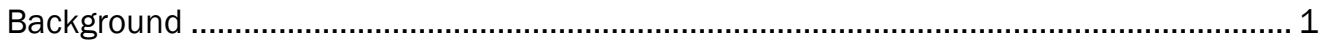

Format of literature review .................................................................................. 2

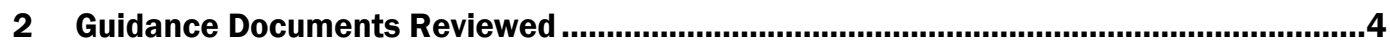

Federal guidance documents, manuals, and practices ..................................................... 4

International guidance documents and manuals ........................................................... 6

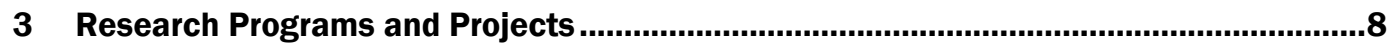

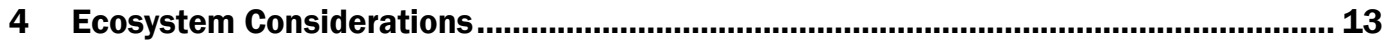

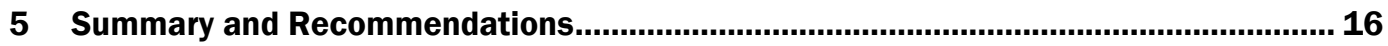

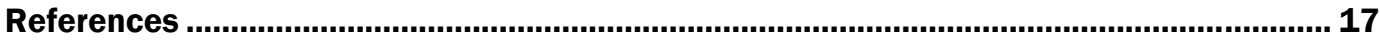

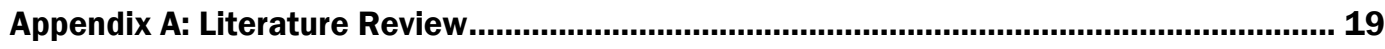

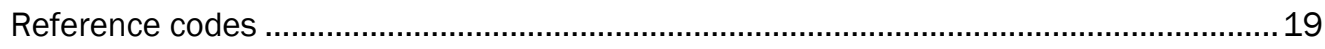

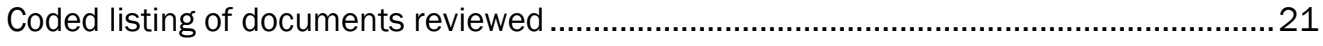

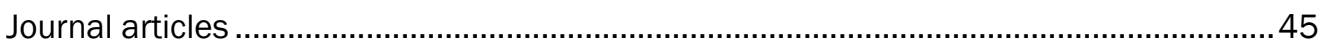

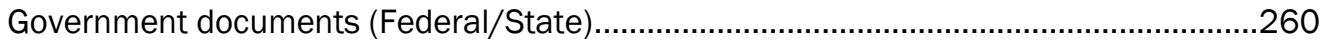

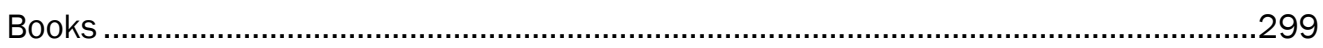

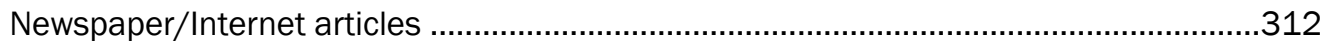

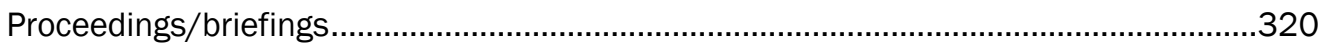

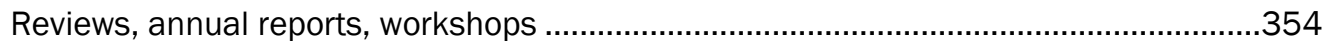

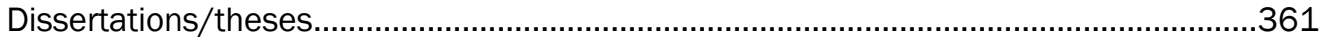

International guidance ..........................................................................................362

\section{Report Documentation Page}




\section{Preface}

The literature review summarized herein was conducted under sponsorship of the Headquarters, U.S. Army Corps of Engineers (USACE), as part of the Water Resources Infrastructure (WRI) research area.

The research was coordinated by personnel of the U.S. Army Engineer Research and Development Center (ERDC), Geotechnical and Structures Laboratory (GSL), Vicksburg, MS. This report was prepared by Dr. Maureen K. Corcoran of the GSL Office of Technical Directors; Landris T. Lee, GSL; Charles D. Little, ERDC Coastal and Hydraulics Laboratory; Pamela Bailey, ERDC Environmental Laboratory; Freddie Pinkard, Vicksburg District, USACE; Dr. Donald H. Gray, University of Michigan, and David S. Biedenharn, Biedenharn Group, LLC.

Direction was provided by Dr. Corcoran, Assistant Technical Director, WRI; Dr. Michael K. Sharp, ERDC Technical Director and Program Manager for WRI; Dr. William P. Grogan, Deputy Director, GSL; and Dr. David W. Pittman, Director, GSL.

COL Kevin J . Wilson was Commander and Executive Director of ERDC. Dr. J effery P. Holland was Director. 


\section{Unit Conversion Factors}

\begin{tabular}{|l|c|l|}
\hline Multiply & By & To Obtain \\
\hline degrees (angle) & 0.01745329 & radians \\
\hline feet & 0.3048 & meters \\
\hline hectares & $1.0 \mathrm{E}+04$ & square meters \\
\hline inches & 0.0254 & meters \\
\hline miles (U.S. statute) & $1,609.347$ & meters \\
\hline pounds (force) per square inch & 6.894757 & kilopascals \\
\hline pounds (mass) & 0.45359237 & kilograms \\
\hline square feet & 0.09290304 & square meters \\
\hline square miles & $2.589998 \mathrm{E}+06$ & square meters \\
\hline
\end{tabular}




\section{Introduction}

\section{Purpose}

At the request of Headquarters, U.S. Army Corps of Engineers (HQUSACE), the U.S. Army Engineer Research and Development Center (ERDC) conducted an extensive literature review of topics related to levee vegetation. An objective of this compilation was to better assess if woody vegetation compromises levee integrity. Other objectives were to identify data gaps within the compiled documents on the effects of woody vegetation on levees and to use this information as a foundation for future research.

In this literature review, vegetation is identified as woody (i.e., trees, bushes, and shrubbery) and non-woody (brush, shrubs, herbs, and grasses). Each vegetation species differs in root system, trunk diameter, and growth pattern; therefore the vegetation species documented in the research publications were identified in this literature review.

Understanding these differences and the interaction of each vegetation species with the levee soil structure is necessary for interpreting the effects of levee vegetation.

\section{Background}

A levee is defined by USACE (2000) as an embankment whose primary purpose is to furnish flood protection from seasonal high water and, which is therefore subject to water loading for periods of only a few days or weeks a year. As such, the function of levees is usually flood control. Although the levee function is ultimately for flood defense, additional secondary benefits, such as providing recreation areas and aquatic and terrestrial habitats may result from the existence of levees and accompanying vegetation.

Material for levee construction is usually excavated from borrow pits on the riverside of the proposed levee. Given the variety of geologic deposits, soil properties, and physiographic settings, the assimilation of data similarities from literature was difficult. For example, levees along the Mississippi River differ in size and material from those levees constructed along the Sacramento River. 
On 29 Aug 2005 and 2 Sept 2005, Hurricane Katrina and Hurricane Rita, respectively, wrecked havoc on both the Mississippi and Louisiana Gulf Coast. The destruction produced from these hurricanes brought levee safety and flood risk management to the forefront of public awareness. Because of this, the National Levee Safety Act of 2007 under the Water Resources Development Act authorized USACE to develop a strategic implementation plan, which required the inventory and inspection of levees. After a nationwide inspection of levee systems in 2007, many deficiencies were attributed to woody vegetation located within 15-ft of the levee toe as required by USACE guidance (USACE 2000). The levee systems included both federally owned and maintained, and locally built and maintained according to USACE standards.

The following discussion highlights only a small portion of the reviewed documents and is meant to summarize topics that are relevant to future research on the effects of woody vegetation on levees. Other equally important documents are included in the appendix of this report.

\section{Format of literature review}

When researching the topic of levee vegetation, it was soon recognized that documents outside this realm could offer an insight into the complexity of soil erosion and vegetation. This report provides a brief description of the literature deemed important by the scientists and engineers conducting this review to the understanding of how vegetation affects a levee system. However, omission of literature is not an attempt to overlook valuable input, but rather a reflection of time constraints. The gathering of anecdotal data was outside the scope of work defined for this review.

The review encompassed journal articles; federal/ state government documents; books; newspaper/Internet articles; proceedings/ briefings; reviews/ annual reports/ workshops; dissertations/ theses; and international guidance. Peer-reviewed documents are noted as such under the category listing. Only documents written in the English language or those translated to English were reviewed.

Instead of the traditional method of a literature review that includes only an annotated bibliography, this review identified research objectives, study location, vegetation, soil properties, observations, and recommendations as defined by the author or authors of each document. Appendix A is a listing of each reviewed document. 
This literature review format catalogues the documents by a coding system, which is listed in Appendix A. A code beside each reference differentiates these documents from those specific to levee vegetation. Of the documents reviewed, 61 were coded LEVVEG, signifying some link between vegetation and levees. However, most of these did not deal directly with vegetation actually on the levee. For example, Dwyer et al. (1997) provides an excellent study of the association between woody river corridors and levee stability, but the issue of woody vegetation on levees is not the focus of their research. 


\section{Guidance Documents Reviewed}

\section{Federal guidance documents, manuals, and practices}

Federal and state agencies provide guidance documents to direct the procedure of levee maintenance and inspection. Within these documents, the issue of vegetation on levees is addressed. It is important to note, however, that some of these guidance documents and policies are based on evaluation of embankment dams and are not always specific to levees.

USACE guidance for vegetation falls under the Rehabilitation and Inspection Program in three documents: Engineer Manual (EM) 1110-21205, Environmental Engineering and Local Flood Control Channels (USACE 1989); EM 1110-2-301, Guidelines for Landscape Planting at Floodwalls, Levees, and Embankment Dams (USACE 2000); and Engineer Regulation 500-1-1, Emergency Employment of Army and Other Resources and Civil Emergency Management Program (USACE 2001). The USACE (2000) guidance was updated and published as Engineer Technical Letter (TL) 1110-2-571, Guidelines for Landscape Planting and Vegetation Management at Levees, Floodwalls, Embankment Dams, and Appurtenant Structures (USACE 2009).

Nolan (1981) reviewed and summarized the USACE guidance in a letter dated 10 Dec 1954 from the Division of Water Resources to the District Engineer, USACE, Sacramento District. An excerpt of his summary follows:

The assumption that the trees along the banks of the Sacramento River have provided a stabilizing effect is contrary to the experience of the engineers in the Division of Water Resources and others familiar with the conditions along the Sacramento River. Most severe slip-outs in levees of the Sacramento River can be directly attributed to the presence of large trees, which place a superimposed load on the relatively unstable embankment, in excess of the ability of the levee material to resist when saturated.

As noted by Shields et al. (1990), USACE standards were justified by the absence of data that would clearly define the relationship between the properties of vegetation on levees and the structural integrity. 
The Federal Emergency Management Agency (FEMA) relays its stance on the impact of vegetation on earthen embankment dams through two guidance documents: Dam Owner's Guide to Plant Impact on Earthen Dams (FEMA L-263) and Technical Manual for Dam Owners: Impacts of Plants on Earthen Dams (FEMA 534).

In FEMA L-263, it was noted that tree roots do not stabilize soil masses, but instead loosen embankment soils and create seepage paths. This document also pointed out that dam inspection is hindered by problem vegetation in that heavy vegetation limits access to critical inspection areas, dense ground cover obscures dam defects, and dense ground cover obscures animal burrows, which can undermine dam integrity.

In FEMA 534, the agency stated that problem vegetation can cause a cascade of adverse effects that undermine the integrity of earthen dams. Specifically, erosive conditions, adverse hydraulic effects, and obscured dam inspections can result from problem vegetation on earthen dams and can lead to maintenance difficulties and potential dam failure.

In a technical evaluation of FEMA 534, Gray (2007) noted serious flaws in this guidance document. One such flaw is that the document characterizes earthen dams and levees as similar structures; however, as Gray noted, they differ significantly in terms of their characteristics, function, and purpose.

The U.S. Bureau of Reclamation (USBR) guidelines regarding removal of vegetation from dams and other water resources structures are considered as guides, not policy. The USBR publication Water Operation and Maintenance Bulletin No. 150 (USBR 1989) stated should trees and/ or other significant vegetation become established, proper operation and maintenance of earth embankment dams, dikes, and conveyance features may require their discriminate removal. The examiners should use these guidelines along with their experience and professional judgment to evaluate the need for removal of such established growth. The primary reasons for establishing guidelines are listed in USBR (1989) as follows:

1. To allow proper surveillance and inspection of the structures and adjacent areas for seepage, cracking, sinkholes, settlement, deflection, and other signs of distress. 
2. To allow adequate access for normal and emergency operation and maintenance activities.

3. To prevent damage to structures due to root growth, such as shortened seepage paths through embankments; voids in embankments from decayed roots or toppled trees; expansion of cracks or joints in concrete walls, canal lining, or pipes; and plugging of perforated or open-jointed drainage pipes.

4. To discourageanimal/rodent activity (by eliminating their food source and habitat), thereby preventing voids within embankments and possible shortened seepage paths.

5. To allow adequate flow-carrying capability of water conveyance channels (for example, spillway inlet and outlet channels; open channels; laterals; and drains).

General guidelines from the California Reclamation Board (1967) take into account the benefits of vegetation without reducing flood protection that levees provide surrounding communities. The guidance stated that vegetation must be maintained in a controlled manner to ensure that it does not compromise the levee integrity or interfere with levee inspection, maintenance, operation, or flood-fight activities.

\section{International guidance documents and manuals}

Several countries other than the United States have guidance addressing levee inspection and maintenance aspects of river management. While the focus of the guidance is not levee vegetation, some information pertaining to vegetation control on levees is available from the guidance documents. For this review, guidance from J apan, the United Kingdom, and the Netherlands will be discussed.

J apan published the Manual for River Works in Japan (1997) for planning purposes. In Section 5.2 (Afforestation of Rivers) of the report, the following excerpt explains the stance of J apan on levee vegetation:

Previously, the afforestation of dikes and riverbanks was prohibited owing to the consideration of its adverse effects on river control facilities, but recently afforestation of riverbanks, etc., has come to be allowed from the viewpoints of the improvement of river environment and planting policies in cities - as long as the afforestation will not obstruct river control measures. 
The manual noted that, for rivers with no high water channel that can be planted with trees, there are no plans for improving the river environment. The manual also restricts the type and position of tree planting by stating:

When trees are planted along the river control road on the riverbank, the necessary control road width shall be secured, and when trees are planted on the dike, the space for afforestation and the depth for root spreading shall be secured outside of the stipulated cross section of the dike.

The manual also mentioned a more detailed draft report, Standard for Afforestation of Riverbanks, specific to the vegetation issue. However, the document could not be obtained for this review.

The Environmental Options (EOs) for Flood Defence Maintenance Works published by the Environment Agency (2003) described the issue of levee vegetation control in the United Kingdom. The Environment Agency is the leading public body protecting and improving the environment in England and Wales. The EOs consider the ecosystem in the management of vegetation. For example, under the Tree and Bush Management EO, all trees and bushes are removed from raised flood embankments, but before and during work, trained persons should look for potential bat roosts and otter holts that would be affected by the work.

The Dutch Guidelines on Dike Protection (Pilarczyk 1987) addressed grass on dikes as a protective mechanism for soil stability. The species of grass was not mentioned, but flume studies on the effects of wave action on a dike with a grass mat concluded that holes previously dug in the grass mat were considerably enlarged from wave action, but the residual strength of a dike was such that its collapse was far from imminent. 


\section{Research Programs and Projects}

During the 1980s and 1990s, USACE published a series of reports and fact sheets focusing on levee embankments under the Repair, Evaluation, Maintenance, and Rehabilitation (REMR) Research Program. Of these documents, three contain information relevant to levee vegetation: REMR Technical Report REMR-EI-5, The Effects of Vegetation on the Structural Integrity of Sandy Levees (Gray et al. 1991), and REMR Technical Notes (TN) EI-M-1.3, Vegetation and the Structural Integrity of Levees: Results of Field Investigations, and EI-M-1.4, Issues Regarding Vegetation Management on Levee Embankments.

The purpose of REMR TN EI-M-1.3 was to present the preliminary results of a field study of effects of vegetation on a Sacramento River levee. The TN discussed the exception to USACE guidelines on levee vegetation that allows taller or woody vegetation on overbuilt levee sections only. The TN also mentioned that before revising the standards, additional knowledge must be developed regarding vegetal components of the geotechnical system. The research for this TN involved studying the amount and distribution of root material. This information was then used to examine slope stability and seepage through the levee under conditions of actual duration of inundation. In REMR TN EI-M-1.4, the authors realized that vegetation management on levees is a complex issue and few data exist on the influence of vegetation on the structural integrity of levees. Two of the authors of the REMR report, Dr. Donald Gray and Dr. Douglas Shields, published their findings in peer-reviewed journals, some prior to the publication of the REMR series.

Nunnally et al. (1987) provided an overview of current issues in the management of woody vegetation on levee embankments, concluding that site-specific management of levee vegetation allows for multi-use of levees without decreasing their structural integrity. Shields (1991) and Shields et al. (1990) discussed the justification for USACE standards for woody vegetation on rock revetments such as those protecting levees along the Sacramento River. Gray et al. (1991) studied the effects of woody vegetation on the structural integrity of sandy levees and stated that engineering guidance must be developed to account for vegetal components of the geotechnical system. 
Gray et al. (1991) investigated the effects of different vegetation types on sandy levees along the Sacramento River. The results from this research found that in situ shear strength measurements showed that roots increased soil shear strength and slope stability analyses indicated larger vegetation made levees more secure. Shields and Gray (1992) pointed out, however, that earlier data collected by Gray et al. (1991) were not adequate to assess vegetal effects on seepage and piping potential and also noted that inspection issues were not addressed. Shields and Gray (1992) described the use of field data and slope stability analyses from a $10-\mathrm{km}$ segment of a channel levee on the Sacramento River near Elkhorn, CA, to conclude that allowing woody shrubs and small trees on levees would provide environmental benefits and would enhance structural integrity without the hazards associated with large trees, such as windthrowing.

In response to the 1993 Flood in the Upper Mississippi River Basin, the White House formed the Scientific Assessment and Strategy Team (SAST) to evaluate the cause of the flood, evaluate current floodplain management techniques, and recommend changes in federal policy to reduce risk from flood events and provide environmental enhancement on floodplains and associated watersheds. The SAST was composed of an interdisciplinary team of senior scientists and engineers from the Department of Agriculture (Natural Resources Conservation Service), the Department of Defense (U.S. Army Corps of Engineers), Department of the Interior (U.S. Fish and Wildlife Service and the U.S. Geological Survey), the Department of Homeland Security (FEMA), and the Environmental Protection Agency. The SAST did not address the issue of vegetation on the levee, but rather referred to trees along the floodplain adjacent to the river and the effect of vegetation (specifically trees and brush) on a river stage.

In May 2006, the USACE established the National Flood Risk Management Program for the purpose of integrating and synchronizing USACE flood risk management programs and activities, both internally and with counterpart activities of FEMA, other federal agencies, state organizations, and regional and local agencies.

In response to the levee failures in New Orleans from Hurricane Katrina in August 2005, J ESCO Environmental and Geotechnical Services, Inc., under the direction of USACE, New Orleans District, produced a report in J anuary 2008 titled Documentation and Analysis of Tree Root Extent and 
Behavior Along and in Levees and Floodwalls in the New Orleans District. The report included a literature review on trees, root systems, and slope effects.

The effects of widespread vegetation removal on the stability of natural slopes have been studied extensively as a result of a timber harvesting practice of widespread removal of trees known as clear-cutting. Clearcutting on natural slopes and streambanks generally leads to an increase in slope failures (Gray and Megahan 1989; O'Loughlin 1974; PollenBankhead et al. 2009; Sidle et al. 1985; Wu and Swanston 1980; Ziemer 1978). In some cases, there may be a short-term benefit from tree removal resulting from a decrease in shear forces transmitted to a slope from wind. The adverse effect of wind depends, however, on such factors as the size and height of the canopy, stand density, and wind direction (Brown and Sheu 1975). The presence of tall, rigid isolated trees growing near the water line of levees may also promote scour erosion around the base of a tree when and if this zone experiences erosive velocities.

The cutting of trees on slopes leads to a gradual decrease in mass stability as a result of the decay of roots that, previously, acted as tensile reinforcements in the slope (O'Loughlin 1974; Ziemer and Swanston 1977; Gray and Megahan 1989). Root decay can also lead to the formation of pipes in a slope, which promote internal or seepage erosion (Pierson 1983; Ziemer 1992). The removal of tree canopy affects slope hydrology via loss of interception and evapotranspiration. Canopy removal can result in less attenuation in the delivery rate of rainfall to the ground surface (Keim and Skaugset 2003).

The extent to which canopy removal results in generally wetter less secure slopes depends largely on the type of slope (streambank, watershed hillside, or levee), rainfall regime, density, and type of canopy. Gray (1977) compared the pore water pressure response versus 3-month antecedent rainfall for six sites in a watershed in central Oregon that was initially forested and then clear-cut. The pore water tension (suction) curve was always higher for the sites in a forested condition except at high antecedent rainfall when the two curves tended to merge. Simon and Collison (2002), on the other hand, have shown that trees may increase or decrease infiltration rates based on antecedent moisture conditions. In their study, trees compensated for these impacts, when negative, by 
increased mechanical stability via root reinforcement. Furthermore, trees performed better than grass in this regard.

Considerably fewer studies have been carried out on the effects of woody vegetation removal on the mass stability of artificial embankments and levees. A legitimate question in this regard is the extent to which findings derived from the effects of clear-cutting trees on natural slopes apply to removal of woody vegetation growing on levees.

The principal difference between the two types of slopes lies in the type of hydraulic loading that occurs. Hill slopes in a watershed are loaded by precipitation and snowmelt, and have lowest heads at the top of the slope. Levees are loaded by riverside flooding as well as precipitation. The distribution of pressure head relative to the slope is different. It should also be noted that levees differ from earthen dams in terms of hydraulic loading conditions. Hydraulic loading of levees is transient, and time is required for the phreatic surface to develop and migrate across the levee cross section (Huang 1986). Levee slopes also differ from typical watershed hillsides in terms of their length and inclination, canopy densities, and geology. Nevertheless, many of the results and findings from clear-cutting studies of natural slopes apply.

Tree removal from levee slopes may result in the formation of void volume defects in the slope - either voids created by removing (pulling) tree stumps (and parts of roots) or holes that result from rotting residual roots. Conventional thinking holds that these voids can be eliminated by backfilling or possibly by grouting. However, both these remedial treatments can result in spatial discontinuities in soil properties (particularly hydraulic conductivity). The placement and compaction of fill in former root ball voids or root holes could create just such hydrologic discontinuities. Slope instabilities caused by small variations in hydraulic conductivity are discussed by Reid (1997).

Finally, a discussion of the effects of woody vegetation removal on slope stability, particularly levee slopes, would not be complete without mention of damage mechanisms that are unrelated to either the presence or absence of trees. These damage mechanisms can result in seepage and internal erosion that lead to stability or washout failures (Martin 2005). Examples of these damage mechanisms and/ or conditions that dispose earthen embankments to internal erosion include: (1) internally unstable 
(gap-graded) particle size distributions (Martin 2005), (2) hydraulic fracturing (Sherard 1986), and (3) the presence of dispersive clays (Khilar et al. 1985). None of these damage mechanisms requires the presence of pre-existing void volume defects, namely, fractures, cracks, or root holes. Accordingly, the presence of woody vegetation, or its removal, will have little or no influence on these types of internal erosion failures in earthen levees. 


\section{Ecosystem Considerations}

Mifkovic and Petersen (1975) examined alternative design and construction practices under study by the USACE, Sacramento District, to minimize adverse environmental effects. The modifications investigated for this study included selective clearing and retention of vegetation and replacement of unavoidably lost vegetation on levee construction sites; restoration of berm areas; preservation of existing berm areas by steepening the protected slope; requiring construction from the waterside by floating equipment; reducing the top of rock revetment to a high sustained flow level; preservation of habitat on protected berms by strong environmental easements; and inclusion of recreation facilities at selected construction sites. The conclusion of the study is that it is possible, through proper planning, to preserve natural environmental resources and to restore aesthetic qualities and riparian habitat of the Sacramento River.

Daar et al. (1984) recognized the significance of encouraging and controlling specific vegetation complexes on levees needed to support wildlife habitat. In conjunction with providing biological habitat, levee management of vegetation also contributes to the aesthetic appeal of the levee and may increase recreational opportunities. Vegetation removal is described by Daar et al. as burning, surface dragging, mowing, and applying herbicide. As noted by Daar et al., one of the major effects of annual vegetation removal is a change in the plant species distributions on the levees.

The concerns of annual vegetation removal as presented by Daar et al. (1984) are summarized as follows:

The practice of yearly vegetation removal and frequent soil disturbance creates and aggravates a series of levee maintenance problems ranging from erosion to ground squirrels.

Daar et al. (1984) offered an integrated pest management (IPM) approach to levee vegetation. The IPM approach recognized flood safety as the primary maintenance objective, but places high value on other goals including improvement of wildlife habitat and recreational opportunities, 
enhanced aesthetics, and reduced pesticide use. The IPM approach suggested recognizing the uniqueness of the levee environments and not treating the entire levee system with the same vegetation clearing approach. The description of the IPM approach is described by Daar et al. (1984) as follows:

Under an IPM vegetation management system, information on current site or pest conditions is integrated with historical data on the construction and maintenance history of a levee reach. Site conditions are evaluated through use of a variety of monitoring techniques and record-keeping systems, which vary in intensity, depending on a priority assigned to a given site. Using the monitoring data, injury and action levels are established for the vegetation, and selective treatments are chosen. Spot treatments, selected from mechanical, cultural, biological, or chemical controls, are timed to minimize side effects on non-target organisms. Strategies and tactics are evaluated for long-term effectiveness and cost.

Daar et al. (1984) noted that these observations contrast with standard levee practices of destroying vegetation on levees, but the IPM approach achieves the dual objectives of maximum levee safety and improved environmental quality.

Nunnally et al. (1987) recognized that increased concern over wildlife habitats resulted in an increasing number of levee projects designed, built, and maintained with environmental objectives in mind. They noted that both institutional and technical problems limit the use of environmental concepts in design and maintenance of levee projects, but perhaps the greatest obstacle is that, in most cases, the control of lands associated with these projects reverts to the preconstruction landowner after construction, greatly limiting the feasibility of environmental management design features and activities. The authors also mentioned that, in the technical realm, more information is needed on vegetal aspects of levee maintenance and addressed this issue by asking the following questions: 
- What types of grasses (and associated maintenance techniques) will adequately control erosion of levee slopes, allow periodic inspection, and yet provide wildlife habitat benefits?

- Can current levee maintenance standards be revised to allow more woody vegetation without increasing hazard?

In a memorandum from Karl Dise, Team Leader of Geotechnical Services, to the area manager in Mills, WY, the periodic facility review report for Pilot Butte Dam was discussed (Dise 19961). The review report recommended removing trees and their root systems growing on the upstream face of the embankment dams. Dise stated that the problems that roots create for embankment dams are twofold. First, their presence in the embankment or foundation can give a material an apparent cohesion. Thus, these materials may become roof-formers that can remain arched over a specific root or on a larger scale beneath a system of roots that affect a large mass. Second, the decay of a root that has been allowed to establish itself in an embankment results in a void. This void can form all or a portion of a pipe in which the internal erosion process begins. Attached to this correspondence was a letter report by Fondelier ${ }^{2}$ (1996) that discussed USACE guidance and summarized the situation of vegetation on levees by stating that there may be individual situations where the presence of trees is acceptable. This decision should be made by an individual experienced and qualified in the design, construction, and operational performance of embankment dams. If there is any doubt, remove the trees.

\footnotetext{
1 K. Dise. 1996. Memorandum to area manager, Mills, WY. Tree removal - Pilot Butte Dam - Pick-Sloan, Missouri Basin Program, Wyoming, 4 April 1996.

2 P. E. Fondelier. 1996. Trees on embankment dams. Letter report.
} 


\section{Summary and Recommendations}

The purpose of this literature review is to better assess if woody vegetation compromises levee integrity. Another objective is to identify data gaps within the compiled documents on the subject of studying the effects of woody vegetation on levees, and to use this information as a foundation for future research.

It is proposed that this literature review be expanded to include additional documents and reports on dam embankments. An extended search for international guidance should also continue for this effort.

The following list highlights the most prevalent issues and data gaps found in the listed literature. This listing provides a basis for future research topics in studying the effect of woody vegetation on levees.

- The influence of woody vegetation on habitat (i.e., animal burrows), and the interaction of these specific habitats on levee integrity should be studied.

- The effect of woody vegetation on maintenance, inspection, and floodfighting access should also be considered.

- Levees should be addressed in terms of ecosystem habitat diversity (as separate environmental communities), and specific guidance should be established for those ecosystems.

- Research should include a system-wide approach to better understand the interaction of woody vegetation with different components of the levee system, environment, and river community.

- Scientific and engineering principles should support guidance addressing woody vegetation on levees.

- Another topic that should be further investigated is the effect of tree root decay and tree throw-down (the hole remaining after a tree has been uprooted) on seepage and levee stability.

- The effect of woody vegetation on slurry cutoff walls needs further investigation.

- Both benefits and risks of converting wooded levees to grass-covered levees, including the engineering feasibility and economic costs of such conversion, have yet to be fully investigated. 


\section{References}

California Reclamation Board. 1967. Levee encroachment: Guide for vegetation on project levees. Sacramento, CA: California Department of Water Resources.

Dwyer, J.P., D. Wallace, and D.R. Larsen. 1997. Value of woody river corridors in levee protection along the Missouri River in 1993. J ournal of the American Water Resources Association 33(2):481-489.

Environmental Agency. 2003. Environmental options for flood defence maintenance works. Environmental Agency, Kingfisher House, Goldhay Way, Orton Goldhay; Peterborough PE2 5ZR, UK

Gray, D.H. 2007. Factors affecting the stability and integrity of earthen levees. Presentation at the Vegetation Challenge Symposium, Sacramento, CA, 28 August 2007. http:/ / www.safca.org/ LeveeVeg-SpeakerPanel.htm (Accessed 24 October 2010).

Gray, D.H., A. MacDonald, T. Thomann, I. Blatz, and F.D. Shields, J r. 1991. The effects of vegetation on the structural integrity of sandy levees. Technical Report No. REMR-EI-5, Vicksburg, MS: U.S. Army Waterways Experiment Station.

J ESCO Environmental \& Geotechnical Services, Inc. 2008. Documentation and analysis of tree root extent and behavior along and in levees and floodwalls in the New Orleans District. Final Report. New Orleans District: U.S. Army Corps of Engineers.

Nicoll, B. C., E.P. Easton, A.D. Milner, C. Walker, and M.P. Coutts. 1995. Wind stability factors in tree selection: Distribution of biomass within root systems of Sitka spruce clones. In Wind and Trees, ed. M.P. Coutts and J . Grace. Cambridge University Press.

Nolan, M.H. 1981. Vegetation on Corps of Engineers project levees in Sacramento/San J oaquin Valley, California. Proceedings: California Riparian Systems Conference, University of California-Davis.

Nunnally, N.R., F.D. Shields, J r., and J . Hynson. 1987. Environmental considerations for levees and floodwalls. Environmental Management 11(2):183-191.

Pilarczyk, K.W. 1987. Sea defences, Dutch guidelines on dike protection. Rijkswaterstaat, Dutch Ministry of Transport and Public Works, Road and Hydraulic Engineering Department. Report WB-NO-87110. Delft, The Netherlands.

Shields, F. D. Jr., L. T. Ethridge, and T. N. Waller. 1990. A study of vegetation on revetments, Sacramento Riverbank protection project; Phase 1, WES Literature Review and Pilot Study. Vicksburg, MS. U.S. Army Engineer Waterways Experiment Station. 
Shields F. D., and D. H. Gray. 1992. Effects of woody vegetation on sandy levee integrity. Water Resources Bulletin 28(5):917-931.

U.S. Army Corps of Engineers. 2000. Guidelines for landscape planting and vegetation management at floodwalls, levees, and embankment dams. Engineer Manual (EM) 1110-2-301. Washington, DC.

U.S. Army Corps of Engineers. 2009. Guidelines for landscape planting and vegetation management at levees, floodwalls, embankment dams, and appurtenant structures. Engineer Technical Letter (TL) 1110-2-571. Washington, DC.

Ziemer, R.R. 1992. Erosion, debris flows and environment in mountain regions, In Proceedings of the Chendu Symposium, J uly 1992, Chendu, China. International Association of Hydrological Sciences Publication No. 209. Wallingford, UK. 187197. 


\section{Appendix A: Literature Review}

\section{Reference codes}

BDWFAL - Blowdown - Windfall - Throw-down

BKSTAB - Bank Stability - Bank Erosion

BKSTAB - Bank Stability - Bank Erosion (Vegetation Removal Effects)

CHSTAB - Channel Stability

CSSTAB - Coastal Stability

DAMVEG - Dam Vegetation

DMCONST - Dam Construction

ECOSYS - Ecosystem

GEOTEX - Geotextile/ Reinforcement

LEVVEG - Levee Vegetation

LEVVEG - Levee Vegetation (Pertinent-vegetation impacting levee integrity)

LVCONS - Levee Construction

LVFLCL - Levee Flood Control

LVSTAB - Levee Stability

RTMODL - Root Model

RTSTAB - Root Stability

RTSYST - Root Systems 


\author{
SLSTAB - Slope Stability \\ SLSTAB(VR) - Slope Stability (Vegetation Removal Effects) \\ SOILER - Soil Erosion \\ SOILER(VR) - Soil Erosion (Vegetation Removal Effects) \\ TREEMD - Tree Model \\ VEGMOD - Vegetation Model
}




\title{
Coded listing of documents reviewed
}

\section{Journal articles}

\author{
BDWFAL (Blowdown - Windfall - Throw-down)
}

Distribution, composition, and orientation of down deadwood in riparian old-growth woodlands of Zoar Valley Canyon, western New York State, USA.

Introducing tree interactions in wind damage simulation

Relating forest damage data to the wind field from highresolution RCM simulations: Case study of Anatol striking Sweden in December 1999

Anchorage of coniferous trees in relation to species, soil type, and rooting depth

A numerical investigation into factors affecting the anchorage of roots in tension 53

Dead wood in European beech (Fagus sylvatica) forest reserves ...... 54

Effects of deforestation on slopes .56

The forest time machine - A multi-purpose forest management decision-support system ....................................................64

Root architecture and wind-firmness of mature Pinus pinaster ........ 65

Recorded storm damage in Swedish forests 1901-2000 ................... 67

Storm damage and long-term mortality in a semi-natural, temperate deciduous forest

Wind stability factors in tree selection: distribution of biomass within root systems of Sitka spruce clones.

Catastrophic windthrow in the southern Appalachians:

Characteristics of pits and mounds and initial vegetation responses.

Root barriers and windthrow potential 72

Wind-induced forces in the near-surface lateral roots of radiata pine.

Patterns of structural failures in urban trees: Coast live oak (Quercus agrifolia)

Strain distribution during anchorage failure of Pinus pinaster Ait. at different ages and tree growth response to windinduced root movement.

The disturbance of forest ecosystems: The ecological basis for conservative management 
Tree uprooting: Review of types and patterns of soil

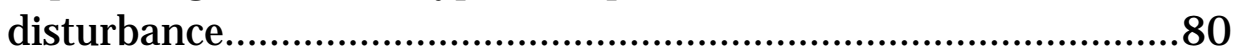

Root architecture and tree stability.................................................. 81

The function of buttress roots: A comparative study of the anchorage systems of buttressed and non-buttressed tropical trees

Influence of wind loading on root system development and architecture in oak (Quercus robur L.) seedlings

The increase in anchorage with tree size of the tropical taprooted tree Mallotus wrayi King (Euphorbiaceae)

Adaptive growth of tree root systems in response to wind action

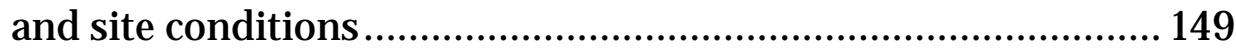

The anchorage mechanics of deep rooted Larch .............................. 150

The architecture of Picea sitchensis structural root systems on horizontal and sloping terrain

Responses of young trees to wind and shading: Effects on root architecture

Root spread can be estimated from crown width of Douglas fir, Lodgepole pine, and other British Columbia tree species 230

BKSTAB (Bank Stability - Bank Erosion)

Temporal and spatial variability in root reinforcement of streambanks: Accounting for soil shear strength and moisture

Enhanced application of root-reinforcement algorithms for bank-stability modeling............................................................... 59

Influence of two woody riparian species on critical conditions for streambank stability: Upper Truckee River, California 60

Estimating the mechanical effects of riparian vegetation on streambank stability using a fiber bundle model....

Influences of cutting diameter and soil moisture on growth and survival of black willow, Salix nigra

Missouri River Flood of 1993: Role of woody corridor width in levee protection

Quantifying the mechanical and hydrologic effects of riparian vegetation on streambank stability ....

Quantifying riverbank erosion with scanning laser altimeter. 86

Root-shoot characteristics of riparian plants in a flood control channel: Implications for bank stabilization 
The distribution and strength of riparian tree roots in relation

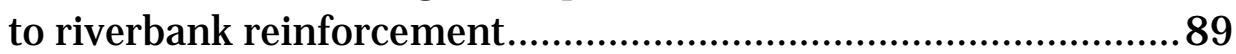

Does the weight of riparian trees destabilize riverbanks? ................... 91

Woody vegetation protects streambank stability during the 1993 Flood in Central Kansas .......................................................93

The effect of riparian tree roots on the mass-stability of

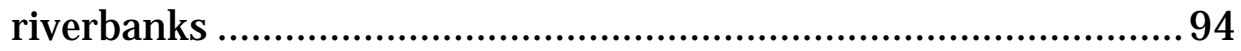

Control of streambank erosion due to bed degradation with

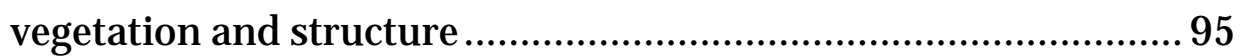

Material and site controls of streambank vegetation .......................... 97

Environmental aspects - Sacramento bank protection ........................114

The role of plant root distribution and strength in moderating erosion of red clay in the Lake Superior watershed .....................240

Effects of riparian vegetation on stream bank subaerial processes in southwestern Virginia USA..................................255

Variation in root density along stream banks................................256

Role of vegetation in riverbank erosion ..........................................324

BKSTAB(VR) (Bank Stability - Bank Erosion (Vegetation Removal Effects))

Destabilization of streambanks by removal of invasive species in Canyon de Chelly National Monument, Arizona ....................... 57

CHSTAB (Channel Stability)

Effects of channel confinement on pioneer woody vegetation structure, composition, and diversity along the River Drome (SE France) 99

Riparian forest effect on lateral stream channel migration in the glacial till plains.

Woody vegetation and channel morphogenesis in low-gradient, gravel-bed streams in the Ozark Plateaus, Missouri and Arkansas. 102

ECOSYS (Ecosystem)

Catastrophic windthrow in the southern Appalachians: Characteristics of pits and mounds and initial vegetation responses.

The disturbance of forest ecosystems: The ecological basis for conservative management 
Effects of channel confinement on pioneer woody vegetation structure, composition, and diversity along the River Drome (SE France) 99

Flood control areas as an opportunity to restore estuarine habitat 104

Root proliferation in decaying roots and old root channels: A nutrient conservation mechanism in oligotrophic mangrove forests? 105

Flora and vegetation of dikes of the middle course of the river Elbe between Magdeburg and Darchau (Translation of German Language Article). Flora und Begetation der Deiche an der mittleren Elbe zwischen Magdeburg und Darchau 106

A global analysis of root distributions for terrestrial biomes 106

On the maximum extent of tree roots. 108

Trench inserts as long-term barriers to root transmission for control of oak wilt 109

Early vegetation succession and management options on a brackish sediment dike

Environmental aspects - Sacramento bank protection .......................114

Environmental considerations for levees and floodwalls.................. 122

The influence of vegetation on the swelling and shrinking of clays in the United States of America............................................ 151

Coarse root architecture of three boreal tree species growing in mixed stands 156

Redistribution of soil water by lateral roots mediated by stem tissues

Root distribution and relationships to soil properties in Missouri oak stands: A productivity index approach. 183

Rooting depths, lateral root spreads and below-ground/ aboveground allometries of plants in water-limited ecosystems 187

Root competition between beech and oak: A hypothesis 189

Seasonal water acquisition and redistribution in the Australian woody phreatophyte Banksia prionotes 195

The redistribution of soil water by tree root systems 206

Root distribution of two tree species under a heterogeneous nutrient environment 209

Maximum rooting depth of vegetation types at the global scale 
Seasonal water uptake and movement in root systems of Australian phraeatophytic plants of dimorphic root morphology: A stable isotope investigation 213

Relationships between oak decline and groundwater class in The Netherlands. 218

Root distribution under some forest types native to West

Virginia

GEOTEX (Geotextile/Reinforcement)

Trench inserts as long-term barriers to root transmission for control of oak wilt 109

LEVVEG (Levee Vegetation)

Analysis of naturalization alternatives for the recovery of moistsoil plants in the floodplain of the Illinois River.

Early vegetation succession and management options on a brackish sediment dike 113

Environmental aspects - Sacramento bank protection 114

Uprooting of vetiver uprooting resistance of vetiver grass (Vetiveria zizanioides). 176

LEVVEG (Levee Vegetation (Pertinent - vegetation impacting levee integrity))

Missouri River Flood of 1993: Role of woody corridor width in levee protection

Rooting of trees in earth dikes: Morphology of tree root systems on slope and risks for embankments

Soil bioengineering techniques on heavily compacted soils:

Experiences from a test site

Value of woody river corridors in levee protection along the Missouri River in 1993.

Effects of woody vegetation on sandy levee integrity 119

Woody vegetation and riprap stability along the Sacramento River mile 84.5 - 119 ...

Environmental considerations for levees and floodwalls 122

Effect of grass, legume, and tree roots on soil shearing resistance 123

Soil reinforcement by roots: Calculation of increased soil shear resistance from root properties 
LVCONS (Levee Construction)

Soil bioengineering techniques on heavily compacted soils:

Experiences from a test site. 116

LVFLCL (Levee Flood Control)

Missouri River Flood of 1993: Role of woody corridor width in levee protection

Flood control areas as an opportunity to restore estuarine

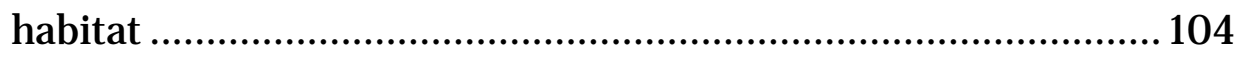

Environmental aspects - Sacramento bank protection ......................114

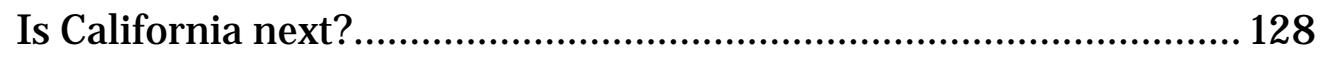

LVSTAB (Levee Stability)

Effects of woody vegetation on sandy levee integrity ..........................119

Detection of levee slides using commercially available remotely

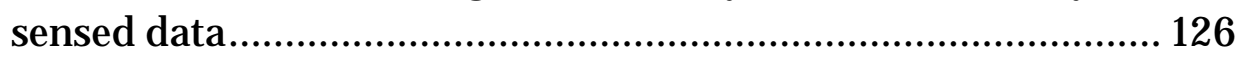

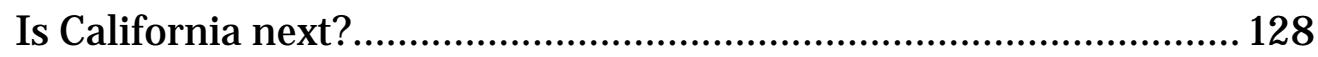

Role of vegetation in riverbank erosion ...........................................324

RTMODL (Root Model)

Soil reinforcement by roots: Calculation of increased soil shear resistance from root properties ................................................. 125

Carbon concentrations variations in the roots, stem, and crown of mature Pinus pinaster Ait. .................................................... 129

A density-based approach for the modeling of root architecture: application to Maritime pine (Pinus pinaster Ait.) root

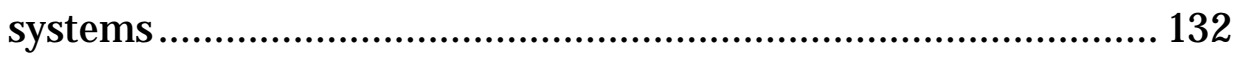

A spatial and temporal model for root cohesion in forest soils......... 133

An evaluation of different methods to investigate root system architecture of urban trees in situ: 1 . Ground-Penetrating Radar ........................................................................................ 135

Characterisation of structural tree root architecture using 3-D digitising and AMAPmod software.............................................. 136

Structural root architecture of 5-year-old Pinus pinaster measured by 3-D digitising and analysed with AMAPmod ........ 138

Soil compaction and plant root growth.............................................. 140

In situ shear test of soil-root systems ............................................... 142

The shear resistance of root-permeated homogeneous and stratified soil 
Point process modeling of root distribution in pure stands of

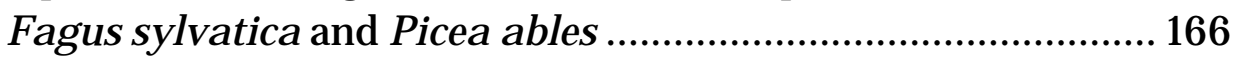

Exploring plant topological structure with the AMAPmod

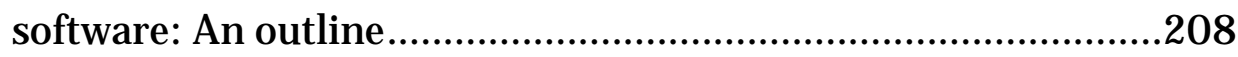

Study of soil-root interaction ........................................................ 219

Strength of tree roots and landslides on Prince of Wales Island,

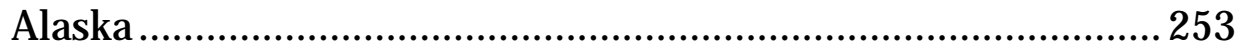

RTSTAB (Root Stability)

Introducing tree interactions in wind damage simulation ...................46

A numerical investigation into factors affecting the anchorage

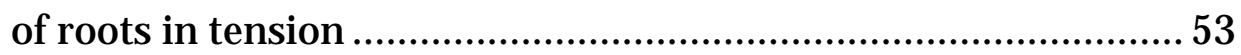

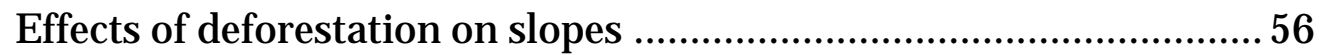

Wind stability factors in tree selection: distribution of biomass within root systems of Sitka spruce clones....................................69

Strain distribution during anchorage failure of Pinus pinaster Ait. at different ages and tree growth response to wind-

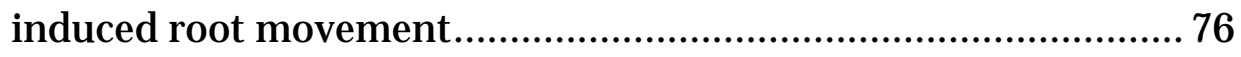

Root architecture and tree stability.................................................... 81

Quantifying the mechanical and hydrologic effects of riparian

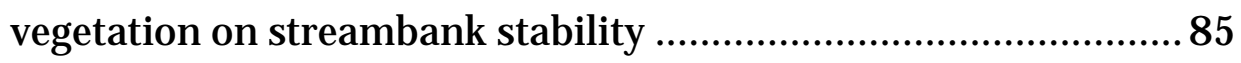

The distribution and strength of riparian tree roots in relation

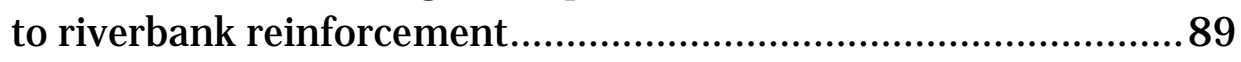

Does the weight of riparian trees destabilize riverbanks? .................... 91

Effect of grass, legume, and tree roots on soil shearing resistance

Carbon concentrations variations in the roots, stem, and crown of mature Pinus pinaster Ait. ................................................. 129

A spatial and temporal model for root cohesion in forest soils......... 133

Soil compaction and plant root growth.............................................. 140

In situ shear test of soil-root systems ............................................ 142

The function of buttress roots: A comparative study of the anchorage systems of buttressed and non-buttressed tropical trees

Influence of wind loading on root system development and architecture in oak (Quercus robur L.) seedlings .... 145

The development of symmetry, rigidity, and anchorage in the structural root system of conifers. 146

The increase in anchorage with tree size of the tropical taprooted tree Mallotus wrayi King (Euphorbiaceae) 
Adaptive growth of tree root systems in response to wind action

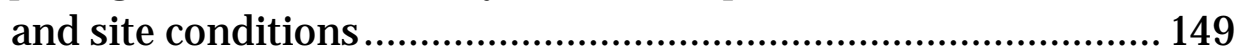

The anchorage mechanics of deep rooted Larch .............................. 150

The influence of vegetation on the swelling and shrinking of clays in the United States of America........................................... 151

An apparatus to measure the crosscut shearing strength of roots .... 152 The shear resistance of root-permeated homogeneous and stratified soil 154

A technique of simulation of radial root growth in soil and some experimental results 155

The role of fine and coarse roots in shallow slope stability and soil erosion control with a focus on root system architectures: A review

Root strength and root area ratio of forest species in Lombardy Poplar (Northern Italy)

Root system architecture of Quercus pubescens trees growing on different sloping conditions. .174

Uprooting of vetiver uprooting resistance of vetiver grass (Vetiveria zizanioides). 176

Root deformation in plantations of container-grown Scots pine trees: Effects on root growth, tree stability, and stem straightness.

SLIP4EX - A program for routine slope stability analysis to include the effects of vegetation, reinforcement, and hydrological changes. 235

Role of tree roots in slope stabilization. 238

Strength of tree roots and landslides on Prince of Wales Island, Alaska 253

The importance of plant root characteristics in controlling concentrated flow erosion rates. 257

Role of vegetation in riverbank erosion 324

RTSYST (Root Systems)

A numerical investigation into factors affecting the anchorage

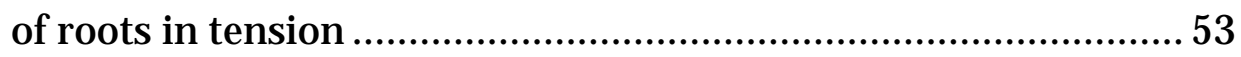

Enhanced application of root-reinforcement algorithms for bank-stability modeling. 59

Estimating the mechanical effects of riparian vegetation on streambank stability using a fiber bundle model 62

Root architecture and wind-firmness of mature Pinus pinaster 65 
Wind stability factors in tree selection: distribution of biomass within root systems of Sitka spruce clones..................................69

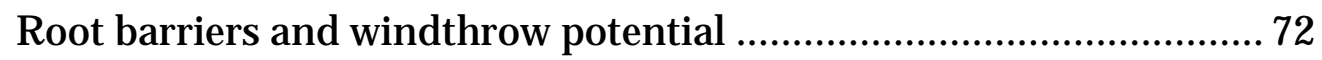

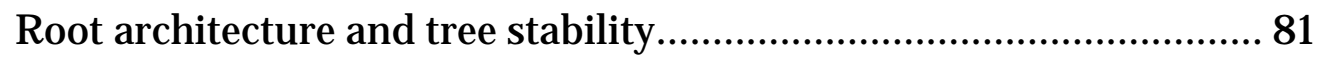

Root proliferation in decaying roots and old root channels: A nutrient conservation mechanism in oligotrophic mangrove

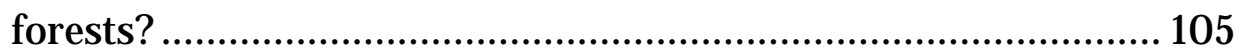

A global analysis of root distributions for terrestrial biomes ............ 106

Trench inserts as long-term barriers to root transmission for

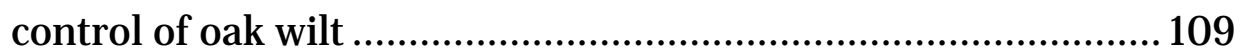

Rooting of trees in earth dikes: Morphology of tree root systems on slope and risks for embankments...........................................116

Soil reinforcement by roots: Calculation of increased soil shear resistance from root properties .................................................. 125

A density-based approach for the modeling of root architecture: application to Maritime pine (Pinus pinaster Ait.) root systems.

A spatial and temporal model for root cohesion in forest soils......... 133

An evaluation of different methods to investigate root system architecture of urban trees in situ: 1 . Ground-Penetrating Radar.

Characterisation of structural tree root architecture using 3-D digitising and AMAPmod software............................................ 136

Structural root architecture of 5-year-old Pinus pinaster measured by 3-D digitising and analysed with AMAPmod ........ 138

The development of symmetry, rigidity, and anchorage in the structural root system of conifers ................................................ 146

The increase in anchorage with tree size of the tropical taprooted tree Mallotus wrayi King (Euphorbiaceae)

Adaptive growth of tree root systems in response to wind action and site conditions.

Coarse root architecture of three boreal tree species growing in mixed stands

Detection of Cryptomeria japonica roots with ground penetrating radar. 157

Electrical measurement of root mass and root location ..................... 158 In situ detection of tree root distribution and biomass by multielectrode resistivity imaging. 160

Geophysical imaging of root-zone, trunk, and moisture heterogeneity 162 
The role of fine and coarse roots in shallow slope stability and soil erosion control with a focus on root system architectures: A review 163

Redistribution of soil water by lateral roots mediated by stem tissues

Root distribution of Eucalyptus grandis and Corymbia maculate in degraded saline soils of south-eastern Australia.... 165

Point process modeling of root distribution in pure stands of Fagus sylvatica and Picea ables 166

Soil compaction: Identification directly in the field 167

The architecture of Picea sitchensis structural root systems on horizontal and sloping terrain 167

Ground-penetrating radar to detect and quantify residual root fragments following peach orchard clearing.... 169

Groundwater use by vegetation in a tropical savanna riparian zone (Daly River, Australia).

Root strength and root area ratio of forest species in Lombardy Poplar (Northern Italy)

Root system architecture of Quercus pubescens trees growing on different sloping conditions.

Uprooting of vetiver uprooting resistance of vetiver grass (Vetiveria zizanioides). 176

Detection of tree roots and determination of root diameters by ground penetrating radar under optimal conditions

Relationships between tree dimension and coarse root biomass in mixed stands of European beech (Fagus sylvatica L.) and Norway spruce (Picea abies [L.] Karst.)

Root Typ: a generic model to depict and analyse the root system architecture

Variation in xylem structure and function in stems and roots of trees to $20 \mathrm{~m}$ depth

Root distribution and relationships to soil properties in

Missouri oak stands: A productivity index approach 183

Utility of ground-penetrating radar as a root biomass survey tool in forest systems

Hydraulic redistribution of soil water during summer drought in two contrasting Pacific Northwest coniferous forests 186

Rooting depths, lateral root spreads and below-ground/aboveground allometries of plants in water-limited ecosystems..... 187

A review of tree root conflicts with sidewalks, curbs, and roads 188 
Root biomass and biomass increment in a beech (Fagus

sylvativa L.) stand in northeastern France................................. 189

Root competition between beech and oak: A hypothesis ................... 189

Spatial distribution of Eucalyptus roots in a deep sandy soil in

the Congo: Relationships with the ability of the stand to take up water and nutrients.

Use of ground-penetrating radar to study tree roots in the southeastern United States

Vertical distribution and radial growth of coarse roots in pure and mixed stands of Fagus sylvatica and Picea abies

Seasonal water acquisition and redistribution in the Australian woody phreatophyte Banksia prionotes

Biomass and distribution of fine and coarse roots from blue oak

(Quercus douglasii) trees in the northern Sierra Nevada foothills of California . 196

Mapping tree root systems with ground-penetrating radar... 198

Root deformation in plantations of container-grown Scots pine trees: Effects on root growth, tree stability, and stem straightness.

Root strength, growth, and rates of decay: root reinforcement changes of two tree species and their contribution to slope stability

Hydraulic lift: Consequences of water efflux from the roots of plants.

Modeling of the hydraulic architecture of root systems: An integrated approach to water absorption-model description .....203

Modeling of the hydraulic architecture of root systems: An integrated approach to water absorption-distribution of axial and radial conductances in maize 204

The redistribution of soil water by tree root systems ........................206

Architecture and development of the oil-palm (Elaeis guineensis J afq.) root system .207

Exploring plant topological structure with the AMAPmod software: An outline. .208

Root distribution of two tree species under a heterogeneous

nutrient environment 209

Root distribution pattern of the wild jack tree (Artocarpus hirsutus Lamk.) as studied by the ${ }^{32} \mathrm{P}$ soil injection method...... 210 Maximum rooting depth of vegetation types at the global scale........211 
Seasonal water uptake and movement in root systems of Australian phraeatophytic plants of dimorphic root morphology: A stable isotope investigation ................................. 213

Responses of young trees to wind and shading: Effects on root architecture.

Growth and functioning of roots and of root systems subjected to soil compaction. Towards a system with multiple signalling?

Rates of water uptake into the mature root system of maize plants.

Orientation of the lateral roots of trees: 1 . Upward growth of surface roots and deflection near the soil surface. 218

Relationships between oak decline and groundwater class in

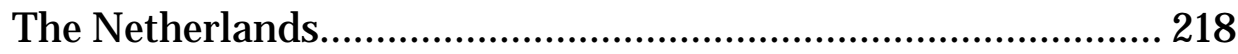

Study of soil-root interaction ........................................................... 219

Developmental processes in tree root systems ................................. 221

An overview of the conference Tree root systems and their

Mycorrhizas'.....

When is the structural root system determined in Sitka spruce? .....223

Root distribution under some forest types native to West

Virginia .224

Root distribution of a plantation-grown red pine in an outwash soil ..... 225

Root extension of trees in surface soils of the North Carolina

Piedmont. 226

Root growth around barriers.

227

Aspen root studies on three sites in northern Utah. 227

Root extension of individual trees in surface soils of a natural

Longleaf pine-Turkey oak stand

Root spread can be estimated from crown width of Douglas fir,

Lodgepole pine, and other British Columbia tree species 230

Characteristics of Douglas-fir root systems ...................................... 231

The root system of aspen.

232

The root system of longleaf pine on the deep sands of western

Florida. 233

The role of woody vegetation in stabilizing slopes in the

Cincinnati area, $\mathrm{OH}$ 


\section{SLSTAB (Slope Stability)}

Rooting of trees in earth dikes: morphology of tree root systems on slope and risks for embankments........................................116

Effect of grass, legume, and tree roots on soil shearing resistance

Soil reinforcement by roots: Calculation of increased soil shear resistance from root properties .............................................. 125

In situ shear test of soil-root systems ............................................ 142

The shear resistance of root-permeated homogeneous and stratified soil 154

The role of fine and coarse roots in shallow slope stability and soil erosion control with a focus on root system architectures: A review

The architecture of Picea sitchensis structural root systems on

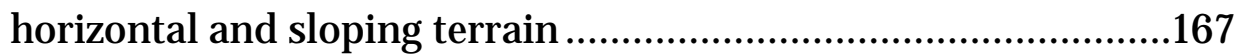

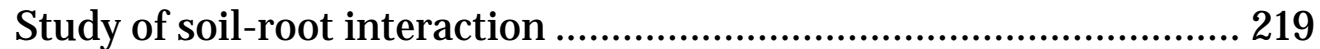

Hydraulic fracturing in embankment dams ......................................2234

SLIP4EX - A program for routine slope stability analysis to include the effects of vegetation, reinforcement, and

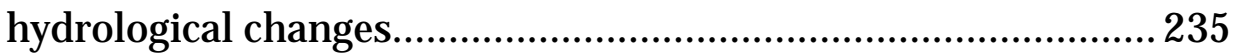

Modelling effects of forest canopies on slope stability ..................... 237

Role of tree roots in slope stabilization...........................................238

Slope instability caused by small variations in hydraulic conductivity 239

The role of plant root distribution and strength in moderating erosion of red clay in the Lake Superior watershed .....................240

Unsteady state phreatic surface in earth dams..................................243

The role of woody vegetation in stabilizing slopes in the Cincinnati area, $\mathrm{OH}$ .244

SLSTAB (VR) (Slope Stability (Vegetation Removal Effects))

Effects of deforestation on slopes 56

A spatial and temporal model for root cohesion in forest soils......... 133

An apparatus to measure the crosscut shearing strength of roots .... 152 Root strength, growth, and rates of decay: root reinforcement changes of two tree species and their contribution to slope stability

A theoretical model of the effects of timber harvesting on slope stability 
Forest vegetation removal and slope stability in the Idaho

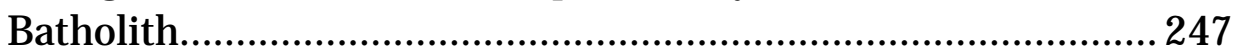

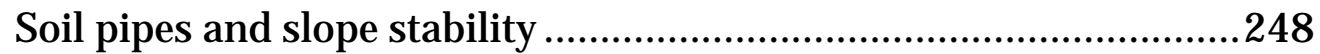

Risk of landsliding in shallow soils and its relation to clear-

cutting in Southeastern Alaska...............................................250

The effects of timber removal on the stability of forest soils............. 251

Strength of tree roots and landslides on Prince of Wales Island,

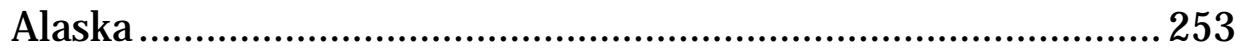

SOILER (Soil Erosion)

Influence of two woody riparian species on critical conditions for streambank stability: Upper Truckee River, California ...........60

Quantifying riverbank erosion with scanning laser altimeter.............86

Woody vegetation protects streambank stability during the

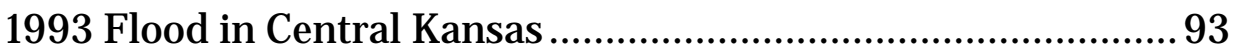

Control of streambank erosion due to bed degradation with vegetation and structure................................................................ 95

The role of fine and coarse roots in shallow slope stability and soil erosion control with a focus on root system architectures: A review 163

Root strength, growth, and rates of decay: root reinforcement changes of two tree species and their contribution to slope stability 200

Hydraulic fracturing in embankment dams 234

The role of plant root distribution and strength in moderating erosion of red clay in the Lake Superior watershed .....................240

Model for piping-plugging in earthen structures .............................252

Model for piping-plugging in earthen structures ............................... 252

Effects of riparian vegetation on stream bank subaerial processes in southwestern Virginia USA......................................25

Variation in root density along stream banks..................................256

The importance of plant root characteristics in controlling concentrated flow erosion rates. 257 SOILER(VR) (Soil Erosion (Vegetation Removal Effects))

Destabilization of streambanks by removal of invasive species in Canyon de Chelly National Monument, Arizona 


\section{TREEMD (Tree Model)}

The forest time machine - A multi-purpose forest management

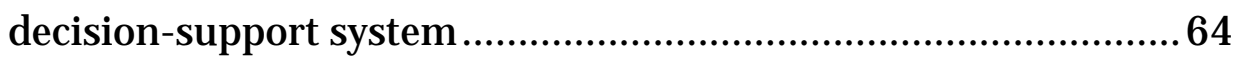

Modelling effects of forest canopies on slope stability ...................... 237

LIGNUM: A tree model based on simple structural units..................258

VEGMOD (Vegetation Model)

Detection of levee slides using commercially available remotely

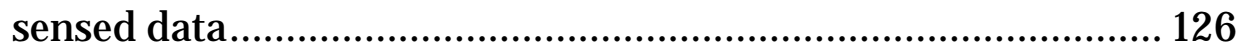

LIGNUM: A tree model based on simple structural units.................258

\section{Government documents (Federal/State)}

BKSTAB (Bank Stability - Bank Erosion)

Environmental features for streambank protection projects 260

Factors affecting streambank and riverbank stability, with an emphasis on vegetation influences, annotated bibliography...... 261

Environmental engineering and local flood control channels...........268 DAMVEG (Dam Vegetation)

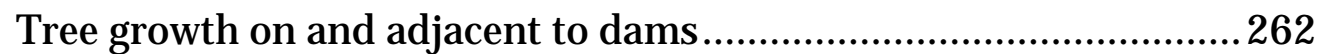

Dam owner's guide to plant impact on earthen dams .......................263

Technical manual for dam owners: Impacts of plants on earthen dams.

A technical manual on the effects of tree and woody vegetation root penetrations on the safety of earthen dams. .266

Guidelines for landscape planting and vegetation management at floodwalls, levees, and embankment dams 281

ECOSYS (Ecosystem)

Environmental engineering and local flood control channels...........268

Environmental features for streamside levee projects .......................268

Incorporation of environmental features in flood control channel projects.

Issues regarding vegetation management on levee embankments. .286

GEOTEX (Geotextile/Reinforcement)

Innovative methods for levee repair 


\section{LEVVEG (Levee Vegetation)}

Technical manual for dam owners: Impacts of plants on

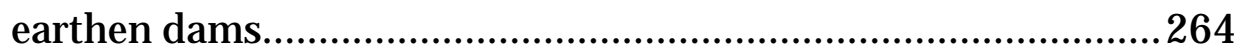

Environmental features for streamside levee projects .......................268

The spring 2008 Midwest flood: Observations of Missouri and

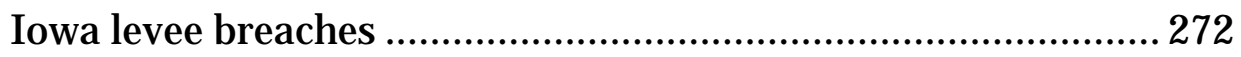

Common ground white paper document - Among California and federal agencies - Regarding vegetation management on levees..... 274

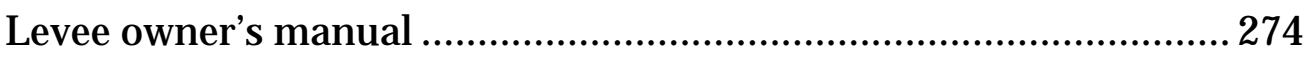

Interim guidelines for selective vegetation maintenance on

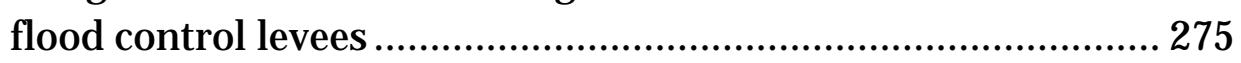

Levee wave wash protection by trees ................................................. 276

Maintenance costs of vegetation on levees ......................................... 277

LEVVEG (Levee Vegetation (Pertinent - vegetation impacting levee integrity))

California water code section 8450: Maintenance costs of

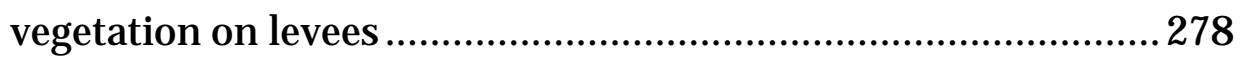

Documentation and analysis of tree root extent and behavior along and in levees in the New Orleans District ........................279

Regional variances to levee vegetation standards ..............................280

Guidelines for landscape planting and vegetation management at floodwalls, levees, and embankment dams .............................. 281

The effects of vegetation on the structural integrity of sandy levees

A study of vegetation on revetments Sacramento Riverbank protection project.

Issues regarding vegetation management on levee embankments.

Interim guidance for vegetation on flood control levees under Reclamation Board Authority, September 16, 1988.

Vegetation and the structural integrity of levees: Results of field investigations 288

Pilot levee maintenance study 290

Flood control operations and maintenance policies. 292 LVCONS (Levee Construction)

Innovative methods for levee repair 271

Design and construction of levees. 
LVFLCL (Levee Flood Control)

Environmental engineering and local flood control channels...........268

Environmental features for streamside levee projects ......................2270

Flood control operations and maintenance policies...........................292

Resistance due to vegetation ............................................................ 297

RTMODL (Root Model)

Effect of simulated roots on the permeability of silty soil ................. 139 RTSTAB (Root Stability)

Root strength changes after logging in southeast Alaska ...................293 RTSYST (Root Systems)

The spring 2008 Midwest flood: Observations of Missouri and

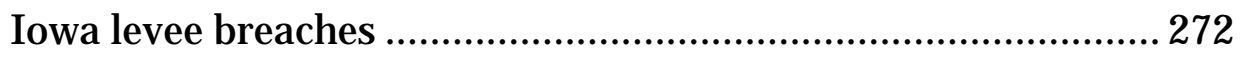

Documentation and analysis of tree root extent and behavior along and in levees in the New Orleans District ........................ 279

Vegetation and the structural integrity of levees: Results of field investigations 288

SLSTAB (Slope Stability)

The effects of vegetation on the structural integrity of sandy

levees 282

SLSTAB (VR) (Slope Stability (Vegetation Removal Effects)

The spring 2008 Midwest flood: Observations of Missouri and

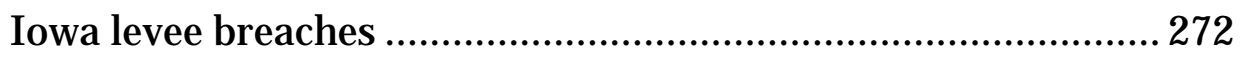

Root strength changes after logging in southeast Alaska...................293

Effects of land management on soil mass-movement ........................294

Creep movement and soil moisture stress in forested vs. cut-

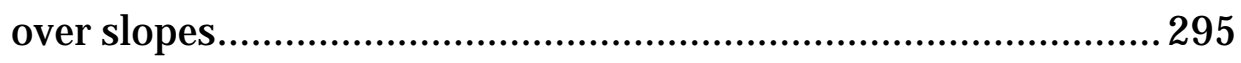

SOILER (Soil Erosion)

Environmental features for streambank protection projects .............260

Environmental engineering and local flood control channels...........268 The spring 2008 Midwest flood: Observations of Missouri and

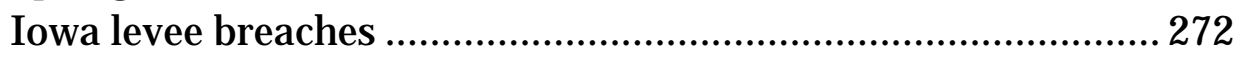

A study of embankment performance during overtopping ................296 
TREEMD (Tree Model)

Levee wave wash protection by trees ....................................... 276 VEGMOD (Vegetation Model)

Resistance due to vegetation ................................................... 297

\section{Books}

BKSTAB (Bank Stability - Bank Erosion)

Biotechnical slope protection and erosion control .............................299

Plant materials for river control and bank protection.........................311

LEVVEG (Levee Vegetation)

Bioengineering for land reclamation and conservation .....................299

Vetiver grass technology for land stabilization, erosion, and sediment control in the Asia-Pacific region .................................304

Influence of vegetation on the stability of slopes.................................305

RTMODL (Root Model)

Soil-root interaction and slope stability............................................302 RTSTAB (Root Stability)

Root properties for design of slope stabilization ............................... 300

Roots of forest trees (Die Wurzeln der Waldbaume - German

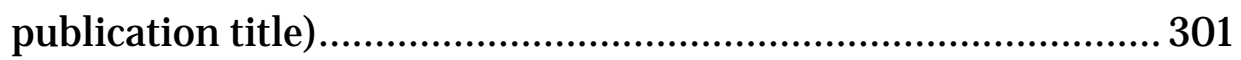

Methods of studying root systems.....................................................303

Vegetation and slope stability ........................................................... 310

RTSYST (Root Systems)

Roots of forest trees (Die Wurzeln der Waldbaume - German

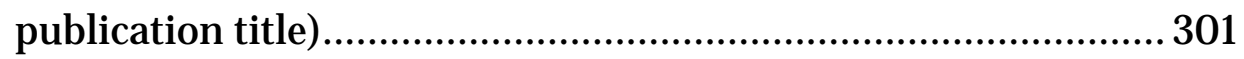

Soil-root interaction and slope stability.............................................302

Methods of studying root systems......................................................303

Tree species performance and slope stability ....................................307

SLSTAB (Slope Stability)

Root properties for design of slope stabilization ............................... 300

Soil-root interaction and slope stability............................................302 
Vetiver grass technology for land stabilization, erosion, and sediment control in the Asia-Pacific region ................................304

Biotechnical and soil bioengineering slope stabilization...................305

Tree species performance and slope stability .................................307

Use of vegetation in civil engineering .................................................309

The way ahead - continuing and future developments in vegetative slope engineering or ecoengineering .........................310

SLSTAB (VR) (Slope Stability (Vegetation Removal Effects))

Influence of vegetation on the stability of slopes................................305

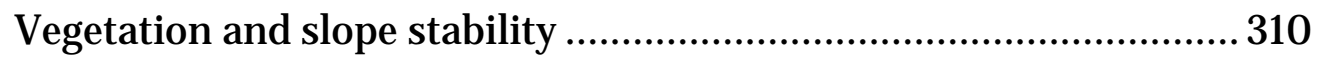

SOILER (Soil Erosion)

Biotechnical slope protection and erosion control ............................299

Soil-root interaction and slope stability...............................................302

Vetiver grass technology for land stabilization, erosion, and

sediment control in the Asia-Pacific region ..................................304

The way ahead-continuing and future developments in

vegetative slope engineering or ecoengineering .........................310

Plant materials for river control and bank protection ..........................311

\section{Newspaper/Internet articles}

LEVVEG (Levee Vegetation)

Corps of Engineers: 37 California levees at risk of failing ......

A way to save the levee habitat? A UC Davis study finds plants

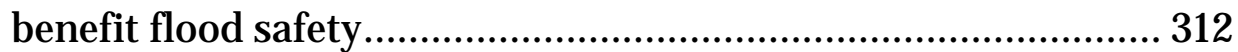

Tree-laden levees flunk federal inspection ...................................... 313

Tree removal on Anacostia begins ..................................................... 314

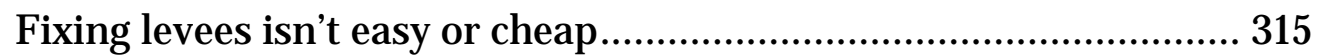

Levee rules could doom hundreds of trees ......................................... 316

Factors affecting the stability and integrity of earthen levees............320

Role of vegetation in levee slope stability and revetment durability. 322

LVSTAB (Levee Stability)

Fixing levees isn't easy or cheap. 315

Role of vegetation in levee slope stability and revetment durability. 
RTMODL (Root Model)

Botanical problems studied by applied geophysics ........................... 317 RTSYST (Root Systems)

Botanical problems studied by applied geophysics ........................... 317

Forestry applications of radar remote sensing with sensors in situ.

\section{Proceedings/briefings}

BDWFAL (Blowdown - Windfall - Throw-down)

Mechanics of root-pullout from soil: A novel image and stress analysis procedure. 340

BKSTAB (Bank Stability)

Scientific basis for streambank stabilization using riparian vegetation

CHSTAB (Channel Stability)

Role of vegetation in hydraulics of channel restoration 326 CSSTAB (Coastal Stability)

Erosion control with saltmarsh vegetation ......................................327

Resistance of grassmat to wave attack...........................................330 DAMVEG (Dam Vegetation)

Trees on embankment dams .334 LEVVEG (Levee Vegetation)

Erosion and overtopping of a grass dike large-scale model tests......328

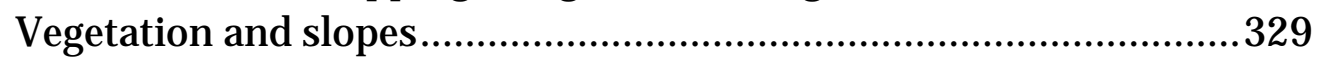

Resistance of grassmat to wave attack ...............................................330

Woody plants on flood protection levees: A contradiction?...............339

Levee armoring: woody biotechnical considerations for strengthening Midwest levee systems .352

Treatment of vegetation within local flood damage reduction

system

River engineering and environmental resources 
The role of vegetation in integrated pest management approach

to levee management ......................................................................333

Trees on embankment dams ...............................................................334

Riparian surrogates in the Sacramento/San J oaquin Delta and their habitat values

Riparian vegetation on flood control project levees: Constraints

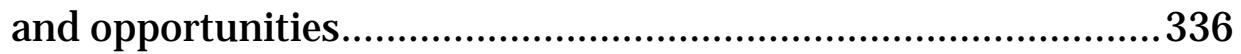

Vegetation on Corps of Engineers projects levees in

Sacramento/ San J oaquin Valley, California

LVFLCL (Levee Flood Control)

Vegetation on Corps of Engineers projects levees in

Sacramento/ San J oaquin Valley, California

LVSTAB (Levee Stability)

Erosion and overtopping of a grass dike large-scale model tests......328

Woody plants on flood protection levees: A contradiction?

RTMODL (Root Model)

A numerical investigation into the influence of soil type and

root architecture on tree anchorage . 345

Effect of tree roots on shallow-seated landslides. 348

RTSTAB (Root Stability)

Woody plants on flood protection levees: A contradiction? 339

Mechanics of root-pullout from soil: A novel image and stress analysis procedure .340

Shear strength of the soil root bond system .342

Roots and the stability of forested slopes ... 343

Effect of tree roots on shallow-seated landslides. 348 RTSYST (Root Systems)

Mapping the extent and activity of tree root zones with Self Potential and Misse a la Masse. 344

A numerical investigation into the influence of soil type and root architecture on tree anchorage .345 SLSTAB (Slope Stability)

Woody plants on flood protection levees: A contradiction? 339 
Dendrogeomorphological observations in a landslide on

Tymfristos Mountain in Central Greece.......................................346

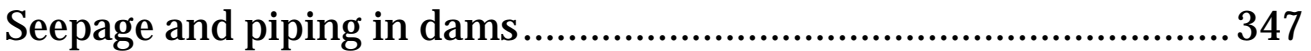

Effect of tree roots on shallow-seated landslides...............................348

Levee armoring: woody biotechnical considerations for

strengthening Midwest levee systems

SLSTAB (VR) (Slope Stability (Vegetation Removal Effects))

Roots and the stability of forested slopes

SOILER (Soil Erosion)

Resistance of grassmat to wave attack ..............................................330

Seepage and piping in dams.............................................................347

Airborne laser scanning for riverbank erosion assessment................350

Levee armoring: woody biotechnical considerations for

strengthening Midwest levee systems

\section{Reviews, annual reports, workshops}

BDWFAL (Blowdown - Windfall- Throw-down)

Forestry strategies to protect floodplain agricultural systems ..........358

BKSTAB (Bank Stability - Bank Erosion)

Evaluation and utilization of biotechnical techniques and

willow posts for stabilizing eroding streambanks. 354

CHSTAB (Channel Stability)

Environmental features for flood-control channels 355 ECOSYS (Ecosystems)

Environmental features for flood-control channels ........................... 355

Forestry strategies to protect floodplain agricultural systems ...........358

LEVVEG (Levee Vegetation)

Use of vegetation to reduce levee erosion in the

Sacramento/ San J oaquin Delta.

LEVVEG (Levee Vegetation (Pertinent - vegetation impacting levee integrity))

Review of Corps of Engineers design for rehabilitation of the perimeter dikes around Cross Lake, MN. 
Forestry strategies to protect floodplain agricultural systems 358 LVCONS (Levee Construction)

Review of Corps of Engineers design for rehabilitation of the perimeter dikes around Cross Lake, MN

LVSTAB (Levee Stability)

Forestry strategies to protect floodplain agricultural systems 358 SOILER (Soil Erosion)

Use of vegetation to reduce levee erosion in the Sacramento/ San J oaquin Delta. 359

\section{Dissertation/theses}

CSSTAB (Coastal Stability)

Wave overtopping and grass cover layer failure on the inner slope of dikes

LEVVEG (Levee Vegetation)

Wave overtopping and grass cover layer failure on the inner slope of dikes. 361

SOILER (Soil Erosion)

Wave overtopping and grass cover layer failure on the inner slope of dikes.

\section{International guidance}

BDWFAL (Blowdown - Windfall - Throw-down)

Windthrow handbook for British Columbia forests 362

BKSTAB (Bank Stability - Bank Erosion)

Guidelines for stabilizing streambanks with riparian vegetation......362 Environmental guidelines for vegetation management on flood protection works to protect public safety and the environment .365 
LEVVEG (Levee Vegetation)

Environmental guidelines for vegetation management on flood protection works to protect public safety and the environment 365

Sea defences, Dutch guidelines on dike protection 367

LEVVEG (Levee Vegetation (Pertinent - vegetation impacting levee integrity))

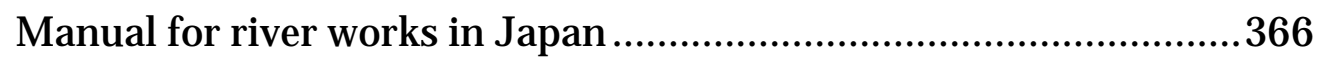
LVCONS (Levee Construction)

Sea defences, Dutch guidelines on dike protection 367 LVSTAB (Levee Stability)

Sea defences, Dutch guidelines on dike protection 367 RTSTAB (Root Stability)

Roots of forest trees (Die Wurzeln der Waldbaume - German publication title). 368 SOILER (Soil Erosion)

Guidelines for stabilizing streambanks with riparian vegetation......362 Sea defences, Dutch guidelines on dike protection 367 


\section{Journal Articles}

Title: Distribution, composition, and orientation of down deadwood in riparian old-growth woodlands of Zoar Valley Canyon, western New York State, USA

Author: Pfeil, E.K., N. Casacchia, G.J . Kerns, and T.P. Diggins

Series/Source: Forest Ecology and Management, 2007. 239:159-168

Peer-reviewed: Yes

Code: BDWFAL

Abstract*: During 2005, we catalogued down deadwood (DDW) in fortyone 30- $\mathrm{m} \times 30-\mathrm{m}$ quadrants on 10 riparian upper terraces within the minimally disturbed Zoar Valley Canyon of western New York State. Woodlands on these former floodplains represent late-successional stages of diversity of broadleaf ecotypes, with increment core-based stand ages up to 351 years. Volume of DDW averaged $84.9 \pm 9.7$ ( \pm S.E.) $\mathrm{m}^{3} / \mathrm{ha}$ among all quadrants, and ranged up to $145.3 \pm 43.2 \mathrm{~m}^{3} /$ ha on individual terraces. Abundance of downed sugar maple reflected this species' prevalence in the live overstory, but American beech deadwood was markedly overabundant due to beech bark disease mortality. Prevalence of very-shade-tolerant (sugar maple, American beech, eastern hemlock) DDW was modest for northern hardwood old growth (45.4 $\pm 4.3 \%$ among all quadrats), and was not related to stand age. We speculate this may reflect the floodplain origin of these woodlands. Down deadwood volume was positively associated with stand age among terraces $\left(\mathrm{R}^{2}-0.446, \mathrm{P}-0.035\right)$, but not at the neighborhood scale of 30 -m quadrates $\left(R^{2}-0.027\right)$, where individual tree mortality may obscure broader patterns. Orientation of DDW was nonuniform (Kolmogorov-Smirnov goodness-of-fit, $\mathrm{P}<0.05$ ) on five of the ten study terraces, where statistical trends in treefall direction suggested the influence of prevailing westerly winds blowing through the east-west canyon (this DDW orientation was also opposite to stream flow). This was an unexpected result, however, as we otherwise found very limited evidence of episodic wind throw within the study area.

Objective(s): The objective was to catalogue downed deadwood (DDW) in woodlands on former floodplains

Study Location: Zoar Valley Canyon of western New York State 
Method: Visual inventory of DDW volume in forty-one 30-m $\times 30-\mathrm{m}$ quadrants within 10 riparian upper terraced woodlands

Vegetation: Northern hardwoods (sugar maple, American beech, eastern hemlock)

Soil Properties: Not Available (N/A)

Observations/Results: Orientation of DDW was nonuniform. Volume of DDW averaged $84.9 \pm 9.7$ ( \pm S.E.) $\mathrm{m}^{3} /$ ha among all quadrants, and ranged up to $145.3 \pm 43.2 \mathrm{~m}^{3} /$ ha on individual terraces. There was very limited evidence of episodic wind throw within the study area

\section{Recommendations: N/A}

* Reprinted from Distribution, composition, and orientation of down deadwood in riparian old-growth woodlands of Zoar Valley Canyon, western New York State, USA, E.K. Pfeil, N. Casacchia, G.J . Kerns, and T.P. Diggins, Forest Ecology and Management 239, 159-168, 2007, with permission granted through Rightslink, Copyright Clearance Center, Inc.

Title: Introducing tree interactions in wind damage simulation Author: Schelhaas, M.J., K. Kramer, H. Peltola, D.C. van der Werf, and S.M.J. Wijdeven

Series/Source: Ecological Modelling, 2007. 207:197-209

Peer-reviewed: Yes

Code: BDWFAL, RTSTAB

Abstract*: Wind throw is an important risk factor in forest management in Northwestern Europe. In recent years, mechanistic models have been developed to estimate critical wind speeds needed to break or uproot the average tree of a forest stand. Based on these models, we developed a wind damage module for the individual tree model ForGEM (Forest Genetics, Ecology, and Management). For a given wind speed this module assesses the forces on each individual tree, based on the tree dimensions, and support and sheltering provided by other trees. Due to this individual approach, irregular stands can also be assessed. The module is demonstrated in Douglas fir stands (Pseudotsuga menziesli [Mirb.] Franco) of different densities in the Netherlands. Patterns of damage are explained, both in freshly exposed stands as well as in sheltered stands. Wind speeds needed to cause damage approximated those of known wind throw events. The wind damage module proved to be very sensitive to 
simulated tree heights and diameters. Furthermore, the newly introduced support mechanism played an important role in the stability of trees and stands. Lower individual tree stability in dense stands was clearly compensated for by the support of other trees.

Objective(s): This study developed a wind damage module for the individual tree model ForGEM (Forest Genetics, Ecology, and Management)

Study Location: Netherlands

Method: For a given wind speed, this module assesses the forces on each individual tree based on the tree dimensions and support, and sheltering provided by other trees.

Vegetation: Douglas fir (Pseudotsuga menziesli [Mirb.] Franco)

Soil Properties: N/A

Observations/Results: Patterns of damage are explained, both in freshly exposed stands as well as in sheltered stands. Wind speeds needed to cause damage approximated those of known wind throw events. The wind damage module proved to be very sensitive to simulated tree heights and diameters. Furthermore, the newly introduced support mechanism played an important role in the stability of trees and stands. Lower individual tree stability in dense stands was clearly compensated for by the support of other trees.

\section{Recommendations: N/A}

* Reprinted from Ecological Modelling 207, M.J . Schelhaas, K. Kramer, H. Peltola, D.C. van der Werf, and S.M.J. Wijdeven, Introducing tree interactions in wind damage simulation, 197-209, 2007, with permission from Elsevier.

Title: Relating forest damage data to the wind field from highresolution RCM simulations: Case study of Anatol striking Sweden in December 1999

Author: Nilsson, C., S. Goyette, and L. Barring

Series/Source: Global and Planetary Change, 2007. 57:161-176

Peer-reviewed: Yes

Code: BDWFAL 
Abstract*: Forestry is of major importance in Europe, and recent devastating windstorms have pinpointed the vulnerability of this economic sector to windstorms. Forest damage is an important economic issue at a country level and may become even of larger concern under future conditions following global warming. An underlying question is to what extent is storm damage due to changes in the wind climate compared to the effect of changes in forest management practices. In this paper, the first part of this rather complex problem is tackled.

By using the Canadian Regional Climate Model (CRCM) including a physically based gust parameterization scheme, NCEP-NCAR reanalysis wind fields for the windstorm Anatol, on December 3-4, 1999, were downscaled, into a nested set-up, to 2-km resolution. The aim is to relate the simulated storm wind field to the observed distribution of storm damaged forests in Scania in southern Sweden, as a first methodological step toward analyzing the effect of future windstorms in Swedish forests at the highest spatial resolution one can afford nowadays.

Our results show that the CRCM produced realistic wind field simulations, compared to station observations, of the windstorm event in 1999. The simulated winds were underestimated at the coasts, but in congruence with inland observations. Most of the damaged forest stands were located on southwesterly (SW) slopes, which indicated a southwesterly wind during the wind throw process. This SW wind direction was evident in the early phase of the simulated storm, but then changed into a westerly flow, at an earlier stage than the true observations specified. Further, most damage occurred in the areas of simulated maximum wind speed greater than $30 \mathrm{~m} \mathrm{~s}^{-1}$.

To conclude, the CRCM has proven to be a useful tool to realistically simulate a forest damaging storm event. Hence, the model could be used for further study cases, preferably driven by a GCM, to reveal a greater understanding about recent storms, which in turn helps us evaluate future climate changes driven storm conditions.

Objective(s): The objective to perform wind-forest management modeling simulations for windstorm events

\section{Study Location: Sweden}

Method: CRCM model

Vegetation: Scandinavian conifer trees

Soil Properties: N/A

Observations/Results: The CRCM produced realistic wind field simulations for a damaging storm event. 
Recommendations: Use CRCM for further study cases

* Reprinted from Global and Planetary Change 57, C. Nilsson, S. Goyette, and L. Barring, Relating forest damage data to the wind field from highresolution RCM simulations: Case study of Anatol striking Sweden in December 1999, 161-176, 2007, with permission from Elsevier.

\title{
Title: Temporal and spatial variability in root reinforcement of streambanks: Accounting for soil shear strength and moisture Author: Pollen, N. \\ Series/Source: Catena, 2007. 69:197- 205 \\ Peer-reviewed: Yes \\ Code: BKSTAB
}

\begin{abstract}
Riparian vegetation exerts a number of mechanical and hydrologic controls on bank stability, which can affect the delivery of sediment to channels. Estimates of root reinforcement of soils have commonly been attained using perpendicular root models that simply sum root tensile strengths and consider these as an add-on factor to soil strength. A major limitation of such perpendicular models is that tensile strength and resistance is wrongly considered independent of soil type and moisture, and therefore variations according to these bank properties are omitted in conventional models. In reality, during mass failure of a streambank, some roots break, and some roots are pulled out of the soil intact; the relative proportions of roots that break or pull out are determined by a combination of soil moisture and shear strength. In this paper, an equation to predict the frictional resistance of root- soil bonds was tested against field data collected at Long Creek, MS, under two soil moisture conditions. The root pullout equations were then included in the root-reinforcement model, RipRoot, and bank stability model runs for Goodwin Creek, MS, were carried out in order to examine the effects of spatial and temporal variations in soil shear strength and rooting density, on streambank factor of safety. Model results showed that at smaller root diameters breaking forces exceeded pullout forces, but at larger root diameters pullout forces exceed breaking forces. The threshold diameter between root pullout and root breaking varied with soil shear strength, with increasing soil shear strength leading to a greater proportion of roots failing by breaking instead of pullout. Root reinforcement estimates were
\end{abstract}


shown to reflect changes in soil shear strength, for example, brought about by variations in soil matric suction. Resulting Factor of Safety (FS) values for the bank during the period modeled ranged from 1.36 to 1.74 with 1000 grass roots/ $\mathrm{m}^{2}$, compared to a range of 0.97 to 1.37 for the nonvegetated bank. Root reinforcement was shown to increase bank stability under the entire range of soil moisture conditions modeled. However, the magnitude of root reinforcement varied in both space and time as determined by soil shear strength and soil moisture.

Objective(s): In this paper, the forces required to pullout roots were investigated in a field study, and the results were tested against a root-soil bonding equation. Root pullout forces were then compared to root breaking forces obtained from tensile strength testing, and the RipRoot model was modified to account for both root-failure mechanisms. The effects of spatial and temporal variations in soil shear strength and rooting density on streambank factor of safety were also examined.

Study Location: Long Creek and Goodwin Creek, MS

Method: Root tensile strengths and root pullout forces were measured using a root puller device. A trench was dug using an excavator to expose the roots of a stand of mature river birch (Betulus nigra) trees located on the streambank. The root puller was attached to the side of the trench opposite each tree, so that the roots being tested were no longer anchored by the tree. Root-soil friction experiments were carried out at the same site, at different times of the year (April and J uly) to test under varying soil moisture conditions. In each experiment, 70 to 80 roots were tested to have sufficient data to distinguish any trends in the data from natural variability.

Vegetation: River birch (Betula nigra)

Soil Properties: N/A

Observations/Results: The data show that above a certain root diameter, all of the roots broke. Below this threshold diameter, some of the roots broke and some were pulled out of the soil intact. This suggests that the theoretical threshold diameter between root pullout and root breaking does exist, above which the friction between the soil and roots exceeds the root tensile strength. Below the threshold, if the force required to break the root- soil friction bond is less than the force required to break the root, the roots were pulled out of the soil. Estimates of root reinforcement of soils have commonly been attained using simple perpendicular root models that calculate root reinforcement as an add-on factor to soil strength, and overestimate root reinforcement strength. The fiber-bundle 
model (RipRoot) accounts for progressive breaking during mass failure and corrects for overestimation. Root breaking is therefore likely to be the predominant mode of root-failure in dry soils or those with higher shear strengths, whereas soils that are moist or have lower shear strength will exhibit greater root pullout than breaking up to a certain root diameter. Root reinforcement was at its lowest when soil moisture was high and soil shear strength was low. Therefore, root reinforcement is likely to be at a minimum value when a bank is most at risk of failure, for example during the receding limb of a hydrograph, when the bank may be saturated and the receding flow-level removes the confining force acting on the bank. Recommendations: N/A

* Reprinted from Catena 69, N. Pollen, Temporal and spatial variability in root reinforcement of streambanks: Accounting for soil shear strength and moisture, 197- 205, 2007, with permission from Elsevier.

\section{Title: Anchorage of coniferous trees in relation to species, soil type, and rooting depth}

Author: Nicoll, B.C., B.A. Gardiner, B. Rayner, and A.J . Peace

Series/Source: Canadian J ournal of Forest Research, 2006. 36:18711883

\section{Peer-reviewed: Yes}

Code: BDWFAL

Abstract*: A database was constructed of tree-anchorage measurements from almost 2000 trees from 12 conifer species that were mechanically overturned on 34 sites in the United Kingdom between 1960 and 2000. Anchorage was compared among species, soil groups (freely draining mineral, gleyed mineral, peaty mineral, and deep peat) and root depth classes using regressions of critical turning moment against stem mass. Sitka spruce was used as a benchmark because it formed the largest part of the database and was the only species with all soil-group and depth-class combinations. Anchorage of Sitka spruce was strongest on peat and poorest on gleyed mineral soils. Deep rooting increased critical turning moments by 10 to $15 \%$ compared with trees of equivalent mass with shallower roots. Significantly better anchorage than Sitka spruce was found for grand fir with various rooting depths on freely draining and gleyed mineral soils and for Douglas fir on medium-depth mineral soil. 
Lodgepole pine had poorer anchorage than Sitka spruce over a range of soil groups and root depth classes. Norway spruce on shallow gleyed mineral soil, and Corsican pine on medium depth mineral soil, also had poorer anchorage. Other combinations had similar anchorage to the equivalent Sitka spruce. These results are discussed with respect to the development of forest wind-risk models.

Objective(s): Development of a forest database for tree anchorage measurements

Study Location: 34 experimental sites in the United Kingdom Method: Tree-pulling methodology and experimental differences were detailed. Anchorage was compared among species, soil groups (freely draining mineral, gleyed mineral, peaty mineral, and deep peat) and root depth classes using regressions of critical turning moment against stem mass. Sitka spruce was used as a benchmark because it formed the largest part of the database and was the only species with all soil-group and depth-class combinations.

Vegetation: Corsican pine (Pinus nigra subsp. laricio Poir. Maire), Douglas fir (Pseudotsuga menziesii [Mirb.] Franco), European larch (Larix decidua Mill.), Grand fir (Abies grandis Lindl.), J apanese larch (Larix kaempfer Carr.), Lodgepole pine (Pinus contorta Douglas ex Loudon)

Soil Properties: Free-draining, gleyed, and peaty mineral soils; deep peats

Observations/Results: Anchorage of Sitka spruce was strongest on peat and poorest on gleyed mineral soils. Deep rooting increased critical turning moments by $10 \%$ to $15 \%$ compared with trees of equivalent mass with shallower roots. Significantly better anchorage than Sitka spruce was found for Grand Fir with various rooting depths on freely draining and gleyed mineral soils and for Douglas fir on medium-depth mineral soil. Lodgepole pine had poorer anchorage than Sitka spruce over a range of soil groups and root depth classes. Norway spruce on shallow gleyed mineral soil, and Corsican pine on medium depth mineral soil, also had poorer anchorage. Other combinations had similar anchorage to the equivalent Sitka spruce. Linear relationships between critical turning moment and stem mass were provided for enabling prediction of tree anchorage using windthrow risk models.

Recommendations: It would be acceptable for wind risk models to use the relevant Sitka spruce regression lines for other conifer species until better data become available. 
* Reprinted from Canadian J ournal of Forest Research 36, B.C. Nicoll, B.A. Gardiner, B. Rayner, and A.J . Peace, Anchorage of coniferous trees in relation to species, soil type, and rooting depth, 1871-1883, 2006, NRC Research Press, with permission granted through Rightslink, Copyright Clearance Center, Inc.

\section{Title: A numerical investigation into factors affecting the anchorage of roots in tension}

Author: Dupuy, L., T. Fourcaud, and A. Stokes

Series/Source: European J ournal of Soil Science, 2005. 56:319-327

Peer-reviewed: Yes

Code: BDWFAL, RTSYST, RTSTAB

Abstract: Permission to publish abstract was not obtained.

Objective(s): The objectives were to answer the questions: (1) Can growth strategy alter the anchorage efficiency of a plant? (2) Do certain characteristics of root geometry influence root tensile resistance more than others?

Study Location: France

Method: When examining root development, consideration is given to two alternatives in every elongation zone of a root: to branch or not to branch. In the latter, the root system will result from longitudinal elongation and directional changes in root growth. Two kinds of branching were distinguished: apex continuation to grow straight and produces second-order lateral branches (herring bone-like systems) or two terminal apices appear and replace the former single apex (dichotomous-like structures). Three groups of root patterns were studied. The rooting patterns within each group of root types were parameterized by numerical parameters to explore the morphological diversity of root systems. To compare the influence of morphology only on uprooting resistance, the volume and material properties were fixed for all the groups during the simulations. Fixing the volume restrains the analysis to a limited class of root dimensions. Geometrical models were determined and material properties of the soil matrix were defined. The soil stress-strain relationship was based on Mohr-Coulomb's Law, with no hardening and associated flow rule. Root elements were placed at the center of a square 
block of soil of side $2.2 \mathrm{sq} \mathrm{m}$. Boundary conditions were defined to reproduce the action of the surrounding infinite earth. The finite element analysis software ABAQUS $\left(\mathrm{HKS}^{\odot}\right.$ ) was selected for the mechanical calculation. The mesh of both the root pattern and the soil matrix consisted of triangles with quadratic nodes and was created automatically from architectural data files.

Vegetation: Maritime pine (Pinus pinaster)

Soil Properties: N/A

Observations/Results: The finite element analysis showed that resistance to pull-out depended on the strength of the roots, plastic properties of the soil, and the resistance of the soil-root interface. Nonbranching root systems were the least resistant to pull-out. The cohesion factor and the angle of root deviation (angle between a root segment and its bearing axis) were the principal parameters governing the resistance. Interaction parameters involving the reference length and the number of directional changes appeared to be the most influential parameters in pull-out resistance.

Three major points can be made: (1) Failure of a single root element is a consequence of the combined effect of failure in the root, failure in the soil and sliding at the root-soil interface. (2) The size and number of root lateral axes are determinant for an element of a given volume. They determine the root's ability to bear a large amount of soil and the area of soil mobilized during pull-out. (3) The resistance of a root element, regardless of the group type studied, is well predicted by the basal diameter and the number of branches in the rooting pattern.

\section{Recommendations: N/A}

Title: Dead wood in European beech (Fagus sylvatica) forest reserves

Author: Christensen, M., K. Hahn, E.P. Mountford, P. Odor, T.

Standovar, D. Rozenbergar, J . Diaci, S. Wijdeven, P. Meyer, S. Winter, and T. Vrska

Series/Source: Forest Ecology and Management, 2005. 210:267-282

Peer-reviewed: Yes

Code: BDWFAL

Abstract*: Data were analyzed on the volume of dead wood in 86 beech forest reserves, covering most of the range of European beech forests. The 
mean volume was $130 \mathrm{~m}^{3} / \mathrm{h}$ and the variation among reserves was high, ranging from almost nil to $550 \mathrm{~m}^{3} / \mathrm{ha}$. The volume depended significantly on forest type, age since reserve establishment, and volume of living wood. More dead wood was found in montane (rather than lowland/ submontane) reserves, longer-established reserves (time since designation) and reserves with higher volumes of living wood.

On average, fallen dead wood contributed more to the total dead wood volume than standing dead wood. The percentage of dead wood that was standing was almost twice as high in montane than in lowland/ submontane forest reserves ( $45 \%$ versus $25 \%$ ). The volume of dead wood at selected sites changed considerably over time. The fluctuations were significantly higher in lowland/ submontane than montane reserves, possibly connected with differences in the disturbance regimes and especially damage caused by windstorms. In NW Europe, the blow down of formerly managed, even-aged stands led to extraordinary high volumes of dead wood shortly after reserve establishment.

The implications for forest management and biodiversity conservation are discussed. An increase in dead wood volumes must be carried out in accordance with the local/ regional forest type and disturbance regime. Thus, in order to fulfill the requirements of as many wood-depending organisms as possible, it is important to preserve not only larger amounts of dead wood, but also dead wood of different types and dimensions as well as securing a long-term continuity of dead wood.

Objective(s): To determine the volume of dead wood in 86 beech forest reserves, covering most of the range of European beech forests.

Study Location: Europe

Method: Inventory of dead wood volumes

Vegetation: Beech (Fagus sylvatica) trees

Soil Properties: N/A

Observations/Results: Fallen dead wood contributed more to the total dead wood volume than did standing dead wood. The mean volume was $130 \mathrm{~m}^{3} / \mathrm{h}$ a and the variation among reserves was high, ranging from almost nil to $550 \mathrm{~m}^{3} / \mathrm{ha}$. The volume depended significantly on forest type, age since reserve establishment, and volume of living wood.

\section{Recommendations: N/A}

* Reprinted from Forest Ecology and Management 210, M. Christensen, K. Hahn, E.P. Mountford, P. Odor, T. Standovar, D. Rozenbergar, J . Diaci, S. Wijdeven, P. Meyer, S. Winter, and T. Vrska, Dead wood in European 
beech (Fagus sylvatica) forest reserves, 267-282, 2005, Elsevier with permission granted through Rightslink, Copyright Clearance Center, Inc.

\title{
Title: Effects of deforestation on slopes
}

Author: Brown, C.B., and M.S. Sheu

Series/Source: J ournal Geotechnical Engineering Division (ASCE), 1975. 101(2):142-165

\section{Peer-reviewed: Yes}

Code: BDWFAL, RTSTAB, SLSTAB(VR)

\begin{abstract}
The creep and stability of slopes before and after logging were analyzed theoretically. The following effects of vegetation were included in the theory: (1) mechanical reinforcement of the soil by root systems; (2) vertical surcharge exerted by the weight of vegetation; (3) surface shears and moments caused by wind in the trees; and (4) modification of soil moisture and groundwater levels by evapo-transpiration. Results of analyses showed that immediately after tree removal a reduction in the overburden decreases creep rate. Also, this reduction and the drop in wind loading increase slope stability. The immediate effect of deforestation is, therefore, favorable, but adverse effects become evident when root systems decay and when a drop in evapo-transpiration causes a rise in the ground water table.
\end{abstract}

Objective(s): The objective of the study was to reconcile and explain differences in creep rate and stability that had been reported previously with regard to the impact of tree removal on slope stability, particularly with respect to the practice of clear-cutting. The paper resulted from a joint University of Michigan and University of Washington research project undertaken in the mid-1970s to investigate the impact of clear-cut logging practices in forested slopes. The University of Michigan team monitored soil moisture stress and creep rates (using slope movement indicators) in forested versus cut-over slopes in the western USA while the University of Washington team conducted theoretical analyses of both creep rates and safety factors in forested slopes versus denuded, clear-cut slopes.

Study Location: Nonspecific

Method: Theoretical idealization of soil, slope, wind shear, surcharge, and soil moisture parameters 


\section{Vegetation: Trees}

Soil Properties: Idealized soil with range of density, cohesion, and friction angle

Observations/Results: The following occur as a result of clear-cutting: (1) gradual loss of root reinforcement from root decay, (2) elimination of vertical surcharge from the weight of the trees, (3) elimination of external shears and moments from wind forces, and (4) increase in moisture content and perched water tables because of loss of evapotranspiration. The surcharge effect is relatively unimportant because the distributed weight of even a well-stocked forest is very minor compared to the weight of the soil. Furthermore, in some cases the vertical surcharge can be beneficial. A significant adverse wind shear effect requires a wind blowing down-slope past trees with large, high canopies (sail effect). Other wind directions may result in windthrow/ uprooting and local disturbance (divots) but have little effect on overall mass stability.

Recommendations: N/A

Title: Destabilization of streambanks by removal of invasive species in Canyon de Chelly National Monument, Arizona Author: Pollen-Bankhead, N., A. Simon, K. J aeger, and E. Wohl Series/Source: Geomorphology, 2009. 103:363- 374

Peer-reviewed: Yes

Code: BKSTAB(VR), SOILER(VR)

Abstract*: As part of a study to investigate the causes of channel narrowing and incision in Canyon de Chelly National Monument, the effects of Tamarisk and Russian-olive on streambank stability were investigated. In this study, root tensile strengths and distributions in streambanks were measured and used in combination with a rootreinforcement model, RipRoot, to estimate the additional cohesion provided to layers of each streambank. The additional cohesion provided by the roots in each $0.1-\mathrm{m}$ layer ranged from 0 to $6.9 \mathrm{kPa}$ for Tamarisk and from 0 to $14.2 \mathrm{kPa}$ for Russian-olive. Average root-reinforcement values over the entire bank profile were 2.5 and $3.2 \mathrm{kPa}$ for Tamarisk and Russian-olive, respectively. The implications of vegetation removal on bank stability and failure frequency were evaluated in two incised reaches by modeling bank-toe erosion and bank stability with and without vegetation. The effects of a series of 1.0- and 1.5-m-deep flows on bank-toe 
erosion, pore-pressure distributions, and bank stability were evaluated first. In addition, bank stability model runs were conducted using iterative modeling of toe erosion and bank stability using a discretized flow and groundwater record for one year. Results showed that the effects of rootreinforcement provided by Tamarisk and Russian-olive have a significant impact on bank stability and bank-failure frequency. Because the bank materials are dominated by sands, cohesion provided by roots is significant to bank stability, providing an average $2.8 \mathrm{kPa}$ of cohesion to otherwise cohesionless bank materials. Bank retreat rates at one site following vegetation removal have approximately doubled when compared to the control reach (from an approximate rate of 0.7 to $0.8 \mathrm{~m} / \mathrm{y}$ between 2003 and 2006 to $1.85 \mathrm{~m} / \mathrm{y}$ during the year modeled). Vegetation removal along the entire riparian corridor in Canyon de Chelly may lead to the introduction of significantly more sediment to the system through bank widening processes, although it is not known whether this change alone would be sufficient to cause a shift in channel morphology to the widebraided channels that were once characteristic of this canyon.

Objective(s): To investigate the causes of channel narrowing and incision in Canyon de Chelly National Monument and the impact of vegetation removal on streambank stability

Study Location: Canyon de Chelly National Monument in northeastern Arizona

Method: Root tensile strengths for Tamarisk and Russian-olive were measured using a device called the Root-Puller, comprised of a metal frame with a winch attached to a load cell and displacement transducer and both connected to a Campbell CR510 data logger. The Root-Puller is attached to the bank face and different-sized roots. Cranking the winch applies a tensile stress to the root (measured as a load, in Newtons) that increases until tensile failure of the root occurs. The diameter of each root is recorded along with the logged history of tensile stress and shear displacement. The maximum load applied to each root before breaking and root diameter were used to calculate the tensile strength of each root. Root diameter- tensile strength relations were established for the two species to use as input to the fiber-bundle root-reinforcement model, RipRoot. Geotechnical properties of the banks were measured in situ with an Iowa Borehole Shear Tester. Samples of bank materials were taken for each stratigraphic layer at each site, and sieved to half-Phi intervals in the laboratory to obtain particle size distributions for bank stability and toe erosion algorithms. In addition, cross-sectional surveys were carried out at 
the sites at the beginning and end of the modeled period to provide bank geometry information to input in the streambank stability model (BSTEM 4.1) and to validate the modeling results.

Vegetation: Tamarisk (Tamarix ramosissima) and Russian-olive (Elaeagnus angustifolia)

Soil Properties: Effective cohesion and friction angle values were assigned for each bank stability model layer, in addition to critical shear stress and erodibility coefficient values.

Observations/Results: The model runs carried out in this study considered only the short-term impact of invasive vegetation removal. The model predictions and field observations after vegetation removal both show accelerated rates of widening once root reinforcement has been removed from these banks, especially in bank materials with little inherent cohesion and/or consolidation. Approximately 2.2 times more erosion was predicted by BSTEM for one streambank site and approximately 4.4 times more erosion was predicted for the other site in the unvegetated versus vegetated scenarios. Removal of the invasive species Tamarisk and Russian-olive and their root-reinforcement affects have been shown to result in increases in bank-erosion rates from 120 to 383\%. Bank-retreat rates are predicted to increase between 300 and $723 \%$.

Recommendations: BSTEM combined with RipRoot can be used in conjunction to quantify the effects of riparian species on streambank stability.

* Reprinted from Geomorphology 103, N. Pollen-Bankhead, A. Simon, K. J aeger, and E. Wohl, Destabilization of streambanks by removal of invasive species in Canyon de Chelly National Monument, Arizona, 363374, 2009, with permission from Elsevier.

Title: Enhanced application of root-reinforcement algorithms for bank-stability modeling

Author: Pollen-Bankhead, N., and A. Simon

Series/Source: Earth Surface Processes and Landforms, 2009. 34:471480

Peer-reviewed: Yes

Code: BKSTAB, RTSYST

Abstract: Permission to publish abstract was not obtained. 
Objective(s): Root-architecture data was used to derive parameters required for modeling temporal and spatial changes in root reinforcement. In addition, the effect of spatial variations in rooting density with depth on streambank stability was modeled using the bank stability and toe erosion model (BSTEM). Three root distributions, all approximating the same average root reinforcement ( $5 \mathrm{kPa}$ ) over the top $1 \mathrm{~m}$ of the bank profile, were modeled. This paper describes a method developed to use root architecture data, obtained in previous studies, to create regressions showing changes in the number of roots crossing a shear plane within a streambank over time. In addition, variations in root density with depth were studied so that root reinforcement estimates obtained by RipRoot can be correctly applied to the layering within model runs of the BSTEM.

Study Location: Data obtained from previous studies Method: Analysis of data obtained from previous studies Vegetation: Black willow (Salix nigra), western cottonwood (Populus fremontii), eastern sycamore (Plantanus occidentalis), river birch (Betula nigra), longleaf pine (Pinus palustrus Miller) and switchgrass (Panicium virgatum)

\section{Soil Properties: N/A}

Observations/Results: The root reinforcement provided by each tree species depends not only on the number of roots crossing the shear plane, but also on the tensile strength of those roots. The tensile strength of sycamore roots was amongst the highest of riparian species tested so far. From BSTEM results, the onset of a rapid increase in FS due to root reinforcement occurred at approximately 3 to 5 years of growth, and for four of the five species included in this study FS greater than 1.3 (FS $>1 \cdot 3=$ stable) was predicted to be attained after 7 to 10 years of tree growth. Change in FS with root reinforcement was similar in all materials, but the relative effect was greatest for sandy-soil streambanks because they have little or no effective cohesion.

Recommendations: N/A

Title: Influence of two woody riparian species on critical conditions for streambank stability: Upper Truckee River, California Author: Simon, A., N. Pollen, and E. Langendoen 
Series/Source: J ournal of the American Water Resources Association, 2006. 42:99-114

Peer-reviewed: Yes

Code: BKSTAB, SOILER

Abstract: Permission to publish abstract was not obtained.

Objective(s): This study combined field data with numerical modeling to identify the critical conditions for bank stability along an unstable reach of the Upper Truckee River, California.

Study Location: Two sites along actively eroding Upper Truckee River streambanks were selected for study because of their accessibility and because they represented three typical bank top conditions: bare, with young lodgepole pine, and with young willows. The lodgepole pine and control sites were along the same reach of the stream, with a total bank length for this reach of approximately $60 \mathrm{~m}$, compared to a reach length of approximately $30 \mathrm{~m}$ for the willow site slightly downstream.

Method: The critical shear stress and erodibility coefficient values for cohesive materials in this study were obtained by direct measurement with the jet index test device. Two jet index tests were conducted at each site where cohesive bed or bank toe material was present. For coarse-grained materials, bulk samples were obtained for particle size analysis. Critical shear stress of these types of materials was calculated as a function of particle size and weight. The magnitude of bank toe erosion and bank steepening by hydraulic forces was calculated using a bank toe erosion algorithm incorporated into the Bank Stability Model (BSM). Bank geometry, soil shear strength (effective cohesion, $\mathrm{c}^{\prime}$, and angle of internal friction, $\varphi^{\prime}$ ), pore water pressure, confining pressure, and mechanical and hydrologic effects of riparian vegetation are used to numerically determine the critical conditions for bank stability.

Vegetation: Lodgepole pine saplings (Pinus contorta) and young (approximately five-year-old) Lemmon's willow (Salix lemmonii)

Soil Properties: Effective cohesion, $\mathrm{C}^{\prime}$, and angle of internal friction, $\varphi^{\prime}$, were determined for each modeled soil layer using the borehole shear test device providing direct, drained shear strength tests on the walls of a borehole.

Observations/Results: Although results of tensile strength testing showed that roots of both species had similar strength characteristics over the range of root diameters, the greater number and larger root areas for Lemmon's willow provided an order of magnitude more strength ( $5.5 \mathrm{kPa})$ 
than the lodgepole pines ( $0.5 \mathrm{kPa})$. Lemmon's willow provides a significant increase in bank strength to streambanks along the Upper Truckee River. The increased stability provided by riparian vegetation indicates that the frequency of bank failures and delivery of fine-grained sediment along the Washoe Meadows reach of the Upper Truckee River could be reduced.

Recommendations: N/A

Title: Estimating the mechanical effects of riparian vegetation on stream bank stability using a fiber bundle model

Author: Pollen, N., and A. Simon

Series/Source: Water Resources Research, 2005. 41:2004WR003801

Peer-reviewed: Yes

Code: BKSTAB, RTSYST

Abstract*: Recent research has suggested that the roots of riparian vegetation dramatically increase the geomechanical stability (i.e., factor of safety) of stream banks. Past research has used a perpendicular root reinforcement model that assumes that all of the tensile strength of the roots is mobilized instantaneously at the moment of bank failure. In reality, as a soil-root matrix shears, the roots contained within the soil have different tensile strengths and thus break progressively, with an associated redistribution of stress as each root breaks. This mode of progressive failure is well described by fiber bundle models in material science. In this paper, we apply a fiber bundle approach to tensile strength data collected from 12 riparian species and compare the root reinforcement estimates against direct shear tests with root-permeated and non-root-permeated samples. The results were then input to a stream bank stability model to assess the impact of the differences between the root models on stream bank factor of safety values. The new fiber bundle model, RipRoot, provided more accurate estimates of root reinforcement through its inclusion of progressive root breaking during mass failure of a stream bank. In cases where bank-driving forces were great enough to break all of the roots, the perpendicular root model overestimated root reinforcement by up to $50 \%$, with overestimation increasing an order of magnitude in model runs where stream bank driving forces did not exceed root strength. For the highest bank modeled $(3 \mathrm{~m})$ the difference in factor of safety values between runs with the two models varied from 0.13 to 2.39 
depending on the riparian species considered. Thus, recent work has almost certainly overestimated the effect of vegetation roots on mass stability of stream banks.

Objective(s): Application of a materials science method (fiber bundle approach) to root strength and stress redistribution during root breakage, and comparison with direct shear test results and root strength model results

Study Location: Mississippi

Method: Data was collected from 12 riparian species the root reinforcement estimates were compared to direct shear tests using rootpermeated and non-root-permeated samples. The results were then input to a streambank stability model to assess the impact of the differences between the root models on streambank factor of safety values. Root tensile strengths and stress displacements were measured using a device called the Root-Puller, composed of a metal frame, with a winch attached to a load cell and displacement transducer, both connected to a Campbell CR510 data logger. The Root-Puller was attached to the side of the trench by tying a rope around the stem of the tree, and different size roots were attached to the load cell and displacement transducer using U-bolts of varying sizes. The winch was then cranked at a steady rate until the root broke, and the diameter of each root was recorded.

Vegetation: Black willow (Salix nigra), Cottonwood (Populus fremontii), Douglas Spirea (Spirea douglasii), Eastern sycamore (Plantanus occidentalis), Gamma grass (Tripsacum dactyloides), Himalayan blackberry (Rubus discolor), Longleaf pine (Pinus palustris miller), Oregon ash (Fraxinus latifolia), River birch (Betula nigra), Sandbar willow (Salix exigua), Sweetgum (Liquidamber stryaciflua), Switchgrass (Panicum virgatum)

Soil Properties: Direct shear tests with silt soil representative of north Mississippi streambanks

Observations/Results: Attempts to quantify root reinforcement of soil have been dominated by the use of simple perpendicular root models which simply require knowledge of the tensile strength of the roots, and the cross-sectional area of fibers crossing the shear plane. Perpendicular root models can be considered static models, in that they estimate maximum root reinforcement at a single instance in time, when all of the roots contained in the soil matrix have reached their maximum tensile strength. The assumptions made by static models of root reinforcement therefore overestimate the increased apparent cohesion provided to the 
soil by a root network, as essentially they simply sum the tensile strengths of all of the roots. Recent work has almost certainly overestimated the effect of vegetation roots on mass stability of streambanks. The new fiber bundle model, RipRoot, provided more accurate estimates of root reinforcement through its inclusion of progressive root breaking during mass failure of a streambank. In cases where bank-driving forces were great enough to break all of the roots, the perpendicular root model overestimated root reinforcement by up to $50 \%$. The estimates of root reinforcement from RipRoot were much more accurate than those calculated using the simple perpendicular root model equations.

\title{
Recommendations: N/A
}

* Pollen, N., and A. Simon. Estimating the mechanical effects of riparian vegetation on stream bank stability using a fiber bundle model. Water Resources Research 41, W07025, doi:10.1029/2004WR003801, 2005. Copyright [2005] American Geophysical Union. Reproduced/modified by permission of American Geophysical Union.

\section{Title: The forest time machine - A multi-purpose forest management decision-support system}

Author: Andersson, M., B. Dahlin, and M. Mossberg Series/Source: Computers and Electronics in Agriculture, 2005. 49:114-128

Peer-reviewed: Yes

Code: BDWFAL, TREEMD

\begin{abstract}
The Forest Machine is a forest decision-support system developed within the SUFOR (Sustainable Forestry in Southern Sweden) research program. The system simulates the development of a forest area of up to about 25,000 ha, and results can be evaluated from a number of different perspectives. For a given area, a management alternative is chosen for each stand and the system calculates the development of the stands in 5-year intervals for a specified time (normally $>100$ years). An ordinary forest stand database is the minimum data requirement. Depending on what kinds of issues are to be analyzed, additional data sources may be included. Particularly for multi-purpose forestry, it is very important to analyze different issues simultaneously. Management alternatives are specified by the user. Its primary purpose is to evaluate
\end{abstract}


and compare different management strategies for achieving multiple objectives over a planning horizon. Because the system is used in conjunction with a geographic information system, it is spatially explicit and has proven useful for analyzing and space interactions.

Objective(s): The system includes modules for tree growth, regeneration, mortality, and decay of dead wood, forestry operations, economics, nutrient balances, and biodiversity indicators. A model for estimating the probability of wind throw is included as well.

\section{Study Location: Sweden}

Method: Forest management modeling

Vegetation: Trees

\section{Soil Properties: N/A}

Observations/Results: Describes a forest management decisionsupport system

\section{Recommendations: N/A}

* Reprinted from Computers and Electronics in Agriculture 49, M. Andersson, B. Dahlin, and M. Mossberg, The forest time machine - A multi-purpose forest management decision-support system, 114-128, 2005, with permission from Elsevier.

\section{Title: Root architecture and wind-firmness of mature Pinus pinaster}

Author: Danjon, F., T. Fourcaud, and D. Bert

Series/Source: New Phytologist, 2005. 168:387-400

Peer-reviewed: Yes

Code: BDWFAL, RTSYST

Abstract: Permission to publish abstract was not obtained.

Introduction: Undamaged and uprooted trees were sampled in a stand damaged by a storm. Mature Pinus pinaster root systems were organized in a rigid 'cage' composed of a taproot, the zone of rapid taper of horizontal surface roots and numerous sinkers and deep roots, imprisoning a large mass of soil and guyed by long horizontal surface roots. Key compartments for stability exhibited strong selective leeward or windward reinforcement. Uprooted trees showed a lower cage volume, a 
larger proportion of oblique and intermediate depth horizontal roots, and less wind-oriented root reinforcement.

Objective(s): This study aims to link three-dimensional (3-D) coarse root architecture to tree stability in mature timber trees with an average of 1-m rooting depth.

Study Location: Landes de Gascogne Forest, $60 \mathrm{~km}$ south of Bordeaux, France

Method: Site was 2.25 ha square plot within which 24 storm-uprooted trees were studied. Root architecture was measured by 3-D digitizing. The distribution of root volume by root type and in wind-orientation sectors was analyzed for uprooted as well as undamaged trees.

Vegetation: Maritime pine (Pinus pinaster)

Soil Properties: Sandy spodosol

Observations/Results: Pinus pinaster stability on moderately deep soils is optimized through a typical rooting pattern and a considerable structural adaptation to the prevailing wind and soil profile. In undamaged trees, the stump comprised $20 \%$ of the total excavated coarse root volume. The taproot proportion was $7.5 \%$ of root volume. The relative volume of hardpan shield and deep root grafts reached 6.5\%, but among the 20 trees growing over a hard pan, only seven undamaged trees and five uprooted trees exhibited a hardpan shield, the corresponding median proportion for these trees being $10.5 \%$. The leeward chuck was a large structure corresponding to $12 \%$ of the root volume, its sinker component averaging $2.6 \%$ of the root volume, which was one-third of the taproot. The typical Pinus pinaster root system is highly structured and efficient for anchorage and exhibits a broad structural adaptation to soil conditions. Wind-firmness is improved by a selective reinforcement in the prevailing wind direction.

Results confirm observations concerning a possible biomechanical adaptation of the root system to the prevailing wind in trees resistant to wind. The stem is mainly anchored on the ground by a large, leeward, reinforced root cage forming a broad and rigid soil plate, which is firmly anchored by windward reinforced shallow roots. This pattern may be altered by waterlogging, competition, or establishment techniques. In climates where the direction of catastrophic wind-blows is close to the prevailing wind direction, trees can improve their stability through prevailing wind-oriented selective reinforcement.

\section{Recommendations: N/A}


Title: Recorded storm damage in Swedish forests 1901-2000 Author: Nilsson, C., I. Stjernquist, L. Barring, P. Schlyter, A.M. J onsson, and H. Samuelsson

Series/Source: Forest Ecology and Management, 2004. 199:165-173

Peer-reviewed: Yes

Code: BDWFAL

Abstract*: Severe storm damage has been a recurring problem to the Swedish forestry sector since, at least, the start of the 19th century. This short communication presents a regionally resolved time-series of storm damage in Swedish forests during the last century. Data on storm damage have been gathered from the National Board of Forestry, the Regional Forestry Boards and scientific reports.

Storm damage in Swedish forests seems to have increased during the century with a peak around the 1980s. In total, 110 million $\mathrm{m}^{3}$ of forest were destroyed by 77 recorded wind storms, with the severe storms in 1954 and 1969 accounting for $49 \%$ of the total damage. Reported damage in southern Sweden was normalized against the area of productive forest with trees older than 40 years, for interannual comparisons. The geostrophic wind was used to describe the regional wind direction during the storm events. Most damage occurred during NNW to SW winds, and by winds from NNE. Apart from a possible shift in storm intensity and frequency, the increase in storm damaged trees can be attributed to changes in regeneration and thinning regimes, variations in storm damage reporting system, increase in forest cover and various damages to root architecture.

Objective(s): This short communication presents a regionally resolved time-series of storm damage in Swedish forests during the last century.

Study Location: Sweden

Method: Review of storm damage records

Vegetation: Swedish forests

Soil Properties: N/A

Observations/Results: Storm damaged tree rate increases can be attributed to changes in regeneration and thinning regimes, variations in the storm damage reporting system, increases in forest cover, and various damages to root architecture.

Recommendations: N/A 
* Reprinted from Forest Ecology and Management 199, C. Nilsson, I. Stjernquist, L. Barring, P. Schlyter, A.M. J onsson, and H. Samuelsson, Recorded storm damage in Swedish forests 1901-2000, 165-173, 2004, with permission from Elsevier.

Title: Storm damage and long-term mortality in a semi-natural, temperate deciduous forest

Author: Wolf, A., P.F. Moller, R.H.W. Bradshaw, and J . Bigler

Series/Source: Forest Ecology and Management, 2004. 188:197-210

Peer-reviewed: Yes

Code: BDWFAL

Abstract*: 1. Wind-damaged trees, following the severe storm of 1999, are compared with data from a 50-year monitoring of Draved Forest, Denmark; to assess differing causes of mortality through time in a Scopus unmanaged semi-natural forest. Species-specific mortality characteristics and the changing effects of tree size and growth rate (diameter increment) on mortality through time are also investigated.

2. Storm was found to be the major mortality factor affecting large trees in this forest. For smaller trees, competition was an important cause of death, as trees that were found standing dead had a slower growth rate (diameter increment) than survivors.

3. Individual species showed different mortality patterns, Betula died more often and Fagus less often than expected from their abundance. Betula, Fagus and Tilia were mainly wind-thrown, whereas for Alnus and Fraxinus, 50\% of the mortality was observed as standing dead trees.

4. Both wind and competition are important mortality factors in Draved Forest.

Objective(s): Determine wind storm damage and mortality patterns in deciduous forests

Study Location: Draved Forest, Denmark

Method: N/A

Vegetation: Deciduous trees: Birch (Betula), Beech (Fagus), Linden (Tilia), Alder (Alnus), and Ash (Fraxinus) species

\section{Soil Properties: N/A}

Observations/Results: Mortality patterns due to either storm damage or growth influences (competition) were noted for each species type. 


\title{
Recommendations: N/A
}

* Reprinted from Forest Ecology and Management 188, A. Wolf, P.F. Moller, R.H.W. Bradshaw, and J . Bigler, Storm damage and long-term mortality in a semi-natural, temperate deciduous forest, 197-210, 2004, (Elsevier), with permission granted through Rightslink, Copyright Clearance Center, Inc.

Title: Wind stability factors in tree selection: Distribution of biomass within root systems of Sitka spruce clones Author: Nicoll, B.C., E.P. Easton, A.D. Milner, C. Walker, and M.P. Coutts

Series/Source: Wind and Trees, 1995. University of Cambridge Press Peer-reviewed: N/A Code: BDWFAL, RTSYST, RTSTAB

\begin{abstract}
The effects of tree improvement on factors likely to influence tree stability were investigated using clonal Sitka spruce trees that had been grown for 11 years on an unploughed nursery site. The distribution of biomass between root and shoot, and within the root systems of trees from five improved clones, was examined and compared with control trees grown from unimproved cuttings and transplants. The direction (azimuth) of growth and dimensions of the main woody roots were also measured. Differences between clones were found in allocation of biomass between root and shoot, and in root system architecture. Large differences were found between clones in proportions of below-ground biomass allocated to stumps and woody roots (which function for anchorage). These results indicate that root: shoot ratio can be a poor indicator of tree stability when the stump is included as part of the root biomass. The distribution of root origins around the stump showed no significant clumping but the allocation of biomass between roots was found to differ between tree types. On average, the improved clones had allocated biomass to fewer roots than the controls. The amount of branching in the proximal $45 \mathrm{~cm}$ of the root system also differed between clones. Distribution of root crosssectional area around the tree was significantly asymmetric in two of the clones. Overall, root biomass was allocated more to the lee side of the prevailing wind direction. The substantial differences found in allocation between root and shoot, and within the root system, may have
\end{abstract}


implications for the wind stability of trees and could present opportunities for improving stability by clonal selection.

Objective(s): The objective was to investigate the applicability of clonal spruce trees (Picea sitchensis) in withstanding windthrow downing.

Study Location: Teindland Forest, northeast Scotland

Method: Nine replicate 11-year-old trees from five clones were harvested, along with control tree groups, for study. Mean height of the trees was

$6.17 \mathrm{~m}$ and mean diameter at $1.3 \mathrm{~m}$ above ground surface was $9.4 \mathrm{~cm}$. High pressure air jets were used to remove soil from root mass. The azimuth and diameter for each root emerging from the stump was recorded.

Vegetation: Sitka spruce (Picea sitchensis)

\section{Soil Properties: N/A}

Observations/Results: Mean root: shoot ratios for the clones ranged between 0.27 and 0.39 and were 0.32 and 0.30 for transplants and cuttings, respectively. The mean root only: shoot ratios were between 0.14 and 0.23 for clones and 0.20 and 0.16 for transplants and cuttings. Root depth never exceeded $60 \mathrm{~cm}$ and the main roots were predominantly in the upper $20 \mathrm{~cm}$ of soil. Improved clones increased total biomass production rather than increased allocation to the shoot at the expense of the roots. An indurated layer in the soil impeded downward root growth penetration. The stiffness of relatively horizontal circular beams (roots) will be proportional to the fourth power of the beams diameter. Large numbers of thin roots offer less resistance to bending than a few substantial roots. Clones had large variations in the support given to the trees.

Recommendations: Continued research may produce more stable clonal trees of the spruce given the genotypic variation observed in this study.

* "Wind stability factors in tree selection: Distribution of biomass within root systems of Sitka spruce clones," by B.C. Nicoll, E.P. Easton, A.D. Milner, C. Walker, and M.P. Coutts (from) Wind and Trees, M.P. Coutts and J. Grace, ed. Copyright ${ }^{\circledR} 1995$ Cambridge University Press. Reprinted with permission. 


\section{Title: Catastrophic windthrow in the southern Appalachians: Characteristics of pits and mounds and initial vegetation responses \\ Author: Clinton, B.D., and C.R. Baker \\ Series/Source: Forest Ecology and Management, 2000. 126:51-60 \\ Peer-reviewed: Yes \\ Code: BDWFAL, ECOSYS}

Abstract*: We characterized pit and mound (PM) topography resulting from catastrophic wind in the Coweeta Basin, and located 48 PMs across a variety of forest types. Our measurements included pit length, width, and depth; and mound height, thickness, and width. Species of fallen trees were identified, and diameter at breast height, $1.37 \mathrm{~m}$ (dbh) was measured for biomass determination. We identified five distinct microsites at each PM: mound face, mound top, pit bottom, pit-wall, and intact forest floor. On each microsite, we measured photosynthetically active radiation (PAR), soil temperature, and soil moisture, and took soil samples from four microsites (intact forest floor, pit wall, pit bottom, mound top) to determine carbon and nitrogen concentrations.

Treefall direction was marginally non-random. Three PM dimensions were significantly related to fallen tree biomass: mound width; mound height; and pit width. Other relationships failed because (1) rooting depth of the fallen tree was not necessarily proportional to tree size; and (2) trees that fell striking other trees often slid back into the pit, altering its dimensions. PAR was highest at mound top and lowest in pit bottom. Mean soil temperature varied about $3 \operatorname{deg} \mathrm{C}$ across microsites, and soil moisture ranged from $24 \%$ on the mound top and mound face to $34 \%$ in the pit bottom. Nitrogen and carbon concentrations were significantly higher on the forest floor than on the other three microsites. Over time, soil nutrition and microsite instability, due to erosion and settling, may be the most influential factors determining rates of vegetative establishment in PMs.

We characterized initial vegetative recovery in 27 blowdown sites. Trees were placed in one of two damage classes: direct wind damage (direct); and damage due to the fall of another tree (indirect). Vasal and/ or bole sprouting and live or dead crowns were noted. Blowdown areas ranged from 181 to 4043 square meters and averaged 1175 square meters. Mean diameter of indirectly damaged trees was $50 \%$ of the mean for trees directly damaged, but both had similar minimum diameters. Overall, the biomass of indirectly damaged trees accounted for $<10 \%$ of total biomass 
but 33\% of the total number of stems. Of the indirectly damaged trees, $38 \%$ were topped, $82 \%$ exhibited basal or bole sprouting, and $21 \%$ had live crowns. By contrast, of the directly damaged trees, only $5 \%$ were topped, $<50 \%$ were sprouting, and only $11 \%$ had live crowns.

Objective(s): Pit and mound (PM) topography resulting from catastrophic wind (Hurricane Opal) was measured across a variety of forest types.

Study Location: Coweeta Basin, western North Carolina Method: Measurements included pit length, width, and depth; and mound height, thickness, and width. Species of fallen trees were identified, and diameter at breast height, $1.37 \mathrm{~m}$ (dbh) was measured for biomass determination. Five distinct microsites were identified at each PM: mound face, mound top, pit bottom, pit-wall, and intact forest floor. On each microsite, photosynthetically active radiation (PAR), soil temperature, and soil moisture were measured, and soil samples were taken from four microsites (intact forest floor, pit wall, pit bottom, mound top) to determine carbon and nitrogen concentrations. Initial vegetative recovery was characterized in 27 blowdown sites.

Vegetation: Trees native to southern U.S. Appalachian Mountains (14 tree species)

\section{Soil Properties: N/A}

Observations/Results: Treefall direction was marginally non-random. Three PM dimensions were significantly related to fallen tree biomass: mound width; mound height; and pit width. Other relationships failed because (1) rooting depth of the fallen tree was not necessarily proportional to tree size; and (2) trees that fell striking other trees often slid back into the pit, altering its dimensions. Over time, soil nutrition and microsite instability, due to erosion and settling, may be the most influential factors determining rates of vegetative establishment in PMs.

\section{Recommendations: N/A}

* Reprinted from Forest Ecology and Management 126, B.D. Clinton, and C.R. Baker, Catastrophic windthrow in the southern Appalachians: Characteristics of pits and mounds and initial vegetation responses, 51-60, 2000, with permission from Elsevier.

\section{Title: Root barriers and windthrow potential}


Author: Smiley, E.T., A. Key, and C. Greco

Series/Source: J ournal of Arboriculture, 2000. 26(4):213-217

Peer-reviewed: No

Code: BDWFAL, RTSYST

\begin{abstract}
This study was developed to determine if commercially available ribbed barriers reduce or increase the stability of trees under severe lateral stress. Green ash (Fraxinus pennsylvanica) was planted in November 1996: six in surrounding-type tree root barriers and six without barriers. Half of each group was pulled over in J uly 1999 under dry ( $14 \%$ water) soil conditions and the other half was pulled over under saturated (33\% water) soil conditions. The force required to pull the trees over was measured as was the wind resistance of the trees. Slightly more force was required to pull over the trees grown within root barriers than the control trees. The force required for the weakest tree, however, was far greater than that exerted by a $100-\mathrm{mph}(160-\mathrm{kph})$ wind. The reason for the increased strength of the root barrier trees appeared to be the deeper root system.
\end{abstract}

Objective(s): A study to determine if commercially available ribbed barriers reduce or increase the stability of Green ash trees under severe lateral stress.

Study Location: Eastern U.S.

Method: Three trees were planted inside tree root barriers and three were planted without barriers. These six trees were pulled out about three years later, and the force and wind resistance characteristics were measured.

Vegetation: Green ash trees (Fraxinus pennsylvanica)

Soil Properties: Cecil sandy clay loam

Observations/Results: Slightly more force was needed to pull out the barrier-enclosed trees, probably due to their slightly deeper root systems.

Recommendations: N/A

* Reprinted from J ournal of Arboriculture 26(4), E. Thomas Smiley, A. Key, and C. Greco, Root barriers and windthrow potential, 213-217, J uly 2000. Copyright International Society of Arboriculture. Used with permission. 


\title{
Title: Wind-induced forces in the near-surface lateral roots of radiata pine \\ Author: Watson, A. \\ Series/Source: Forest Ecology and Management, 2000. 135:133-142 \\ Peer-reviewed: Yes \\ Code: BDWFAL
}

\begin{abstract}
The wind-induced movement within near-surface lateral roots of a radiata pine (Pinus radiata D. Don) tree was investigated to determine whether relationships exist between the resistive bending moment at the base of a tree and stresses in the near-surface lateral roots. The primary instrumentation consisted of four load cells split between windward and leeward roots, and two extensometers set at right angles to record stem deflection in the $x-y$ plane. All instruments output signals were controlled by a data logger, and triggered at pre-set wind velocities to target data collection during specific storm events. The tree was calibrated by winching to obtain the forces that produced the range of stem deflections measured during storm events. After data collection, the test roots were calibrated in a laboratory to obtain the forces required to produce the wind-induced root deformation. The calibrations gave an estimation of relationships between root and tree movement, and root force and bending moment. A comparison of the forces measured in the leeward and windward roots during a storm event indicated a ratio of between 1:2 and 1:3 as the relative contribution to the strength of root anchorage provided by these roots.
\end{abstract}

Objective(s): The wind-induced movement within near-surface lateral roots of a radiata pine tree was investigated to determine relationships between the resistive bending moment at the tree base and lateral root stresses.

Study Location: Radiata pine plantation on South Island, New Zealand Method: Strain gage load cells were fitted to two leeward and two windward near-surface lateral roots. Extensometers measured the tree stem deflection. Wind sensors were mounted above the plantation, and measurements of all components were taken during selected threshold high-wind events.

Vegetation: Radiata pine (Pinus radiata D. Don)

Soil Properties: Alluvial greywacke gravel 
Observations/Results: Leeward lateral roots provide about 25\% of anchorage, and about $75 \%$ is provided by windward lateral roots. Detailed dynamic deflection and force measurements were given.

Recommendations: A larger database and further studies are needed.

* Reprint from Forest Ecology and Management 135, A. Watson, Windinduced forces in the near-surface lateral roots of radiata pine, 133-142, 2000, with permission from Elsevier.

Title: Patterns of structural failures in urban trees: Coast live oak (Quercus agrifolia)

Author: Edberg, R., and A. Berry

Series/Source: J ournal of Arboriculture, 1999. 25(1):48-54

Peer-reviewed: Yes

Code: BDWFAL

Abstract*: Data from the California Tree Failure Report Program (CTFRP) were analyzed to develop a profile of the structural failure characteristics for coast live oak (Quercus agrifolia). The most common pattern of structural failure for coast live oak reported in the CTFRP is a root or low trunk failure of a naturally occurring tree growing in a residential site. Decay, site grade changes, and low wind speeds are significantly more frequently associated with coast live oak failures than with other hardwoods, conifers, or eucalyptus. Decay of roots and lower trunk was a major contributing factor to failure of coast live oak (83\%). Saturated soil conditions associated with root failure were also more frequent for coast live oak than for other species groups. Careful attention to controlling excess soil moisture, avoiding or correcting grade change and compaction, and monitoring decay are essential to maintain the health of coast live oak.

Objective(s): Data from the California Tree Failure Report Program (CTFRP) were analyzed to develop a profile of the structural failure characteristics for coast live oak (Quercus agrifolia).

\section{Study Location: California}

Method: Data were analyzed from the CTFRP database using statistical software.

Vegetation: Coast live oak (Quercus agrifolia) 


\title{
Soil Properties: N/A
}

Observations/Results: The most common pattern of structural failure for coast live oak reported in the CTFRP is a root or low trunk failure of a naturally occurring tree growing in a residential site. Decay, site grade changes, and low wind speeds are significantly more frequently associated with coast live oak failures than with other hardwoods, conifers, or eucalyptus. Decay of roots and lower trunk was a major contributing factor to failure of coast live oak (83\%). Saturated soil conditions associated with root failure were also more frequent for coast live oak than for other species groups. Careful attention to controlling excess soil moisture, avoiding or correcting grade change and compaction, and monitoring decay are essential to maintain the health of coast live oak.

\section{Recommendations: N/A}

* Reprinted from J ournal of Arboriculture 25(1), R. Edberg, and A. Berry, Patterns of structural failures in urban trees: Coast live oak (Quercus agrifolia), 48-54, J anuary 1999. Copyright International Society of Arboriculture. Used with permission from the International Society of Arboriculture.

Title: Strain distribution during anchorage failure of Pinus pinaster Ait. at different ages and tree growth response to windinduced root movement

Author: Stokes, A.

Series/Source: Plant and Soil, 1999. 217:17-27

Peer-reviewed: Yes

Code: BDWFAL, RTSTAB

\begin{abstract}
Winching tests were carried out on 5-, 13-, and 17-year-old tap rooted Maritime pine (Pinus pinaster Ait.) in order to determine how the mode of anchorage failure changes throughout the life of a tree. As trees were pulled sideways, strain along the lateral roots was recorded using strain gauges attached to a strain indicator. Measurements of strain in the root system, taken during winching, provide information about root movement when loaded by wind. The mode of mechanical failure appeared to depend on tree age. The youngest trees bent over completely during winching, but did not break due to the plasticity of their trunks. The 13-year-old trees either broke at the base of the tree (due to the
\end{abstract}


presence of grafting scar tissue) or at the base of the taproot. The oldest trees broke at the base of the taproot and sounds of roots breaking were also heard. Strain was twice as great in the trunk compared to the roots in the 5- and 13-year-old trees and was three times greater in the compression roots of 17-year-old trees compared to that in the trunk. In one 17-year-old tree, strain was found to increase at a distance of $35 \mathrm{~cm}$ in tension roots before decreasing again. Although the mode of failure changed with tree size, anchorage strength increased proportionally with the third power of trunk diameter, therefore another reason why failure differs with tree age must exist. In order to determine if different types of wood were being laid down in the lateral roots in response to wind loading, maturation strains, indicating the existence of mechanical stress in developing wood cells, were measured at different points along the roots. A high correlation was found between maturation strain and strain measured during winching, in roots that lay in the wind direction only. Therefore, trees appear to be able to respond to external loading stress, even at a local level within a root.

Objective(s): Study to determine root anchorage failure changes during tree lifespans.

Study Location: Gironde, southwest France

Method: Hand winch with force transducer was attached to 5- to 17-yrold tree trunks (strain-gaged), and the trees were pulled over.

Vegetation: Maritime pine (Pinus pinaster Ait)

Soil Properties: Medium humid sandy podzol

Observations/Results: The root anchorage of taller trees becomes weaker with time compared to their trunk strength. Resistance to trunk breakage increases as a function of diameter to the third power while anchorage strength is a function of height times diameter to the second power.

Recommendations: The best time to harvest trees is at the beginning of the growth season so the remaining tree root systems have time to adapt to new wind exposure.

* Reprinted from Plant and Soil 217, A. Stokes, Strain distribution during anchorage failure of Pinus pinaster Ait. at different ages and tree growth response to wind-induced root movement, 17-27, 1999, with permission from Springer. 
Title: The disturbance of forest ecosystems: The ecological basis for conservative management

Author: Attiwil, P.M.

Series/Source: Forest Ecology and Management, 1994. 63:247-300

Peer-reviewed:

Code: BDWFAL, ECOSYS

Abstract*: The extensive literature on natural disturbance in forests is reviewed in terms of the hypotheses: (1) that disturbance is a major force moulding the development, structure, and function of forests; and (2) that management of forests for all their benefits can be controlled so that the effects can be contained within those which result from natural disturbance. The casual factors of natural disturbance are both endogenous and exogenous; there are major difficulties in the formal characterization of disturbance and of recovery after disturbance. As to the latter, the acceptance of classical generalizations of the nature of succession has led to particular difficulties in the assessment and interpretation of recovery.

Tree fall, which creates gaps, is fundamental to the development of many forests, and has been most intensively studied in tropical forests of Central America and the Amazon and in temperate forests of North America. Tree fall is part of autogenic change; mechanisms of gap-filling and subsequent growth and species composition vary widely with forest type and geography.

Disturbance by wind is particularly difficult to characterize. Wind varies along a continuum; the blow-down of an individual tree may be mostly due to autogenic processes of aging and decay, whereas catastrophic hurricanes and cyclones may be defined as wholly exogenous. Nevertheless, the resilience in terms of species diversity of tropical forests following catastrophic disturbance by hurricane is remarkable. A number of studies support the view that the tropical forest in hurricane-prone areas is not a stable steady-state ecosystem but rather that heterogeneity is maintained by catastrophe. The ability to regenerate by suckers and the coincidence of regenerative space and gregarious flowering are important components of the response of rainforest following disturbance.

For much of the world, 'fire is the dominant fact of forest history.' As examples, fire and its effects are reviewed for the northern boreal forests, oak-pine forests and northwestern sub-alpine forests of North America. The effect of fire on species composition varies with intensity and 
frequency. That, together with the popular view of fire as unnatural and therefore unacceptable, places great demands on management of forests for all of their benefits, including national parks and reserves. These difficulties also affect management of other ecosystems, such as Mediterranean-type shrublands and heathlands where species diversity, productivity, and cycles of regeneration and degradation are governed by fire as a natural disturbance.

Shifting agriculture is a traditional form of agriculture used by at least 240 million people in the humid tropics. Shifting agriculture, together with wind, lightning, and fire, is an exogenous disturbance, which has little effect on soil fertility and on structure and composition of the rainforest which re-establishes after abandonment. As the intensity of disturbance of rainforest increases, resilience of the forest decreases and the current problems of extensive clearing for improved pasture and of uncontrolled logging are resulting in degraded ecosystems.

Regeneration follows the often extensive death of trees caused by outbreaks of insects in many coniferous forests of northern America. This disturbance by herbivory halts increasing stagnation (as measured by decreasing rates of ecosystem production and nutrient cycling) and reinitiates succession. Other disturbances to forests occur through damage from ice storms, snow avalanches, erosional and earthquake landslides, and volcanic activity; the development of Nothofagus forests in Chile and New Zealand is determined by such catastrophic mass movements.

An extensive literature supports the hypothesis that natural disturbance is fundamental to the development of structure and function of forest ecosystems. It follows that our management of natural forests should be based on an ecological understanding of the processes of natural disturbance. Whether or not we want to do this, and the extent to which we want to derive all of the benefits from the forest, including timber, depends on social attitudes. Whereas humanism may treat conservation as the wise husbanding of forests in the interests of social traditions and harmony, animism may give nature unalienable rights. The conclusion from this review is that the ecological framework of natural disturbance and the knowledge of its component processes and effects provides the basis on which we can manage our forests as a renewable resource, which can be used so that the forests 'retain their diversity and richness for mankind's continuing benefit.' Nowhere is this management more desperately needed than for the protection of the world's tropical forests, its peoples and their cultures. 
Objective(s): An overview of forest ecosystem disturbance effects Study Location: Worldwide forest ecosystem locations

Method: Extensive literature review

Vegetation: N/A

Soil Properties: N/A

Observations/Results: Not related to levee vegetation

Recommendations: N/A

* Reprinted from Forest Ecology and Management 63, P.M. Attiwil, The disturbance of forest ecosystems: The ecological basis for conservative management, 247-300, 1994, with permission granted through Rightslink, Copyright Clearance Center.

Title: Tree uprooting: Review of types and patterns of soil disturbance

Author: Schaetzl, R.J ., S.R. Burns, T.W. Small, and D.L. J ohnson

Series/Source: Physical Geography, 1990. 11(3):277-291

Peer-reviewed: Yes

Code: BDWFAL

Abstract*: This paper reviews the process of tree uprooting, examines the classification of pit and mound midrotopography and assesses the effects of tree uprooting on soil mixing and genesis. The processes by which soil-horizon clasts are mixed as they slump off the root plate, and the ultimate patterns of soil horizonation within mounds, are primary foci of the paper. Longevity of treethrow mounds can exceed 2000 years, making these landforms more lasting features than is often assumed. Because of their great longevity, the pits and mound formed by uprooting have lasting effects on soil morphology. Soils of these microsites often classify in different soil orders or suborders than do adjacent, less disturbed soils. The importance of tree uprooting to mass movement processes is examined. In some areas, uprooting may be the primary mass wasting mechanism. Nonetheless, estimates of the amount of sediment moved and the net distance of transport vary greatly and may in some cases be overestimated.

Objective: Summarizes part of the extensive and highly diverse literature concerning soil disturbance by tree uprooting. The objective is to explore relationships between tree uprooting, soil mounds, and soil pits. 


\title{
Study Location: N/A
}

Method: This paper is a literature review of soil disturbance from uprooted trees.

\section{Vegetation: N/A}

\section{Soil Properties: N/A}

Observations/Results: Pits and mound formed by uprooting have lasting effects on soil morphology.

Recommendations: Future uprooting research should be performed at larger scales and over longer time periods.

* Reprinted with permission from Physical Geography, Vol. 11, No. 3, pp. 277-291. (CBellwether Publishing, Ltd., 8640 Guilford Road, Suite 200, Columbia, MD 21046. All rights reserved.

\section{Title: Root architecture and tree stability}

Author: Coutts, M.P.

Series/Source: Plant and Soil, 1983. 71:171-188

Peer-reviewed: Yes

Code: BDWFAL, RTSYST, RTSTAB

\begin{abstract}
Root anchorage is discussed with a view to determining the optimum use of root material for enhanced stability. Field observations were made on Sitka spruce root systems while lateral forces were applied to the stem with a winch to pull the tree over. Measurements included the applied force, angles of inclination, soil and root movement, timing of the sound of root breakage using buried microphones, weight and shape of the root-soil plate, and damage to the roots.

Components of anchorage include the dimensions and mass of the root-soil plate levered from the ground by the displaced stem, and tensile strength of roots and soil beneath the plate; root and soil tensile strength and root/ soil resistance on the windward perimeter; and on the lee side the stiffness of the hinge at the fulcrum.

Strength properties of roots and soil are reviewed. Models devised for landslip are extended to consider behavior under tension, or roots singly and in groups, and the concept is developed of a 'critical rooting density' at which root/ soil resistance exceeds soil strength, giving rise to the characteristic root-soil plate on uprooted trees. The lee side part of the root-soil plate acts as a cantilevered beam and determines the distance of
\end{abstract}


the fulcrum from the tree. Physical laws defining the reduced stiffness of beams as a result of subdivision indicate the importance of the number/ size distribution of roots and weakening effects of branching.

On the windward side, upward movement of the root-soil plate causes sequential breakage of soil and roots. Under an increasing applied load, failure occurs in parts of the soil-root system before the maximum force for uprooting is achieved. A preliminary approach is made to modeling where the changing contributions of the components of anchorage are allowed for throughout the uprooting process.

Objective(s): The objective is a study of root anchorage based on field measurements of winched-over Sitka spruce trees.

Study Location: Kershope Forest, Scotland

Method: Root breakage was acoustically monitored with microphones.

Field measurements included applied force, inclination angles, soil and root deformations, characteristics of the root-soil plate, root damage, and tensile strength properties of the soil and root system.

Vegetation: Mature Sitka spruce (Picea sitchensis Bong. Carr), the "main commercial forest species widely grown in Great Britain"

Soil Properties: Peaty gley soil

Observations/ Results: The leeside (winched side) of the root-soil plate acted as a cantilever beam and determined the distance of the fulcrum from the tree stem. On the windward side, upward movement of the rootsoil plate caused sequential root breakage. With an increasingly applied load, failure occurred in parts of the soil-root system before the maximum force for uprooting was achieved.

\section{Recommendations: N/A}

* Reprinted from Plant and Soil 71, M.P. Coutts, Root architecture and tree stability, 171-188, 1983, with permission from Springer.

Title: Influences of cutting diameter and soil moisture on growth and survival of black willow, Salix nigra

Author: Greer, E., S.R. Pezeshki, and F.D. Shields, Jr.

Series/Source: J ournal of Soil and Water Conservation, 2006.

61(5):311-323

Peer-reviewed: Yes

Code: BKSTAB 
Abstract*: Streambank restoration projects utilize large black willow (Salix nigra) cuttings otherwise known as posts; however, potential exists that smaller size cuttings alone or in combination may improve success efforts. Furthermore, the effects of soil moisture conditions and the potential interaction between size of the cutting and soil moisture regime have not been tested. Therefore, a greenhouse study was conducted to quantify cutting performance in response to the combined effects of soil moisture and diameter size. Replicated cuttings with basal diameters measuring 1, 5, or $10 \mathrm{~cm}(0.4,2$, or 4 in.) were placed in three soil moisture regimes including well-watered, periodic flooding and drought. Biomass accumulation and partitioning, height, and survival were measured. Under periodic flooded conditions, 10-cm (4-in.) cuttings had greater leaf number and weight $(\mathrm{p}<05)$, leaf area index $(\mathrm{p}<05)$, shoot weight $(\mathrm{p}<05)$ and height growth $(\mathrm{p}<05)$ compared to 1 - and 5-cm $(0.4-$ and 2-in.) cuttings ( $\mathrm{p}<05$ ). Survival was best for 1 -cm ( $0.4 \mathrm{in}$.) cuttings in all three moisture regimes (100\%) and for 10-cm (4-in.) cuttings under flooded conditions (100\%). Growth and biomass of 10-cm (4-in.) cuttings were reduced by drought compared to periodic flooding treatment (p-.02). Based on the data, it appears that planting strategies using 1-cm (0.4-in.) cuttings for black willow in any given moisture regime may lead to increased survival rates. Planting larger cuttings may improve overall restoration success. The technique of planting a combination of these two diameters may help to further stabilize streambanks.

Objective(s): The objective was to examine the effects of cutting diameter and soil moisture on the survival and performance of black willow.

Study Location: Loosahatchie River floodplain, western TN Method: Selected sizes of black willow were collected from field areas to test in greenhouse pots for a series of soil moisture conditions. Soil redox potential levels remained in an aerated range (soil redox potential $>+350$ ) in all periodic flooding pots prior to treatment initiation.

Vegetation: Salix nigra (willow)

Soil Properties: Soil pots contained two parts commercial sand and one part field soil (Fayala Soil Series) collected from the same area as the cuttings.

Observations/Results: In periodically flooded conditions, 10-cm(4-in.-) diam cuttings thrived, producing greater biomass and height growth than the other diameter sizes. The 1-cm- (0.4-in.-) diam cuttings 
had a comparable root production and survival rate compared to that of the larger diameter cuttings. The effects of moisture treatments were clearly seen in the 10-cm- (4-in.-) diam cuttings compared to control and drought treatments, whereas drought reduced height growth compared to control and periodic flooding treatments.

Recommendations: Planting techniques for streambank restoration focusing on cutting diameter sizes needs further evaluation. Additional research in field settings might prove helpful in transferring data acquired in this study into practice. Measuring plant physiological functions, such as photosynthesis or transpiration, will help with the detailed evaluation of plant performance.

* Reprinted from E. Greer, S.R. Pezeshki, and F.D. Shields, Jr. 2006. Influences of cutting diameter and soil moisture on growth and survival of black willow, Salix nigra. J ournal of Soil and Water Conservation 61(5):311-323 with permission from the Soil and Water Conservation Society (SWCS).

Title: Missouri River Flood of 1993: Role of woody corridor width in levee protection

Author: Allen, S.B., J .P. Dwyer, D.C. Wallace, and E.A. Cook

Series/Source: J ournal of the American Water Resources Association, 2003. 39(4):923-933

Peer-reviewed: Yes

Code: BKSTAB, LEVVEG, LVFLCL

Abstract: Permission to publish abstract was not obtained.

Objective(s): This research investigated relationships between levee damage and woody corridor after a major flood event

Study Location: Missouri River, MO

Method: Unknown (probably visual investigations)

Vegetation: Riparian woody plants

Soil Properties: N/A

Observations/Results: Forty-one percent of levee failures occurred in areas with no woody corridor, while $74 \%$ and $83 \%$ of failures occurred where woody corridor widths were less than $300 \mathrm{ft}$ and less than $500 \mathrm{ft}$, respectively. Median failure lengths with a woody corridor present were 
$50.3 \%$ shorter than median failure lengths with no woody corridor present. Levees without failures had significantly wider median woody corridor widths than levees that failed.

Recommendations: A woody corridor between the riverbank and primary levee helps to reduce or prevent flood related damage to levees.

\section{Title: Quantifying the mechanical and hydrologic effects of riparian vegetation on streambank stability}

Author: Simon, A., and A. Collison

Series/Source: Earth Surface Processes and Landforms, 2002.

27:527-546

Peer-reviewed: Yes

Code: BKSTAB, RTSTAB

Abstract: Permission to publish abstract was not obtained.

Objective(s): This paper presents results from an experiment in which the hydrologic and mechanical effects of four riparian tree species and two erosion-control grasses were quantified in relation to bank stability.

Study Location: North Mississippi

Method: Geotechnical and pore-water pressure data from streambank plots under three riparian covers (mature trees, clump grasses and bare/ cropped turf grass) were used to drive the U.S. Dept of Agriculture's bank stability model, and the resulting factor of safety $\left(F_{s}\right)$ was broken down into its constituent parts to assess the contribution (beneficial or detrimental) of individual hydrologic and mechanical effects (soil moisture modification, root reinforcement and surcharge).

Vegetation: Sycamore, River birch, Sweetgum, Gamma grass, Black willow, and Switch grass

Soil Properties: Streambank soils

Observations/Results: Vegetation increases soil strength due to the tensile strength and spatial density of roots. Tree roots were found to increase soil strength by 2 to 8 kiloPascals $(\mathrm{KPa})$ depending on species, while grass roots contributed 6 to $18 \mathrm{kPa}$. Following a very dry antecedent period, the mechanical effects of the tree cover increased $F_{s}$ by $32 \%$, while the hydrologic effects increased $F_{s}$ by $71 \%$. For grasses, the figures were $70 \%$ for mechanical effects and a reduction of $\mathrm{F}_{\mathrm{s}}$ by $10 \%$ for the hydrologic effects. Following a wetter than average antecedent period, the mechanical 
effects of the tree cover to increase $\mathrm{F}_{\mathrm{s}}$ by $46 \%$, while hydrologic effects added $29 \%$. For grasses, the figures were $49 \%$ and $-15 \%$, respectively.

Following a wetter than average antecedent period, the hydrologic effects of the tree cover reduced bank stability, though this was always offset by the stabilizing mechanical effects.

Recommendations: This study highlights the need to select riparian vegetation based on hydrologic as well as mechanical and ecological criteria.

\section{Title: Quantifying riverbank erosion with scanning laser altimeter}

Author: Thoma, D.P., S.C. Gupta, and M.E. Bauer

Series/Source: International Archives of Photogrammetry and Remote Sensing, Oct. 2001. 34:169-174

Peer-reviewed: Yes

Code: BKSTAB, SOILER

Abstract: Permission to publish abstract was not obtained.

Objective(s): The objective was to evaluate the potential of laser scanning altimetry to determine the extent of bank erosion and identify banks that are more vulnerable to bank collapse and thus require stabilization efforts.

Study Location: Blue Earth River near Mankato, MN

Method: A 56-km length of the main stem of the Blue Earth River corridor was scanned with a helicopter mounted Topeye laser system. Ground elevation measurements on both banks were surveyed using a total station, and vegetation density at eight locations along the river was noted. A bare earth model was then constructed and was being calibrated with elevation measurements.

Vegetation: Riparian species

Soil Properties: Bulk densities in the river valley were measured Observations/Results: This project examined the potential of scanning laser altimetry to measure comprehensive mass wasting rates from actively eroding riverbanks, a heretofore-improbable task using traditional surveying means. Plans are to make another scan in a year or more to calculate volumetric change in the river valley due to bank erosion/ bank 
collapse. This volume change along with solid bulk density along the river corridor will be used to assess the extent of bank erosion.

\title{
Recommendations: N/A
}

\section{Title: Root-shoot characteristics of riparian plants in a flood control channel: Implications for bank stabilization}

Author: Mallik, A.Z., and H. Rasid

Series/Source: Ecological Engineering, 1993. 2:149-158

Peer-reviewed: Yes

Code: BKSTAB

\begin{abstract}
Root-shoot dimensions and dry biomass of samples of ten dominant species from the bank profiles of the Neebing-McIntyre Floodway, Thunder Bay, Ontario, Canada were significantly different from one micro-habitat to another. These differences were used as the basis of interpreting allocation of energy in different components of plants that helped them colonize specific micro-habitats along the bank profiles of the floodway. Thus, Deschampsia jlexuosa, the dominant plant on the bank slope, allocates about $90 \%$ of its biomass in its shallow but dense root systems (compared to its shoots), which provides protection to the bank slope from surface runoff. Alnus rugosa and Salix bebbiana, dominant on erosional scarps, allocate about equal amounts of biomass in their aboveground and below-ground components, but have long tap roots, which help them colonize the steep scarp face. Plants on the bench and underwater shelf, such as J uncus nodosus and Saggitaria latifolia, allocate disproportionately large amounts of biomass to their aboveground components, which are exposed to the dynamic forces of waves and currents. Overall, the study indicates that root-shoot architecture and biomass can be used as biotechnical criteria in selecting riparian plants for bank stabilization of flood control channels.
\end{abstract}

Objective(s): This study examines root-shoot characteristics of selected riparian plants that have colonized along the banks of a newly constructed flood control channel and suggests a simple and inexpensive procedure for the selection of species that help stabilize the bank.

Study Location: Neebing-McIntyre Floodway, north shore of Lake Superior near the intercity area of Thunder Bay, Ontario, Canada. 
Method: This study divided the bank profile on the main floodway into four micro-habitats: bank slope, scarp face, above-water bench and underwater depositional shelf. Ten dominant species of these micro-habitats were sampled from selected transects to obtain ten samples of each species. The dominant species were selected from an earlier transect and quadrant survey in which 123 species were identified from 215 quadrats along 20 profiles.

Out of the ten species sampled from the four micro-habitats, only Deschampsia flexuosa and Trifolium pratense were planted on the bank slope. The remaining eight species were selected from the naturally colonized plants along the lower sections of the bank profile. The samples were collected by a stratified random sampling procedure, with samples stratified by micro-habitat types.

A simple, workable field/ laboratory method for measuring root-shoot dimensions was designed. First was excavation of the entire root-shoot structures of individual plants/ clumps. For some samples of Deschampsia flexuosa and Phalaris arundinacea the root systems of adjoining clumps were separated manually following excavation. The samples were thoroughly washed in water to remove soil and litter and the spread of roots and shoots was measured by holding them in a tank of clear water. For dry biomass determination, all samples were separated into roots, rhizomes and shoots (including leaves) and oven-dried in paper bags at $80^{\circ} \mathrm{C}$ until they attained constant weight.

Vegetation: Naturally occurring Canadian riparian grass, shrub, and brush vegetation species including: Deschampsia flexuosa, Trifolium pratense, Phalaris arundinacea, Salix bebbiana, Alnus rugosa, Elymus repens, Scirpus rubrotinctus, J uncus nodosus, Sagittaria latifolia, and Myriophyllum exalbescens

\section{Soil Properties: N/A}

Observations/Results: The root-shoot architecture and biomass allocation patterns of riparian plants along the bank profiles of the Neebing-McIntyre Floodway were related to the dynamic forces of the micro-habitats in which these plants were established.

Recommendations: Local riparian species should be used in streambank erosion projects because these plants are likely to adapt well in a comparable environmental setting. Second, it may be desirable to select species that have the ability to colonize the post-constructional habitats fairly rapidly. Third, certain species that may seem to be ideal from the point of view of morphologic stabilization may have adverse effects on channel capacity. Myriophyllum exalbescens, for example, 
induces sedimentation and buildup of the under-water depositional shelf. Excessive buildup of the shelf may, in the long run, result in a loss of the useable storage (life) of the floodway. Only those species that have characteristics to adapt well along the edge of water, but do not affect channel capacity significantly or do not cause maintenance problems, should be selected.

* Reprinted from Ecological Engineering 2, A.Z. Mallik, and H. Rasid, Root-shoot characteristics of riparian plants in a flood control channel: Implications for bank stabilization, 149-158, 1993, with permission from Elsevier.

\title{
Title: The distribution and strength of riparian tree roots in relation to riverbank reinforcement
}

Author: Abernethy, B., and I.D. Rutherfurd

Series/Source: Hydrological Processes, 2001. 15:63-79.

Peer-reviewed: Yes

Code: BKSTAB, RTSTAB

\begin{abstract}
The main influences of plants on the mass stability of riverbanks are those influences that affect the strength of bank sediments. Plants enhance bank strength by reducing soil pore-water pressures and by directly reinforcing bank materials with their roots. In this paper, we do not consider bank hydrology, but focus on quantifying increases in sediment strength due to root reinforcement. Root reinforcement is a function of root strength, interface friction between the roots and the soil, and the distribution of roots within the soil. Field and laboratory studies of Australian riparian trees, river red gum (Eucalyptus camaldulensis) and swamp paperback (Melanleuca ericifolia) indicate that bank reinforcement, due to the roots of these species, decreases exponentially with depth below the soil surface and distance away from the trees. Differences in the spatial distribution of root reinforcement are illustrated by a comparison of the apparent cohesion due to roots $\left(\mathrm{C}_{\mathrm{r}}\right)$ with the effective cohesion of the saturated bank material ( $15 \mathrm{kPa})$. Directly below the river red gum, root reinforcement is equal to effective cohesion at 1.7- $\mathrm{m}$ depth. At the drip line (17 $\mathrm{m}$ from the trunk), root reinforcement is equal to material strength at 0.4-m depth. For the swamp paperbark, $\mathrm{C}_{\mathrm{r}}=$ $15 \mathrm{kPa}$ at $1.1-\mathrm{m}$ depth beneath surface, at the trunks, and at 0.4-m depth at
\end{abstract}


the dripline ( $2.5 \mathrm{~m}$ from the trunk). A description of the spatial distribution of root reinforcement is important in the riverbank context. We find that interspecies differences in the tensile strength of living roots have less significance for bank reinforcement than interspecies differences in root distribution.

Objective(s): The objective was to quantify the magnitude and spatial distribution of the soil shear strength reinforcement provided by riparian tree roots.

Study Location: Field work was conducted at two bank sites (approximately 116 miles east-southeast of Melbourne, Australia) of the lower Latrobe River near Rosedale in Gippsland, Victoria.

Method: Variations in root density were assessed at each of the sites by mapping the size and location of all roots intersected by a number of vertical profile walls. Only roots with diameters $<20 \mathrm{~mm}$ were used to calculate the root area ratio by depth. Roots were tested in the laboratory and in situ under a range of field conditions.

Vegetation: Australian riparian trees: River red gum (Eucalyptus camaldulensis) and Swamp paperback (Melanleuca ericifolia)

Soil Properties: Fluvial bank sediments, silty loam soils Observations/Results: Shear stresses in the soil mobilize tensile resistance in the roots, which in turn imparts greater strength to the soil. Interspecies differences in the tensile strength of living roots are probably less significant to bank stability that are interspecies differences in root distribution. Root distribution and tensile strength measurements can be used with soil geotechnical data to compare the stability of riverbanks with and without root reinforcement. An advantage of characterizing the spatial distribution of root reinforcement by depth and distance away from the trunk is that the influence of tree position on the mass failure of riverbanks can be assessed.

Recommendations: An advantage of characterizing the spatial distribution of root reinforcement by depth and distance away from the trunk is that the influence of tree position on the mass failure of riverbanks can be assessed.

* Reprinted from Hydrological Processes 15, B. Abernethy, and I.D. Rutherfurd, The distribution and strength of riparian tree roots in relation to riverbank reinforcement, 63-79, 2001, with permission from J ohn Wiley and Sons Ltd. 
Title: Does the weight of riparian trees destabilize riverbanks?

Author: Abernethy, B., and I.D. Rutherfurd

Series/Source: Regulated Rivers Research and Management, 2000.

16:565-576

Peer-reviewed: Yes

Code: BKSTAB, RTSTAB

Abstract*: In contrast to the generally accepted stabilizing effects of riparian vegetation, the surcharge weight of trees on riverbanks has been widely implicated as a source of bank instability. Fieldwork conducted along the Latrobe River in Victoria, Australia, shows that the bankdestabilizing effects of surcharge due to silver wattle (Acacia dealbata) are minimal. Field observations indicate that it is unlikely that the weight of silver wattles growing on an otherwise stable bank section will directly cause mass failure. Observations of deep-seated failures and silver wattle stands on the Latrobe River indicate that where average-sized slump blocks support an average number of the average-sized silver wattles, the trees represent $41 \%$ of the total saturated slump mass. Infinite slope stability analysis indicates the additional weight of the trees may contribute to affect overall instability. However, manipulation of other stability parameters within reasonable constraints negates the effect of surcharge so it is not possible to demonstrate conclusively a destabilizing influence of silver wattles.

Objective(s): The objective was to determine whether the weight (surcharge) of trees along the Latrobe Riverbanks is a source of bank instability.

Study Location: Latrobe River, Victoria, Australia

Method: Authors made qualitative assessments of the extent of the destabilizing influence exerted by riparian trees. The constituent components (soil, water, vegetation) of slump-blocks were observed and compared. Infinite slope stability analyses of individual bank sections were performed. Comparisons were made of bank sections with and without trees that were prone to shallow-planar sliding failure. Estimates of the weight of the bank material and water content of slump-blocks were made. The number and weight of silver wattles able to grow in natural densities were estimated. The surcharge of trees as a proportion of the total saturated mass of the slump-block was assessed. The dimensions of 
twenty-eight slump-blocks were measured; most measured slumps were in grass sections. The volume of aboveground tree parts were estimated and the root mass was estimated to be $10 \%$ of the aerial portion of the trees. Given the wood density variations of above ground and root mass material from area to area, due to environmental conditions (root masses were prone to develop shallow root mass when growing in material over stiff clay), sections of above ground trees and root masses were taken from a variety of locations along the river reach. A significant density difference between the two wood materials was determined. A field verification of the above ground wood density was conducted by cutting down and weighing trees. Combining tree spacing and mass with slump-block dimensions and bulk densities, the potential surcharge of silver wattles was estimated as a proportion of total mass of slump-blocks. Worst-case soil strength parameters were derived from tri-axial compression tests of undisturbed samples. Wind-throw loads on trees were deliberately eliminated from this study.

Vegetation: Silver wattle (Acacia dealbata)

Soil Properties: N/A

Observations/Results: Of failure mechanisms observed, shallowplanar slides on undercut bank sections appeared to be most vulnerable to additional forces of tree surcharge. Landowners typically nominate silver wattle as the problem species for bank stability. Silver wattle produces monoculture stands on very steep riverbanks that are often undercut. This study demonstrated that on the Latrobe River, the likely effect of surcharge is small in comparison to other destabilizing forces. Even where trees appear to be implicated in bank failure by their direct association with failed slump-blocks or by their position on undercut banks, analysis with worst-case parameters failed to show a direct link between the additional tree weight and increased potential for failure. The variety of slump-block shapes, sizes, and failure mechanisms prevented the drawing of a conclusion that the trees had a negative or positive influence on the bank failures. The mass of trees is small in comparison to the mass slumpblock total mass, about $4 \%$ of the total mass was silver wattle mass.

Observations of bank geometry, tree location, and stand density suggest banks prone to shallow-planar slide failures were most vulnerable to the additional weight of trees. Although the effect of tree surcharge on the stability of undercut banks is negative, the overall influence is not great.

Within the scope of this study, the effect of silver wattle tree weight on bank stability is minimal. Root reinforcement is more important than tree weight in controlling the incidence and type of riverbank failure. 


\title{
Recommendations: N/A
}

* Reprinted from Regulated Rivers Research and Management 16B. Abernethy, and I.D. Rutherfurd, Does the weight of riparian trees destabilize riverbanks? 565-576, 2000, with permission from J ohn Wiley and Sons Ltd.

\section{Title: Woody vegetation protects streambank stability during the 1993 Flood in Central Kansas}

Author: Geyer, W.A., T. Neppl, K. Brooks, and J . Carlisle

Series/Source: J ournal of Soil and Water Conservation, 2000. 55:483486

Peer-reviewed: Yes

Code: BKSTAB, SOILER

\begin{abstract}
Streambank changes after the Kansas Flood of 1993 were examined using aerial photography to determine the relationship of streambank stability to natural riparian vegetation, stream channel morphology, and soil type. The flooding event that occurred that summer along river courses in the central plains area of the United States was considered in the magnitude of a 100- to 500-year category. Water flooded riverbanks and farmlands for a two-month period in the summer. Lateral streambank erosion was significantly related to vegetative cover and soil types; erosion was greatest on cropland and minimal on the forested streambanks and greater on sandy than on silty soils. Channel position or the interaction of soils with cover type or channel position did not influence lateral erosion, but the interaction of channel position with cover type was significant. Stream characteristics of radius of curvature, width, and ratio of radius to width did not influence erosion. The flood was so large that the water flowed over the banks for great distances much of the time, masking the dynamic effect of water at various channel positions.
\end{abstract}

Objective(s): The objective of the research was to investigate the influence of riparian vegetation, channel position, soil, and stream characteristics on streambank erosion/ deposition following an extremely large flood.

Study Location: Kansas River Basin, near Manhattan, KS 
Method: Aerial photographic images were chosen to compare pre- and post-flood channel positions using identified features, such as riparian vegetation and streambank edge. Data collection points were selected at 152-m intervals along the river. Land cover inventories of the $30 \mathrm{~m}$ were conducted next to the 1992 riverbank streambank.

Vegetation: The riparian woody vegetation consisted of many deciduous broadleaf forest species, including cottonwood (Populus deltoides Marsh), box elder (Acer negundo L), elm species (Ulmus sp), hackberry (Celtis occidentalis L), willow species (Salix sp.), silver maple (Acer saccharinum L), and sycamore (Plantanus occidentalis L)

Soil Properties: Sandy and silty fluvial sediments Observations/Results: Woody riparian vegetation has a highly beneficial effect in protecting streambanks against erosion during large floods. Tree cover reduced the extent of streambank erosion caused by the extreme flood of 1993 on the Kansas River. Forested areas on both sides of the river sustained less erosion than those reaches that had no woody vegetation cover.

Recommendations: Cultivating areas next to the streambanks should be avoided due to the high acreage loss during high water events.

* Reprinted from J ournal of Soil and Water Conservation 55, W.A. Geyer, T. Neppl, K. Brooks, and J . Carlisle, Woody vegetation protects streambank stability during the 1993 Flood in Central Kansas, 483-486, 2000, with permission from the J ournal of Soil and Water Conservation.

\title{
Title: The effect of riparian tree roots on the mass-stability of riverbanks
}

Author: Abernethy, B., and I.D. Rutherfurd

Series/Source: Earth Surface Processes and Landforms, 1999. 25:921937

\section{Peer-reviewed: Yes}

Code: BKSTAB

\begin{abstract}
Plants interact with and modify the processes of riverbank erosion by altering bank hydrology, flow hydraulics and bank geotechnical properties. The physically based slope stability model GWEDGEM (General WEDGE Method) was used to assess how changes in bank geotechnical properties due to the roots of native Australian riparian trees
\end{abstract}


affected the stability of bank sections surveyed along the Latrobe River. Modeling bank stability against mass failure with and without the reinforcing effects of River Red Gum (Eucalyptus camaldulensis) or Swamp Paperbark (Melaleuca ericifolia) indicates the root reinforcement of an otherwise unstable bank section can raise the factor of safety from Fs-1.0 up to about Fs-1.6. The addition of roots to riverbanks improves stability even under the worst-case hydrological conditions and is apparent over a range of bank geometries, varying with tree position. Trees growing close to potential failure plane locations, either low on the bank or on the floodplain, realize the greatest bank reinforcement.

Objective(s): The objective was to assess how changes in bank geotechnical properties due to the roots of native Australian riparian trees affected the stability of bank sections surveyed.

Study Location: Latrobe River, Victoria, Australia

Method: N/A

Vegetation: River Red Gum (Eucalyptus camaldulensis) and Swamp Paperbark (Melaleuca ericifolia)

\section{Soil Properties: N/A}

Observations/Results: Vegetation plays a major role in stabilizing riverbanks and moderating erosion, but botanical factors are rarely considered in traditional bank stability analyses. Bank erosion on the lower Latrobe River is the result of a combination of lateral and vertical scour at the bank toe followed by mass failure of the overlying bank portions. The presence of mature trees on the banks increases bank stability against mass failure by reinforcing the bank sediment with roots. Recommendations: Trees growing close to potential failure plane locations, either low on the bank or on the floodplain, realize the greatest bank reinforcement.

* Reprinted from Earth Surface Processes and Landforms 25, B. Abernethy, and I. D. Rutherfurd, The effect of riparian tree roots on the mass-stability of riverbanks, 921-937, 1999, with permission from J ohn Wiley and Sons Ltd.

Title: Control of streambank erosion due to bed degradation with vegetation and structure

Author: Shields, F.D. Jr., A.J . Bowie, and C.M. Cooper 
Series/Source: Water Resources Bulletin, 1995. 31(3):475-489

Peer-reviewed: Yes

Code: BKSTAB, SOILER

\begin{abstract}
Combinations of vegetation and structure were applied to control streambank erosion along incised stream channels in northwest Mississippi. Eleven sites along seven channels with contributing drainage areas ranging from 12 to $300 \mathrm{~km}^{2}$ were used for testing. Tested configurations included eroding banks protected by vegetation alone, vegetation with structural toe protection, vegetation planted on regraded banks, and vegetation planted on regarded banks with toe protection. Monitoring continued for up to 10 years and casual observation for up to 18 years. Sixteen woody and thirteen non-woody species were tested. Native woody species, particularly willow, appear to be best adapted to streambank environments. Sericea lespedza and Alamo switchgrass were the best non-woody species tested. Vegetation succeeded in reaches where the bed was not degrading, competition from kudzu was absent, and bank slopes were stabilized by grading or toes protection. Natural vegetation invaded planted and unplanted stable banks composed of fertile soils. Designs involving riprap toe protection in the form of a longitudinal dike and woody vegetation appeared to be most cost-effective. The exotic vine kudzu presents perhaps the greatest long-term obstacle to restoring stable, functional riparian zones along incised channels in our region. This paper evaluates the effectiveness of the different species and the different designs.
\end{abstract}

Objective(s): To test the effects of vegetation and structure as a control for streambank erosion along incised stream channels. These tests could provide information useful for selecting plants and combinations of plants and structures for stabilizing and restoring banks of incised channels.

Study Location: Northwest Mississippi hills forming the eastern border of the Lower Mississippi alluvial plain

Method: Meteorological and geologic setting data were collected for the study site by literature search of extensive resources. Tests were conducted using vegetation in three configurations on eroding banks: alone, in combination with structural protection at the bank toe, and in combination with structural toe protection on reshaped banks. Eleven sites were planted with woody or non-woody vegetation along seven stream channels. 
Vegetation: Woody Species - Black willow, Arnot bristly locust, Carolina willow, Cottonwood, False anil indigo, Gilf willow, Halbert willow, Hazel alder, Indigo bush, Halifax maidencane, Multiflora rose, River birch, Slender willow, Streamco willow, Sycamore, and Water elm. Non-woody species - Alamo switchgrass, annual ryegrass, Appalow sericea, Boston ivy, Buffalograss, common Bermudagrass, common Reedgrass, Penngift crownvetch, English ivy, Kudzu, Pensacola bahiagrass, Reen canarygrass, Sericea lespedeza, and Subterranean clover

Soil Properties: Meander belt alluvium and early Holocene silts Observations/Results: Short-term (one to three growing seasons) survival rates for woody species varied from 0 to $56 \%$. Mortality was due to drought, bank erosion, covering by sediment, abrasion flows, poor soils, and competition with the exotic vine kudzu. Seventeen years after the experiment, headcut erosion moved through the reach causing bed erosion and bank failure. Five of the six unplanted plots were stable and supported dense woody vegetation, equaling or exceeding the performance of the treatments involving planting. All three of the reaches protected by vegetation and structure at the bank toe remained stable despite rigorous environmental conditions. Study reaches with shaped banks were subjected to severe climatic stresses during a 12-year period, but they remained well vegetated and stable.

\title{
Recommendations: N/A
}

* Formal permission not required. Covered under Fair Use in Title 17 of the US Code.

Title: Material and site controls of streambank vegetation Author: Grissinger, E.H., and A.J . Bowie Series/Source: Transactions of the American Society of Agricultural Engineers, 1984. 27:1829-1835

\section{Peer-reviewed: Yes}

Code: BKSTAB

\begin{abstract}
This article describes three specific conditions which limit the establishment of permanent vegetative cover on many streambanks in northern Mississippi. Critical conditions are imposed either directly or indirectly by the properties and failure mechanisms of the bank materials. These materials are primarily outcrops of valley-fill units that were
\end{abstract}


deposited during the Holocene Epoch. Material properties and failure mechanisms are relatively consistent within units but differ between units.

Two of these specific conditions involve bank height and angle. For a given material, these site conditions indirectly limit vegetation by controlling mass failure frequencies. Bank instability occurred when bank heights and/ or angles were greater than critical, resulting in a loss of vegetative cover. The third condition was imposed by distinctive properties of the early-Holocene massive silt unit. This material is dense and has a well-developed polygonal structure that causes near-vertical bank angles. Outcrops of this material in the channel bank are typically barren of vegetation, but many such outcrops have been relatively stable except where channel entrenchment has exposed excessively weak toe materials.

These results establish that bed and bank-toe stability is a prerequisite to the development of permanent vegetation of channel banks for this study in northern Mississippi. Additionally, these results illustrate the usefulness of classifying channel bed and bank materials as units of the valley-fill system.

Objective(s): The objective was to compare conditions that limit permanent vegetative cover on streambanks in north Mississippi.

Study Location: The study area included two adjacent catchments, J ohnson and Goodwin Creek catchments, in the southeast quarter of Panola County, northern Mississippi. Both catchments are primarily within the Bluff Hills physiographic sub-province, a loess covered area of relatively high relief immediately east of the flat Mississippi Alluvial Plain (colloquially termed the Mississippi Delta).

Method: Visual evaluation

Vegetation: Streambank riparian species

Soil Properties: Valley-fill outcrops including silt banks

Observations/Results: Many channel reaches have depths greater than critical due to (a) the surficial deposits of historic sediments, (b) knickpoint incision, and (c) excessive transport of unconsolidated bed material out of transport reaches. Gravity-induced bank instability has been imposed by this excessive channel deepening and this type of instability has been aggravated by exposure of relatively weak toe materials, by the development of vertical tension cracks in the lateHolocene materials, and by rapid removal of bank slough deposits. This slough material removal oversteepens the banks and regenerates failure processes. Bed and bank-toe stability is a prerequisite to the development 
of permanent vegetation of channel banks for this study in northern Mississippi. Additionally, these results illustrate the usefulness of classifying channel bed and bank materials as units of the valley-fill system.

Recommendations: This reference applies to a zoned bank protection approach and should be used as a reference to the type of native vegetation in Mississippi.

* Reprinted from Transactions of the American Society of Agricultural Engineers 27, E.H. Grissinger, and A.J . Bowie, Material and site controls of stream bank vegetation, 11829-1835, 1984, with permission from American Society of Agricultural Engineers.

\title{
Title: Effects of channel confinement on pioneer woody
} vegetation structure, composition, and diversity along the River Drome (SE France)

Author: Dufour, S., N. Barsoum, E. Muller, and H. Piegay

Series/Source: Earth Surface Processes and Landforms, 2007. 32:1244-1256.

Peer-reviewed: Yes

Code: CHSTAB, ECOSYS

\begin{abstract}
River embankments are one of the main causes of a loss in active channel movement. The knock-on effects of river channel stabilization include important shifts in the ecohydrological conditions in the protected zone behind embankments. However, few authors have attempted to investigate changes to pioneer units of vegetation colonizing the active channel following the construction of dikes. As a consequence, we studied the structure, composition and diversity of pioneer vegetation units dominated by willow and poplar along the River Drome in two adjacent, but contrasting, river reaches: an embanked reach and an unconstrained reach, each subject to the same flow regime, but offering very different hydrogeomorphological contexts for vegetation colonization. Our results clearly demonstrate that river embankments affect channel geometry. A reduction in channel width (from between 200 and $500 \mathrm{~m}$ to less than $100 \mathrm{~m}$ ) leads to steeper elevational gradients with an overall coarser grain size and consequently drier overall conditions, on colonizable landforms in the channelized reach. Pioneer vegetation
\end{abstract}


responded by occurring in smaller units within the channelized study reach. There was also a reduction in species diversity, a homogenization in vegetation unit structure, and a predominance of more drought-tolerant ligneous species (P. Nigra) in pioneer vegetation units in the channelized study reach.

Objective(s): The objective was to analyze the hydrological impacts on pioneer vegetation community composition, structure, and diversity as well as sediment changes resulting from diked channel confinement. Study Location: Two reaches of the River Drome, a sixth-order freeflowing piedmont river in southeast France

Method: The methodology included construction of topographical profiles, characterization of vegetation communities in embanked and unconstrained study reaches, patterns of sedimentation, and the collection of soil and tree cores.

Vegetation: Annual meadow grass (Poa annua), Virginia creeper (Parthenocissus inserta), red clover (Trifolium pretens), black poplar (Populus nigra), rosemary willow (Salix eleagnos), and purple willow (Saliz purpurea)

Soil Properties: Fluvial and floodplain deposits (fine sand and finer sediments)

Observations/Results: In the embanked reach, active channel width ranged from 70 to $110 \mathrm{~m}$, while in the unconstrained reach active channel width ranged from 200 to $500 \mathrm{~m}$. Median relative elevations above the deepest point for each cross section were highest in the embanked study reach $(1.3 \mathrm{~m}$ versus $1.1 \mathrm{~m})$. The number and surface area of pioneer islands in the unconstrained reach were much greater when compared with the embanked reach. At the scale of each pioneer island, vegetation species richness was lower in the embanked reach compared with the unconstrained reach ( 24 and 23 versus 43 and 49 species). Fine sediment thickness was significantly lower in the pioneer units of the embanked reach, where maximum sediment thickness was $24 \mathrm{~cm}$ compared with $96 \mathrm{~cm}$ in the pioneer vegetation units of the unconstrained reach. Differences in hydraulic conditions between the embanked and unconstrained river reaches contribute to a narrower active zone and greater contrasts in the elevations of colonizable landforms in the embanked reach compared with the unconstrained reach. The higher frequency of the P. nigra in the embanked reach is explained by its greater tolerance of rapid water table drawdown rates compared with the willow species commonly found along the River Drome. Several differences 
observed among pioneer woody vegetation units were linked to differences in active channel planform and notably island size. Heterogeneity of pioneer vegetation units appears to be directly linked to island type. Recommendations: The preservation of functional sites for pioneer species conservation must be managed at the river basin scale. While there is no single solution for managing embanked reaches along gravel bed rivers, our results indicate how pioneer communities can be used as relevant indicators of the hydrogeomorphic functional status of a river and thus of restoration practice that can be considered successful in terms of habitat diversification and increases in riparian species richness following embankment removal.

* Reprinted from Earth Surface Processes and Landforms 32, S. Dufour, N. Barsoum, E. Muller, and H. Piegay, Effects of channel confinement on pioneer woody vegetation structure, composition, and diversity along the River Drome (SE France), 1244-1256, 2007, J ohn Wiley and Sons Interscience with permission from Blackwell Publishing.

Title: Riparian forest effect on lateral stream channel migration in the glacial till plains

Author: Burckhardt, J .C., and B.L. Todd

Series/Source: J ournal of the American Water Resources Association, 1998. 34(1):179-184

Peer-reviewed: Yes

Code: CHSTAB

Abstract: Permission to publish abstract was not obtained.

Objective(s): The objective was to determine if riparian forests influenced lateral migration rates of stream channels in the glacial till plains of north central Missouri.

Study Location: Glacial till plains of north central Missouri Method: Tree-aging analyses of trees growing on old point bars (stream bends) along seven streams in Missouri

Vegetation: Riparian trees

Soil Properties: N/A

Observations/Results: The study confirmed that riparian trees are effective in slowing lateral channel migration on characteristic streams of 
north central Missouri. The investigation supported resource managers' efforts to establish and maintain forested corridors along streams.

Recommendations: N/A

Title: Woody vegetation and channel morphogenesis in lowgradient, gravel-bed streams in the Ozark Plateaus, Missouri and Arkansas

Author: McKenney, R., R.B. J acobson, and R.C. Wertheimer

Series/Source: Geomorphology, 1995. 13:175-198

Peer-reviewed: Yes

Code: CHSTAB

Abstract*: Woody vegetation affects channel morphogenesis in Ozark streams of Missouri and Arkansas by increasing local roughness, increasing bank strength, providing sedimentation sites, and creating obstructions to flow. Variation in physiographic controls on channel morphology results in systematic changes in vegetation patterns and geomorphic functions with increasing drainage basin area. In upstream reaches, streams have abundant bedrock control and bank heights that typically are less than or equal to the rooting depth of trees. In downstream reaches where valleys are wider and alluvial banks are higher, vegetation has different geomorphic functions. At drainage areas of greater than 100 to $200 \mathrm{~km}^{2}$, Ozarks streams are characterized by longitudinally juxtaposed reaches of high and low lateral channeled migration rates, referred to as disturbance reaches and stable reaches, respectively. Whereas stable reaches can develop stable forested floodplains (if they are not farmed), disturbance reaches are characterized by dynamic vegetation communities that interact with erosion and deposition processes.

Disturbance reaches can be subdivided into low-gradient longitudinal zones. Low-energy zones are characterized by incremental, unidirectional lateral channel migration and deposition of gravel and sand bars. The bars are characterized by prominent bands of woody vegetation and ridge and swale topography. Channel monitoring data indicate that densely vegetated bands of woody vegetation formed depositional sites during bedload-transporting events. The same floods caused up to $20 \mathrm{~m}$ of erosion of adjacent cutbanks, scoured non-vegetated areas between vegetation bands, and increased thalweg depth and definition. In high- 
energy (or riffle) zones, channel movement is dominated by avulsion. In these zones, vegetation creates areas of erosional resistance that become temporary islands as the channel avulses around or through them. Woody vegetation on islands creates steep, root-defended banks that contribute to narrow channels with high velocities.

Calculation of hydraulic roughness from density and average diameter of woody vegetation groups of different ages indicates that flow resistance provided by vegetation decreases systematically with group age, mainly decreasing stem density. If all other factors remain constant, the stabilizing effect of a group of woody vegetation on a gravel bar decreases with vegetation age.

Objective(s): The goal of this paper was to present results of research studying the relations between woody vegetation and channel morphogenesis in gravel-bed streams of the Ozark Plateaus.

Study Location: J acks Fork, MO, Buffalo River, AR, within the Ozark Plateau

Method: Channel cross sections were topographically surveyed and tree stem cores were sampled.

Vegetation: Sycamore (Platanus occidentalis), willow (Salix), elm (Ulmus), honey locust (Gleditsia triacanthos), osage orange (Maclura pomifera), black locust (Robinia pseudoacacia), box elder (Acer negundo), Ohio buckeye (Aesculus glabra), witchhazel (Hamamelis virginiana), grape (Vitis), poison ivy (Rhus radicans), hackberry (Celtis occidentalis), greenbrier (Smilax), dogwood (Cornus), redbud (Cercis Canadensis), paw paw (Asimina triloba), eastern red cedar (J uniperus virginiana), oak (Quercus), and sweetgum (Liquidambar styraciflua) Soil Properties: Several examples of success or failure of various geologic settings (gravel banks, bedrock, meander belt stream sediments, etc.) were reviewed with only general descriptions of soils.

Observations/Results: Vegetation-landform associations reflected the temporal range of channel stability and different geomorphic functions of vegetation in channel morphogenesis in Ozark streams. Young, dense vegetation can contribute substantially to flow resistance. Flow resistance provided by vegetation decreases systematically with group age, mainly through decreasing stem density. If all other factors remain constant, the stabilizing effect of a group of woody vegetation on a gravel bar decreases with vegetation age.

Recommendations: N/A 
* Reprinted from Geomorphology 13, R. McKenney, R.B. J acobson, and R.C. Wertheimer, Woody vegetation and channel morphogenesis in lowgradient, gravel-bed streams in the Ozark Plateaus, Missouri and Arkansas, 175-198, 1995, with permission from Elsevier.

Title: Flood control areas as an opportunity to restore estuarine habitat

Author: Cox, T., T. Maris, P. De Vleeschauwer, T. De Mulder, K. Saetaert, and P. Meire

Series/Source: Ecological Engineering, 2006. 28:55-63

Peer-reviewed: Yes

Code: ECOSYS, LVFLCL

Abstract*: Intertidal areas in estuaries play a multi-functional role, from energy dissipation and mitigation of floods over provision of natural habitat to a contribution in the cycling and recycling of nutrients. Many of these intertidal areas have been claimed for urban, agricultural, or Industrial expansion. When considering restoration in a land-scarce environment, managed realignment is not always an option and thus other approaches need to be considered. In this paper, we investigate the possibility to combine the concept of a flood control area (FCA) with nature development and the functions of intertidal areas, by use of simple sluice constructions to introduce a controlled reduced tide (CRT). Model results show the possibility to introduce acceptable tidal influence in FCAs. Nevertheless, there are major differences with tidal characteristics of natural outer dike marshes: the spring-neap tidal range is strongly reduced, the tidal curve flattened. Also, the relation between inundation time (IT) and inundation frequency (IF) shows strong distortion compared to the natural situation, with roughly doubled inundation times as compared with a natural outer dike marsh. This has important implications for nature and vegetation development. Further research and monitoring of test sites is necessary to conclude about the desirability of the implementation on larger scale of this concept.

Objective(s): Modeling exercises were done to study the possibilities of enhancing natural intertidal development by introducing a CRT in a FCA, using simple sluices.

Study Location: Europe 
Method: Coastal dike marsh study

Vegetation: Intertidal marsh plants

Soil Properties: N/A

Observations/Results: Although both intertidal flat and intertidal marsh development are desired from an ecological point of view, arguments of social acceptability, possibility for recreation, and nature compensation favor the latter.

Recommendations: More research is needed.

* Reprinted from Ecological Engineering 28, T. Cox, T. Maris, P. De Vleeschauwer, T. De Mulder, K. Saetaert, and P. Meire, Flood control areas as an opportunity to restore estuarine habitat, 55-63, 2006, with permission from Elsevier.

Title: Root proliferation in decaying roots and old root channels: A nutrient conservation mechanism in oligotrophic mangrove forests?

Author: McKee, Karen L.

Series/Source: J ournal of Ecology, 2001. 89:876-887

Peer-reviewed: Yes

Code: ECOSYS, RTSYST

Abstract: Permission to publish abstract was not obtained.

Objective(s): The objectives of this study were to quantify the proliferation of roots in oligotrophic (nutrient-poor) habitats and to determine what causes this response.

Study Location: Nutrient-poor mangrove islands along coastal Belize, Central America

Method: Peat-based soils were characterized by the presence of decaying roots and numerous old root channels $(0.1$ to $3.5 \mathrm{~cm}$ diam) that become filled with living and highly branched roots of mangrove trees. Artificial channels constructed of PVC pipe were buried in the peat for 2 years and then analyzed for root growth characteristics.

Vegetation: Red mangrove (Rhizophora mangle) and black mangrove (Avicennia germinans)

Soil Properties: Peat derived from decomposing mangrove biomass 
Observations/Results: For mangrove root growth and distribution in a nutrient-poor soil (muck), the roots' nutrient availability is more important than either the root growth spatial availability or root growth spatial impediments. Artificial channels constructed of PVC pipe filled with nutrient-rich organic matter had six times more roots than empty or sand-filled channels, indicating a response to greater nutrient availability rather than to greater space or less impedance to root growth.

Recommendations: N/A

Title: Flora and vegetation of dikes of the middle course of the river Elbe between Magdeburg and Darchau (Translation of German Language Article). Flora und Begetation der Deiche an der mittleren Elbe zwischen Magdeburg und Darchau Author: Magdeburg and Darchau (Germany).Brandes-Dietmar Series/Source: Braunschweiger-Naturkundliche-Schriften, 2000. 6(1):199-217

Peer-reviewed: N/A

Code: ECOSYS

Abstract: Permission to publish abstract was not obtained.

Objective(s): The objective was to evaluate the ecological importance of vegetation and flora on dikes.

Study Location: Elbe River, Germany, between Magdeburg and Darchau Method: N/A

Vegetation: Various flora

Soil Properties: N/A

Observations/Results: There appears to be no significant differences in flora between the riverside and landside sections of the dike.

Recommendations: N/A

Title: A global analysis of root distributions for terrestrial biomes

Author: J ackson, R.B., J . Canadell, J.R. Ehleringer, H.A. Mooney, O.E.

Sala, and E.D. Schulze

Series/Source: Oecologia, 1996. 108:389-411 


\section{Peer-reviewed: Yes}

\section{Code: ECOSYS, RTSYST}

Abstract*: Understanding and predicting ecosystem functioning (e.g., carbon and water fluxes) and the role of soils in carbon storage requires an accurate assessment of plant rooting distributions. Here, in a comprehensive literature synthesis, we analyze rooting patterns for terrestrial biomes and compare distributions for various plant functional groups. We compiled a database of 250 root studies, subdividing suitable results into 11 biomes, and fitted the depth coefficient $\beta$ to the data for each biome (Gale and Grigal $1987^{*}$ ). $\beta$ is a simple numerical index of rooting distribution based on the asymptotic equation $Y=l-\beta^{d}$, where $d=$ depth and $Y=$ the proportion of roots from the surface to depth $d$. High values of $\beta$ correspond to a greater proportion of roots with depth. Tundra, boreal forest, and temperate grasslands showed the shallowest rooting profiles ( $\beta=0.913,0.943$, and 0.943 , respectively), with 80 to $90 \%$ of roots in the top $30 \mathrm{~cm}$ of soil; deserts and temperate coniferous forests showed the deepest profiles ( $\beta=0.975$ and 0.976 , respectively) and had only $50 \%$ of their roots in the upper $30 \mathrm{~cm}$. Standing root biomass varied by over an order of magnitude across biomes, from approximately 0.2 to $5 \mathrm{~kg} \mathrm{~m}^{-2}$. Tropical evergreen forests had the highest root biomass $\left(5 \mathrm{~kg} \mathrm{~m}^{-2}\right)$, but other forest biomes and sclerophyllous shrublands were of similar magnitude. Root biomass for croplands, deserts, tundra and grasslands was below $1.5 \mathrm{~kg} \mathrm{~m}^{-2}$. Root/ shoot (RIS) ratios were highest for tundra, grasslands, and cold deserts (ranging from 4 to 7); forest ecosystems and croplands had the lowest RIS ratios (approximately 0.1 to 0.5). Comparing data across biomes for plant functional groups, grasses had $44 \%$ of their roots in the top $10 \mathrm{~cm}$ of soil $(\beta=0.952)$, while shrubs had only $21 \%$ in the same depth increment $(\beta=0.978)$. The rooting distribution of all temperate and tropical trees was $\beta=0.970$ with $26 \%$ of roots in the top $10 \mathrm{~cm}$ and $60 \%$ in the top $30 \mathrm{~cm}$. Overall, the globally averaged root distribution for all ecosystems was $\beta=0.966\left(\mathrm{r}^{2}=0.89\right)$ with approximately $30 \%, 50 \%$, and $75 \%$ of roots in the top $10 \mathrm{~cm}, 20 \mathrm{~cm}$, and $40 \mathrm{~cm}$, respectively. We discuss the merits and possible shortcomings of our analysis in the context of root biomass and root functioning.

Objective(s): The objective was to compile a comprehensive literature synthesis to analyze rooting patterns for terrestrial biomes and compare distributions for various plant functional groups

Study Location: Worldwide 
Method: A database was compiled from 250 root studies, subdividing suitable results into 11 biomes, and the depth coefficient $\beta$ was fitted to the data for each biome. $\beta$ is a simple numerical index of rooting distribution based on the asymptotic equation $Y=l-\beta d$, where $d=\operatorname{depth}$ and $Y=$ the proportion of roots from the surface to depth $\mathrm{d}$. High values of $\beta$ correspond to a greater proportion of roots with depth.

Vegetation: Separated into 11 biome ecosystems Soil Properties: N/A

Observations/Results: Tropical evergreen forests had the highest root biomass, but other forest biomes and sclerophyllous shrublands were of similar magnitude. Root/ shoot (RIS) ratios were highest for tundra, grasslands, and cold deserts; forest ecosystems and croplands had the lowest RIS ratios. Comparing data across biomes for plant functional groups, grasses had $44 \%$ of their roots in the top $10 \mathrm{~cm}$ of soil, while shrubs had only $21 \%$ in the same depth increment. The rooting distribution of all temperate and tropical trees showed $26 \%$ of roots in the top $10 \mathrm{~cm}$ and $60 \%$ in the top $30 \mathrm{~cm}$.

\section{Recommendations: N/A}

*Gale, M.R., and D.K. Grigal (1987). "Vertical root distributions of northern tree species in relation to successional status." Canadian J ournal of Forestry Research 17:829-834.

* Reprinted from Oecologia 108, R.B. J ackson, J . Canadell, J.R. Ehleringer, H.A. Mooney, O.E. Sala, and E.D. Schulze, A global analysis of root distributions for terrestrial biomes, 389-411, 1996, with permission from Springer.

\section{Title: On the maximum extent of tree roots}

Author: Stone, E.L., and P.J . Kalisz

Series/Source: Forest Ecology and Management, 1991. 46:59-102

Peer-reviewed: Yes

Code: ECOSYS, RTSYST

Abstract*: Based on literature reports, personal communications and our own observations, maximum vertical and radial root extents were tabulated for various woody species, primarily forest trees and shrubs, and horticultural trees. Data were summarized for 49 families, 96 genera, and 
211 species, as well as for forest stands composed of mixtures of species. These data demonstrate the inherent capability of many species to develop deep or far-reaching roots in the absence of restrictive soil or substrate characteristics. These data also suggest that extensive roots may play a more important role in uptake of water and nutrients than indicated by their density alone, and that actual, rather than assumed, root extent must be evaluated on a site-specific basis to provide realistic estimates of ecosystem properties and processes.

Objective(s): The objective was to compile a maximum vertical and radial root extents for various woody species, primarily forest trees and shrubs, and horticultural trees

\section{Study Location: N/A}

Method: Literature reports, personal communications and observations formed the basis for tabulation of maximum vertical and radial root extents for various woody species, primarily forest trees and shrubs, and horticultural trees. Data were summarized for 49 families, 96 genera, and 211 species, as well as for forest stands composed of mixtures of species.

Vegetation: Trees and shrubs

Soil Properties: Various

Observations/Results: Many species develop deep or far-reaching roots in the absence of restrictive soil or substrate characteristics.

Extensive root systems may play a more important role in uptake of water and nutrients than indicated by their density alone, and actual root extent must be evaluated on a site-specific basis.

\section{Recommendations: N/A}

* Reprinted from Forest Ecology and Management 46, E.L. Stone, and P.J. Kalisz, On the maximum extent of tree roots, 59-102, 1991, with permission from Elsevier.

Title: Trench inserts as long-term barriers to root transmission for control of oak wilt

Author: Wilson, A.D., and D.G. Lester

Series/Source: Plant Disease, 2002. 86:1067-1074,

http://www.apsnet.org/pd/search/2002/0809-01r.asp

Peer-reviewed: Yes

Code: GEOTEX, ECOSYS, RTSYST 
Abstract*: Physical and chemical barriers to root penetration and root grafting across trenches were evaluated for their effectiveness in improving trenches as barriers to root transmission of the oak wilt fungus in live oaks. Four trench insert materials were tested, including waterpermeable Typar and Biobarrier, and water-impermeable Geomembrane of two thicknesses. Systemic fungicide treatments of trees immediately outside of trenches also were tested. In the first several years following trench installation, an abundance of small adventitious roots commonly formed from roots severed by trenching. These roots provided opportunities for initiation of root grafts across trenches in subsequent years. Although trench inserts did not significantly improve trenches during the first three years following trench installation, water-permeable inserts did effectively improve the performance of trenches beyond the third posttrenching year, when trenches are normally effective, and extended trench longevity indefinitely. The water-permeable inserts were more effective root barriers because they did not direct root growth from the point of root contact. The water-impermeable materials, however, did tend to direct root growth around these barriers, leading to the development of new root graft connections and associated oak wilt root transmission across the trench. The additional cost of trench inserts above trenching costs was justified in urban and rural homestead sites, where high-value landscape trees required more protection and additional retrenching costs were avoided.

Objective(s): Experimental methods to reduce root transmission of the oak wilt disease (fungus) by improving the traditional trenching method (severing root connections between healthy trees to stop the spread of the disease).

Study Location: Near Austin, TX

Method: A 7-yr study using various trench insert materials as well as fungicide treatments. Water permeable and water impermeable materials in four types of commercially available trench-inserts were tested. The trenches were then backfilled with soil and re-excavated at stages within the 7-yr period to analyze root characteristics and treatment success.

Vegetation: Oak trees (Quercus species)

Soil Properties: Rocky and sandy clay-loam

Observations/Results: The water-permeable inserts were more

effective root barriers because they did not direct root growth from the point of root contact. The water-impermeable materials, however, did tend 
to direct root growth around these barriers, leading to the development of new root graft connections and associated oak wilt root disease transmission across the trench. Fungicide injections were ineffective in preventing root disease transmission. Brand-name trench-insert material evaluations and comparisons were discussed.

\section{Recommendations: N/A}

* Formal permission not required. Covered under Fair Use in Title 17 of the US Code.

Title: Analysis of naturalization alternatives for the recovery of moist-soil plants in the floodplain of the Illinois River

Author: Ahn, C., D.M. J ohnston, R.E. Sparks, and D.C. White

Series/Source: Hydrobiologia, 2006. 565:217-228

Peer-reviewed: Yes

Code: LEVVEG

Abstract*: The hydrologic regime of the Illinois River has been substantially altered by floodplain levees, navigation dams, and water diversion. Unnaturally frequent and untimely water level fluctuations, large and small, have decreased the productivity of many floodplain vegetation comunities that provide important ecological services, including the moist-soil plant community. We simulated three scenarios, including two that were expected to benefit moist-soil plants: (1) existing conditions with levees and navigation dams closed during the summer growing season; (2) levees opened to reconnect the river and its floodplain during the growing season; and (3) both the downstream navigation dam and the levees opened during the growing season. A 1-dimensional hydraulic model generated daily hydrographs of the river at three positions in the 135-km study reach: (1) near the downstream dam, (2) in the middle of the reach, and (3) near the upstream dam. These hydrographs then were used to run a model that predicts the grouth of moist-soil plants at a range of floodplain elevations. As expected, the model predicted that plants would grow over a larger area during the growing season after breaching the levees, but the outcomes showed a strong location dependency. Moist-soil plant production would increase in the upper and mid-reach locations, but there would be no change near the downstream dam despite opening the levees. Modeling revealed that the 
existing operation of the navigation dam permanently floods most of the floodplain zone where moist soil plants might grow for at least 15-km upstream of the dam. Trees currently grow all the way to the low water line and are likely to exclude moist soil plants from any restored portion of the floodplain. Sites for reconnecting the river with its floodplain should be carefully chosen to maximize the chances of recovering the important moist-soil plant community in this regulated river.

Objective(s): The objective was to describe a modeling effort to assess plant growth scenarios along a representative section of the Lower Illinois River between the La Grange Dam and Peoria Dam. Rather extreme scenarios were examined involving opening the levees and the La Grange Dam. The approach and analysis provided information and insights that are useful in selecting restoration sites and in addressing the controversy over isolating vs. connecting the converted levee districts to the river. Study Location: 135-km (La Grange) Reach of the Illinois River. Method: A hydraulic model, Unsteady flow through a full NETwork of open channels (UNET), for the La Grange Reach was calibrated using 61 years of daily water level elevations at three gages within the reach. The open (i.e., breached) levee scenario was represented in the model by removing the levees from the elevation cross-sections across the channel and floodplain. The resulting simulated hydrographs from UNET were used as input to a moist-soil plant growth model, which quantified moistsoil plant "success" in terms of germination and growth.

Vegetation: Moist-soil plants

Soil Properties: N/A

Observations/Results: Under existing conditions, the spring flood and smaller rises in water levels were moderated as they moved down the La Grange Reach, because of the well-known dampening effects of flow resistance and hydraulic storage capacity in the channel itself and in the floodplain and associated channels. Opening the levees would reduce flood heights during the spring and early growing season. The reduction would be over $0.5-\mathrm{m}$ for the upper $15-\mathrm{km}$ segment of the reach and somewhat less in the mid-reach segment. Opening the downstream dam would have the greatest effect on the downstream segment and, as expected, water levels would drop markedly close to the dam. Moist-soil plants are a good indicator for the naturalistic water level regime, but not for riverfloodplain connectivity because the flooding pattern these plants require can be created by regulated flooding within leveed areas of the floodplain. If the entire floodplain was reconnected to the river near the downstream 
dam in the study reach, moist soil plants were unlikely to grow there because of the effects of the dam on the water levels.

\title{
Recommendations: N/A
}

* Reprinted from Hydrobiologia 565, C. Ahn, D.M. J ohnston, R.E. Sparks, and D.C. White, Analysis of naturalization alternatives for the recovery of moist-soil plants in the floodplain of the Illinois River, 217-228, 2006, with permission from Springer.

\section{Title: Early vegetation succession and management options on a brackish sediment dike}

Author: Piesschaert, F., J . Mertens, W. Huybrechts, and P. De Rache

Series/Source: Ecological Engineering, 2005. 25:349-364

Peer-reviewed: Yes

Code: LEVVEG, ECOSYS

\begin{abstract}
Port authorities worldwide are confronted with a continuous stream of dredged sediment that needs to be disposed. One of the solutions being considered for the Port of Antwerp (Belgium) is the beneficial use of constructing landscape dikes with dredged material. This paper examines spontaneous development, whether or not combined with mowing or sowing, is a valuable alternative to afforestation for revalorizing brackish sediment dikes. Early vegetation succession was followed on an experiment dike along the river Scheldt. The pioneer vegetation was closely related to flood-mark communities of the Atriplicetum littoralis. The most important abiotic variables for determining consecutive development were the salt grading originating along the topographic gradient, and the mowing management. When halophytic pioneer species have disappeared, the successional pathways on dredged-sediment dikes are very similar to those described for anther hyper-eutrophicated soils, such as abandoned arable fields. Zero-management results in species-poor Urtica-Elymus stands. Mowing and cut removal leads to ruderal grassland related to the Artemisietea. Grass species need to be sown to obtain target communities of the Arrhenatherion. The consequences of these findings for the construction, design, and management of future landscape dikes are discussed.
\end{abstract}


Objective(s): Experiments were performed to determine if spontaneous vegetation development (in combination with either mowing or sowing) on dredged material disposal dikes is a valuable alternative to afforestation.

Study Location: Port of Antwerp, Belgium

Method: Five contiguous zones of $20 \mathrm{~m} \times 50 \mathrm{~m}$ were established parallel to the altitudinal gradient and subjected to four treatments: spontaneous development, mowing, sowing with grass mixture and mowing, and sowing with herb/ grass mixtures and mowing. Unconstrained ordinations were also carried out. The vegetation matrix consisted of 135 records and 126 species. Logarithmic transformation was applied to cover percentage data to avoid extreme influence of dominant species.

Vegetation: Atriplicetum littoralis, Urtica-Elymus, Arrhenatherion, Artemisietea Epilobium species, and J uncus species (126 species of herbs and grasses)

Soil Properties: Saline dredged material reclaimed for beneficial-use Observations/Results: Many attempts to restore grasslands in fail because early successional species establish vigorously and persistently, whereas late successional species remain absent. Applying seed mixtures can promote or enable the establishment of late successional species. A suitable species resistant to the high initial salt concentrations might be weeping alkaligrass (Puccinellia distans).

\section{Recommendations: N/A}

* Reprinted from Ecological Engineering 25, F. Piesschaert, J . Mertens, W. Huybrechts, and P. De Rache, Early vegetation succession and management options on a brackish sediment dike, 349-364, 2005, with permission from Elsevier.

Title: Environmental aspects - Sacramento bank protection Author: Mifkovic, C.S., and M.S. Petersen Series/Source: J ournal of the Hydraulics Division, 1975. 101(5):543555.

Peer-reviewed: Yes

Code: LEVVEG, BKSTAB, ECOSYS, LVFLCL

Abstract*: The Sacramento River is an alluvial meandering stream draining 26,300 square miles $\left(68,100 \mathrm{~km}^{2}\right)$ of the northern Central Valley 
of California. Through the ages, flood deposits from the Sacramento River created natural levees (rimlands) so that the river now flows through an incised channel flanked on either side by broad upraised rimlands, and, beyond, by low-lying flood basins. These flood basins are prime agricultural land; the first low levees to protect the land from flooding were constructed by early settlers in the 1800 s. The levees generally consisted of sand with sufficient clays to make them impervious; however, erosion continually weakened the levees, and as development progressed, the necessity for improved levee design and protection against levee failure became imperative. An example of the disastrous consequences of a levee failure occurred on a tributary of the Sacramento River in 1955, resulting in the loss of 40 lives and damages of about $\$ 48,000,000$ at the time of flooding.

Objective(s): The purpose of this paper was to examine alternative design and construction practices that have been implemented on a test basis or are under study by the Sacramento District, Corps of Engineers, to minimize adverse environmental effects.

Study Location: Sacramento River, northern Central Valley, CA Method: Summaries of applicable Corps efforts

Vegetation: Riparian vegetation

Soil Properties: Sand and clays

Observations/Results: Erosion was threatening the levees and berms of the Sacramento Valley. The Corps of Engineers began investigating modifications for protection of vegetation and wildlife habitat. These modifications include: (1) selective clearing and retention of vegetation and replacement of unavoidably lost vegetation at construction sites, (2) restoration of berm areas, (3) preservation of existing berm areas by steepening the protected slope, (4) requiring construction from the waterside by floating equipment, (5) reducing the top of rock revetment to a high sustained flow level, (6) preservation of habitat on protected berms by strong environmental easements, and (7) inclusion of recreation facilities at selected construction sites.

\section{Recommendations: N/A}

* Formal permission for abstract publication not required, but bibliographic link is requested. 
Title: Rooting of trees in earth dikes: Morphology of tree root systems on slope and risks for embankments

Author: Zanetti, C., M. Vennetier, P. Meriaux, and P. Royet

Series/Source: Geophysical Research Abstracts, 2008. 10:3

Peer-reviewed: Access reviewed.

Code: LEVVEG, RTSYST, SLSTAB

Abstract*: Although the positive effects of woody root systems on slope stabilization were shown many times these conclusions are however not directly transposable with the cases of dikes. Trees' rooting in earth dikes generates two types of risks: internal erosion which is related to root existence in earth embankments, and external erosion (slopes and crest) which is often related to trees uprooting. In order to characterize the incidence of woody root systems on the structure and the durability of the embankment dikes, it is necessary to observe the characteristics of woody root systems for representative species (poplar, black locust, oak, ash, maple).

Objective(s): The objective was to study the effects of tree roots on dikes (levees).

Study Location: Rhone River canal dikes in France

Method: Thirty-one tree stumps were excavated with mechanical shovels. Detailed observations of the root architectural characteristics were noted.

Vegetation: Poplar, black locust, oak, ash, maple (no specific species listed)

Soil Properties: N/A. Average dike slopes were 30\% to 50\%.

Observations/Results: Generic qualitative observations were listed; no results were quantified.

\section{Recommendations: N/A}

* Geophysical Research Abstracts are licensed under the Creative Commons Attribution License together with an author copyright; therefore, permission from the publisher is not necessary.

Title: Soil bioengineering techniques on heavily compacted soils: Experiences from a test site Author: Lammeranner, W., H. Meixner, and F. Florineth Series/Source: Geophysical Research Abstracts, 2008. 10 Peer-reviewed: Access reviewed. 


\section{Code: LEVVEG, LVCONS}

Abstract*: Geotechnical regulations usually recommend the highest practical soil compaction for levees to provide structural integrity and controlled rates of seepage. From a soil bioengineering point of view compacted soils impede rooting and plant growth. High soil bulk densities reduce development of roots, resulting in decreased absorption of water and nutrients. Consequently, plant grouth is limited, depending on soil condition and plant species.

Within the frame of research project carried out by the Institute of Soil Bioengineering and Landscape Construction (University of Natural Resources and Applied Life Sciences, Vienna), focusing on woody plants on levees, research levees were planted with different soil bioengineering techniques. The soil material used for the levees consisted of a sand-silt composite. Measured plant parameters were vitality, shoot lengths and shoot diameters, determining above ground biomass. Root growth was investigated in an extra plot area allowing excavation of the plants. Estimated rooting parameters were rooting depth, spatial pattern, and below ground biomass.

The proposed contribution discusses the effects of high soil compactions on plants and describes design and construction of the soil bioengineering techniques at the test site. Methodology of research and initial results of the vegetation performance after one year of growth are presented.

Objective(s): The objective was to test bioengineering techniques on test levees including a variety of vegetative material and examination of root depth, spatial pattern, and biomass.

Study Location: University of Natural Resources and Applied Life Sciences, Vienna, Austria

Method: Research levees were planted with different soil bioengineering techniques. Various species of vegetation were in planted in longitudinal and traverse arrays. From May to J une 2007 the levees were planted with the following soil bioengineering techniques: (1) dormant cuttings; (2) living brush mattresses (longitudinal); (3) living brush mattresses (traversal) and (4) jute netting mulch seeding. For better initial growth, under dry site conditions, an irrigation system was installed.

Vegetation: Used were (1) dormant cuttings; (2) living brush mattresses (longitudinal); (3) living brush mattresses (traversal) and (4) jute netting mulch seeding. The dormant cuttings and living branches tested 
originated from the Purple-willow (Salix purpurea L.). A mixture of grassand herb-seeds, suited to dry conditions was used for the jute netting mulch seeding.

Soil Properties: Sand-silt composite. A standard compaction test of the material resulted in a maximum density of $2.028 \mathrm{~g} / \mathrm{cm}^{3}$ and optimum moisture content of $9.7 \%$. The research levees should comply with modern construction standards and reach a minimum degree of compaction of $97 \%$ Proctor, meaning a dry density of $1.968 \mathrm{~g} / \mathrm{cm}^{3}$. Investigations with a gamma probe and soil sample rings at the research levees lead to dry densities between 1.886 and $2.028 \mathrm{~g} / \mathrm{cm}^{3}$ and 93 and 100\% Proctor, with an average value of $97 \%$.

Observations/Results: Discussed are the effects of high soil compaction on plants and the soil bioengineering techniques (design and construction) at the test site. Initial results of the vegetation performance after one year of growth were presented.

Recommendations: N/A

* Geophysical Research Abstracts are licensed under the Creative Commons Attribution License together with an author copyright. Permission granted from W. Lammeranner.

Title: Value of woody river corridors in levee protection along the Missouri River in 1993

Author: Dwyer, J.P., D. Wallace, and D.R. Larsen

Series/Source: J ournal of the American Water Resources Association, 1997. 33(2):481-489

Peer-reviewed: Yes

Code: LEVVEG

Abstract: Permission to publish abstract not granted.

Objective(s): To determine the possible relationship between woody vegetation and levee stability during the 1993 flood, a study was designed to determine whether the levees that did not fail, had a wider woody corridor than the levees that did fail. Secondly, for the levees which did fail, could an association between the size of the levee failure and the size of the woody corridor be detected? Finally, was there some minimum woody corridor width where levee failure was reduced? 
Study Location: Missouri River

Method: Study reach - Missouri River Mile 185 to River Mile 146, a distance of 39 miles that represented the full array of conditions left behind by the 1993 flood. October 1993 aerial photography was used to collect river characterization and levee failure inventory data on the primary levees. No ground reconnaissance was conducted.

Vegetation: Woody vegetation - tree canopy

\section{Soil Properties: N/A}

Observations/Results: The analysis of woody corridors along a 39-mile stretch of the Missouri River indicated that a woody corridor reduced the chance of primary levee failure and severity of damage to levee failures during the 1993 flood event. As the width of the woody corridor between the riverbank and the primary levee increased, the damage - both in numbers and size of levee failure - decreased. Floodplain width was not a significant controlling factor in levee stability. Seventy-seven percent of failures occurred when the woody corridor widths were less than $100 \mathrm{ft}$ wide; those with no woody corridors had the highest rate of entry failures as opposed to exit failures.

A woody corridor would increase levee protection and stability and reduce negative flood impacts, such as scouring, deposition, and infrastructure damage. In addition, woody corridors would increase wildlife habitat diversity, reestablish natural riparian ecosystems, and provide an opportunity to manage the woody corridor for the sustainable production of secondary wood products and at the same time provide for the continued recruitment of young, densely grown saplings, increasing vegetation roughness.

Recommendations: Data suggest that a minimum width of $300 \mathrm{ft}$ for the woody corridor may be effective in protecting the primary levee system for this river segment and under these flow conditions. Properly designed flood corridors with woody vegetation will slow floodwater velocities, dissipate energy, reduce scouring potential, and increase soil shear strengths. To effectively reduce levee failures in the studied reaches, the woody corridor would have to exceed a width of $179 \mathrm{ft}$, as there was no difference in the protection of corridors less than $179 \mathrm{ft}$ wide and those areas without woody vegetation.

Title: Effects of woody vegetation on sandy levee integrity Author: Shields, F.D., J r., and D.H. Gray 
Series/Source: Water Resources Bulletin, 1992. 28(5):917-931

Peer-reviewed: Yes

Code: LEVVEG, LVSTAB

Abstract: Permission to publish abstract not granted.

Objective(s): The objective was to study the effects of woody vegetation on the integrity of a sandy levee.

Study Location: A 10-km segment of a channel levee on the Sacramento River near Elkhorn, CA

Method: Botanical (above and below ground) and soil samples were collected to characterize the site consisting of seventeen 1-mile quadrants. The vegetation was mapped by species and class and categorized as trees, shrubs, or ground cover. Seepage analyses were run assuming steady hydraulic conditions. Water level elevations on the riverward slope was assumed to correspond to an elevation equivalent to $90 \%$ of the embankment height above the landward toe. The water surface elevation on the landward side was assumed to be at the toe. Riverward slopes were slightly less steep than the $3 \mathrm{H}: 1 \mathrm{~V}$ standard and were not uniform. The landward slopes were $2 \mathrm{H}: 1 \mathrm{~V}$.

Vegetation: Valley oak (Quercus lobata), cottonwood (Populus fremontii) and Licorice (Glycyrrhize sp.) were in the study areas. The control sites had California rose, telegraph weed, and lotus.

Soil Properties: Sand, medium to fine sands (SP) with a little clay and silt. Soil samples for analysis were collected from boreholes and from trench walls.

Observations/Results: Allowing woody shrubs and small trees on levees would provide environmental benefits and enhance structural integrity without the hazards associated with large trees such as wind throwing. Vertical distribution of roots in the sandy levee reflected site adaptation. The disappearance of roots with depth was observed more gradual than reported by other workers working in western grasslands. Root area ratio computed from profile wall samples are indicative of root distributions in vertical planes, but root distributions across major slip surfaces are more important for slope stability. Woody vegetation has been kept off of earthen embankments because of the potential for piping initiated along living or dead roots. Woody species, which have larger roots at depth than herbaceous plants, are also more effective in preventing deeper-seated sliding. Infinite slope analyses indicated increasing root area ratio from $0.01 \%$ to $1 \%$ increased the factor of safety 
from less than one to more than seven. Circular arc analyses indicated that even the lower measured root concentrations sufficed to increase safety factors for arcs with maximum depths of about $1 \mathrm{~m}$ from less than $1 \mathrm{~m}$ to about $1.2 \mathrm{~m}$.

Recommendations: Levee maintenance standards that permit woody shrubs and small trees would benefit the environmental and would enhance levee integrity without the hazards associated with large trees such as wind throwing.

Title: Woody vegetation and riprap stability along the Sacramento River mile 84.5 - 119

Author: Shields, F.D. Jr.

Series/Source: J ournal of the American Water Resources Association, 1991. 27(3):527-536

\section{Peer-reviewed: Yes}

Code: LEVVEG

Abstract: Permission to publish abstract not granted.

Objective(s): The objective of this paper was to portray the outcomes of an experimental study of a specific river reach that could be beneficial to engineers who want to improve the riprap design to include vegetative factors.

Study Location: miles 84.5 to 119 of the Sacramento River in Northern California

Method: Pre- and post-flood vegetative cover on revetments in the study area were mapped from records of semiannual inspections during the fall of 1985 and spring of 1986 and aerial photo magnifications from 19841985 and 1986-1987. The occurrence of vegetation and the size from the inspections and photos were mapped onto a series of overlays. The size of the woody vegetation was evaluated using crown size, texture, shadow length, and stereo interpretation and was classified and mapped according to size. Type 1 included bare soil or rock or herbaceous growth less than $4 \mathrm{ft}$ high, type 2 was woody vegetation between 4 to $12 \mathrm{ft} \mathrm{high,} \mathrm{and} \mathrm{type} 3$ was woody vegetation larger than $12 \mathrm{ft}$ high. A separate overlay based on the September 1989 revetment vegetation inspection data was mapped. Using the previously mentioned base maps and overlays, a digital database was created. Each record in the database symbolized a 100-ft-long 
segment of revetted bank lines which were running parallel to the channel. The data base fields consisted of spatial location, bank curvature, date of construction, material of the revetment, vegetation type from pre- and post-flood inspections and aerial photos, and condition of the revetment; and was analyzed using graphical techniques, cross-tabulation, and summary statistics.

Vegetation: Herbaceous and woody

\section{Soil Properties: N/A}

Observations/Results: Aerial photography revealed that about $11 \%$ of the revetted segments sustained vegetation of types 2 and 3 before the flood, but after the flood, they only sustained about $9 \%$. Evaluation of the Public Law 84-99 showed five occurrences of damage to revetments because of the 1986 flood and none of the sites consisted of woody vegetation prior to or following the flood. The database was split into 18 subset pairs, revetment age, bank curvature, and material types, to observe the associations between the presence of woody vegetation and damage rates. Damage rates were calculated for each subset and the results showed that the damage rates for revetments with woody vegetation tended to be lower than unvegetated revetments of the same material. The effect of vegetation on stability was evaluated by studying the overlays and by plotting a schematic of the reach which revealed damage and vegetation locations; this revealed that the proximity of vegetation had no effect on stability.

\section{Recommendations: N/A}

\section{Title: Environmental considerations for levees and floodwalls}

Author: Nunnally, N.R., F.D. Shields, Jr., and J . Hynson

Series/Source: Environmental Management, 1987. 11(2):183-191

Peer-reviewed: Yes

Code: LEVVEG, ECOSYS

Abstract*: Levees and floodwalls are used extensively throughout the United States for flood control. Levee projects often lack ecological, recreational, and aesthetic values, except for incidental fish and wildlife benefits derived from borrow pits and recreational facilities found in some urban settings. In recent years, increased environmental concern within construction agencies and greater responsiveness to public opinion have resulted in increasing numbers of levee projects designed, built, and 
maintained with environmental objectives in mind. This paper reviews environmental concepts successfully employed on levee projects constructed in recent years by the U.S. Army Corps of Engineers. Some of the most innovative concepts are described and illustrated and design considerations are discussed.

Objective(s): The objective was to review environmental concepts successfully employed on levee projects constructed in recent (1980s) years by the U.S. Army Corps of Engineers.

Study Location: U.S.-wide

Method: Case history and literature reviews

Vegetation: Mixture of vegetation types

\section{Soil Properties: N/A}

Observations/Results: The ubiquity of levees and their riparian location create a situation with numerous opportunities for environmental quality features. Institutional and technical problems limit the use of environmental concepts in design and maintenance of levee projects.

Recommendation(s): More information is needed on vegetal aspects of levee maintenance (i.e., what types of grasses and maintenance techniques will subsequently control erosion of levee slopes, allow periodic inspection, and provide wildlife habitat benefits).

* Reprinted from Environmental Management, 11(2), N.R. Nunnally, F.D. Shields, J r., and J . Hynson, Environmental considerations for levees and floodwalls, 183-191, 1987, with permission from Springer.

Title: Effect of grass, legume, and tree roots on soil shearing resistance

Author: Waldron, L.J ., and S. Dakessian

Series/Source: Soil Science Society of America J ournal, 1982. 46:894899

Peer-reviewed: Yes

Code: LEVVEG, SLSTAB, RTSTAB

Abstract*: Plants enhance soil stability against downslope mass movement through the removal of soil water by transpiration and by the mechanical reinforcement of their roots. To assess the magnitude of this reinforcement, direct shear measurements were made on $0.25-\mathrm{m}$-diam 
cylindrical soil columns packed both homogeneously and in layers which simulated water and/ or root-impeding horizons. In all cases, the matric potential was adjusted to zero before shearing. Twelve plant species were used including seven grasses: Phalaris tuberosa, Lolium rigidium, Dactylis glomerata, Bromus mottis, Sorgum bicolor sudanense, Triticum oestivum, Hordeum vulgare. Two legumes were used: Vicia dascarpa, Medicago saliva, and two trees were used: Pinus ponderosa and Quercus agrifolia.

The ratio of the shear resistance at 25-mm displacement of the rooted and unrooted specimens was used as a measure of root reinforcement. Roots of several grasses planted in early fall and sheared the following spring gave about a threefold increase in shear resistance at the $0.3-\mathrm{m}$ depth in homogeneous saturated clay loam. In the same material, roots of oak produced a similar increase only after 3-years' growth. One-year-old alfalfa produced a fourfold increase. At the 0.45 -m depth at the interface between soil and a dense gravel-sand mixture simulating weathered rock, yellow pine gave a 1.5-fold increase after 16 months and a 2.5-fold increase after 52 months. Harding grass was almost equally effective after only 7 months.

In almost all cases where roots increased soil shear resistance, the resistance continued to increase beyond 25- $\mathrm{mm}$ displacement so that the selection of 25-mm displacement was conservative, i.e., it may underestimate the root reinforcing effect. Factor of safety calculations for shallow planar slides using measured shear strengths show that plant roots can make large increases in slope stability.

Objective(s): The objective was to assess the magnitude of the root reinforcement effect related to slope stability.

Study Location: California

Method: Cylindrical samples containing rooted and root-free compacted soil materials were each sheared along a predetermined plane perpendicular to the cylinder axis. Containers were $0.61 \mathrm{~m}$ in length made from two sections of 0.25-m-diam tubular concrete forms taped together with a 3-mm-thick spacer at the joint. The shear plane was in the plane of the spacer.

Vegetation: Twelve plant species were used, including seven grasses: Phalaris tuberose, Lolium rigidium, Dactylis glomerata, Bromus mollis, Sorgum bicolor sudanense, Triticum oestivum, Hordeum vulgare. Two legumes were used: Vicia dascarpa, Medicago sativa, and two trees were used: Pinus ponderosa and Quercus agrifolia. 
Soil Properties: Four soil profiles were tested: silty clay loam, clay loam, compacted silty clay loam, and gravelly silt.

Observations/Results: The general conclusion from reports of vegetation removal effects on slide frequency, engineering analyses, and laboratory strength measurements of rooted soil is that plants significantly increase the stability of soil on slopes.

Roots of some grass species planted in early fall produced approximately threefold increases in soil shear resistance. Roots of Ponderosa pine and oak produced shear resistance increase comparable to alfalfa and other vigorous grasses after longer growth periods. The factor of safety calculations used to measure values of soil shear resistance at 25-mm displacement show that roots have the potential for significantly increasing the stability of shallow soils on steep slopes.

Recommendations: A model or concept of root reinforcement in which roots of small trees, legumes, and grasses are treated as flexible linear elements is useful in analyzing slope stability.

* Formal permission not required. Covered under Fair Use in Title 17 of the US Code.

Title: Soil reinforcement by roots: Calculation of increased soil shear resistance from root properties

Author: Waldron, L.J ., and S. Dakessian

Series/Source: Soil Science, 1981. 132(6):427-35

Peer-reviewed: Yes

Code: LEVVEG, RTMODL, RTSYST, SLSTAB

\begin{abstract}
A root-soil model developed previously has been extended to predict the amount of increase in soil shear resistance (root

reinforcement) produced by stretching, slipping, and breaking roots of various sizes. We measured Young's moduli, tensile strengths, and diameters of pine and barley roots, finding that both moduli and strengths decreased with increasing root diameter. These data and root diameter distributions in the shear zone of 0.25-m-diam (pine) and 0.1-m-diam (barley) soil columns were applied to the model. Comparisons of model simulations with experiments showed that the strength of the soil-root bond is the most important unmeasured model parameter. Its value,
\end{abstract}


rather than root strength, limited root reinforcement in saturated clay loam with both plant species and was of the order of $25 \mathrm{~g} / \mathrm{cm}^{2}$.

Objective(s): The objective was to predict the amount of increase in soil shear resistance (root reinforcement) produced by stretching, slipping, and breaking roots of various sizes.

Study Location: Western U.S.

Method: Ponderosa pine seedlings were allowed to grow for 52 months prior to being transferred for soil shear testing. Barley was similarly grown in packed clay loam, but was only grown for 10 weeks prior to shear testing. Roots were taken from the shear-tested specimens for measurement of tensile properties. The model was based on the Coulomb equation in which soil shearing resistance is developed by cohesive and frictional forces.

Vegetation: Ponderosa pine and barley roots

Soil Properties: Compacted clay loam

Observations/Results: Young's moduli and tensile strengths decreased with increasing root diameters. Comparisons of model simulations with experiments showed that the strength of the soil-root bond is the most important unmeasured model parameter. Its value, rather than root strength, limited root reinforcement in saturated clay loam with both plant species and was of the order of $25 \mathrm{~g} / \mathrm{cm}^{2}$.

Recommendations: N/A

* Formal permission not required. Covered under Fair Use in Title 17 of the US Code.

Title: Detection of levee slides using commercially available remotely sensed data

Author: Hossain, A.K.M.A., G. Easson, and K. Hasan

Series/Source: Environmental and Engineering Geoscience, 2006.

12(3):235-246

Peer-reviewed: N/A

Code: LVSTAB, VEGMOD

Abstract*: Surficial failures or slides in the levees along the Mississippi River have been recorded since 1964. The current method of detecting these slides involves a physical survey that is neither time nor cost 
efficient. This research was designed to evaluate the potential of commercially available high-resolution multispectral and hyperspectral imagery as a tool to detect levee slides. QuickBird, IKONOS, and CASI II imagery were used to evaluate a 20-mi (32-km) levee reach near Gunnison in Bolivar County, Mississippi. Field investigations were combined with image processing techniques including pan-sharpening, ISODATA clustering, Spectral Angle Mapper classification, and Tasseled Cap transformation. Field observations and processing of both multispectral and hyperspectral imagery suggest that it is possible to detect slides by the nature of the vegetation and land use in the slide area. Certain types of plants were found in slide-affected areas and appear to be a good indicator of slides in the field and in imagery. QuickBird and IKONOSZ imagery are both suitable for detecting slides by visual inspection and for monitoring recorded slides. Hyperspectral CASI II imagery can be used to identify slide indicative vegetation. Soil Brightness Index and Greenness Index obtained from a Tasseled Cap transformed IKONOS imagery was used to develop a slide detection model. The slide detection model did not determine the exact location of all slides but was able to narrow the search area for slides.

Objective(s): The objective was to test a remote sensing methodology for the detection of scattered and widespread levee problems (slides) to provide lead time in selection of and implementation of levee maintenance activities.

Study Location: Near Gunnison in Bolivar County, MS Method: Relative irradiance was measured in the range of 400 to $1,000 \mathrm{~nm}$ to obtain the spectral curves for samples. The imagery was georeferenced, coregistered, and subset according to the defined zones. A mosaic was made of the hyperspectral CASI II imagery and subset according to area of interest. A spectral library for use in hyperspectral image classification was created using the collected field- and imagederived spectra. Each of the field derived spectra consisted of 2,048 continuous irradiance values of which 48 values were sorted and selected according to the midpoint values of 48 spectral bands of the obtained CASI II imagery. The images vary in their spatial, spectral, and radiometric resolutions and in their feature identification capability. Attempts were made to detect slides using various image processing techniques, including visual inspection of imagery, image enhancements, image classification, and Tasseled Cap transformation. Very dark green vegetation was selected to represent slide areas. 
Vegetation: Green and dry grasses, Bermuda grass, J ohnson grass, Silver-leaf Horsenettle (or Red Vine) weeds, trees, and Red Vine on wet and dry soils

Soil Properties: Clayey soils of varying plasticity in levee reach in Bolivar County, MS

Observations/Results: Slides or shallow surficial features along the levee are a result of the aging process that alters the water retention properties of levee soils. Image processing and analyses of high-resolution multispectral and hyperspectral imagery suggest that it is possible to detect levee slides using commercially available remotely sensed data. Recommendations: Multispectral IKONOS imagery and hyperspectral CASI II imagery with high spatial resolution are the most suitable imagery for slide detection. IKONOS imagery may be replaced by QuickBird imagery if the coefficients for Tasseled Cap transformation of Quick-Bird imagery are available.

* Formal permission not required. Covered under Fair Use in Title 17 of the US Code.

\title{
Title: Is California next?
}

Author: Reid, R.L.

Series/Source: Civil Engineering, 2005. pp 38-47(84-85).

Peer-reviewed: Yes

Code: LVSTAB, LVFLCL

\begin{abstract}
An extensive, but decaying, system of levees protects key urban areas in California's Central Valley and keeps drinking water safe for 20 million people who rely on the watershed formed by the delta of the Sacramento and San J oaquin rivers. But some experts wonder if the levees are leaving these regions vulnerable to a disaster far greater than the one inflicted on New Orleans by Hurricane Katrina.

Major floods occur every decade or so in the Central Valley. Three people died during the last major flood, in J anuary 1997, when a levee failed on the left bank of the Feather River, the Sutter floodwater bypass failed without warning, and more than 30 levees failed on the San J oaquin River. More than 120,000 people were forced from their homes and 55,000 of them were sent to temporary shelters.
\end{abstract}


Objective(s): The objective was to define problems with the Central Valley levees.

Study Location: Central Valley, California

Method: N/A

Vegetation: N/A

Soil Properties: N/A

Observations/Results: Compared to other major cities (Tacoma, Dallas, St. Louis, Kansas City, and New Orleans, all with greater than 250-year flood event protection), Sacramento has protection based on only a 100-year event level. A major flood in the Sacramento area would impact 400,000 people and cause an estimated 7 to 15 billion dollars in damages.

Unfortunately for the Central Valley, its flood control system of levees, channels, and weirs is large, old, and "significantly deteriorated, partly due to deficiencies in the original design and partly due to deferred maintenance," concedes the Department of Water Resources' J anuary 2005 report, "Flood Warnings: Responding to California's Flood Crisis." The system comprises roughly 1,600 mi (2,570 km) of earthen levees built primarily by local farmers and large agricultural interests over a period ranging from California's Gold Rush in the mid-1880s, to the early 1960s.

The potential for catastrophe is enormous and well known. The solutions, however, are more elusive and, in some cases, quite long term or prohibitively expensive.

Earthquakes strong enough to devastate the delta cannot be predicted with any accuracy, but major floods hit the Central Valley every 7 to 10 years.

\section{Recommendations: N/A}

* Formal permission for abstract publication not required, but bibliographic link is requested.

http://cedb.asce.org/cgi/WWWdisplay.cgi?0530111

Title: Carbon concentrations variations in the roots, stem, and crown of mature Pinus pinaster Ait.

Author: Bert, D., and F. Danjon

Series/Source: Forest Ecology and Management, 2006. 222:279-295

Peer-reviewed: Yes

Code: RTMODL, RTSTAB 
Abstract*: Stands of maritime pine (Pinus pinaster Ait.) cover about one million hectares of land in southwestern France and produce 19\% of all French timber, thanks to the intensive management methods employed. Evaluations of carbon fixation and storage in this forest are facilitated by its general homogeneity with respect to soil, climate, and tree genetics. However, initial assessments were based on basic values for expansion factors and carbon concentration in the biomass, and more accurate results could be obtained.

The aim of the present study was to estimate the carbon concentration in the 13 main compartments of mature P. pinaster shoots and roots, describing sources of variation within these compartments, and quantifying precisely the corresponding carbon contents.

The biomass distribution per compartment in the shoots and roots of 12 trees with a range of social status is given. It was obtained by joint architecture and dry weight measurement. The root systems were uprooted with a mechanical shovel and measured by 3-D digitizing. Biomass allometric prediction equations per compartment according to girth and breast height were developed. The carbon concentration was analysed in 300 samples from four trees, taking into account their architecture.

The carbon concentration varied largely between compartments and showed a quadratic relationship with relative height in the four stem compartments and in branches and buds. It showed a negative exponential relation with root diameter. The carbon concentration of needles was not related to their age or their relative height in the crown. Carbon concentrations variations were in accordance with the tissue chemical composition found in literature. The biochemical concentration of softwoods organs is extensively reviewed in the paper. The weighted mean carbon concentration reached $53.6 \%$ in the shoots and $51.7 \%$ in the roots. This resulted to $53.2 \%$ at tree level. The carbon content in the pine stand was $74 \mathrm{tC}$ per hectare.

Between and within compartment variations in carbon concentration should be considered in carbon content evaluations and in structuralfunctional models. The underestimation of carbon storage in mature P. pinaster stands and sawnwood products reaches $6 \%$ when the usual $50 \%$ conversion factor is used.

Objective(s): This research sought to improve carbon content assessments, variations, and concentrations by assessing the carbon concentration in maritime pines near the end of a 50-yr harvesting- 
replanting plan; to learn carbon concentrations between tree compartments, variations within each compartment, average carbon concentration (in compartment, whole tree and stand) and the applications of this data to forest inventories.

Study Location: Southwestern France, Landes de Gascogne forest Method: For each annual growth unit sample, the extraction included four cores for chemical analyses, which were split into heartwood and sapwood in the field as a function of color and transparency. One crosssection was used to sample the phloem and bark on a quarter or an eighth of its circumference. The "phloem" compartment had a maximum with of $0.7 \mathrm{~cm}$ and was in fact made up of phloem, phelloderm, and phellogen. The "bark" compartment comprised only of phellem, which reached a thickness of $7 \mathrm{~cm}$ in this study area. Root systems were uprooted mechanically and cleaned with hand tools, and velocity air jets. Root system architecture, including topology and geometry, was measured with a Pohemus 3-D digitizer driven by Diplami software.

Vegetation: Maritime pine (Pinus pinaster)

\section{Soil Properties: N/A}

Observations/Results: Carbon concentrations of various tree compartments were provided. The carbon $\left(\mathrm{C}_{103}\right)$ values for taproot wood and trunk sapwood were similar. In the wood of second and fourth order roots, the diameter of root samples was more closely linked to $\mathrm{C}_{103}$ than either the cross section area of the root, the distance from the root base, or depth in the soil. This study offers the first comprehensive description of intra-tree variations in carbon concentration at the whole tree level. An accurate estimate of carbon content is also a key element in the life cycle assessment of products, i.e., quantification of all environmental impacts from raw material acquisition to final disposal.

Recommendations: Sampling strategies for future assessments of carbon content variations between stands will benefit from this intensive within-stand characterization.

* Reprinted from Forest Ecology and Management 222, D. Bert, and F. Danjon, Carbon concentrations variations in the roots, stem, and crown of mature Pinus pinaster (Ait.), 279-295, 2006, with permission from Elsevier. 
Title: A density-based approach for the modeling of root architecture: application to Maritime pine (Pinus pinaster Ait.) root systems

Author: Dupuy, L., T. Foucaud, A. Stokes, and F. Danjon

Series/Source: J ournal of Theoretical Biology, 2005. 236:323-334

Peer-reviewed: Yes

Code: RTMODL, RTSYST

Abstract*: Root morphology strongly influences plant/ soil interactions. However, the complexity of root architecture is a major barrier when analyzing many phenomena, e.g., anchorage, water, or nutrient uptake. Therefore, we have developed a new approach for the representation and modeling of root architecture based on branching density. A general root branching density in a space of finite dimension was used and enabled us to consider various morphological properties. A root system model was then constructed, which minimized the difference between measured and simulated root systems, expressed with functions which map root density in the soil. The model was tested in 2-D using data from Maritime pine Pinus pinaster Ait. structural roots as input. We showed that simulated and real root systems had similar root distributions in terms of radial distance, depth, branching angle, and branching order. These results indicate that general density functions are not only a powerful basis for constructing models of architecture, but can also be used to represent such structures when considering root/ soil interaction. These models are particularly useful in that they provide a local morphological characterization, which is aggregated in a given unit of soil volume.

Objective(s): The objective of this study was to develop a new modeling approach using general density functions. This approach is based on the mathematical representation of the distribution of root properties in soil, e.g., number, angle, or diameter.

Study Location: France

Method: A root system model was constructed to map root density in the soil.

Vegetation: Maritime pine (Pinus pinaster)

Soil Properties: N/A

Observations/Results: Computing of root systems using the different bootstrap samples produced a range of simplified root architectures. The discretization of variables had a coarse simplifying effect, but the different structures showed similarities with real root systems. Real root systems 
were mainly constituted of a large vertical taproot, several surface and intermediate depth horizontal roots, and a large number of secondary sinkers branching from secondary lateral roots. Root architecture influences water and nutrient absorption, plant mechanical stability and also has an impact on soil hydrology and mechanics. This model was able to reconstruct a realistic root system avoiding the measurement of complex topological data. The difference between density-based models and "apex"- based models is fundamental. The experimental density function represents a target towards which models tend to converge. This approach is therefore deterministic and not sensitive to error propagation during the simulation. However, "apex"-based methods are naturally well adapted to represent a plant's elementary mechanisms of growth. The combination of the two approaches would be very beneficial to the understanding of root dynamics.

Recommendations: The method developed for the modeling of root systems using density functions of root branching points was relatively simple and could be developed further.

* Reprinted from J ournal of Theoretical Biology 236, L. Dupuy, T. Foucaud, A. Stokes, and F. Danjon, A density-based approach for the modeling of root architecture: application to Maritime pine (Pinus pinaster Ait.) root systems, 323-334, 2005, with permission from Elsevier.

\section{Title: A spatial and temporal model for root cohesion in forest} soils

Author: Sakals, M.E., and R.C. Sidle

Series/Source: Canadian J ournal of Forest Research, 2004. 34:950958

Peer-reviewed: Yes

Code: RTMODL, RTSTAB, RTSYST, SLSTAB (VR)

Abstract*: Root cohesion is an important parameter governing slope stability in steep forested terrain. Forest harvesting impacts root cohesion, and although the temporal effects have been noted, this dynamic parameter is often assumed to be spatially uniform. A model was developed to simulate the variation in root cohesion on a hillslope resulting from various forest management treatments. The model combines physical data on the horizontal rooting distribution of Douglas- 
fir (Pseudotsuga menziesii (Mirb.) Franco var. menziesii) together with a temporal relation of root cohesion decay. Harvesting methods examined include clear-cutting, single tree selection cutting, and strip-cutting. Model outputs are analysed qualitatively for regions of root cohesion minima and quantitatively for the average root cohesion within the simulated hillslope. A selection cutting simulation maintained the highest average root cohesion value, decreasing to only $81 \%$ of the preharvest condition. In contrast, the minimum root cohesion following clear-cutting declined to $38 \%$ of the preharvest value. Selection and strip-cutting scenarios resulted in smaller areas of reduced root cohesion that were adjacent to areas with high root cohesion. Such partial cutting methods shorten the period of reduced root cohesion following timber harvesting compared with clearcutting.

Objective(s): The objective was to develop a model, based on field data, that assesses the spatial (at a scale of $0.25 \mathrm{~m}^{2}$ ) and temporal variability of root cohesion during forest harvesting and stand tending.

Study Location: Two experimental forests in the coastal region of British Columbia: The University of British Columbia Malcolm Knapp Research Forest in Haney, B.C. and the Roberts Creek Experimental Forest on the Sunshine coast of British Columbia Method: Site indices for coastal Douglas fir for all sampling sites ranged from 27 to 32 (predicted tree height in meters at a breast-height age of $50 \mathrm{yr}$ ). Root systems selected were from soils that were moderately to well drained, with a silty to sandy textures and 40 to $65 \%$ coarse fractions. Low sites or sites where gleying was present within the $30 \mathrm{~cm}$ soil depth below the root plate hollow, as such features may have high water tables that could influence root morphology. Only recently exposed root systems were selected.

Vegetation: Douglas fir (Pseudotsuga menziesii (Mirb.) Franco var. menziesii)

Soil Properties: Silty to sandy textured soils with 40 to $65 \%$ coarse fractions

Observations/Results: Many parameters affect the root cohesion at a particular location; including tree species, stand density, vigor, and age, soil fertility, soil drainage, and other site conditions. The method of measuring root cohesion can influence the value obtained. Data collected from spatially limited areas, soil pits or in situ shear box tests provided information on the root cohesion conditions at one location of the slope; these results become less reliable when extrapolated. A computational 
model was developed that used field data on root size distribution together with root decay relationship to simulate the spatial and temporal variability in root cohesion in a forested hillslope. Clear cutting produced the greatest decline in root cohesion, from $4.36 \mathrm{kPa}$ before harvesting to a minimum of $1.67 \mathrm{kPa} 30$ years after harvesting. It is highly beneficial to the maintenance of root cohesion to retain living root systems, including understory species. Findings imply that clear-cutting could increase the numbers of landslides as well as the probability of larger landslides, whereas partial cutting may affect a lesser increase on small landslides.

\section{Recommendations: N/A}

* Reprinted from Canadian J ournal of Forest Research 34, M.E. Sakals, and R.C. Sidle, A spatial and temporal model for root cohesion in forest soils. 950-958, 2004, with permission from NRC Research Press.

Title: An evaluation of different methods to investigate root system architecture of urban trees in situ: 1. GroundPenetrating Radar

Author: Stokes, A., T. Fourcaud, J . Hruska, J . Cermak, N. Nadyezdhina, V. Nadyezhdin, and L. Praus

Series/Source: J ournal of Arboriculture, 2002. 28(1):2-10

Peer-reviewed: Yes

Code: RTMODL, RTSYST

Abstract*: To evaluate the efficiency of ground-penetrating radar (GPR) to map root systems of urban trees in situ, this technique was tested on three trees in an urban environment. After carrying out the extremely rapid GPR tests around the bases of the sample trees, root systems were excavated with an air spade, which produces a supersonic jet of air used to remove soil from roots. Photographs were taken of root system transects for comparison with GPR images. Root system architecture was then quantified for one pine tree, and a two-dimensional image of the root system was reconstructed using Plant Architecture Analysis (AMAPmod) software. A comparison of actual roots with images and hand drawn from the GPR data showed that the technique is reliable for mapping large roots in the horizontal plane only. Most errors in data from the GPR method were introduced when the root systems were manually redrawn and from roots running parallel to the electromagnetic signal in the vertical plane. 
These roots could not be identified by GPR. The GPR technique could be considered a valuable nondestructive tool for the arborist, but it still needs development, especially with regard to software that could reconstruct 3-D images of root system architecture from raw data.

Objective(s): The objective was to evaluate usage of ground-penetrating radar (GPR) to map root systems of urban trees in situ.

\section{Study Location: Urban area}

Method: GPR tests around the bases of the sample trees; root systems excavated with an air spade; photographs of root system transects for comparison with GPR images; and root system architecture quantified for one pine tree. A two-dimensional image of the root system was then reconstructed using Plant Architecture Mapping (AMAPmod) software. Vegetation: Pine tree (Pinus nigra)

\section{Soil Properties: N/A}

Observations/Results: GPR data showed that the technique is reliable for mapping large roots in the horizontal plane only. Roots running parallel to the electromagnetic signal in the vertical plane could not be identified by GPR.

Recommendations: The GPR technique needs development, especially with regard to software to reconstruct 3-D images of root system architecture from raw data.

* Reprinted from J ournal of Arboriculture 28(1), Stokes, A., T. Fourcaud, J. Hruska, J . Cermak, N. Nadyezdhina, V. Nadyezhdin, and L. Praus, An evaluation of different methods to investigate root system architecture of urban trees in situ: 1. Ground-Penetrating Radar. J anuary 2002. Copyright International Society of Arboriculture. Used with permission from the International Society of Arboriculture.

Title: Characterisation of structural tree root architecture using 3-D digitising and AMAPmod software

Author: Danjon, F., H. Sinoquet, C. Godin, F. Colin, and M. Drexhage

Series/Source: Plant and Soil, 1999. 211:241-258

Peer-reviewed: Yes

Code: RTMODL, RTSYST 
Abstract*: A low-magnetic-field digitizing device and a plant analysis model (AMAPmod, software designed to analyze plant architecture) provided a very efficient method for measuring and studying the geometry and topology of the structural roots of trees. The digitizing device measures co-ordinates in a 3-D space. AMAPmod was used to assess several characteristics of the root architecture including spatial position, root lengths and volumes, branching order and branching pattern, and to reconstruct 3-D images from the data to check for measurement errors. Structural root systems of three 20- to 28-yr-old Quercus petraea and thirty 5-yr-old Pinus pinaster were uprooted by using rapid mechanized techniques. Only roots with a diameter larger than $2 \mathrm{~mm}$ were measured. A fast and precise spatial localization in combination with the topological characterisation of all root segments was carried out. Oak showed a stronger more oblique and vertical rooting, more branches, more forks and narrower branching angles than pine. Oak had only few small roots in the northwest direction, whereas half of pine root volume was located in the $10 \mathrm{~cm}$ upper soil volume. The contribution of this new method in the characterization of structural root systems is discussed and other possible applications of this method in root studies are proposed. Because this method is precise and fairly rapid, it may be used for agronomic testing (i.e., comparing treatments) involving several dozen root systems. Almost all parameters needed for tree root system simulations can be estimated from such data.

Objective(s): The objective was to combine tree root 3-D coordinate measurements with a root architecture model.

Study Location: France (near Nancy)

Method: Structural root systems of three 20- to 28-yr-old Quercus petraea and thirty 5-yr-old Pinus pinaster were uprooted by using rapid mechanized techniques. A digitizing device measured root co-ordinates in a 3-D space. AMAPmod was used to assess several characteristics of the root architecture including spatial position, root lengths and volumes, branching order and branching pattern, and to reconstruct 3-D images from the data to check for measurement errors.

Vegetation: Sessile oak (Quercis petraea), Maritime pine (Pinus pinaster)

Soil Properties: Ranged from brown podsolic to psuedogley Observations/Results: A new precise and fairly rapid method to characterize structural root systems was discussed and other possible applications for root studies were proposed. 


\section{Recommendations: N/A}

* With kind permission from Springer Science+Business Media:

Plant and Soil 211, F. Danjon, H. Sinoquet, C. Godin, F. Colin, and M. Drexhage, Characterisation of structural tree root architecture using 3-D digitizing and AMAPmod software, 241-258, 1999.

\section{Title: Structural root architecture of 5-year-old Pinus pinaster measured by 3-D digitising and analysed with AMAPmod}

Author: Danjon, F., D. Bert, C. Godin, and P. Trichet

Series/Source: Plant and Soil, 1999. 217:49-63

Peer-reviewed: Yes

Code: RTMODL, RTSYST

Abstract*: Pinus pinaster (Ait.) is a high yielding forest tree, producing nearly a fourth of French marketed timber essentially from intensively managed stands located in southwestern France, in the Landes Forest. This species has generally poor stem straightness, especially when it is grown in poor sandy podzol of the Landes Forest, affected by summer droughts and winter floods. Above- and below-ground architecture and biomass as well as stem straightness were measured on twenty-nine 5-year-old planted trees uprooted by pulling with a lumber crane. A very precise numeric representation of the geometry and topology of structural root architectures was gained using a low-magnetic-field digitizing device (Danjon et al. 1999, Sinoquet and Rivet 1997). Data were analyzed with plant root architecture software (AMAPmod) (Godin et al. 1997). Several characteristics of root architecture were extracted by queries including root number, length, diameter, volume, spatial position, ramification order, branching angle and inter-laterals length. Differences between root systems originated from their dimensions, but also from the proportion of deep roots and the taproot size, which represented $8 \%$ of the total root volume. The proportion of root volume in the zone of rapid taper was negatively correlated with the proportion of root volume in the taproot indicating compensation between taproot and main lateral root volume. Among all studies of root characteristics, the maximal rooting depth, the proportion of deep roots, and the root-partitioning coefficient were correlated with stem straightness. 
Objective(s): This study analyzes the geometry and topology of structural root architectures using a low-magnetic-field digitizing device and modeled using AMAPmod software.

Study Location: Southwestern France

Method: Above- and below-ground architecture and biomass as well as stem straightness were measured on twenty-nine 5-year-old planted trees uprooted by pulling with a lumber crane. A very precise numeric representation of the geometry and topology of structural root architectures was gained using a low-magnetic-field digitizing device and modeled using AMAPmod.

Vegetation: Maritime pine (Pinus pinaster)

Soil Properties: Sandy podzol

Observations/Results: The proportion of root volume in the zone of rapid taper was negatively correlated with the proportion of root volume in the taproot indicating compensation between taproot and main lateral root volume. Among all studies of root characteristics, the maximal rooting depth, the proportion of deep roots, and the root-partitioning coefficient were correlated with stem straightness.

\section{Recommendations: N/A}

Danjon, F, H. Sinoquet, C. Godin, F. Colin, and M. Drexhage. 1999. Characterisation of structural tree root architecture using 3-D digitizing and AMAPmod software. Plant Soil 211:241-258. Godin, C., E. Costes, and Y Caraglio. 1997. Exploring plant topological structure with the AMAPmod software: An outline. Silva Fennica 31:355-366.

Sinoquet, H., P. Rivet, and C. Godin. 1997. Assessment of the threedimensional architecture of walnut trees using digitizing. Silva Fennica 31:265-273.

* Reprinted from Plant and Soil 217, F. Danjon, D. Bert, C. Godin, and P. Trichet, Structural root architecture of 5-year-old Pinus pinaster measured by 3-D digitising and analysed with AMAPmod, 49-63, 1999, with permission from Springer.

Title: Effect of simulated roots on the permeability of silty soil Author: Gabr, M.A., M. Akram, and H.M. Taylor Series/Source: Geotechnical Testing J ournal (GTJ ) 18(1), 1995. 
Peer-reviewed: No

Code: RTMODL

Abstract: Permission to publish abstract was not obtained.

Objective(s): Published research did not address the impact of roots system on the hydraulic conductivity of soils forming levee structures. Therefore, a preliminary testing program was conducted to assess the effect of inclusions, in this case a simulated root system, on the hydraulic conductivity of silty soil. Roots were simulated using balsa wood.

Study Location: Laboratory study

Method: Testing apparatus included rigid-wall-double-ring permeameters and flexible-wall permeameters. The simulated roots were made using balsa wood having a square cross section of 1.65 by $1.65 \mathrm{~mm}$ and approximately 12 to $15 \mathrm{~mm}$ in length. The samples were tested with 0 , 1 , and $2 \%$ by volume of roots at a hydraulic gradient of 30.3 . Specimens were prepared by mixing the test soil thoroughly with the desired volume of simulated roots at given molding water content.

Vegetation: Balsa wood was used to simulate roots.

Soil Properties: Silty sand

Observations/ Results: While the flexible-wall tests were characterized by an absence of side-wall leakage, invariably some side-wall leakage was observed during the rigid-wall tests. The general trend of the measured $\mathrm{k}$ values seems to be a decrease in $\mathrm{k}$ as a percent by volume of simulated roots was increased. Results indicated that the reduction in $\mathrm{k}$ due to the inclusion of the simulated roots increased as a function of the moisture content. The synthetic roots used in this study are not necessarily representative of in situ condition.

Recommendations: Based on the limited work performed in this study, the rigid-wall permeameters may not be the best device for evaluating $\mathrm{k}$ for sandy silt soil specimen with roots.

\section{Title: Soil compaction and plant root growth}

Author: Hettiaratchi, D.R.P., M.J . Goss, J.A. Harris, P.H. Nye, and K.A. Smith

Series/Source: Philosophical Transactions of the Royal Society of London, Series B. 1990. 329:343-355

Peer-reviewed: Yes 


\title{
Code: RTMODL, RTSTAB
}

\begin{abstract}
Plant roots are subjected to mechanical impedance when soil pore space cannot accommodate the extending root system. The paper examines briefly the theoretical aspects of the combined effects of stress and moisture history in modifying both the pore space available for root growth and soil strength that limits the ability of roots to deform the soil.

A root extension model that requires cyclic changes in root apex geometry to overcome pore space confinement is described. Cells in the growth zone of roots are analyzed as pressurized thin-walled structures of simple geometrical shape made of a polymeric elastomer reinforced by a network of symmetrical inextensible fibrils. Such structures exhibit somewhat unexpected but unique changes in shape governed by both fibril arrangement and contact stresses acting on the external surfaces.

A simplified model of a root apex can be constructed from these structural units and the behavior of this model lends support to the proposed variable root apex geometry routine evolved by roots to penetrate compact soils. This analysis highlights the crucial role played by physical factors in the growth processes of roots and the disparate models described provide the basis for the development of a comprehensive quantitative model of root proliferation.
\end{abstract}

Objective(s): The objective was to describe a root extension model that requires cyclic changes in root apex geometry to overcome pore space confinement. This paper attempted to spin together soil mechanics and cellular biomechanics to formulate the basic elements of a unified quantitative model describing plant root growth in compacted soils.

Study Location: University of Newcastle upon Tyne, Scotland Method: A modified triaxial cell to allow seedling root growth, called the Newcastle "triaxial rhizometer" was used in this research. Experiments included barley growing in a sandy loam; rice in clay, and barley in glass beads.

Vegetation: Agricultural plants (barley and rice) Soil Properties: Various combinations of triaxial cell pressures were experimentally conducted in the "triaxial rhizometer."

Observations/Results: A variable apex geometry cyclic growth routine enables plant roots to penetrate compacted soil. Detailed treatment of soil mechanics concepts coupled with root physiology and biomechanics is given.

\section{Recommendations: N/A}


* Reprinted from Philosophical Transactions of the Royal Society of London, Series B, 329, D.R.P. Hettiaratchi, M.J . Goss, J .A. Harris, P.H. Nye, and K.A. Smith. 1990. Soil compaction and plant root grouth, 343355, with permission from the Royal Society of London.

Title: In situ shear test of soil-root systems

Author: Wu, T.H., P.E. Beal, and C. Lan

Series/Source: J ournal of Geotechnical Engineering (ASCE), 1988. 114(12):1376-1394.

Peer-reviewed: Yes

Code: RTMODL, RTSTAB, SLSTAB

Abstract*: In-situ shear tests were performed on soils reinforced by roots. Analytical models of soil-root interaction presented in a companion paper were used to compute the forces in the roots and the contribution of the roots to the shearing resistance of the soil-root system. General agreement between measured and computed shearing resistances was taken as verification of the analytical models. Results of the computations also showed the influence of the dimensions of the shear box on the measured shear strength. The shear strengths measured by the in situ tests were found to be less than the shear strength along a potential slip surface in slope stability problems. Methods for estimating the shear strengths for stability analysis are presented.

Objective(s): One objective was to test the magnitude of soil reinforcement and slope stability contributions of tree roots. Another objective was to estimate the shear strength of the root-reinforced soil along with a potential slip surface in a slope stability problem.

Study Location: Mapleton, OR; Alvin Bay, AK; Peterson Cr., AK; and Columbus, $\mathrm{OH}$

Method: An in situ shear box was designed and applied for testing the soil-root shear strength.

Vegetation: Western hemlock, Alaska cedar, and Silver maple.

Soil Properties: Silty sand (SM), silty sand - gravel (SM-GM), wellgraded sand (SW), and low-plasticity silts and clays (CL-ML).

Observations/Results: Resistance measured in the in-situ test was accounted for by soil-root interaction models. The analysis also revealed 
that the resistance contributed by the roots depends on the orientation of the roots with respect to the shear surface and the dimensions of the shear box. Root forces estimated with the analytical models are in general agreement with measured forces and observed soil root-mass behavior. Methods for estimating the shear strengths for stability analysis were presented. The shear strengths measured by the in situ tests were found to be less than the shear strength along a potential slip surface in slope stability problems.

Recommendations: Three methods were recommended for estimating the shear strength of the root-reinforced soil along a potential slip surface in a slope stability problem.

* Formal permission for abstract publication not required, but bibliographic link is requested.

http://cedb.asce.org/cgi/WWWdisplay.cgi?58630\#

\title{
Title: The function of buttress roots: A comparative study of the anchorage systems of buttressed and non-buttressed tropical trees
}

Author: Crook, M.J ., A.R. Ennos, and J.R. Banks

Series/Source: J ournal of Experimental Botany, 1997. 48(314):17031716

\section{Peer-reviewed: Yes}

Code: RTSTAB, BDWFAL

\begin{abstract}
The anchorage mechanics of mature buttressed trees of Aglaia and Nephelium, and of non-buttressed Mallotus wrayi have been investigated by combining a study of the morphology of their root systems with a series of anchorage tests.

Both types possessed taproots, but only buttressed trees possessed sinker roots, which branched from the ends of the buttresses. The anchorage strength of the buttressed trees was almost double $(10.6 \mathrm{kNm})$ that of the unbuttressed ones $(4.9 \mathrm{kNm})$, and the maximum moment was generated at lower angles. In buttressed trees, the leeward buttresses were pushed into the soil before bending and eventually breaking towards their tip, whilst the windward buttresses pulled out of the soil or delaminated if they possessed sinker roots. The taproot rotated in the soil to windward. In contrast, during failure of unbuttressed trees the taproot both moved and
\end{abstract}


bent towards the leeward, the windward roots were pulled out of the soil, and the leeward laterals simply buckled. Strains along buttresses were much higher than along the laterals of unbuttressed trees.

These results suggest that buttresses act in both tension and compression and make a much larger contribution to anchorage than the thin laterals of nonbuttressed trees. The relative contribution of the buttresses was determined by carrying out a further series of anchorage tests in which both buttressed and unbuttressed trees were pulled over after all their laterals had been cut away. These trees were therefore only anchored by their taproot. Failure of both types was similar to intact unbuttressed trees, and they had similar anchorage strengths to each other, $4 \mathrm{kNm}$, around $80 \%$ of the value for intact non-buttressed trees, but only $40 \%$ of the strength of intact buttressed trees. Buttresses therefore contribute around $60 \%$ of the anchorage of buttressed trees, producing around six times more anchorage than the thin laterals of unbuttressed trees.

Objective(s): The objective was to compare buttress-rooted and nonbuttressed trees' anchorage

Study Location: Lowland tropical rainforest in Malaysia

Method: Trees were uprooted by using a hand-operated mechanical winch only after rainfall infiltration reduced the soil shear strength to below $100 \mathrm{kPa}$ in the root vicinity. Strain gages were placed on the trunk and lateral roots and recorded during winching. Anchorage mechanisms and root damage patterns were recorded and discussed in detail.

Vegetation: Aglaia (genus Mahogany), Pulasan (Nephelium ramboutan), and Mallotus wrayi trees native to Southeast Asia

Soil Properties: Clay soil with average ("shearvane") shear strength of $68 \mathrm{kPa}$

Observations/Results: Among numerous other observations regarding root damage patterns for buttressed versus non-buttressed tree roots, it was noted that buttress-rooted trees were twice as well anchored as the non-buttressed trees. Larger trees tend to be more frequently buttressed than smaller trees.

\section{Recommendations: N/A}

* Reprinted from J ournal of Experimental Botany 48(314), M.J. Crook, A.R. Ennos, and J.R. Banks, The function of buttress roots: A comparative study of the anchorage systems of buttressed and non-buttressed tropical 
trees, 1703-1716, 1997, Oxford Press, with permission granted through Rightslink, Copyright Clearance Center, Inc.

Title: Influence of wind loading on root system development and architecture in oak (Quercus robur L.) seedlings

Author: Tamasi, E., A. Stokes, B. Lasserre, F. Danjon, S. Berthier, T.

Fourcaud, and D. Chiatante

Series/Source: Trees, 2005. 19:374-384

Peer-reviewed: Yes

Code: RTSTAB, BDWFAL

\begin{abstract}
The effect of wind loading on English oak seedlings was investigated. Instead of using a traditional wind tunnel, an innovative ventilation system was designed. This device was set up in the field and composed of a rotating arm supporting an electrical fan which emitted an air current similar to that of wind loading. Oaks were sown from seed in a circle around the device. A block of control plants was situated nearby, and was not subjected to artificial wind loading. After 7 months, 16 plants from each treatment were excavated, and root architecture and morphological characteristics measured using a 3-D digitizer. The resulting geometrical and topological data were then analysed using AMAPmod software. Results showed that total lateral root volume did not differ significantly between treatments. In comparing lateral root characteristics between the two populations, it was found that mean root length, diameter, and volume were similar between the two treatments. In trees subjected to wind loading, an accentuated asymmetry of root distribution and mean root length was found between the windward and leeward sides of the root system, with windward roots being significantly more numerous and longer than leeward roots. However, no differences were found when the two sectors perpendicular to the wind direction were compared. Mean taproot length was significantly higher in control samples compared to wind stressed plants, while mean diameter was greater in the latter. Wind loading appears to result in increased growth of lateral roots at the expense of the taproot. Development of the lateral root system may therefore ensure better anchorage of young trees subjected to wind loading under certain conditions.
\end{abstract}


Objective(s): The objective was to identify the influence of wind loading on root system growth of oak seedlings.

Study Location: Nursery laboratory in southwest France

Method: 100 oak seedlings were planted along the perimeter of a 5-m radius circle, and allowed to grow for 7 months in simulated wind conditions. The seedlings were then excavated and the root system dimensions were 3-D digitized. Control (no wind loading) seedlings were also analyzed.

Vegetation: English oak (Quercus robur L.)

Soil Properties: Non-sloping sandy podzolic soil characteristic of the region.

Observations/Results: Unlike conifers like the Sitka spruce, which tend to develop a shallow plate root system characterized by large horizontal lateral roots, oak trees have a taproot and a more oblique root system. Wind-stressed seedlings increased lateral root production and greater development of windward roots resulting in better tree anchorage. The 3-D digitizing technique worked well.

\section{Recommendations: N/A}

* Reprinted from Trees 19, E. Tamasi, A. Stokes, B. Lasserre, F. Danjon, S. Berthier, T. Fourcaud, and D. Chiatante, Influence of wind loading on root system development and architecture in oak (Quercus robur L.) seedlings, 374-384, 2005, with permission from Springer.

Title: The development of symmetry, rigidity, and anchorage in the structural root system of conifers

Author: Coutts, M.P., C.C.N. Nielsen, and B.C. Nicoll

Series/Source: Plant and Soil, 1999. 217:1-15

Peer-reviewed: Yes

Code: RTSTAB, RTSYST

Abstract*: The stability of shallowly rooted trees can be strongly influenced by the symmetry of the 'structural' system of woody roots. Root systems of forest trees are often markedly asymmetric, and many of the factors affecting symmetry, including root initiation and the growth of primary and woody roots, are poorly understood. The internal and environmental factors that control the development, with respect to symmetry and rigidity, of shallow structural root systems are reviewed and 
discussed with particular reference to Sitka spruce (Picea sitchensis Bong. Carr.). Areas where there is insufficient knowledge are highlighted. A scheme is proposed that represents the root system as a set of spokes that are variable in number, size, and radial distribution. Rigidity can vary between and along each of the spokes. The root system is presented as a zone of competition for assimilates, where allocation to individual roots depends upon their position and local variations in conditions. Factors considered include the production of root primordia of different sizes, effects of soil conditions such as the supply of mineral nutrients and water on growth of primary and woody roots, and the effect of forces caused by wind action on growth of the cambium, giving rise to roots which, in cross section, resemble I- or T-beams, and efficiently resist bending.

Objective(s): The objective was to collate information on root system architecture and growth required for modeling root system development with respect to symmetry and rigidity.

\section{Study Location: N/A}

Method: Collection of information on root system characteristics of Sitka spruce.

Vegetation: Sitka spruce (Picea sitchensis Bong. Carr.)

\section{Soil Properties: N/A}

Observations/Results: The root systems are represented as sets of spokes that are variable in number, size, and radial distribution. Rigidity varies between and along each of the spokes. The proportion of the total cross section area of the woody roots increased with the decreasing root sizes. A diagram was presented which summarized the structural root system development in response to environment, allocation, and physiology factors.

\section{Recommendations: N/A}

* Reprinted from Plant and Soil 217, M.P. Coutts, C.C.N. Nielsen, and B.C. Nicoll, The development of symmetry, rigidity, and anchorage in the structural root system of conifers, 1-15, 1999, with permission from Springer.

Title: The increase in anchorage with tree size of the tropical taprooted tree Mallotus wrayi King (Euphorbiaceae) Author: Crook, M.J . and A.R. Ennos 
Series/Source: Annals of Botany, 1998. 82:291-296

Peer-reviewed: Yes

Code: RTSTAB, RTSYST, BDWFAL

\begin{abstract}
The mechanical development of the anchorage system of the taprooted tropical species Mallotus wr'ayi King (Euphorbiaceae) was investigated by pulling over and examining trees with a diameter at breast height ( $\mathrm{dbh}$ ) of $4.2 \mathrm{~cm}$ to $14.3 \mathrm{~cm}$. The mode of mechanical failure depended upon the size of the tree: thicker trees $\left(d_{b h}\right.$ approx. $9 \mathrm{~cm}$ ) failed in the ground with their taproots pushing into the soil on the winchward side; in smaller trees ( $d_{b h}$ approx. $7 \mathrm{~cm}$ ) the trunk snapped before anchorage failure; and in very small trees ( of $d_{b h}<6 \mathrm{~cm}$ ) neither type of failure occurred and the trees returned to their original upright position undamaged after the test. The anchorage strength of the trees was correlated with the second power of trunk diameter rather than with the third power that theory suggests is optimal because tap roots did not show an isometric increase in length or diameter. Therefore as trees grow larger the 'factor of safety' against anchorage failure falls, making them prone to fail in their roots. These results suggest that only relatively small tree species can rely solely on the taproot to prevent uprooting. It may be for this reason that most large trees develop thick lateral roots.
\end{abstract}

Objective(s): The objective was to study root anchorage strength for a single tap-rooted tree species.

Study Location: Malaysia

Method: 35 trees were cut down $3 \mathrm{~m}$ above the stump and then winched over. The root systems were then excavated and characterized.

Vegetation: Tropical tree Mallotus wrayi King (Euphorbiaceae)

Soil Properties: Clay soil with average shear strength $65 \pm 17 \mathrm{kPa}$

Observations/Results: Either a root anchorage failure occurred or the tree trunk broke. The largest trees failed at the taproot, but most of the big trees failed at the trunk.

Recommendations: Future research should look at lateral root anchorage as well as the taproot anchorage mechanisms in this study.

* Reprinted from Annals of Botany 82, M.J . Crook, and A.R. Ennos, The increase in anchorage with tree size of the tropical taprooted tree Mallotus wrayi King (Euphorbiaceae), 291-296, 1998, with permission from Oxford Press. 
Title: Adaptive growth of tree root systems in response to wind action and site conditions

Author: Nicoll, B.C., and D. Ray

Series/Source: Tree Physiology, 1996. 16:891-898

Peer-reviewed: Yes

Code: RTSTAB, RTSYST, BDWFAL

Abstract*: Soil-root plate dimensions and structural root architecture were examined on 46-year-old Sitka spruce (Picea sitchensis (Bong.) Carr.) trees that had been mechanically uprooted. Rooting depth was restricted by a water table, and root system morphology had adapted to resist the wind movement associated with shallow rooting. The spread of the root system and the ratio of root mass to shoot mass (root/ shoot ratio) were both negatively related to soil-root plate depth. Root systems had more structural root mass on the leeward side than the windward side of the tree relative to the prevailing wind direction.

Cross sections of structural roots were obtained at distances of 0.5 , $0.75,1.0$, and $1.25 \mathrm{~m}$ from the tree center. Buttressed parts of roots had greater lateral and vertical secondary thickening above rather than below the biological center. This uneven growth, which produced a shape similar in cross section to a T-beam, was greater on the leeward side of the tree, and was greatest at $0.5 \mathrm{~m}$ from the tree center of shallow rooted trees. Further from the tree, particularly on the windward side, many roots developed eccentric cross-sectional shapes comparable to I-beams, which would efficiently resist vertical flexing. Roots became more ovoid in shape with increasing distance from the tree, especially on deep rooted trees where lateral roots tapered rapidly to a small diameter.

We conclude that these forms of adaptive growth in response to wind movement improve the rigidity of the soil-root plate and counteract the increasing vulnerability to windthrow as the tree grows.

Objective(s): The objective was to study root structure and anchorage mechanisms of 46-yr-old Sitka spruce growing on slopes.

Study Location: Cumbria, U.K. (Scotland)

Method: Tree stumps were winched over and removed Vegetation: Sitka spruce (Picea sitchensis (Bong.) Carr.)

Soil Properties: Gley on steep slopes to peaty-gley on gentle slopes. 
Observations/Results: Rooting depth was restricted by the water table, and root system morphology had adapted to resist the wind movement associated with shallow rooting. The root system spread was negatively related to the soil-root plate depth. Adaptive root growth as the tree grows improves the soil-root plate rigidity and counteracts the vulnerability to windthrow.

\section{Recommendations: N/A}

* Reprinted from Tree Physiology 16, B.C. Nicoll, and D. Ray, Adaptive growth of tree root systems in response to wind action and site conditions, 891-898, 1996, Oxford Press, with permission granted through Rightslink, Copyright Clearance Center, Inc.

Title: The anchorage mechanics of deep rooted Larch Author: Crook, M.J ., and A.R. Ennos Series/Source: J ournal of Experimental Botany, 1996. 47(303):15091517

Peer-reviewed: Yes

Code: RTSTAB, BDWFAL

Abstract*: The anchorage of deep rooted 16-year-old larch trees, Larix europea $\mathrm{x}$ japonica, has been studied by combining winching tests with analyses of strain around the base of the trunk and root system and mechanical tests on individual roots. These showed that anchorage is provided by the laterals which emerge from around the stem base, sinker roots which emerge along their length, and tap roots positioned directly underneath the bole. During anchorage failure, the leeward laterals are bent and eventually break close to their base, whilst the windward laterals are pulled out of the ground, with their sinker roots intact. After initially being confined by the soil and bending, the taproot rotates in the soil. Anchorage failure is similar when the soil is dry as when it is wet, but failure occurs closer to the trunk. Strain measurements along the lateral roots revealed that the stresses were highest close to the trunk and that these regions of the roots contribute most to tree stability.

The two major components of anchorage were found to be the resistance of leeward laterals to bending and the resistance of taproots and windward sinkers to uprooting. Bending tests on leeward laterals revealed that they provide around $25 \%$ of tree anchorage. Almost $75 \%$ of the 
anchorage strength must, therefore, be provided by the windward sinkers and taproots. Anchorage strength of roots was positively correlated to their cross-sectional area. The vertical orientation of the sinkers makes the anchorage system of larch more efficient than the plate system formed by Sitka spruce on waterlogged soils and means that no root-soil plate is formed.

Objective(s): The study involved the anchorage of deep-rooted 16-yearold larch trees, combining winching tests with analyses of strain around the base of the trunk and root system with mechanical tests on individual roots.

Study Location: University of Manchester (England)

Method: Simulating windthrow conditions, 16-yr old trees were pulled over using a winch, and the root damage, center of rotation, and anchorage mechanisms were reported.

Vegetation: Larch trees (Larix europa X L. japonica)

Soil Properties: Sandy clay loam

Observations/Results: As the trees were winched, the root breakage patterns were detailed and discussed. Root anchorage did not vary with soil moisture content, but root failure occurred closer to the trunk as the moisture content increased.

Recommendations: Examine the windthrow-induced damage patterns for other tree species.

* Reprinted from J ournal of Experimental Botany 47(303), M.J . Crook, and A.R. Ennos, The anchorage mechanics of deep rooted Larch, 15091517, 1996, Oxford Press, with permission granted through Rightslink, Copyright Clearance Center, Inc.

Title: The influence of vegetation on the swelling and shrinking of clays in the United States of America

Author: Holtz, W.G.

Series/Source: Geotechnique, 1983. 33:159-163

Peer-reviewed: Yes

Code: RTSTAB, ECOSYS

Abstract*: Soils subject to swelling and shrinking can be found in most of the states in the continental U.S., extending from the east coast to the west 
coast and from the north to the south. The cost of damage to structures placed on these soils is said to exceed the combined cost of all damage caused by earthquakes, tornadoes, hurricanes, and floods. A significant portion of volume changes caused by shrinking and swelling can be attributed to the desiccation effects of vegetation. In the more humid areas of the U.S., the greater portion of shrinkage is caused by transpiration from vegetation. In the arid and semi-arid parts of the country, evaporation is a major factor but transpiration losses can be very significant, often adversely tipping the damage scale. The effects of vegetation on soil moisture changes are very complex. These involve trees, shrubs, and grasses, which may not only draw moisture from the soils, but may also cause changes in soil temperatures, soil chemistry, infiltration of water and soil moisture patterns. Problems associated with the removal of trees and other vegetation should be recognized with regard to damage corrections, new land developments, and the establishment of new landscaping.

Objective(s): This article provided an overview of vegetation-related causes of shrinkage and swelling soil problems.

Study Location: U.S.-wide

Method: Literature review and selected projects are discussed.

Vegetation: Woody and non-woody vegetation.

Soil Properties: Clays with shrink-swell potential

Observations/Results: Vegetation can have an adverse effect in the vicinity of structures founded on soils having shrink-swell potential. Large broadleaf deciduous trees have the greatest effect.

Recommendations: General recommendations for taking vegetation effects into account for structures built on shrink-swell clays were discussed.

* Reprinted from Geotechnique 33, W.G. Holtz, The influence of vegetation on the swelling and shrinking of clays in the United States of America, 159-163, 1983, Thomas Telford, with permission from publisher.

Title: An apparatus to measure the crosscut shearing strength of roots

Author: Ziemer, R.R.

Series/Source: Canadian J ournal of Forest Research, 1978. 8:142-144 
Peer-reviewed: Yes

Code: RTSTAB, SLSTAB (VR)

Abstract*: Deterioration of tree root strength after timber cutting is a principal mechanism leading to slope failure and landslides. Measurement of root shear strength changes can be useful in evaluating effects of logging on slope stability. The simple apparatus described measures shear strength directly on roots up to $50-\mathrm{mm}$ diam. Tests on live roots showed excellent correlation between measurements of shear strength and tensile strength.

Objective(s): The objective was to present a simple apparatus for testing root shear strength using selected vegetation types.

Study Location: Northwest U.S. and Canada Pacific coastal forests.

Method: Roots were placed in a vertical apparatus designed for shearing roots as a means to measure temporal deterioration in root shear and tensile strengths.

Vegetation: Douglas fir (Pseudotsuga menziesii [Mirb.] France), redwood (Sequoia sempervirens [D.Don] Carr.), western hemlock (Tsuga heterophylla [Raf.] Sarg.) and Sitka spruce (Picea sitchensis [Bong.] Carr.).

\section{Soil Properties: N/A}

Observations/Results: Shear strength measurements are essentially independent of root segment length. A weak point in the root segment does not influence a shear measurement at an adjacent strong point. Tensile strength measurements reflect the weakest point in the root segment. When a bent root is pulled, individual root fibers break sequentially as the root straightens. The probability of finding a tensile strength weak point in a straight root is a function of the segment length. In uncut stands, hemlock roots were consistently stronger than Sitka spruce. As tree roots decay following cutting, residual hemlock roots were consistently stronger than Sitka spruce roots up to 4 years after cutting. Hemlock lost about one-third of its root shear strength and Sitka spruce lost about one-half of its root strength within 2 years following cutting. Large stump roots did not significantly lose shear strength until approximately 6 years after tree harvesting and onset of stump root decay. Recommendations: The authors expected average shear strength measurements to underestimate the loss of tensile strength in roots due to decay. Further study is needed to test this hypothesis. 
* Reprinted from Canadian J ournal of Forest Research 8, R.R. Ziemer, An apparatus to measure the crosscut shearing strength of roots, 142-144, 1978, with permission from NRC Research Press.

Title: The shear resistance of root-permeated homogeneous and stratified soil

Author: Waldron, L.J .

Series/Source: Soil Science Society of America Proceedings, 1977.

41:843-849

Peer-reviewed: Yes

Code: RTSTAB, RTMODL, SLSTAB

Abstract*: Mechanical reinforcement, which stabilizes soil on slopes, has been attributed to plant roots. To measure such reinforcement, direct shear tests were made on 25-cm-diam root permeated soil columns. Roots of alfalfa (Medicago sativa), barley (Horedeum vulgare), and yellow pine (Pinus ponderosa), each increased the sheer resistance of homogeneous and compacted layers of silty clay loam at 30-cm depth. One-year-old alfalfa had a much greater reinforcing effect than pine trees 16 months after transplanting or barley at its maximum growth. Barley had a greater effect in the clay loam than the pine, but its effectiveness decreased as depth increased from 15 to 30 to $45 \mathrm{~cm}$. Alfalfa roots were more effective than either pine or barley roots increasing the resistance to shearing between a dense gravel-sand layer (simulating weathered rock) and the overlying soil, increasing shearing resistance to as much as five times that of fallow soil. A model is presented of soil reinforced by non-rigid roots. Calculations are given of slope safety factor increases from root reinforcement.

Objective(s): The objective was to determine if plant roots aid in mechanical reinforcement of soil on slopes.

Study Location: Eel River watershed of northern California Method: A direct shear device was used to study the effect of plant roots on soil shearing resistance. Cylindrical containers (cardboard concrete forms) were found to be adequate for getting a large enough sample and collecting samples for the various root sizes encountered. 
Vegetation: Alfalfa (Medicago sativa), barley (Hordeum vulgare), Ponderosa (yellow) pine (Pinus ponderosa), and Alder trees (Alnus glutinosa)

Soil Properties: Silty clay loams, loamy sand, sand, and gravel. Observations/Results: Alfalfa roots in the homogeneous clay loam had a larger reinforcing effect than young European alder trees (Alnus glutinosa). Alder roots increased soil shear resistance at the 20 - $\mathrm{cm}$ depth by $83.7 \mathrm{~g} / \mathrm{sq} \mathrm{cm}$ compared to $100 \mathrm{~g} / \mathrm{sq} \mathrm{cm}$ for alfalfa at 30-cm depth. Root reinforced silt may be analyzed as if it were a composite material in which fibers of high tensile strength are embedded in a matrix of lower tensile strength, similar to the concept of reinforced earth. Roots may be strained beyond elastic limits or they may break or slip through the soil.

\section{Recommendations: N/A}

* Reprinted from Soil Science Society of America Proceedings 41, L.J . Waldron, The shear resistance of root-permeated homogeneous and stratified soil, 843-849, 1997, with permission from the Soil Science Society of America.

Title: A technique of simulation of radial root growth in soil and some experimental results

Author: Evans, G.N.

Series/Source: Soil Science, 1970. 109(6):376-387

Peer-reviewed: Yes

Code: RTSTAB

Abstract*: This paper reports experiments in which a radially growing root was simulated by a cylindrical rubber tube forced to expand in a pack of soil by application of internal pressure. The object of the experiments was to test the technique, which is new; to observe the internal press/ soil deformation relationship; and to see how the soil deformation depended on soil bulk density and, to a limited extent, moisture content, for the particular soil used. The use of such a model facilitates the study of soil properties free of complicating biological effects.

Objective(s): The objective was to test a new technique for simulating radial root growth, observe the test device pressure/ soil deformation 
relationship, and observe how the soil lateral deformation depended on the soil's bulk density.

\title{
Study Location: Laboratory
}

Method: The test device consisted of a brass cylinder (22 cm deep by $10 \mathrm{~cm}$ diam) having a central vertical rubber tube surrounded by packed soil. The rubber tube was expanded to simulate root growth inside the cylinder filled with compacted soil. Tube pressure, soil density, and deformation were recorded during each test.

Vegetation: N/A

Soil Properties: Merrimac sandy loam from Windsor, CT ( $70 \%$ sand, $26 \%$ silt, $4 \%$ clay).

Observations/Results: Soil lateral deformation (tube expansion) was related to bulk density. Results may be useful for calculating the volume available to a living root for a given root pressure in a given soil.

\section{Recommendations: N/A}

* Reprinted from Soil Science 109(6), G.N. Evans, A technique of simulation of radial root growth in soil and some experimental results, 376-387, 1970, with permission from Springer.

\section{Title: Coarse root architecture of three boreal tree species growing in mixed stands}

Author: Kalliokoski, T., P. Nygren, and R. Sievanen

Series/Source: Silva Fennica, 2008. 42(2):189-210

Peer-reviewed: Yes

Code: RTSYST, ECOSYS

\begin{abstract}
Root system architecture determines many of the vital functions of a tree, e.g., stability of anchorage and resource uptake. The shoot: root ratio is determined through the allocation of resources. Studies on below-ground architectural elements in boreal mixed forests are relatively scarce despite the fact that knowledge on below-ground interactions and allocation changes in relation to stand developmental stage and soil fertility is needed both in ecological and silvicultural research. In this study, sixty tree root systems of three different tree species, Betula pendula, Picea abies and Pinus sylvestris, were excavated in five mixed forest stands in order to quantify differences between the species and sites in terms of rooting behaviour. Root architecture differed greatly between
\end{abstract}


the species, implying different solutions for the functions of root systems. Half of the P. sylvestris had developed a taproot as a response to anchorage needs, while P. abies correspondingly had pronounced secondary growth of proximal roots. Betula pendula had the most extensive root system, illustrating the greater demand of deciduous trees for water. Betula pendula was also the most sensitive to soil fertility. It favoured exploration on the poorest site, as illustrated by the high total root length, whereas on the most fertile site its strategy was to efficiently exploit soil resources through increased branching intensity. The results obtained in this study provide basic knowledge on the architectural characteristics of boreal tree root systems for use by forestry professionals and modellers.

Objective(s): The objective was to study the root architecture of boreal mixed forest trees

Study Location: southern Finland, University of Helsinki's Forestry Station

Method: Sixty tree root systems of three different tree species, Betula pendula, Picea abies and Pinus sylvestris, were excavated using a Soil Pick (air jet tool) in five mixed-forest stands and the root systems were mapped in order to quantify differences between the species and sites in terms of rooting behaviour.

Vegetation: Birch (Betula pendula), Spruce (Picea abies), and Pine (Pinus sylvestris)

Soil Properties: Humus and mineral soil layers were tested for chemical elements to characterize soil fertility and nutrients.

Observations/Results: The results obtained in this study provide basic knowledge on the architectural characteristics of boreal tree root systems for use by forestry professionals and modellers.

\section{Recommendations: N/A}

* Reprinted from Silva Fennica 42(2), T. Kalliokoski, P. Nygren, and R. Sievanen, Coarse root architecture of three boreal tree species growing in mixed stands, 189-210, 2008, with permission from Silva Fennica.

\section{Title: Detection of Cryptomeria japonica roots with ground penetrating radar}

Author: Dannoura, M., Y. Hirano, T. Igarashi, M. Ishii, K. Aono, K. Yamase, and Y. Kanazawa 
Series/Source: Plant Biosystems, 2008. 142(2):375-380

Peer-reviewed: Yes

Code: RTSYST

Abstract: Permission to publish abstract was not obtained.

Objective(s): The objective was to conduct an experimental study to determine whether the roots of Cryptomeria japonica, a major plantation species in J apan, can be detected with GPR

\section{Study Location: J apan}

Method: Roots and wooden dowels of C. japonica were buried $30 \mathrm{~cm}$ deep in sandy granite soil. From GPR measurements with a $900 \mathrm{MHz}$ antenna, the distribution and diameter of samples in several transects were recorded.

Vegetation: J aponica (Cryptomeria japonica)

Soil Properties: Sandy soil

Observations/Results: GPR can be used as a non-destructive tool, but further investigation is needed to determine optimal conditions (e.g., water content) and analytical methods for using GPR to examine roots in forest sites. The buried roots were detected clearly and could be distinguished at diameters of 1.1 to $5.2 \mathrm{~cm}$. There were significant positive relationships between root diameter and parameters extracted from the resultant GPR waveform. The difference in water content between roots and soil is a crucial factor impacting the ability to detect roots with GPR. Recommendations: N/A

Title: Electrical measurement of root mass and root location Author: Ellis, T., K. Feher, W. Murray, K. Paul, J . Brophy, K. J acobsen, V. Koul, P. Leppert, and J . Smith

Series/Source: Australian Rural Industries Research and Development Corporation (RIRDC), April 2008. Publication 08/042, 25 pages

Peer-reviewed: No

Code: RTSYST

Introduction*: This report investigates two electrical methods for the measurement of roots, which have previously shown promise for the development of rapid non-destructive techniques for use by researchers or plant breeders. We show that: (1) low frequency ( $\mathrm{kHz}$ range) capacitance 
measurements can be indicative of the mass and length of the root systems of eucalypts; and (2) roots can transmit detectable high frequency ( $\mathrm{MHz}$ range) signals over short distances $(\sim 1 \mathrm{~m})$. The use of the latter, however, appears limited by the relative electromagnetic properties of soil and roots.

Objective(s): The objective is to evaluate the low frequency electrical capacitance method for the measurement of tree root mass and root length; and to determine the governing principles and limits for the transmission of electromagnetic signals through a root system.

Study Location: Australia

Method: Capacitance measurements were made on plantation eucalyptus prior to their destructive sampling for the measurement of below ground biomass (undertaken by another project). Two laboratory experiments were done to (a) measure the attenuation (signal loss) along a length of root embedded in sand; and (b) measured the dielectric properties of sand, loam and root materials for use with antenna theory to allow interpretation and an understanding of the likely limits to signal propagation in roots.

Vegetation: Eucalyptus trees (Eucalyptus cladocalyx and Corymbia maculata)

\section{Soil Properties: Various}

Observations/Results: Low Frequency Capacitance - Low frequency capacitance (C) measurements can be related to root mass and, possibly, to root length of plantation eucalyptus. Trees at three mature plantation sites produced similar relationships between $\mathrm{C}$ and root mass. The one younger site showed a different relationship between $\mathrm{C}$ and root mass, but the results from the four sites produced a relatively unified relationship between $\mathrm{C}$ and root length, although the latter was inferred and not directly measured. This is consistent with root capacitance theory. It is likely that the younger site had a greater proportion of fine ( $<2 \mathrm{~mm}$ diam) roots and therefore a greater total root length.

High Frequency Measurement of Root Location - signals can be transmitted from plant stems to roots, which tend to act as underground antennas, emitting electromagnetic fields which can be detected remotely. However, it appears that the relative dielectric properties of roots and soils are such that signals will travel only relatively short distances ( 2 to $3 \mathrm{~m}$ ) along large diameter ( 10 to $20 \mathrm{~mm}$ ) roots, before becoming too small to detect. 
Recommendations: Because the destructive measurement of tree roots is typically a laborious and expensive process, electrical capacitance measurements should be routinely considered for preliminary investigations as they are rapid, easily performed and could augment other sampling methods. Interpretation of results should include consideration of differences in age of the trees, and hence differences in the proportion of fine roots and total root length.

Preliminary results suggested that the high frequency method is unlikely to provide a ready path toward the development of routine methods for the location of roots in soil. However, because these investigations were not exhaustive, it was suggested that root researchers and geophysicists keep in mind the possibility that a greater efficacy in this technique may be realized through further investigation in the future (i.e., more research is needed).

* Reprinted from RIRDC Publication number 08-042, T. Ellis, K. Feher, W. Murray, K. Paul, and J. Brophy, Electrical measurement of root mass and root location, with permission from RIRDC.

Title: In situ detection of tree root distribution and biomass by multi-electrode resistivity imaging

Author: Amato, M., B. Basso, G. Celano, G. Bitella, G. Morelli, and R. Rossi

Series/Source: Tree Physiology, 2008. 28:1441- 1448

Peer-reviewed: Yes

Code: RTSYST

Abstract*: Traditional methods for studying tree roots are destructive and labor intensive, but available nondestructive techniques are applicable only to small-scale studies or are strongly limited by soil conditions and root size. Soil electrical resistivity measured by geoelectrical methods has the potential to detect belowground plant structures, but quantitative relationships of these measurements with root traits have not been assessed. We tested the ability of two-dimensional (2-D) DC resistivity tomography to detect the spatial variability of roots and to quantify their biomass in a tree stand. A high-resolution resistivity tomogram was generated along an 11.75-m transect under an Alnus glutinosa (L.) Gaertn. stand based on an alpha-Wenner configuration with 48 electrodes spaced 
$0.25 \mathrm{~m}$ apart. Data were processed by a 2-D finite-element inversion algorithm and corrected for soil temperature. Data acquisition, inversion, and imaging were completed in the field within $60 \mathrm{~min}$. Root dry mass per unit soil volume (root mass density, RMD) was measured destructively on soil samples collected to a depth of $1.05 \mathrm{~m}$. Soil sand, silt, clay and organic matter contents, electrical conductivity, water content, and $\mathrm{pH}$ were measured on a subset of samples. The spatial pattern of soil resistivity closely matched the spatial distribution of RMD. Multiple linear regression showed that only RMD and soil water content were related to soil resistivity along the transect. Regression analysis of RMD against soil resistivity revealed a highly significant logistic relationship $(\mathrm{n}=97)$, which was confirmed on a separate dataset $(n=67)$, showing that soil resistivity was quantitatively related to belowground tree root biomass. This relationship provides a basis for developing quick nondestructive methods for detecting root distribution and quantifying root biomass, as well as for optimizing sampling strategies for studying root-driven phenomena.

Objective(s): Two-dimensional (2-D) DC resistivity tomography was used to detect the spatial variability of roots and to quantify their biomass in a tree stand.

Study Location: Potenza, Italy

Method: A high-resolution resistivity tomogram was generated along an 11.75-m transect under an Alnus glutinosa (L.) Gaertn. stand based on an alpha-Wenner configuration with 48 electrodes spaced $0.25 \mathrm{~m}$ apart. Data were processed by a 2-D finite-element inversion algorithm, and corrected for soil temperature. Data acquisition, inversion, and imaging were completed in the field within $60 \mathrm{~min}$. Root dry mass per unit soil volume (root mass density, RMD) was measured destructively on soil samples collected to a depth of $1.05 \mathrm{~m}$. Soil sand, silt, clay and organic matter contents, electrical conductivity, water content, and $\mathrm{pH}$ were measured on a subset of samples.

Vegetation: Alnus glutinosa (L.) Gaertn.

Soil Properties: Sand, silt, clay, and organic matter

Observations/Results: The spatial pattern of soil resistivity closely matched the spatial distribution of RMD. Multiple linear regression showed that only RMD and soil water content were related to soil resistivity along the transect. Regression analysis of RMD against soil resistivity revealed a highly significant logistic relationship $(n=97)$, which was confirmed on a separate dataset $(n=67)$, showing that soil resistivity was quantitatively related to belowground tree root biomass. This 
relationship provides a basis for developing quick nondestructive methods for detecting root distribution and quantifying root biomass, as well as for optimizing sampling strategies for studying root-driven phenomena.

\section{Recommendations: N/A}

* Reprinted from Tree Physiology 28, M. Amato, B. Basso, G. Celano, G. Bitella, G. Morelli, and R. Rossi, In situ detection of tree root distribution and biomass by multi-electrode resistivity imaging, 1441-1448, 2008, Oxford Press, with permission granted through Rightslink, Copyright Clearance Center, Inc.

Title: Geophysical imaging of root-zone, trunk, and moisture heterogeneity

Author: Attia, Al Hagrey S.

Series/Source: J ournal of Experimental Botany, 2007. 58(4):839-54

Peer-reviewed: Yes

Code: RTSYST

Abstract: Permission to publish abstract was not obtained.

Objective(s): This review presents some in situ and in vivo applications of electric, radar, and seismic methods for studying water status and movement in soils, roots, and tree trunks.

\section{Study Location: N/A}

Method: Literature review

Vegetation: N/A

\section{Soil Properties: N/A}

Observations/Results: Seismic trunk tomography differentiates between decayed and healthy woods. The electrical properties of a rootzone are a consequence of their moisture content. Electrical imaging discriminates resistive, woody roots from conductive, soft roots. Both types are recognized by low radar velocities and high attenuation.

\section{Recommendations: N/A}


Title: The role of fine and coarse roots in shallow slope stability and soil erosion control with a focus on root system architectures: A review

Author: Reubens, B., J . Poesen, F. Danjon, G. Geudens, and B. Muys

Series/Source: Trees, 2007. 21: 385-402

Peer-reviewed: Yes

Code: RTSYST, SLSTAB, RTSTAB, SOILER

Abstract*: The contribution of plant root systems to slope stability and soil erosion control has received a lot of attention in recent years. The plant root system is an intricate and adaptive object, and understanding the details of soil-root interaction is a difficult task. Although the morphology of a root system greatly influences its soil-fixing efficiency, limited architectural work has been done in the context of slope stabilization and erosion control, and hence it remains unknown exactly which characteristics are important. Many of the published research methods are tedious and time-consuming. This review deals with the underlying mechanisms of shallow slope stabilization and erosion control by roots, especially as determined by their architectural characteristics. The effect of soil properties as well as the relative importance of different root sizes and of woody versus non-woody species is briefly discussed.

Empirically and intuitively, architectural features seem to determine the effect of root systems on erosion phenomena and an effort is therefore made here to link both aspects. Still, the research to underpin this relationship is poorly developed. A variety of methods are available for detailed root system architectural measurement and analysis. Although, generally time-consuming, a full 3-D architectural description followed by analysis in software such as AMAPmod offers the possibility to extract relevant information on almost any root system architectural characteristic. Combining several methods of measurement and analysis in a complementary way may be a useful option, especially in a context of modeling.

Objective(s): The objective was to review and comment on the influence of root systems on slope stability and erosion control. This review deals with the underlying mechanisms of shallow slope stabilization and erosion control by roots, especially as determined by their architectural characteristics.

Study Location: N/A

Method: An overview of root system architecture characteristics. 


\section{Vegetation: N/A}

\section{Soil Properties: N/A}

Observations/Results: Although the mechanical and hydrological mechanisms of soil-root interaction are rather well described for simple processes such as sheet, rill or interrill erosion, this knowledge is almost nonexistent for complex processes such as gully erosion. This hampers understanding the importance of root system architecture for these processes. This leaves, therefore, an open question as to whether detailed architectural analysis is worth the effort in research focusing on soil erosion control and slope stability. Even though the relative importance of many of these root characteristics may turn out to be limited in the end, the recent development of fast and accurate measurement and analysis methods makes the effort of further detailed investigation worthwhile. Recommendations: Three-dimensional digitizing methods provide a tremendous potential for in-depth study of the effects of as good as any root system architectural characteristic. Models should be further fed with field data to represent reality in an accurate way, and model results should then again be validated with data from field studies and highly controlled experiments.

* Reprinted from Trees 21. Reubens, J . Poesen, F. Danjon, G. Geudens, and B. Muys, The role of fine and coarse roots in shallow slope stability and soil erosion control with a focus on root system architectures: A review, B385-402, 2007, with permission from Springer.

\section{Title: Redistribution of soil water by lateral roots mediated by stem tissues}

Author: Burgess, S.O., and T.M. Bleby

Series/Source: J ournal of Experimental Botany, 2006. 57(12):32833291

Peer-reviewed: Yes

Code: RTSYST, ECOSYS

Abstract: Permission to publish abstract was not obtained.

Objective(s): The objective was to study the soil water redistribution and flow pathways.

Study Location: Corrigin, western Australia wheat-belt region 
Method: Sap flow was measured using the heat ratio technique (temperature probes spaced around tree trunk and excavated roots). Vegetation: Salmon gum (Eucalyptus salmonophloia) and Eucalyptus wandoo (Eucalyptus wandoo) trees

Soil Properties: Sandy loam to clay loam

Observations/Results: Substantial and rapid hydraulic redistribution occurred among roots after rains, suggesting transfer of water among roots at different depths.

Recommendations: N/A

Title: Root distribution of Eucaly ptus grandis and Cory mbia maculate in degraded saline soils of south-eastern Australia Author: Falkiner, R.A., E.K.S. Nambiar, P.J . Polglase, S. Theiveyanathan, and L.G. Stewart

Series/Source: Agroforestry Systems, 2006. 67:279-291

Peer-reviewed: Yes

Code: RTSYST

Abstract: Permission to publish abstract was not obtained.

Objective(s): The study was a comparison of three different methods for determining root distributions in soil profiles, and investigated the effect of ripping, tree position, and soil properties.

Study Location: Southeastern Australia (Murray Riverina region) Method: Three root-sampling procedures were conducted and the data were statistically analyzed to estimate within-plot variation for a range of measured parameters.

Vegetation: Rose gum (Eucalyptus grandis) and Spotted gum (Corymbia maculata)

Soil Properties: Clay loam overlying medium clay, saline, sodic, and alkaline subsoil with a saline water table at $2.8 \mathrm{~m}$ depth.

Observations/Results: Root distributions in the surface soil were similar at all the sites, but differences in root growth in the capillary zones paralleled differences in groundwater uptake by trees.

Recommendations: Root systems of tree species have different abilities to uptake groundwater and mitigate saline water table rise, but the tree species selection must be chosen based on the site characteristics, 
especially for commercial enterprises such as tree farms and timber production.

Title: Point process modeling of root distribution in pure stands of Fagus sylvatica and Picea abies

Author: Fleischer, F., S. Eckel, I. Schmid, V. Schmidt, and M. Kazda

Series/Source: Canadian J ournal of Forestry Research, 2006. 36:227237

Peer-reviewed: Yes

Code: RTSYST, RTMODL

Abstract: Permission to publish abstract was not obtained.

Objective(s): This research is a study of root distribution in pure stands of Norway spruce and European beech

Study Location: Near Wilhelmburg, Austria Method: Ten 2-m $\times 1$ - $\mathrm{m}$ soil pits were excavated and 20 vertical profile walls of beech and 16 vertical profile walls of spruce were root-mapped. Statistical methods were applied to analyze the root distribution patterns. Planar point process models have been applied to investigate the spatial (two-dimensional) distribution of data for roots between 2- and 5-mm diam. After a homogenization with respect to the vertical axis, the pair correlation function and the L function were estimated to fit Materncluster point process models to the given root data. The models were finally vertically retransformed to provide information on the inhomogeneous spatial patterns of small roots as well as on the original shape and size of the root clusters.

Vegetation: Norway spruce (Picea abies) and European beech (Fagus sylvatica)

Soil Properties: Stagnic Cambisols developed from Flysch sediments, having 4-cm thin organic layers.

Observations/Results: All models based on vertically transformed data confirmed that the root distribution patterns are not completely random, as they indicated root clustering for both species, with different degrees of exploitation intensity (clustering) between the two species. According to the Matern-cluster models, Norway spruce had stronger clustering in smaller cluster regions, while roots of European beech formed weaker clusters in larger cluster regions. Furthermore, beech root clusters seemed 
to avoid overlapping. Together with previous studies on the root system of both species, the present study indicates more intensive belowground intraspecific competition for spruce than for beech. On the other hand, the clustering characteristics described indicate that European beech has a more sophisticated rooting system than Norway spruce.

Recommendations: N/A

Title: Soil compaction: Identification directly in the field Author: Batey, T., and D.C. McKenzie

Series/Source: Soil Use and Management, 2006. 22:123-131

Peer-reviewed: Yes

Code: RTSYST

Abstract: Permission to publish abstract was not obtained.

Objective(s): The objective was a visual examination and evaluation methods for assessing agriculturally compacted soil.

Study Location: UK (England) and Australia

Method: An overview of tillage compaction evaluation (objective and subjective methodologies)

Vegetation: Agricultural crops

Soil Properties: Various soil types ranging from cohesive to sandy

Observations/Results: There was a detailed discussion of root penetration affected by compacted soil layers. Roots growing in compacted soil layers are much thicker and distorted. If the roots do not penetrate the compacted layer, they tend to run horizontally above the compacted layer. In sandy soils, root penetration is generally less than 4 in. $(10 \mathrm{~cm})$.

Recommendations: N/A

Title: The architecture of Picea sitchensis structural root systems on horizontal and sloping terrain

Author: Nicoll, B.C., S. Berthier, A. Achim, K. Gouskon, F. Danjon, and

L.P.H. van Beek

Series/Source: Trees, 2006. 20:701-712

Peer-reviewed: Yes

Code: RTSYST, SLSTAB, BDWFAL 
Abstract*: The coarse root systems of 24 Sitka spruce (Picea sitchensis (Bong.) Carr.) trees from a 40-year-old plantation in west Scotland were extracted and digitized in three dimensions, and root topology was recorded. Roots were from trees grown on a steep (ca. 30 deg) northfacing slope, and from an adjacent horizontal area with similar gleyed mineral soil. The prevailing wind was across-slope from the west. Analysis of below ground parts of the trees in comparison with those above ground revealed a positive linear relationship between coarse root volume and stem volume. Most non-directional characteristics of the root system were similar between trees on the slope and on flat terrain. Allocation of root mass around trees was examined in relation to the slope and the prevailing wind direction. Trees on the horizontal area had more root mass in the leeward sectors than other sectors, but trees on the slopes had more root mass in the windward sectors than other sectors. Centers of mass of the root systems from the horizontal part of the site were not significantly clustered in any direction, but root systems of trees on the slope had centers of mass significantly clustered across the slope in the windward direction. For trees on the slope, the mean direction of the largest sector without structural roots was $4 \mathrm{deg}$ from north, i.e., downslope. The results are discussed in relation to soil characteristics and the biomechanical behavior of trees on slopes.

Objective(s): The objective was to compare the coarse root architecture between trees grown on a steep slope with those grown on an adjacent horizontal area on a uniform soil in a plantation of Sitka spruce (Picea sitchensis (Bong.) Carr.). Analysis was done with respect to slope and prevailing wind direction.

Study Location: West Scotland

Method: Trees were mechanically overturned in three dominant, three co-dominant and three sub-dominant trees on the slope, in each of three directions, upslope, downslope, and across slope, i.e., nine trees per direction. On the horizontal surface, nine trees were overturned (three dominant, three co-dominant, and three sub-dominant) in random directions. Root mass and distribution measurements were taken.

Vegetation: Sitka spruce (Picea sitchensis)

Soil Properties: Soil on both the horizontal and inclined slope was gleyed mineral soil, defined using the Scotland Forestry Commission soil classification as a surface-water gley. Three soil pits revealed, from the horizontal site to the up slope site, an A horizon with abundant animal 
activity, to a B horizon that was underlain by a stony layer at the transition to the $\mathrm{C}$ horizon. The $\mathrm{C}$ horizon formed a barrier to root penetration. Observations/Results: AMAPmod (Plant Architecture Analysis) plots were used to illustrate typical coarse root architecture on the site. Comparisons of architecture characteristics indicated that root systems were largely similar between sloped and horizontal sites. There was a positive linear relationship between root volume and stem volume $\left(\mathrm{R}^{2}\right.$ 0.74) for both treatments combined. Root system depth and maximum radial extension $(2 \mathrm{~m}$ ) were similar for both treatments. Root volume decreased exponentially with lateral distance and root volume also decreased rapidly with depth with almost no mass deeper than $1.26 \mathrm{~m}$ below the soil surface. Roots in the A soil horizon grew horizontally, but roots that grew into the $C$ horizon soils tended to grow steeply of vertically downwards. Authors cited other studies where the downslope lateral root growth/ mass was less than the upslope and where the root mass was concentrated across slope. Also, the authors alluded to the observations in several studies where Sitka spruce trees put larger allocation of assimilates into windward roots on slopes, but leeward roots on the horizontal surface sites. The allocation of mass to roots growing in each soil horizon will have different impacts on long-term belowground carbon storage. Root decomposition and carbon cycling below ground varies with depth and soil aeration. Deeper roots make a greater contribution to the accumulation of soil organic matter in mineral horizons.

Recommendations: Further studies of tree root architecture in relation to soil physical conditions will be required to improve models of below ground carbon allocations.

* With kind permission from Springer Science+Business Media: Trees - Structure and Function, The architecture of Picea sitchensis structural root systems on horizontal and sloping terrain, Vol. 20(6), 2006, 701-712, B. C. Nicoll, S. Berthier, A. Achim, K. Gouskon, F. Danjon, and L.P.H. van Beek.

Title: Ground-penetrating radar to detect and quantify residual root fragments following peach orchard clearing

Author: Cox, K.D., H. Scherm, and N. Serman

Series/Source: Horttechnology, 2005. 15(3):600-607

Peer-reviewed: Yes 


\section{Code: RTSYST}

Abstract: Permission to publish abstract was not obtained.

Objective(s): The objective was to investigate the utility of groundpenetrating radar (GPR) to characterize reflector signals from peach root fragments in a controlled burial experiment and to quantify the amount of residual roots remaining after typical commercial orchard clearing.

Study Location: Athens, GA

Method: In the burial experiment, roots ranging from 2.5 to $8.2 \mathrm{~cm}$ in diameter were buried at depths of 11 to $114 \mathrm{~cm}$. In a peach orchard in which trees and roots had been removed following typical commercial practice (i.e., trees were pushed over, burned, and tree rows subsoiled), a GPR survey was done on six $4 \times 8$-m plots.

Vegetation: Peach (Prunus persica)

Soil Properties: N/A

Observations/Results: The buried roots produced characteristic parabolic reflector signals in radar profiles. At the tree removal sites, the majority of reflector signals indicative of root fragments were located in the upper 30 to $40 \mathrm{~cm}$ of soil. Based on ground-truth excavation of selected sites within plots, reflectors showing a strong parabolic curvature in the radar profiles corresponded to residual root fragments with $100 \%$ accuracy, whereas those displaying a high amplitude area represented roots in $86.1 \%$ of the cases.

Recommendations: N/A

Title: Groundwater use by vegetation in a tropical savanna riparian zone (Daly River, Australia)

Author: Lamontagne, S., P.G. Cook, A. O'Grady, and D. Eamus

Series/Source: J ournal of Hydrology, 2005. 310:280-293

Peer-reviewed: Yes

Code: RTSYST

Abstract*: Soil water matric potentials $\left(\Psi_{\mathrm{m}}\right)$ and the deuterium $\left(\delta^{2} \mathrm{H}\right)$ composition at natural abundance levels of xylem water, soil water, river water and groundwater were used to evaluate whether trees use groundwater during the dry season in the riparian zone of the Daly River (Northern Territory, Australia). Groundwater was significant source of 
water for plant transpiration, probably accounting for more than $50 \%$ of the water transpired during the dry season. Groundwater use occurred either when trees used water from the capillary fringe or when low $\Psi_{\mathrm{m}}$ induced by soil water uptake lifted groundwater in the vadose zone. Several water use strategies were inferred within the riparian plant community. Melaleuca argentea W. Fritzg and Barringtonia acutangula (L.) Gaertn. appeared to be obligate phreatophytes as they used groundwater almost exclusively and were associated with riverbanks and lower terraces with shallow $(<5-\mathrm{m})$ water tables. Several species appeared to be facultative phreatophytes (including Cathorium umbellatum (Vahl.) Kosterm. and Acacia auriculiformis A. Cunn. Ex Benth) and tended to rely more heavily on soil water with increased elevation in the riparian zone. The levee-bound Corymbia bella K.D. Hill and L.A.S. J ohnson mostly used soil water and is either a facultative phreatophytes or a nonphreatophyte. The temporal variability in groundwater utilization by the trees is unclear because the study focused on the end of the dry season only. A decline in the regional water table as a result of groundwater pumping may affect the health of riparian zone vegetation in the Daly River because groundwater use is significant during the dry season.

Objective(s): The objectives were to evaluate whether trees use groundwater during the dry season in the riparian zone of the Daly River, and to present the first assessment of groundwater dependency in a riparian plant community in the Australian tropical savanna.

Study Location: Daly River, Northern Territory, Australia Method: River water, xylem water, soil water, and groundwater were collected along transects. Xylem water ( 1 to 3 trees per species per transect) was sampled by collecting three twig samples of 10-to 25-mm diam from the canopy using pruning shears.

Vegetation: Eucalyptus woodlands, Melaleuca communities, Nauclea orientalis (L.), Barringtonia acutangula (L.), Melaleuca argentea W., Melaleuca leucadendra (L.), Cathorium umbellatum (Vahl.), Leptospermum grandiflorum Lood., Strichnos lucida R., Corymbia bella, Acacia auriculiformis A. Cunn., and Casuarina cunninghamiana Miq.

\section{Soil Properties: N/A}

Observations/Results: Unlike some other forest types in the Northern Territory, a difference in the deuterium signature of soil water and groundwater can be used to determine from where in the soil profile trees are accessing water in the Daly River riparian zone. These differences in deuterium levels suggest that soil water and groundwater have different 
origins in this system. Groundwater holds relatively steady state deuterium concentrations. The more negative deuterium $\left(\delta^{2} \mathrm{H}\right)$ values found in soil water indicate that wet season rainfall and overbank flows could be significant sources of water to the vadose zone component of the riparian zone.

Recommendations: It is possible to determine the water sourcing strategies for some of the more common species found in the Daly River riparian zone.

* Reprinted from J ournal of Hydrology 310, S. Lamontagne, P. G. Cook, A. O'Grady, and D. Eamus, Groundwater use by vegetation in a tropical savanna riparian zone (Daly River, Australia), 280-293, 2005, with permission from Elsevier.

Title: Root strength and root area ratio of forest species in Lombardy Poplar (Northern Italy)

Author: Bischetti, G.B., E.A. Chiaradia, T. Simonato, B.V. Speziali, P. Vullo and A. Zocco

Series/Source: Plant and Soil, 2005. 278:11-22

Peer-reviewed: Yes

Code: RTSYST, RTSTAB

Abstract*: Forest vegetation is known to increase hillslope stability by reinforcing soil shear resistance and by influencing hydrologic conditions of soil. Although the importance of plant root systems for hillslope stability has received considerable attention in recent years, the quantification of such an effect needs more investigation. In this paper, we present a synthesis of the data gathered in the last 5 years for some species in different locations of the Alps and Pre-Alps of Lombardy (Northern Italy) with the aim of increasing our knowledge on root tensile strength and on Root Area Ratio distribution within the soil. Concerning root tensile strength, we developed tensile strength-diameter relationships for eight species: green alder (Alnus viridis (Chaix) D.C.), beech (Fagus sylvatica L.), red willow (Salix purpurea L.), goat willow (Salix caprea L.), hazel (Corylus avellana L.), European ash (Fraxinus excelsior L.), Norway spruce (Picea avies (L.) Karst.) and European larch (Larix decidua Mill.). Results show a great variability among the different species and also for the same species. In general, however, root strength (in terms of tension) 
tends to decrease with diameter according to a power law, as observed by other authors. Comparing the power law fitting curves for the considered species, it can be observed that they fall in a relatively narrow band, with the exception of hazel, which appears the most resistant. Concerning the evaluation of root distribution within the soil, we estimated the Root Area Ratio (the ratio between the areas occupied by roots in a unit area of soil) according to its depth for five species (beech, Norway spruce, European larch, mixed hazel, and ash) in three locations of Lombardy. Results show that there is a great variability of root density for the same species well as for different points at the same locality. The general behavior of root density, in any case, is to decrease with depth according to a gamma function for all the studied species. The results presented in this paper contribute to expand the knowledge on root resistance behavior and on root density distribution within the soil. The studied location has allowed the implementation of soil-root reinforcement models and the evaluation of the vegetation contribution to soil stability.

Objective(s): The objective was a synthesis of the data gathered in the last 5 years for several species in different locations within the Lombardy (Northern Italy) region, with the aim of increasing knowledge of root tensile strength and on Root Area Ratio distribution within the soil.

Study Location: Lombardy region of Northern Italy

Method: Synthesis of 5 years of experimental data Vegetation: Green alder (Alnus viridis (Chaix) D.C.), beech (Fagus sylvatica L.), red willow (Salix purpurea L.), goat willow (Salix caprea L.), hazel (Corylus avellana L.), European ash (Fraxinus excelsior L.), Norway spruce (Picea avies (L.) Karst.) and European larch (Larix decidua Mill.)

Soil Properties: Eroded slopes of overconsolidated glacial till (sand and gravel in a silty matrix)

Observations/Results: The results presented in this paper contributed to the knowledge of root resistance behavior and root density distribution within the soil. The study location allowed the implementation of soil-root reinforcement models and the evaluation of the vegetation contribution to soil stability. It confirmed the power law relationship between tensile strength and root diameter.

\section{Recommendations: N/A}

* With kind permission from Springer Science+Business Media: 
Plant and Soil 278 (1-2), G.B. Bischetti, E.A. Chiaradia, T. Simonato, B.V. Speziali, P. Vullo, and A. Zocco, Root strength and root area ratio of forest species in Lombardy Poplar (Northern Italy), 11-22(12), 2005.

Title: Root system architecture of Quercus pubescens trees growing on different sloping conditions

Author: Di Iorio, A., B. Lasserre, G.S. Scippa, and D. Chiatante

Series/Source: Annals of Botany, 2005. 95(2):351-361

Peer-reviewed: Partial

Code: RTSYST, RTSTAB

\begin{abstract}
Background and Aims. Plant roots' growth direction has important implications for plant development and survival; moreover, it plays an effective and vital role in stabilizing weathered soil on a steep slope. The aim of this work was to assess the influence of slope on the architecture of woody root systems.

Methods. Five mature, single-stemmed Quercus pubescens trees growing on a steep slope and five on a shallow slope were excavated to a root diameter of $1 \mathrm{~cm}$. A very precise numeric representation of the geometry and topology of structural root architecture was gained using a low-magnetic-field digitizing device (Fastrak, Polhemus). Several characteristics of root architecture were extracted by macros, including root volume, diameter, length, number, spatial position and branching order.
\end{abstract}

Key Results. The diameter at breast height (dbh) was the best predictor of the root volume but had no correlation with length and number of roots. The slope affected the root volume for each branching order, and the basal cross-sectional area (CSA), number and length of the first-order roots. Number and length of the second- and third-order laterals were closely related in both conditions, although this relationship was closer in the shallow trees, suggesting the influence of a genetic control. Sloping trees showed a clustering tendency of the first- and second-order lateral roots in the up-slope direction, suggesting that the laterals rather than the taproots provide much of the anchorage. In a steep-slope condition, the taproot tapering was positively correlated with the asymmetry magnitude of firstorder roots, indicating compensation between taproot and main lateral roots' clustering tendency. 
Conclusions. These results suggest that on a slope, on clayey soils, root asymmetry appears to be a consequence of several environmental factors such as inclination, shallow-slides and soil compactness. In addition, this adaptive growth seems to counteract the turning moment induced by the self-loading forces acting in slope conditions, and as a consequence improves the tree stability.

Objective(s): The growth direction of plant roots has important implications for plant development and survival; moreover, it plays an effective and vital role in stabilizing weathered soil on a steep slope. The objective of this work was to assess the influence of slope on the architecture of woody root systems.

\section{Study Location: N/A}

Method: Five mature, single-stemmed Quercus pubescens trees growing on a steep slope and five on a shallow slope were excavated to a root diameter of $1 \mathrm{~cm}$. A very precise numeric representation of the geometry and topology of structural root architecture was gained using a lowmagnetic-field digitizing device. Several characteristics of root architecture were extracted by macros, including root volume, diameter, length, number, spatial position and branching order.

Vegetation: Oak (Quercus pubescens)

Soil Properties: Clayey soils

Observations/Results: The diameter was the best predictor for the root volume but had no correlation with length and number of roots. The slope affected the root volume for each branching order, and the basal crosssectional area, number and length of the first-order roots. The number and length of the second- and third-order laterals were closely related in both conditions, although this relationship was closer in the shallow trees, suggesting the influence of a genetic control. Sloping trees showed a clustering tendency of the first- and second-order lateral roots in the upslope direction, suggesting that the laterals rather than the taproots provided much of the anchorage. In a steep-slope condition, the taproot tapering was positively correlated with the asymmetry magnitude of firstorder roots, indicating compensation between taproot and main lateral roots' clustering tendency.

The results suggested that on a slope with clayey soils, root asymmetry appeared to be a consequence of several environmental factors such as inclination, shallow-slides, and soil compactness. In addition, this adaptive growth seemed to counteract the turning moment induced by the 
self-loading forces acting in slope conditions, and, as a consequence, improves the tree stability.

\title{
Recommendations: N/A
}

* Reprinted from Annals of Botany 95, A. Di Iorio, B. Lasserre, G. S. Scippa, and D. Chiatante, Root system architecture of Quercus pubescens trees growing on different sloping conditions, 351-361, 2005, with permission from Oxford University Press.

\section{Title: Uprooting of vetiver uprooting resistance of vetiver grass (Vetiveria zizanioides)}

Author: Mickovski, S.B., L.P.H van Beek, and F. Salin

Series/Source: Plant and Soil, 2005. 278:33-41

Peer-reviewed: Yes

Code: RTSYST, RTSTAB, LEVVEG

\begin{abstract}
Vetiver grass (Vetiveria zizanioides), also known as Chrysopogon zizanioides, is a graminaceous plant native to tropical and subtropical India. The southern cultivar is sterile; it flowers but sets no seeds. It is a densely tufted, perennial grass that is considered sterile outside its natural habitat. It grows 0.5 to $1.5 \mathrm{~m}$ high, stiff stems in large clumps from a much branched root stock. The roots of vetiver grass are fibrous and reported to reach depths up to $3 \mathrm{~m}$ thus being able to stabilize the soil and its use for this purpose is promoted by the World Bank. Uprooting tests were carried out on vetiver grass in Spain in order to ascertain the resistance the root system can provide when torrential runoffs and sediments are trying to uproot the plant. Uprooting resistance of each plant was correlated to the shoot and root morphological characteristics. In order to investigate any differences between root morphology of vetiver grass in its native habitat reported in the literature, and the one planted in a sub-humid environment in Spain, excavation techniques were used to show root distribution in the soil. Results show that vetiver grass possesses the root strength to withstand torrential runoff. Planted in rows along the contours, it may act as a barrier to the movement of both water and soil. However, the establishment of the vetiver lags behind the reported rates in its native tropical environment due to adverse climatic conditions in the Mediterranean. This arrested
\end{abstract}


development is the main limitation to the use of vetiver in these environments although its root strength is more than sufficient.

Objective(s): Uprooting tests were carried out on vetiver grass in a Mediterranean location in order to ascertain the resistance the root system can provide when torrential runoffs and sediments try to uproot the plant, as part of the European EcoSlopes project.

Study Location: Spain (Alcoy region)

Method: Uprooting tests were conducted to measure uprooting resistance

Vegetation: Vetiver grass

Soil Properties: Silt with direct shear test results $4.8 \mathrm{kPa}$ cohesion and 34 deg friction angle

Observations/Results: Results showed that vetiver grass possesses the root strength to withstand torrential runoff. Planted in rows along the contours, it may act as a barrier to the movement of both water and soil. However, the establishment of the vetiver lags behind the reported rates in its native tropical environment due to adverse climatic conditions in the Mediterranean.

Recommendations: Vetiver is more suitable for engineered sites that are properly prepared, irrigated, and maintained.

* Reprinted from Plant and Soil 278(1), S.B. Mickovski, L.P.H van Beek, and F. Salin, Uprooting of vetiver uprooting resistance of vetiver grass (Vetiveria zizanioides), 33-41, November 30, 2005, with permission from Springer Online.

http://www.springerlink.com/content/y5gmx04276454514/?p=2d4c7c8125e743e49b8cf9ad62eb8986 $\underline{\text { \& } \mathrm{i}=3}$

Title: Detection of tree roots and determination of root diameters by ground penetrating radar under optimal conditions

Author: Barton, C.V.M., and K.D. Montagu

Series/Source: Tree Physiology, 2004. 24:1323-1331

Peer-reviewed: Yes

Code: RTSYST 
Abstract*: A tree's root system accounts for between $10 \%$ and $65 \%$ of its total biomass, yet our understanding of the factors that cause this proportion to vary is limited because of the difficulty encountered when studying tree root systems. There is a need to develop new sampling and measuring techniques for tree root systems. Ground penetrating radar (GPR) offers the potential for direct nondestructive measurements of tree root biomass and root distributions to be made. We tested the ability of GPR, with $500 \mathrm{MHz}, 800 \mathrm{MHz}$, and $1 \mathrm{GHz}$ antennas, to detect tree roots and determine root size by burying roots in a $32 \mathrm{~m}^{3}$ pit containing damp sand. Within this test bed, tree roots were buried in two configurations: (1) roots of various diameters $(1-10 \mathrm{~cm})$ were buried at a single depth $(50 \mathrm{~cm})$; and (2) roots of similar diameter (about $5 \mathrm{~cm}$ ) were buried at various depths (15-155 cm). Radar antennas were drawn along transects perpendicular to the buried roots. Radar profile normalization, filtration, and migration were undertaken based on standard algorithms. All antennas produced characteristic reflection hyperbolas on the radar profiles allowing visual identification of most root locations. The $800 \mathrm{MHz}$ antenna resulted in the clearest radar profiles. An unsupervised, maximum-convexity migration algorithm was used to focus information contained in the hyperbolas back to a point. This resulted in a significant gain in clarity with roots appearing as discrete shapes, thereby reducing confusion due to overlapping of hyperbolas when many roots are detected. More importantly, parameters extracted from the resultant waveform through the center of a root correlated well with root diameter for the $500 \mathrm{MHz}$ antenna, but not for the other two antennas. A multiple regression model based on the extracted parameters was calibrated on half of the data $\left(\mathrm{R}^{2}=0.89\right)$ and produced good predictions when tested on the remaining data. Root diameters were predicted with a root mean squared error of $0.6 \mathrm{~cm}$, allowing detection and quantification of roots as small as $1 \mathrm{~cm}$ in diameter. An advantage of this processing technique is that it produces results independently of signal strength. These waveform parameters represent a major advance in the processing of GPR profiles for estimating root diameters. We conclude that enhanced data analysis routines combined with improvements in GPR hardware design could make GPR a valuable tool for studying tree root systems.

Objective(s): The objective was to test the ability of GPR with $500 \mathrm{MHz}$, $800 \mathrm{MHz}$, and $1 \mathrm{GHz}$ antennas to detect roots and root sizes of buried root samples.

Study Location: Laboratory tests 
Method: A $4 \mathrm{~m} \times 4 \mathrm{~m} \times 2 \mathrm{~m}$ pit was dug into a steep slope side and lined with wood to prevent water infiltration. Selected root samples were buried inside this pit filled with damp sand. A field-portable GPR system was used to measure the tree root system.

Vegetation: Eucalyptus (Eucalyptus sp.) roots

Soil Properties: Washed coarse river sand ( $<3 \mathrm{~mm}$ particle diameter). Observations/Results: The $500 \mathrm{MHz}$ antenna produced the best results for determining root diameters.

\title{
Recommendations: N/A
}

* Reprinted from Tree Physiology 24, C.V.M. Barton, and K.D. Montagu, Detection of tree roots and determination of root diameters by ground penetrating radar under optimal conditions, 1323-1331, 2004, Oxford Press, with permission granted through Rightslink, Copyright Clearance Center, Inc.

\section{Title: Relationships between tree dimension and coarse root} biomass in mixed stands of European beech (Fagus sylvatica L.) and Norway spruce (Picea abies [L.] Karst.)

Author: Bolte, A., T. Rahmann, M. Kuhr, P. Pogoda, D. Murach, and K.V. Gadow

Series/Source: Plant and Soil, 2004. 264:1-11

Peer-reviewed: Yes

Code: RTSYST

\begin{abstract}
Relationships between tree parameters above ground and the biomass of the coarse root system were examined in six mixed sprucebeech stands in the Solling Mountain region in northwest Germany. The selected stands were located on comparable sites and covered an age range of 44 to 114 years. Coarse roots $(\mathrm{d} \geq 2 \mathrm{~mm}$ ) of 42 spruce and 27 beech trees were sampled by excavating the entire root system. A linear model with logarithmic transformation of the variables was developed to describe the relationship between the coarse root biomass (CRB, dry weight) and the corresponding tree diameter at breast height (DBH). The coefficients of determination (R2) attained values between 0.92 for spruce and 0.94 for beech; the logarithmic standard deviation values were between 0.29 and 0.43 . A significantly different effect of tree species on the model estimates could not be detected by an analysis of covariance (ANCOVA). For spruce,
\end{abstract}


the derived relationships were similar to those reported in previous studies, but not for beech. Biomass partitioning in the tree compartments above and below ground differs significantly between spruce (coarse root/ shoot ratio $0.16 \pm 0.06$ ) and beech (coarse root/ shoot ratio $0.10 \pm 0.03$ ) in the mixed stands. These results are similar to those given in other studies involving pure spruce and beech stands on comparable sites in the region, although the ratios of pure stands in other regions growing under different site conditions are somewhat higher. Comparing trees of the same DBH classes, root/ shoot ratios of spruce are 1.2 to 3 times higher than those of beech. Dominant spruce trees ( $\mathrm{DBH}>60 \mathrm{~cm}$ ) attained the highest ratios, suppressed beech trees $(\mathrm{DBH}<10 \mathrm{~cm})$ the lowest. Site conditions of varying climate and soils and interspecific tree competition are likely to affect root/ shoot ratio and DBH-coarse root biomass relationships. The greater variability in beech compared with spruce indicates a high 'plasticity' and adaptability of beech carbon allocation. Thus, the derived equations are useful for biomass estimates of coarse roots involving trees of different ages in mixed stands of spruce and beech in the Solling Mountains. However, application of these relationships to stands in other regions would need further testing.

Objective(s): The objective was to correlate of root system characteristics to trunk diameters.

Study Location: Six mixed beech-spruce stands in the Solling mountain region of Lower Saxony (northwest Germany)

Method: 42 spruce and 27 beech trees were selected for sampling aboveand below-ground characteristics. The roots were exposed using a skidder and cable winch.

Vegetation: European beech (Fagus sylvatica L.) and Norway spruce (Picea abies [L.] Karst.) trees

Soil Properties: Podzolic brown soil (loess and sandstone sediment) Observations/Results: There was strong correlation between root biomass and tree diameter, but site conditions of varying climate, soils, and tree competition affect root/ shoot ratio and diameter/ root biomass relationships.

\section{Recommendations: N/A}

* Reprinted from Plant and Soil 264, A. Bolte, T. Rahmann, M. Kuhr, P. Pogoda, D. Murach, and K.V. Gadow, Relationships between tree dimension and coarse root biomass in mixed stands of European beech 
(Fagus sylvatica L.) and Norway spruce (Picea abies [L.] Karst.), 1-11, 2004, with permission from Springer.

\title{
Title: Root Typ: A generic model to depict and analyse the root system architecture
}

Author: Pagès, Loïc, Gilles Vercambre, J ean Louis Drouet, François Lecompte, Cathering Collet, and J acques Le Bot

Series/Source: Plant and Soil, 2004. 258:103-119

Peer-reviewed: Yes

Code: RTSYST

\begin{abstract}
Dynamic models of root system development and architecture integrate various developmental processes and let simulate multiple dynamic interactions. They are recognized as valuable tools to study the soil-plant-atmosphere continuum. In the recent years, some models have emerged from fractal descriptions. Others arose from developmental approaches but most efforts met little success for genericity. Among the difficulties with models are their growing complexity and their inability to detail evenly all important mechanisms often due to a deficit of independent and suitable data for model testing. We propose here a generic model called 'Root Typ' dedicated to quantitative and global analyses of root system architectures and simplified representation of architectural diversity. It aims at (i) detailing evenly a large range of developmental processes, (ii) generalizing the concept of root type, and (iii) representing in a very simplified way soil effects on developmental processes. The model implements several developmental processes including: root emission, axial and radial growth, sequential branching, reiteration, transition, decay and abscission, which are all discussed in details. Finally, its ability to mimic a diversity of root architectures is tested against representative root systems depicted in the book of Kutschera (1960) which represents an independent database collected on a large number of plant species and soil conditions, and gives an overall synthetic view upon root systems.
\end{abstract}

Objective(s): The objective was to develop a root architectural model "Root Typ."

Study Location: N/A 
Method: The model proposed a synthetic approach to root system growth dynamics.

\section{Vegetation: N/A}

\section{Soil Properties: N/A}

Observations/Results: "Root Typ" is able to mimic a diversity of root architecture.

\section{Recommendations: N/A}

Kutschera, L. 1960. Wurzetlas mitteoevropaischer Ackerundkrauter und Kulturpflanzen. DLG Verlag, Frankfort, Germany.

* Reprinted from Plant and Soil 258, Loïc Pagès, Gilles Vercambre, J ean Louis Drouet, François Lecompte, Cathering Collet, and J acques Le Bot, Root Typ: A generic model to depict and analyse the root system architecture, 103-119, 2004, with permission from Springer.

\section{Title: Variation in xylem structure and function in stems and roots of trees to $20 \mathrm{~m}$ depth}

Author: McElrone, Andrew J., William T. Pockman, J ordi MartínezVilalta, and Robert B. Jackson

Series/Source: New Phytologist, 2004. 163:507-517

Peer-reviewed: Yes

Code: RTSYST

Abstract: Permission to publish abstract was not obtained.

Objective(s): Xylem anatomy, vulnerability to cavitation $\left(\Psi_{50}\right)$ and specific hydraulic conductivity $\left(\mathrm{K}_{\mathrm{s}}\right)$ of tree stems, shallow roots, and deep roots were analyzed to characterize their hydraulic architecture and limitations to water transport.

Study Location: Edwards Plateau of central Texas (a karst region with shallow soils on top of fractured limestone)

Method: Stems, shallow roots, and deep roots were sampled from adult trees. The deep roots were either excavated from soil on the cave floor/ walls and along the banks of the underground stream, or sampled while hanging vertically. Anatomical measurements, electron micrographs, hydraulic measurements, centrifuge, and air injection techniques were used to characterize the samples. 
Vegetation: Savanna and woodland dominated by trees in the genera Juniperus, Bumelia, Quercus, Ulmus, and Celtis

Soil Properties: Shallow $(<20 \mathrm{~cm})$ depth soils overlying limestone bedrock.

Observations/Results: Deep roots differ in structure and function from their shallower counterparts.

Recommendations: N/A

Title: Root distribution relationships to soil properties in Missouri oak stands: A productivity index approach Author: Udawatta, Ranjith P., and Gray S. Henderson Series/Source: Soil Science Society of America J ournal, 2003. 67:18691878

Peer-reviewed: Yes

Code: RTSYST, ECOSYS

Abstract*: This study examined the feasibility of adapting a soil-based productivity index (PI) to predict root distribution in Missouri oak (Quercus spp.) stands. Roots and soil were sampled to $150 \mathrm{~cm}$ in 58 plots in the Missouri Ozarks and Missouri River hills. Soil pH, bulk density, and moisture holding capacity were determined by horizon, and the data were used in equations designed to quantify "sufficiency" for root growth. The resulting sufficiency values were used to calculate individual and combined soil property indices for each plot. First, sufficiency values for combined indices were calculated in three ways-multiplicative, geometric, and arithmetic. Then, the indices were derived by multiplying individual or combined sufficiency values by a root index factor, which this study found to be representative of proportional root distribution in "ideal" soil, and then summing the weighted values. Of the individual indices, soil $\mathrm{pH}$ explained $30 \%$ of fine root length variability and $29 \%$ of the total root length variability. Neither soil bulk density nor soil moisture explained root length variability. In fact, these properties actually reduced predictability when included in combined indices. Of the combined indices, the multiplicative-based index explained a greater percentage of root length variation than either the geometric- or arithmetic-based indices. However, no combined index accounted for more than $11 \%$ of the variation in root length distribution. This suggests that, to be usable in 
forestry, the soil-based productivity index needs to be refined and/ or expanded to include variables such as nutrients and climate.

Objective(s): The objective was to explore the feasibility of adapting a soil-based productivity index (PI) to predict root distribution in Missouri oak (Quercus spp.) stands.

Study Location: Southeast and central Missouri

Method: Roots and soil were sampled to $150 \mathrm{~cm}$ in 58 plots in the Missouri Ozarks and Missouri River hills. Soil pH, bulk density, and moisture holding capacity were determined by horizon, and the data were used in equations designed to quantify "sufficiency" for root growth. The resulting sufficiency values were used to calculate individual and combined soil property indices for each plot.

Vegetation: Red and white oak trees (Quercus spp.)

Soil Properties: Ranged from thick loess to sandstone residuum deposits

Observations/Results: Neither soil bulk density nor soil moisture explained root length variability. Of the combined indices, none accounted for more than $11 \%$ of the variation in root length distribution. To be usable in forestry, the soil-based productivity index (PI) needs to be refined and/ or expanded to include variables such as nutrients and climate.

\section{Recommendations: N/A}

* Formal permission not required. Covered under Fair Use in Title 17 of the US Code.

Title: Utility of ground-penetrating radar as a root biomass survey tool in forest systems

Author: Butnor, J.R., J .A. Doolittle, K.H. J ohnsen, L. Samuelson, T. Stokes, and L. Kress

Series/Source: Soil Science Society of America J ournal, 2003. 67:16071615

Peer-reviewed: Yes

Code: RTSYST

Abstract*: Traditional methods of measuring tree root biomass are labor intensive and destructive in nature. We studied the utility of groundpenetrating radar (GPR) to measure tree root biomass in situ within a 
replicated, intensive culture forestry experiment planted with loblolly pine (Pinus taeda L.). The study site was located in Decatur County, GA, in an area of the Troup and Lucy (loamy, kaolinitic, thermic Grossarenic Kandiudults and Arenic Kandiudults, respectively) soils. With the aid of a digital signal processing GPR, estimates of root biomass to a depth of $30 \mathrm{~cm}$ were correlated to harvested root samples using soil cores. Significant effects of fertilizer application on signal attenuation were observed and corrected. The correlation coefficient between actual root biomass in soil cores and GPR estimates with corrections for fertilizer application were highly significant $(r=0.86, n=60, p<0.0001)$. Where site conditions are favorable to radar investigation, GPR can be a powerful cost-effective tool to measure root biomass. Verification with some destructive harvesting is required since universal calibrations for root biomass are unlikely, even across similar soil types. Use of GPR can drastically reduce the number of soil cores needed to assess tree root biomass and biomass distribution. The quality and quantity of information resulting from a detailed GPR survey, combined with soil cores on a subset of plots, can be used to rapidly estimate root biomass and provide a valuable assessment of lateral root biomass distribution and quantity.

Objective(s): This research is a study of ground-penetrating radar (GPR) for depicting root volume of loblolly pine trees.

Study Location: Decatur County, GA

Method: GPR scans were done along the mid-point between trees growing in rows enabling the scans to be perpendicular to the roots. Roots were scanned to only 12 in. $(30 \mathrm{~cm})$ depth. Four hours of scanning covered 1000 linear feet ( $305 \mathrm{~m}$ ) on the smooth, pine-straw covered soil surface.

Vegetation: Loblolly pine (Pinus taeda L.)

Soil Properties: Loamy sand

Observations/Results: Good agreement was reached between the GPR data and root data from soil cores.

Recommendations: GPR calibration is needed for each soil condition even when the soils are similar. Site conditions need to be uniform. Destructive harvesting is required to verify root biomass results.

* Formal permission not required. Covered under Fair Use in Title 17 of the US Code. 
Title: Hydraulic redistribution of soil water during summer drought in two contrasting Pacific Northwest coniferous forests

Author: Brooks, J.R., F.C. Meinzer, R. Coulombe, and J . Gregg

Series/Source: Tree Physiology, 2002. 22:1107-1117

Peer-reviewed: Yes

Code: RTSYST

Abstract*: The magnitude of hydraulic redistribution of soil water by roots and its impact on soil water balance were estimated by monitoring time courses of soil water status at multiple depths and root sap flow under drought conditions in a dry ponderosa pine (Pinus ponderosa Dougl. ex Laws) ecosystem and in a moist Douglas fir (Pseudotsuga menziesii [Mirb.]) Franco) ecosystem. The fate of deuterated water applied to small plots to create a strong horizontal soil water potential gradient was also monitored to assess the potential for horizontal redistribution of water and utilization of redistributed water by co-occurring shallow-rooted plants. In a 20-year-old Douglas-fir stand, approximately $28 \%$ of the water removed daily from the upper $2 \mathrm{~m}$ of soil was replaced by nocturnal hydraulic redistribution during late August. In an old-grouth ponderosa pine stand, approximately $35 \%$ of the total daily water utilization from the upper $2 \mathrm{~m}$ of soil appeared to be replaced by hydraulic redistribution duringJ uly and August. By late September, hydraulic redistribution in the ponderosa pine stand was no longer apparent, even though total water use from the upper $2 \mathrm{~m}$ of soil was nearly identical to that observed earlier. Based on these results, hydraulic redistribution would allow 21 and 16 additional days of stored water to remain in the upper soil horizons in the ponderosa pine and Douglas fir stands, respectively, after a 60-day drought. At both sites, localized applications of deuterated water induced strong reversal of root sap flow and caused soil water content to cease declining or even temporarily increase at locations too distant from the site of water application to have been influenced by movement of water through the soil without facilitation by roots. Xylem water deuterium values of ponderosa pine seedlings suggested utilization of redistributed water. Therefore, hydraulic redistribution may enhance seedling survival and maintain overstory transpiration during summer drought. These first approximations of the extent of hydraulic redistribution in these ecosystems suggest that it is likely to be an important process in both wet and dry forests of the Pacific Northwest. 
Objective(s): This research explored root system water redistribution processes at dry Ponderosa pine sites and moist Douglas fir sites.

\section{Study Location: OR, WA}

Method: A multi-sensor frequency domain capacitance technique monitored soil volumetric water content continuously at seven depth intervals (to 1-m depth) at selected tree sites. Soil water potential was measured using psychrometers and data loggers. Deuterated water was added to the soil at various locations around the trees. The water was extracted from root and soil samples using cryogenic vacuum distillation, and then analyzed for hydrogen isotope ratios using an isotope ratio mass spectrometer. Root sap flow was measured using a thermal dissipation technique.

Vegetation: Douglas fir (Pseudotsuga menziesii) and Ponderosa pine (Pinus ponderosa)

Soil Properties: Sandy loam ( $73 \%$ sand, $21 \%$ silt, $6 \%$ clay) Observations/Results: Root sap flow and root-soil flow occurs on a daily basis. Hydraulic redistribution through the root system into the surrounding soil matrix occurs at night (nocturnal). In Pacific Northwest forests, hydraulically redistributed water can constitute a significant fraction of the total daily evapotranspiration during the dry summer months and can retard the rate of water depletion in the upper soil layers.

\section{Recommendations: N/A}

* Reprinted from Tree Physiology 22, J.R. Brooks, F.C. Meinzer, R. Coulombe, and J . Gregg, Hydraulic redistribution of soil water during summer drought in two contrasting Pacific Northwest coniferous forests, 1107-1117, 2002, Oxford Press, with permission granted through Rightslink, Copyright Clearance Center, Inc.

Title: Rooting depths, lateral root spreads and below-ground/ above-ground allometries of plants in water-limited ecosystems Author: Schenk, H. J ochen, and Robert B. J ackson Series/Source: J ournal of Ecology, 2002. 90:480-494

Peer-reviewed: Yes

Code: RTSYST, ECOSYS

Abstract: Permission to publish abstract was not obtained. 
Objective(s): The goal of this study was to predict root system sizes and shapes for different plant growth forms using data on above-ground plant sizes, climate, and soil texture.

\section{Study Location: N/A}

Method: Literature review of data on rooting depths and lateral root spreads of individual plants from arid regions (deserts, grasslands, savannas, etc.)

Vegetation: Water-limited ecosystem vegetation ranging from grass to trees

Soil Properties: N/A

Observations/Results: Listed in above Abstract.

Recommendations: N/A

Title: A review of tree root conflicts with sidewalks, curbs, and roads

Author: Randrup, T.B., E.G. McPherson, and L.R. Costello

Series/Source: Urban Ecosystems, 2001. 5:209-225

Peer-reviewed: Yes

Code: RTSYST

Abstract: Permission to publish abstract was not obtained.

Objective(s): A literature review of issues related to tree root damage to infrastructure elements (sidewalks, curbs, and roads).

Study Location: Various worldwide locations where studies have been performed.

Method: An overview of published literature related to rootinfrastructure conflicts. Construction protocols, urban soils, root growth, and causal factors (soil conditions, limited planting space, tree size, variation in root architecture, management practices, and construction materials) are discussed. Because costs related to sidewalk and curb damage are substantial, a review of research addressing repair, mitigation, prevention, and litigation costs is included.

Vegetation: Trees and landscaped vegetation

Soil Properties: N/A

Observations/Results: Cities are spending substantial sums of money to address conflicts between tree roots and infrastructure. More 
knowledge is needed about interactions between root growth and management techniques, such as pruning and irrigation.

Recommendations: Additional research is needed on this subject.

Title: Root biomass and biomass increment in a beech (Fagus sylvativa L.) stand in northeastern France

Author: LeGoff, N., and J . Ottorini

Series/Source: Annals of Forestry Science, 2001. 58(2001):1-13

Peer-reviewed: Yes

Code: RTSYST

Abstract: Permission to publish abstract was not obtained.

Objective(s): The objective was to quantify the root biomass of European beech.

Study Location: Near Nancy, France

Method: Sixteen tree root systems were excavated, measured, ovendried, and weighed.

Vegetation: European beech (Fagus sylvativa L.)

Soil Properties: Clay

Observations/Results: Coarse root biomass increased with tree diameter, and represented an average of $86 \%$ of the total root system.

Recommendations: N/A

Title: Root competition between beech and oak: A hypothesis Author: Leuschner, C., D. Hertel, H. Coners, and V. Buttner

Series/Source: Oecologia, 2001. 126:276-284

Peer-reviewed: Yes

Code: RTSYST, ECOSYS

Abstract*: Little is known about below-ground competition between different tree species in mixed forests. We investigated the evidence for asymmetric competition between fine roots ( $<2 \mathrm{~mm}$ ) of adult European beech (Fagus sylvatica) and sessile oak (Quercus petraea) trees in a mixed temperate beech-oak forest by (1) conducting fine-root growth experiments in the field (root chamber technique), (2) comparing the 
fine-root mass of two-species and monospecific plots, and (3) analysing the density and overlap of beech and oak root systems in shared soil volumes. Field experiments with root chambers, which allow fine-root endings to grow under controlled conditions for several months, showed that beech grew more rapidly than oak roots when both species were grown together. In the mixed beech-oak wood, where stem densities and leaf areas of the two species were similar, beech outnumbered oak threeto five-fold in fine-root biomass, and root tip and ectomycorrhiza numbers, which led to a much greater root:shoot ratio (root area index:leaf area index, RAI:LAI) for beech (3.9) than oak (1.7). The remarkably small fine-root biomass of oak was attributed to competitive replacement by beech roots as indicated by comparison with monospecific oak wood. Although oak had much less fine-root mass than beech, oak outnumbered beech in the coarse root fraction $(2<\mathrm{d}<5 \mathrm{~mm})$ resulting in a greater fine root: coarse root ratio in beech than oak. The fine-root systems of the two species completely overlapped in the nitrogen-rich organic topsoil but differed with respect to their horizontal distribution patterns: beech root biomass increased with increasing distance from a beech stem whereas oak root mass was not dependent on stem distance. Beech (but not oak) root mass was correlated with the thickness of the organic topsoil horizons which, at average, were thicker at greater distances from beech stems. We conclude that beech fine roots colonize nitrogen-rich patches in the organic horizons of this forest more successfully than do oak roots. Our results (root chamber experiments, oak root abundance in mixed vs. monospecific wood, beech root dominance in the organic topsoil) suggest that asymmetric interspecific root competition in favour of beech exists in this stand.

Objective(s): This research was a study of the root competition between fine and coarse roots of mature European beech and Sessile oak trees in a mixed temperate beech-oak forest.

Study Location: Diluvial lowlands of NW (Lower Saxony) Germany Method: Root cores were taken through the soil layers. Species were visually distinguished.

Vegetation: Fagus sylvatica and Quercus petraea

Soil Properties: Cambisols with thick organic layers

Observations/Results: The fine roots of beech trees were more successful in colonizing the upper layers of organic soils than were the oaks.

\section{Recommendations: N/A}


* Reprinted from Oecologia 126, C. Leuschner, D. Hertel, H. Coners, and V. Buttner, Root competition between beech and oak: A hypothesis, 276284, 2001, with permission from Springer.

Title: Spatial distribution of Eucalyptus roots in a deep sandy soil in the Congo: Relationships with the ability of the stand to take up water and nutrients

Author: Laclau, J.P., M. Arnaud, J .P. Bouillet, and J . Ranger

Series/Source: Tree Physiology, 2001. 21:129-136

Peer-reviewed: Yes

Code: RTSYST

Abstract*: Spatial statistical analyses were performed to describe root distribution and changes in soil strength in a mature clonal plantation of Eucalyptus spp. in the Congo. The objective was to analyze spatial variability in root distribution. Relationships between root distribution, soil strength, and the water and nutrient uptake by the stand were also investigated.

We studied three, 2.35-m-wide, vertical soil profiles perpendicular to the planting row and at various distances from a representative tree. The soil profiles were divided into $25-\mathrm{cm}^{2}$ grid cells and the number of roots in each of three diameter classes counted in each grid cell. Two profiles were $2 \mathrm{~m}$ deep and the third profile was $5 \mathrm{~m}$ deep.

There was both vertical and horizontal anisotropy in the distribution of fine roots in the three profiles, with root density decreasing sharply with depth and increasing with distance from the stump. Roots were present in areas with high soil strength values ( $>6000 \mathrm{kPa}$ ). There was a close relationship between soil water content and soil strength in this sandy soil. Soil strength increased during the dry season mainly because of water uptake by fine roots. There were large areas with low root density, even in the topsoil. Below a depth of $3 \mathrm{~m}$, fine roots were spatially concentrated and most of the soil volume was not explored by roots. This suggests the presence of drainage channels, resulting from the severe hydrophobicity of the upper soil.

Objective(s): This research is a study of root distribution and spatial variability of a mature Eucalyptus plantation. 
Study Location: Atlantic coast of Congo Africa

Method: Vertical excavations were dug perpendicular to the tree row. Soil water content was measured with time domain reflectometry (TDR) and soil lysimeters. Soil strength was measured with a hand-held penetrometer. Soil calcium content was measured by inductively coupled plasma (ICP) emission spectroscopy of sampled soil solutions.

Vegetation: Mature Eucalyptus trees

Soil Properties: Arenosols (sand content > 85\%), well-drained, and deep

Observations/Results: In the upper $6.5 \mathrm{ft}(2 \mathrm{~m})$ of soil, the fine root density was highly heterogeneous, and significantly decreased with soil depth. Calcium decreased with soil depth, indicating that the roots obtain nutrients from the forest floor and upper soil layer.

\section{Recommendations: N/A}

* Reprinted from Tree Physiology 21, J .P. Laclau, M. Arnaud, J .P. Bouillet, and J. Ranger, Spatial distribution of Eucalyptus roots in a deep sandy soil in the Congo: Relationships with the ability of the stand to take up water and nutrients, 129-136, 2001, Oxford Press, with permission granted through Rightslink, Copyright Clearance Center, Inc.

Title: Use of ground-penetrating radar to study tree roots in the southeastern United States

Author: Butnor, J.R., J .A. Doolittle, L. Kress, S. Cohen, and K.H. J ohnsen Series/Source: Tree Physiology, 2001. 21:1269-1278

Peer-reviewed: Yes

Code: RTSYST

Abstract*: The objectives of our study were to assess the feasibility of using ground-penetrating radar (GPR) to study roots over a broad range of soil conditions in the southeastern United States. Study sites were located in the Southern Piedmont, Carolina Sandhills, and Atlantic Coast Flatwoods. At each site, we tested for selection of the appropriate antenna (400 MHz versus $1.5 \mathrm{GHz}$ ), determined the ability of GPR to resolve roots and buried organic debris, assessed root size, estimated root biomass, and gauged the practicality of using GPR. Resolution of roots was best in sandy, excessively drained soils, whereas soils with high soil water and clay contents seriously degraded resolution and observation depth. In 
the Carolina Sandhills, $161 \times 1-\mathrm{m}$ plots were scanned with the $1.5 \mathrm{GHz}$ antenna using overlapping grids. Plots were subsequently excavated, larger roots ( $>0.5-\mathrm{cm}$ diameter) sketched on graph paper before removal, and all roots oven-dried, classified by size and weighed. Roots as small as $0.5 \mathrm{~cm}$ in diameter were detected with GPR. We were able to size roots ( 0.5 to $6.5 \mathrm{~cm}$ in diameter) that were oriented perpendicular to the radar sweep ( $\left.r^{2}=0.81, P=0.0004\right)$. Use of image analysis software to relate the magnitude of radar parabolas to actual root biomass resulted in significant correlations ( $\left.\mathrm{r}^{2}=0.55, \mathrm{P}=0.0274\right)$. Orientation and geometry of the reflective surface seemed to have a greater influence on parabola dimensions than did root size. We conclude that the utility of current GPR technology for estimating root biomass is site-specific, and that GPR is ineffective in soils with high clay or water content and at sites with rough terrain (most forests). Under particular soil and site conditions, GPR appears to be useful for augmenting traditional biomass sampling.

Objective(s): This study is an assessment of feasibility of using ground penetrating radar to study root systems over a broad range of soil conditions in the southeastern U.S.

Study Location: Sites near Olar and Moncks Corner, SC; Scotland County and Durham, NC

Method: Tested for selection of the appropriate antenna (400 MHz versus $1.5 \mathrm{GHz}$ ), determined the ability of GPR to resolve roots and buried organic debris, assessed root size, estimated root biomass, and gauged the practicality of using GPR

Vegetation: Cottonwood (Populus deltoides Bartr.) and loblolly pine (Pinus taeda L.)

Soil Properties: Ranged from sandy to clay at various sites

Observations/Results: Ground penetrating radar (GPR) is reliable when used correctly and when scanned perpendicular to roots. GPR is not adequate for clay soils, excessively wet soils, and soils with obstructions of various sizes. Uneven surface soils presented severe problems. Water tables severely distort root signals. Live roots were detectable, but dead roots were often undetected even at much larger diameters. In clay soils, the inclusions of coarse fragments and rocks were generally mistaken for roots.

\section{Recommendations: N/A}

* Reprinted from Tree Physiology 21, J.R. Butnor, J .A. Doolittle, L. Kress, S. Cohen, and K.H. J ohnsen, Use of ground-penetrating radar to study tree 
roots in the southeastern United States, 1269-1278, 2001, Oxford Press, with permission granted through Rightslink, Copyright Clearance Center, Inc.

Title: Vertical distribution and radial growth of coarse roots in pure and mixed stands of Fagus sylvatica and Picea abies

Author: Schmid, I., and M. Kazda

Series/Source: Canadian J ournal of Forest Research, 2001. 31:539-548

Peer-reviewed: Yes

Code: RTSYST

\begin{abstract}
The vertical distribution of roots greater than 2-mm diam was determined from digital images covering profile walls in soil pits dug in pure stands of European beech and Norway spruce, and in a mixed stand of both species. Radial root growth was assessed for roots greater than 5 -mm diam by grouth ring analysis. Beech roots showed maximum density at the 10- to 20-cm depth, whereas the spruce root density decreased exponentially with increasing soil depth. Roots of both species reached the maximum excavation depth $(1 \mathrm{~m})$ in their monospecific stands. However, the root system of spruce was shallower in the mixture with beech, where large roots (diameter $>20 \mathrm{~mm}$ ) were limited to the upper $10 \mathrm{~cm}$. Beech roots reached the same rooting depth as in the pure stand but showed higher root densities in deeper soil layers. Neither root diameter nor root growth of any species was correlated with soil depth. Radial root growth of beech exceeded that of spruce significantly in both pure and mixed stands. Radial growth rate of beech roots further increased when mixed with spruce. The enhancement of beech root growth in the mixed stand suggests a higher belowground competitive ability of beech compared with spruce; as a result the spruce root system developed even shallower in the mixed versus in the pure stand.
\end{abstract}

Objective(s): This research is a study of European beech and Norway spruce root distributions in pure versus mixed tree stands.

Study Location: Near Wilhelmsburg, Austria

Method: Trench profile wall technique with digital photography of the subsurface root systems was used to assess the vertical distribution of roots. 
Vegetation: European beech (Fagus sylvatica) and Norway spruce (Picea abies)

Soil Properties: Heavily textured (clay loam) with clay content ranging from $40 \%$ to $60 \%$.

Observations/Results: Neither root diameter nor root growth of any species was correlated with soil depth. Radial root growth of beech exceeded that of spruce significantly in both pure and mixed stands. Radial growth rate of beech roots further increased when mixed with spruce. The enhancement of beech root growth in the mixed stand suggested a higher belowground competitive ability of beech compared with spruce; as a result, the spruce root system developed even shallower in the mixed versus in the pure stand.

\section{Recommendations: N/A}

* Reprinted from Canadian J ournal of Forest Research 31, I. Schmid, and M. Kazda, Vertical distribution and radial growth of coarse roots in pure and mixed stands of Fagus sylvatica and Picea abies, 539-548, 2001, with permission granted through Rightslink, Copyright Clearance Center.

Title: Seasonal water acquisition and redistribution in the Australian woody phreatophyte Banksia prionotes

Author: Burgess, S.O., J.S. Pate, M.A. Adams, and T.E. Dawson

Series/Source: Annals of Botany, 2000. 85:215-224

Peer-reviewed: Yes

Code: RTSYST, ECOSYS

Abstract*: Sap flows in the xylem of plant roots in response to water
potential gradients, either between soil and atmosphere (transpiration) or
soil layers of different moisture content (hydraulic redistribution). The
latter has the potential to influence water budgets and species interactions,
but we lack information for all but a few plant communities. We combined
heat pulse measurements of sap flow with dye and isotope tracing
techniques to gauge the movement of xylem sap within, and exudation
from, roots of Banksia prionotes (Lindley). We demonstrated 'hydraulic
lift' during the dry season and provide some evidence that extremely dry
soils limit hydraulic lift. In addition, we report difficulties posed by
spiralled xylem tissue in roots for the application of heat pulse techniques. 
Objective(s): This study examined the hydraulic redistribution during the dry season for the Banksia tree.

Study Location: Moora, Western Australia

Method: Measurement of sap flow in the trunk and five lateral roots was done using the heat ratio method (thermocouple sensors inserted into the xylem tissue to determine sap flow velocity). Dye injection was conducted on selected roots, and a stable isotope (deuterium) technique was used to demonstrate reversible flow of xylem sap in lateral roots and water efflux from the finer feeding roots.

Vegetation: Banksia trees

Soil Properties: Arid site, sandy

Observations/Results: The lateral roots of Banksia trees could both absorb and exude water in response to water potential gradients between the roots and the surrounding soil.

\section{Recommendations: N/A}

* Reprinted from Annals of Botany 85, S.O. Burgess, J .S. Pate, M.A. Adams, and T.E. Dawson, Seasonal water acquisition and redistribution in the Australian woody phreatophyte Banksia prionotes, 215-224, 2000, Oxford Press, with permission granted through Rightslink, Copyright Clearance Center, Inc.

Title: Biomass and distribution of fine and coarse roots from blue oak (Quercus douglasii) trees in the northern Sierra Nevada foothills of California

Author: Millikin, Catherine S., and Caroline S. Bledsoe

Series/Source: Plant and Soil, 1999. 214:27-38

Peer-reviewed: Yes

Code: RTSYST

Abstract*: This research adds to the limited data on coarse and fine root biomass for blue oak (Quercus douglasii Hook and Arn.), a California deciduous oak species found extensively throughout the interior foothills surrounding the Central Valley. Root systems of six blue oak trees were analyzed using three methods-backhoe excavation, quantitative pits, and soil cores. Coarse root biomass ranged from 7 to $177 \mathrm{~kg}$ per tree. Rooting depth for the main root system ranged from 0.5 to $1.5 \mathrm{~m}$, with an average of $70 \%$ of excavated root biomass located above $0.5 \mathrm{~m}$. Of the total 
biomass in excavated central root systems, primary roots (including burls) accounted for $56 \%$ and large lateral roots ( $>20 \mathrm{~mm}$ diam) accounted for $36 \%$. Data from cores indicated that most biomass outside of the root crown was located in fine roots and that fine root biomass decreased with depth. At surface depths ( 0 to $20 \mathrm{~cm}$ ), small-fine ( $<0.5 \mathrm{~mm}$ diam) roots accounted for $71 \%$, large-fine $(0.5$ to $2.0 \mathrm{~mm}$ ) for $25 \%$, and coarse ( $>2 \mathrm{~mm}$ ) for $4 \%$ of total root biomass collected with cores. Mean fine root biomass density in the top $50 \mathrm{~cm}$ was $0.43 \mathrm{~kg} \mathrm{~m}^{-3}$. Fine root biomass did not change with increasing distance from the trees (up to approximately $5 \mathrm{~m}$ ). Thus, fine roots were not concentrated under the tree canopies. Our results emphasize the importance of the smallest size class of roots $(<0.5 \mathrm{~mm})$, which had both higher $\mathrm{N}$ concentration and, in the area outside the central root system, greater biomass than large fine ( 0.5 to $2.0 \mathrm{~mm}$ ) or coarse $(>2.0 \mathrm{~mm})$ roots.

Objective(s): The objective was an analysis of coarse and fine root biomass for blue oak (Quercus douglasii Hook and Arn.), a California deciduous oak species found extensively throughout the interior foothills surrounding the Central Valley.

Study Location: Marysville, CA

Method: Root systems of six blue oak trees were analyzed using three methods-backhoe excavation, quantitative pits, and soil cores. Root diameters were noted, and representative samples were analyzed for total carbon $(\mathrm{C})$ and nitrogen $(\mathrm{N})$.

Vegetation: Blue oak (Quercus douglasii Hook and Arn.)

Soil Properties: Well-drained, neutral to slightly acidic $\mathrm{pH}$ soils derived from greenstone bedrock.

Observations/ Results: The smallest size class of roots $(<0.5 \mathrm{~mm})$ had both higher $\mathrm{N}$ concentration and, in the area outside the central root system, greater biomass than large fine $(0.5$ to $2.0 \mathrm{~mm}$ ) or coarse $(>2.0 \mathrm{~mm})$ roots. Fine root biomass did not change with increasing distance from the trees (up to approximately $5 \mathrm{~m}$ ), so the fine roots were not concentrated under the tree canopies.

\section{Recommendations: N/A}

* Reprinted from Plant and Soil 214, Catherine S. Millikin, and Caroline S. Bledsoe, Biomass and distribution of fine and coarse roots from blue oak (Quercus douglasii) trees in the northern Sierra Nevada foothills of California, 27-38, 1999, with permission from Springer. 
Title: Mapping tree root systems with ground-penetrating radar Author: Hruska, J ., J . Cermak, and S. Sustek

Series/Source: Tree Physiology, 1999. 19:125-130

Peer-reviewed: Yes

Code: RTSYST

\begin{abstract}
A ground-penetrating radar (GPR) technique was used to study the three-dimensional distribution of root systems of large $(\mathrm{DBH}=$ 14 to $35 \mathrm{~cm}$ ) oak trees (Quercus petraea (Mattusch.) Liebl.) in relatively dry, luvisoil on loamy deluvium and weathered granodiorite. We used a pulse EKKO $1000 \mathrm{GPR}$ system, a profile grid of $0.25 \times 0.25 \mathrm{~m}$, at $0.05-\mathrm{m}$ intervals, and a signal frequency of $450 \mathrm{MHz}$, to assure resolution of about $3 \mathrm{~cm}$ in both directions (further increases in resolution up to $1 \mathrm{~cm}$ are possible with the system). Coarse root density was $6.5 \mathrm{~m} \mathrm{~m}^{-2}$ of stand area and $3.3 \mathrm{~m} \mathrm{~m}^{-3}$ of soil volume. Maximum rooting depth of the experimental oaks was $2 \mathrm{~m}$, and the root ground plan was significantly larger (about 1.5 times) than the crown ground plan. Based on earlier studies of Quercus robur L. from floodplain forests, where the extent of the root systems was much smaller (root ground plan: crown ground plan ratio of 0.6), we conclude that the high root ground plan:crown ground plan ratio indicates less favorable conditions of water supply at the experimental site than in the floodplain forest. The ground-penetrating radar system is noninvasive and allows relatively rapid and repeated measurements of the distribution of coarse root systems of trees.
\end{abstract}

Objective(s): The objective was to use GPR to measured coarse roots of an oak tree.

Study Location: Near Brno, Czech Republic

Method: GPR scan depth was $6.5 \mathrm{ft}(2 \mathrm{~m})$. A $20 \mathrm{ft}$ by $20 \mathrm{ft}$ ( $6 \mathrm{~m}$ by $6 \mathrm{~m}$ ) scan took $6 \mathrm{hr}$ and $30 \mathrm{hr}$ of post-processing. Frequency was $450 \mathrm{MHz}$.

Vegetation: Oak (Quercus petraea) trees

Soil Properties: Dry luvisoil on loamy deluvium and weathered granodiorite

Observations/Results: Roots were detected down to $1.1 \mathrm{in} .(3 \mathrm{~cm})$ diameter and depth to $6.5 \mathrm{ft}(2 \mathrm{~m})$. GPR was an efficient method for 3-D mapping of tree roots in dry loamy soils.

Recommendations: N/A 
* Reprinted from Tree Physiology 19. J. Hruska, J . Cermak, and S. Sustek, Mapping tree root systems with ground-penetrating radar, 125-130, 1999, Oxford Press, with permission granted through Rightslink, Copyright Clearance Center, Inc.

Title: Root deformation in plantations of container-grown Scots pine trees: Effects on root growth, tree stability, and stem straightness

Author: Lindstrom, A., and G. Rune

Series/Source: Plant and Soil, 1999. 217:29-37

Peer-reviewed: Yes

Code: RTSYST, RTSTAB

Abstract*: Root system deformation was studied in 23 Scots pine (Pinus sylvestris L.) stands in central Sweden. The study comprised both plantations created with container-grown plants (Paperpot) and natural stands including young (7 to 9-year-old) and older (19 to 24-year-old) trees. Trees were measured with regards to distribution of roots, 'root deformation, stability, stem straightness, and wood properties in stumps. Root distribution was most uniform for naturally regenerated trees. Older trees generally showed a better root distribution than young trees. The young planted trees displayed a high frequency of severely spiralled root systems, while only a few of the older trees had spiralled root systems. No severe root deformations were observed on naturally regenerated trees. Naturally, regenerated trees were more stable than those which had been planted. Differences in bending moment, when trees were pulled to an angle of $10^{\circ}$, were considerable between young planted and naturally regenerated trees, but less pronounced for the older trees. Young planted trees had the highest frequency of severely crooked stem bases, while naturally regenerated trees had the straightest mode of growth. Tensile strength in peripheral wood samples of the stumps was substantially lower for planted than for naturally regenerated trees. Strain values to breakage of wood samples, taken from the root collar and the central- and peripheral part of the stump were lower for planted trees. The conclusions from this study are that root distribution, tree stability and stem straightness of planted Paperpot-grown trees will improve after a certain time and approach the state of naturally regenerated trees. As trees grow older, early established crooked stem bases will be compensated by radial 
growth and the tree will appear straighter. Inside the stem, however, problems may still remain with abnormal fibre direction and compression wood together with inferior root strength due to fibre disturbances as a result of spiralled roots.

Objective(s): The objective was a comparative study of root deformation and growth development in container-grown and naturally regenerated trees.

Study Location: Central Sweden Method: Twenty-three Scots pine stands were sampled. Tree measurements were taken, trees were winched over while a dynanometer measured the pulling force and bending moment, and selected trees had their roots excavated for further measurements of root architecture.

Vegetation: Pinus sylvestris L.

Soil Properties: Sandy loam till

Observations/Results: The root distribution, tree stability, and stem straightness of planted container-grown seedlings will improve and eventually approach those characteristics of naturally regenerated trees.

\section{Recommendations: N/A}

* Reprinted from Plant and Soil 217, A. Lindstrom, and G. Rune, Root deformation in plantations of container-grown Scots pine trees: Effects on root growth, tree stability, and stem straightness, 29-37, 1999, with permission from Springer.

Title: Root strength, growth, and rates of decay: root reinforcement changes of two tree species and their contribution to slope stability

Author: Watson, A., C. Phillips, and M. Marden

Series/Source: Plant and Soil, 1999. 217:39-47

Peer-reviewed: Yes

Code: RTSYST, SOILER, SLSTAB (VR)

Abstract: Permission to publish abstract was not obtained.

Objective(s): Information on live root-wood strength, rates of root decay and root growth of two tree species were combined to form a generalized conceptual model of changes in net root reinforcement. 
Study Location: East Cape region of the North Island, New Zealand Method: Root samples were retrieved and individually tested for tensile strength by clamping the root at both ends and applying a tensile force. Thirteen pine and 15 kanuka root systems were excavated using highpressure water. The root systems were then architecturally mapped. Growth and decay rate curves were generated, and correlations to expected flood events provided estimates of erosion-susceptibility probabilities.

Vegetation: Radiata pine (Pinus radiata D. Don) and kanuka (Kunzea ericoides (A. Rich.) J oy Thomps. var. ericoides)

\section{Soil Properties: N/A}

Observations/Results: A generalized conceptual model of changes in net root reinforcement provided an initial opportunity to rank the plant species having specific belowground rooting habits that can be used to control erosion, and when linked with extreme flood probability can be used to indicate the risk of a storm likely to cause slope instability in the period between clear-felling and regrowth. Erosion-susceptible slopes planted one year after clearfelling in radiata pine at 1250 stems ha $^{-1}$ regain root site-occupancy in 4.7 years, an interval during which there is an $80 \%$ chance of experiencing an extreme flood. Similarly, for radiata planted at 800 and 400 stems ha $^{-1}$, root site-occupancy is regained in 5.6 and 7.5 years, and the probability of occurrence of an extreme event within these periods is 85 and $90 \%$, respectively. For erosion-susceptible slopes on which kanuka has become established, the probability of a significant event within the 2.8 years prior to root site-occupancy is $60 \%$. Slopes felled of radiata pine are potentially more vulnerable to the stresses promoting slope instability, at least in the earlier years.

\section{Recommendations: N/A}

Title: Hydraulic lift: Consequences of water efflux from the roots of plants

Author: Caldwell, M.M., T. E. Dawson, and J.H. Richards

Series/Source: Oecologia, 1998. 113:151-161

Peer-reviewed: Yes

Code: RTSYST

Abstract*: Hydraulic lift is the passive movement of water from roots into soil layers with lower water potential, while other parts of the root 
system in moister soil layers, usually at depth, are absorbing water. Here, we review the brief history of laboratory and field evidence supporting this phenomenon and discuss some of the consequences of this below-ground behavior for the ecology of plants. Hydraulic lift has been shown in a relatively small number of species ( 27 species of herbs, grasses, shrubs, and trees), but there is no fundamental reason why it should not be more common as long as active root systems are spanning a gradient in soil water potential (psi) and that the resistance to water loss from roots is low. While the majority of documented cases of hydraulic lift in the field are for semiarid and arid land species inhabiting desert and steppe environments, recent studies indicate that hydraulic lift is not restricted to these species or regions. Large quantities of water, amounting to an appreciable fraction of daily transpiration, are lifted at night. This temporary partial rehydration of upper soil layers provides a source of water, along with soil moisture deeper in the profile, for transpiration the following day and, under conditions of high atmospheric demand, can substantially facilitate water movement through the soil-plant-atmosphere system. Release of water into the upper soil layers has been shown to afford the opportunity for neighboring plants to utilize this source of water. Also, because soils tend to dry from the surface downward and nutrients are usually most plentiful in the upper soil layers, lifted water may provide moisture that facilitates favorable biogeochemical conditions for enhancing mineral nutrient availability, microbial processes, and the acquisition of nutrients by roots. Hydraulic lift may also prolong or enhance fine-root activity by keeping them hydrated. Such indirect benefits of hydraulic lift may have been the primary selective force in the evolution of this process. Alternatively, hydraulic lift may simply be the consequence of roots not possessing true rectifying properties (i.e., roots are leaky to water). Finally, the direction of water movement may also be downward or horizontal if the prevailing $\Psi_{\mathrm{s}}$ gradient so dictates, i.e., inverse, or lateral, hydraulic lift. Such downward movement through the root system may allow growth of roots in otherwise dry soil at depth, permitting the establishment of many phreatophytic species.

Objective(s): This research provides a review of laboratory and field evidence supporting hydraulic lift,' which is the passive water movement from roots into soil with lower water potential, at the same time that other parts of the root system in wetter soil layers are absorbing water, usually at depth.

\section{Study Location: N/A}


Method: Literature review

Vegetation: N/A

Soil Properties: N/A

Observations/Results: Hydraulic lift has been shown in a small number of species (27 species of herbs, grasses, shrubs, and trees), but there is no fundamental reason why it should not be more common in all plants.

\title{
Recommendations: N/A
}

* Reprinted from Oecologia 113, M.M. Caldwell, T. E. Dawson, and J.H. Richards, Hydraulic lift: Consequences of water efflux from the roots of plants, 151-161, 1998, with permission from Springer.

Title: Modeling of the hydraulic architecture of root systems: An integrated approach to water absorption-model description Author: Doussan, C., G. Vercambre, and L. Pages

Series/Source: Annals of Botany, 1998. 81:213-223

Peer-reviewed: Yes

Code: RTSYST

\begin{abstract}
A numerical model simulating water uptake by root systems is presented. This model can combine the locally measured root hydraulic conductances with data on the root system architecture to give a detailed description of water absorption, from the single root level to the entire root system. This is achieved by coupling a three-dimensional root system architecture model with laws describing water flow in roots. In addition to water absorption studies, the model has been developed so that it can be included in a soil water transfer simulator to analyse soil-plant interactions for water uptake. The use of the model in describing water absorption is illustrated for a specific case where the hydraulic conductances are considered uniform in the whole root system. In this way, analytical results of Landsberg and Fowkes (Annals of Botany 42:493-508, 1978) are extended from the single root to the root system level. The influence of the type of root system architecture, axial conductance between crowns of maize nodal roots, transpiration in the course of the day, and non-homogeneous soil water potential on fluxes and water potentials in the root system are examined. The dynamics of the total conductance of the maize root system with plant grouth is also
\end{abstract}


shown for this case of uniform conductance in the root system. Cases which consider other distributions of the conductance in the root system are presented in an accompanying paper.

Objective(s): The objective was to simulate water uptake by roots. Study Location: N/A

Method: Numerical model development, based on three-dimensional root architecture

Vegetation: Corn (Zea mays L.)

Soil Properties: N/A

Observations/Results: The model outputs maps of xylem water potential and fluxes of the root system.

\section{Recommendations: N/A}

* Reprinted from Annals of Botany 81. C. Doussan, G. Vercambre, and L. Pages, Modeling of the hydraulic architecture of root systems: An integrated approach to water absorption-model description, 213-223, 1998. Oxford Press, with permission granted through Rightslink, Copyright Clearance Center, Inc.

Title: Modeling of the hydraulic architecture of root systems: An integrated approach to water absorption-distribution of axial and radial conductances in maize

Author: Doussan, C., G. Vercambre, and L. Pages

Series/Source: Annals of Botany, 1998. 81:225-232

Peer-reviewed: Partial

Code: RTSYST

Abstract*: The 'Hydraulic Tree Model' of the root system simulates water uptake through root systems by coupling a root architecture model with laws for water flow into and along roots (Doussan, Pages and Vercambre, Annals of Botany 81: 213-223, 1998). A detailed picture of water absorption in all roots comprising the root system is thus provided. Moreover, the influence of different distributions of radial and axial hydraulic conductances in the root system on the patterns of water uptake can be analyzed. Use of the model with Varney and Canny's data (New Phytologist, 1993. 123:775-786) for flow along maize roots demonstrated that a constant conductance in the root system couldn't reproduce the 
observed water flux profiles. Taking into account the existing data on hydraulic conductances in maize roots, we fitted the distribution of conductances in the root system to the observed flux data. The result is that, during root tissue maturation, the radial conductivity decreases by one order of magnitude while the axial conductance increases by about three orders of magnitude. Both types of conductance exhibit abrupt changes in their evolution. Due to the conductance distribution in the root system, appreciable water potential gradients may develop in the roots, in both the branch roots and main axes. An important point is that the conductance distribution in the branch roots described by the model should be related to the age of the tissue (and not the distance from the branch root tip) and is therefore closely related to the development process. Thus, for branch roots, which represent about $90 \%$ of the calculated total water uptake in 43-day-old maize), water absorption will depend on the opening of the metaxylem in the axes, and the time dependent variation of the conductances in the branch roots.

Objective(s): This research adapted the 'Hydraulic Tree Model' to obtain a maize root system architecture similar to that described in earlier experiments. By adjusting the conductance distribution in the root system in an attempt to reproduce the water absorption profile along roots measured by Varney and Canny (1993), a satisfactory fit of the model to the experimental flux data was achieved.

\section{Study Location: N/A}

Method: Used existing data on hydraulic conductances in maize roots (observed flux data) coupled to a root architecture model to fit a distribution of conductances in the root system.

Vegetation: Maize (corn)

\section{Soil Properties: N/A}

Observations/Results: As the distribution of conductances is heterogeneous in the root system because of the maturation processes, the spatial distribution of water absorption from the soil will also be heterogeneous. The modeling experiment on water uptake highlights some gaps in the knowledge of hydraulic characteristics in root systems.

\section{Recommendations: N/A}

* Reprinted from Annals of Botany 81, C. Doussan, G. Vercambre, and L. Pages, Modeling of the hydraulic architecture of root systems: An integrated approach to water absorption-distribution of axial and radial 
conductances in maize, 225-232, 1998, Oxford Press, with permission granted through Rightslink, Copyright Clearance Center, Inc.

Title: The redistribution of soil water by tree root systems

Author: Burgess, S.O., M. Adams, N. Turner, and C. Ong

Series/Source: Oecologia, 1998. 115:306-311

Peer-reviewed: Yes

Code: RTSYST, ECOSYS

\begin{abstract}
Plant roots transfer water between soil layers of different water potential thereby significantly affecting the distribution and availability of water in the soil profile. We used a modification of the heat pulse method to measure sap flow in roots of Grevillea robusta and Eucalyptus camaldulensis and demonstrated a redistribution of soil water from deeper in the profile to dry surface horizons by the root system. This phenomenon, termed "hydraulic lift" has been reported previously. However, we also demonstrated that after the surface soils were rewetted at the break of season, water was transported by roots from the surface to deeper soil horizons - the reverse of the "hydraulic lift" behaviour described for other woody species. We suggest that "hydraulic redistribution" of water in tree roots is significant in maintaining root viability, facilitating root growth in dry soils, and modifying resource availability.
\end{abstract}

Objective(s): The objective is a study of hydraulic redistribution of water by tree roots both upward in dry conditions and downward in wet conditions.

Study Location: Kenya (Silk oak) and southwest Australia (River redgum)

Method: Thermocouple temperature probes inserted into the tree stem xylem tissue were spaced given distances from a line heater to measure the heat pulse velocity of sap flow.

Vegetation: Silk oak (Grevillea robusta) and River redgum (Eucalyptus camaldulensis)

Soil Properties: Well-drained sandy clay loam overlying petroplinthite (murram) in Kenya; sand layer over heavy clay in Australia

Observations/Results: Before rain, sap flow rates in lateral roots moved from the stem toward the root tip during nighttime and during 
times of low transpiration. After rainfall, the sap flowed from the roots up into the stem. Water was withdrawn from the soil at different depths and transferred to other soil zones, enabling root growth and survival during water shortages.

\title{
Recommendations: N/A
}

* Reprinted from Oecologia 115, S.O. Burgess, M. Adams, N. Turner, and C. Ong, The redistribution of soil water by tree root systems, 306-311, 1998, with permission from Springer.

\section{Title: Architecture and development of the oil-palm (Elaeis guineensis J acq.) root system}

Author: J ourdan, C., and H. Rey

Series/Source: Plant and Soil, 1997. 189:33-48

Peer-reviewed: Yes

Code: RTSYST

\begin{abstract}
The growth dynamics and architecture of the oil-palm root system are described. Following a transitional juvenile phase, eight different morphological types of roots have been distinguished according to their development pattern and state of differentiation: primary vertical and horizontal roots, secondary horizontal roots, upward growing secondary vertical roots and downward growing secondary vertical roots, superficial and deep tertiary roots and quaternary roots. The relative position of these types of roots determines a morphological and functional unit of the root system called "root architectural unit" of the oil palm. This root polymorphism enabled us to define a morphogenetic gradient, which reflected the oil-palm root-system ontogenesis.
\end{abstract}

Objective(s): The objective was to describe the growth dynamics and architecture of the oil-palm root system.

Study Location: Southeastern Cote d'Ivoire, West Africa

Method: Roots were partially or totally excavated and the root architecture and geometry were described in detail.

Vegetation: Oil palm tree (Elaeis guineensis J acq.)

Soil Properties: Coarse to loamy sand 
Observations/Results: Oil-palm roots have diverse diameters, growth rate, growth direction, type of branching processes, and life spans. Root architectural analyses established a root topology of different root axes.

\title{
Recommendations: N/A
}

* Reprinted from Plant and Soil 189, C. J ourdan, and H. Rey, Architecture and development of the oil-palm (Elaeis guineensis J acq.) root system, 3348, 1997, with permission from Springer.

\section{Title: Exploring plant topological structure with the AMAPmod} software: An outline

Author: Godin, C., E. Costes, and Y. Caraglio

Series/Source: Silva Fennica, 1997. 31(3):357-368

Peer-reviewed: Yes

Code: RTSYST, RTMODL

\begin{abstract}
In the last decades, architectural analysis has been used to understand and to model plant development. These studies have lead us to reconsider the problem of measuring plants while taking into account their topological structure at several scales of detail. A computational platform, called Plant Architecture Mapping (AMAPmod), was created to work on such plant representations. The paper outlines the general methodology used in AMAPmod to represent plant topological structures and to explore these special types of databases. Plant structures are first encoded to build corresponding formal representations. Then a dedicated language, AML, enables the user to extract various types of information from the plant databases and provides appropriate analyzing tools.
\end{abstract}

Objective(s): The objective was to develop a methodology for analyzing plant topological structures by expressing the modularity and the multiscale nature of plant structures (internodes, axes, and macroscopic scales of branching systems).

\section{Study Location: N/A}

Method: Plants are described by enumerating the vertices consecutively using their names. The name of a vertex is constructed in such a way that it clearly defines the topological location of a given vertex in the overall multiscale graph. The vertices and their features are described using formal language in a "code file." The formal representation of a plant, 
more generally of a set of plants, can be built by AMAPmod from its code file. This can be used for plant superstructure and roots. Preservation of plant topological and spatial information in measurements enables the achievement of independence between plant databases and end-user applications. Potentially, various types of analyses can be applied on the same database.

Vegetation: N/A

Soil Properties: N/A

Observations/Results: A common language, which can be used to describe a wide range of species, and the need to develop computer tools to work on plant structure databases have been major motivations in the development of AMAPmod. A key issue in using AMAPmod is related to the definition of plant corpora. This enables research scientists to efficiently exchange plant data. This would, in turn, enable modelers to compare their models on the basis of public sets of data. Morphological characteristics and plant structure descriptions can be used to study the coupling of structure and physiological functions of plants.

Recommendations: N/A

* Reprinted from Silva Fennica 31(3), C. Godin, E. Costes, and Y. Caraglio, Exploring plant topological structure with the AMAPmod software: An outline, 357-368, 1997, with permission from Silva Fennica.

Title: Root distribution of two tree species under a heterogeneous nutrient environment

Author: Mou, Pu, Robert J. Mitchell, and Robert H. J ones

Series/Source: J ournal of Applied Ecology, 1997. 34:645-656

Peer-reviewed: Yes

Code: RTSYST, ECOSYS

Abstract: Permission to publish abstract was not obtained.

Objective(s): This research is a study of root foraging (growth) competition between sweetgum and pine seedlings in a laboratory environment.

Study Location: Auburn University, AL

Method: Potted sweetgum Liquidambar styraciflua and loblolly pine Pinus taeda seedlings were grown for four months in a greenhouse to test 
the effects of soil nutrient heterogeneity on plant root development. The same quantity of fertilizer was applied either uniformly to the entire pot soil surface or to just one quarter of it. Pots were placed in full sunlight or underneath shade cloth that attenuated light to $30 \%$ of full sunlight. The plants were harvested and their biomass characteristics were measured and analyzed.

Vegetation: Sweetgum (Liquidambar styraciflua) and loblolly pine (Pinus taeda) seedlings

Soil Properties: Fine sand

Observations/Results: It was hypothesized that root development in nutrient-heterogeneous soil is not only species specific, but also related to aboveground competition for light. Competitive interactions between sweetgum and loblolly pine may be affected by the spatial heterogeneity of soil resources. Sweetgum and loblolly pine might have different nutrient foraging strategies and that the strategies shift as light availability changes. The spatial development of root systems of both species was strongly influenced by the fertilization arrangements, but they reacted to soil nutrient heterogeneity differently; sweetgum roots concentrated in the fertilized patch, while loblolly pine roots extended much more to the unfertilized patches. Root system morphology was also affected by nutrient arrangements. For both species, root interbranch length increased and fine roots were thinner in nutrient-rich patches. Root branching angles were either unaffected by nutrient patchiness or too variable to detect a trend. Root proliferation in the rich patches was primarily due to fine root elongation and development of higher order lateral roots.

Recommendations: These hypotheses need to be tested in a natural forest ecosystem.

Title: Root distribution pattern of the wild jack tree (Artocarpus hirsutus Lamk.) as studied by the $32 P$ soil injection method Author: J amaludheen, V., B.M. Kumar, P.A. Wahid, and N.V. Kamalum Series/Source: Agroforestry Systems, 1997. 35:329-336

Peer-reviewed: Yes

Code: RTSYST

Abstract*: Root distribution of the wild jack tree was determined by selective placement of ${ }^{32} \mathrm{P}$ at various depths and lateral distances from the 
tree, in Kerala, India. In 8.5-yr-old trees growing on a lateritic site, absorption of ${ }^{32} \mathrm{P}$ from a lateral distance of 75- and 30-cm depth was much greater than from 150- and 225-cm lateral distance and 60- and 90-cm depth. Root activity declined with increasing depth and lateral distance. Most of the physiologically active roots were concentrated within a radius of 75- and 30-cm depth, although the taproot might reach even deeper. Possibly, surface accumulation of feeder roots may cause considerable overlap of the tree and crop root zones in intercropping situations.

However, as the tree roots seldom extend beyond $2.25 \mathrm{~m}$ laterally from the trunk, the effect of overlapping root zones and the associated competitive effects may not be a serious problem for intercropping during the first few years ( $<10$ years after planting) of tree growth.

Objective(s): The objective was to determine if wild jack tree roots interfere with other crops.

Study Location: Kerala, India

Method: ${ }^{32} \mathrm{P}$ was placed at various depths and lateral distances from the tree, and leaf sampling radioassay determined the root activity percentage.

Vegetation: Wild jack tree (Artocarpus hirsutus Lamk.)

Soil Properties: Lateritic oxisol with a pH of 6.7

Observations/ Results: The effect of overlapping root zones and the associated competitive effects may not be a serious problem for intercropping during the first few years ( $<10$ years after planting) of tree growth. Root pattern distribution of the wild jack tree was observed and documented.

\section{Recommendations: N/A}

* Reprinted from Agroforestry Systems 35, V. J amaludheen, B.M. Kumar, P.A. Wahid, and N.V. Kamalum Root distribution pattern of the wild jack tree (Artocarpus hirsutus Lamk.) as studied by the 32P soil injection method, 329-336, 1997, with permission from Springer.

\section{Title: Maximum rooting depth of vegetation types at the global} scale

Author: Canadell, J ., R.B. J ackson, J .B. Ebleringer, H.A. Mooney, O.E. Sala, and E.D. Schulze

Series/Source: Oecologia, 1996. 108:583-595

Peer-reviewed: Yes 


\title{
Code: RTSYST, ECOSYS
}

\begin{abstract}
The depth at which plants are able to grow roots has important implications for the whole ecosystem hydrological balance, as well as for carbon and nutrient cycling. Here we summarize what we know about the maximum rooting depth of species belonging to the major terrestrial biomes. We found 290 observations of maximum rooting depth in the literature which covered 253 woody and herbaceous species. Maximum rooting depth ranged from $0.3 \mathrm{~m}$ for some tundra species to $68 \mathrm{~m}$ for Boscia albitrunca in the central Kalahari; 194 species had roots at least $2 \mathrm{~m}$ deep, 50 species had roots at a depth of $5 \mathrm{~m}$, and 22 species had roots as deep as $10 \mathrm{~m}$ or more. The average for the globe was $4.6 \pm 0.5 \mathrm{~m}$. Maximum rooting depth by biome was $2.0 \pm 0.3 \mathrm{~m}$ for boreal forest, $2.1 \pm 0.2 \mathrm{~m}$ for cropland, $9.5 \pm 2.4 \mathrm{~m}$ for desert, $5.2 \pm 0.8 \mathrm{~m}$ for sclerophyllous shrubland and forest, $3.9 \pm 0.4 \mathrm{~m}$ for temperate coniferous forest, $2.9 \pm 0.2 \mathrm{~m}$ for temperate deciduous forest, $2.6 \pm 0.2 \mathrm{~m}$ for temperate grassland, $3.7 \pm 0.5 \mathrm{~m}$ for tropical deciduous forest, $7.3 \pm 2.8 \mathrm{~m}$ for tropical evergreen forest, $15.0 \pm 5.4 \mathrm{~m}$ for tropical grassland/savanna, and $0.5 \pm 0.1 \mathrm{~m}$ for tundra. Grouping all the species across biomes (except croplands) by three basic functional groups: trees, shrubs, and herbaceous plants, the maximum rooting depth was $7.0 \pm 1.2 \mathrm{~m}$ for trees, $5.1 \pm 0.8 \mathrm{~m}$ for shrubs, and $2.6 \pm 0.1 \mathrm{~m}$ for herbaceous plants. These data show that deep root habits are quite common in woody and herbaceous species across most of the terrestrial biomes, far deeper than the traditional view has held up to now. This finding has important implications for a better understanding of ecosystem function and its application in developing ecosystem models.
\end{abstract}

Objective(s): The objective was to compile a summary of maximum rooting depths of vegetation in the major terrestrial ecosystems around the world.

Study Location: World-wide

Method: A total of 290 observations of rooting depths were noted. Vegetation: N/A

Soil Properties: N/A

Observations/Results: Of the 290 observed cases, 194 had roots at least $6.5 \mathrm{ft}(2 \mathrm{~m})$ deep, 50 had roots at least $16.4 \mathrm{ft}(5 \mathrm{~m})$ deep, and $22 \mathrm{had}$ roots at least $33 \mathrm{ft}$ ( $10 \mathrm{~m}$ ) deep. Trees produce the deepest roots, followed by shrubs, herbaceous plants, and then crops. Desert plants produce very deep roots allowing them to tap into deep water sources. 


\section{Recommendations: N/A}

* Reprinted from Maximum rooting depth of vegetation types at the global scale, J . Canadell, R.B. J ackson, J .B. Ebleringer, H.A. Mooney, O.E. Sala, and E.D. Schulze, Oecologia 108, 83-595, 1996, with permission from Springer.

Title: Seasonal water uptake and movement in root systems of Australian phraeatophytic plants of dimorphic root morphology: A stable isotope investigation

Author: Dawson, T.E., and J.S. Pate

Series/Source: Oecologia, 1996. 107:13-20

Peer-reviewed: Yes

Code: RTSYST, ECOSYS

Abstract*: A natural abundance hydrogen stable isotope technique was used to study seasonal changes in source water utilization and water movement in the xylem of dimorphic root systems and stem bases of several woody shrubs or trees in Mediterranean-type ecosystems of south Western Australia. Samples collected from the native tree Banksia prionotes over 18 months indicated that shallow lateral roots and deeply penetrating tap (sinker) roots obtained water of different origins over the course of a winter-wet/ summer-dry annual cycle. During the wet season lateral roots acquired water mostly by uptake of recent precipitation (rain water) contained within the upper soil layers, and tap roots derived water from the underlying water table. The shoot obtained a mixture of these two water sources. As the dry season approached dependence on recent rainwater decreased while that on ground water increased. In high summer, shallow lateral roots remained well-hydrated and shoots well supplied with ground water taken up by the tap root. This enabled plants to continue transpiration and carbon assimilation and thus complete their seasonal extension growth during the long (4- to 6-month) dry season. Parallel studies of other native species and two plantation-grown species of Eucalyptus all demonstrated behavior similar to that of B. prionotes. For B. prionotes, there was a strong negative correlation between the percentage of water in the stem base of a plant which was derived from the taproot (ground water) and the amount of precipitation which fell at the site. These data suggested that during the dry season plants derive the 
majority of the water they use from deeper sources while in the wet season most of the water they use is derived from shallower sources supplied by lateral roots in the upper soil layers. The data collected in this study support the notion that the dimorphic rooting habit can be advantageous for large woody species of floristically rich, open, woodlands and heathlands where the acquisition of seasonally limited water is at a premium.

Objective(s): This research is a study of the dynamics of water uptake and movement during a wet-dry cycle for selected phreatophytes having shallow lateral root systems and deep taproots.

Study Location: Southwest Australia Method: Xylem water samples were taken from the root systems and analyzed.

Vegetation: Eucalyptus species and Bull Banksia (Banksia grandis) Soil Properties: Arid sand

Observations/Results: Shallow lateral roots in the upper 16 in. $(40 \mathrm{~cm})$ of soil supplied water uptake during wet periods, and the deep ( $23 \mathrm{ft}$ or $7 \mathrm{~m}$ ) taproots supplied water during the dry periods.

\section{Recommendations: N/A}

* Reprinted from Oecologia 107, T.E. Dawson, and J.S. Pate, Seasonal water uptake and movement in root systems of Australian phraeatophytic plants of dimorphic root morphology: A stable isotope investigation, 1320, 1996, with permission from Springer.

Title: Responses of young trees to wind and shading: Effects on root architecture

Author: Stokes, A., A.H. Fitter, and M.P. Coutts

Series/Source: J ournal of Experimental Botany, 1995. 46(9):1139-1146

Peer-reviewed: Yes

Code: RTSYST, BDWFAL

Abstract*: Two wind tunnels were designed to detect influences of wind on the development of the root systems of young trees: Picea sitchensis and Larix decidua were grown in the first and L.decidua only in the second. In the second experiment, the taproot of each L. decidua seedling was removed in order to mimic the formation of a shallow root-plate. 
Responses of shoot grouth to wind stress were small, although uneven irradiance levels resulted in asymmetric growth of both shoots and roots; the distribution of root biomass around the tree was related spatially to that of shoot growth.

In both experiments, there was an increase in the number of large windward and leeward roots in both species. In the first experiment, the sum of the cross-sectional area of later root bases was greater on the windward side of the tree in both species, whereas in the second experiment, it was greatest on the leeward side. Windward woody lateral roots of $\mathrm{P}$. sitchensis had a higher incidence of branching than leeward roots. Woody tips of windward roots were significantly longer with a larger diameter than on leeward roots.

It appears that wind action stimulates diameter growth and alters morphogenesis of those roots most important for anchorage. As a tree sways in the wind, leeward and especially windward lateral roots are placed under the most stress. Larger roots or a greater branching density in these areas will counteract wind stresses on the tree.

Objective(s): This research is a study relating wind action to root architecture and morphogenesis.

Study Location: Laboratory (greenhouse) wind tunnel

Method: Potted tree plants were subjected to wind during 30 months of growth

Vegetation: Sitka spruce (Picea sitchensis) and European larch (Larix decidua)

Soil Properties: Irish Shamrock peat with fertilizer in plastic pots

Observations/Results: Wind action stimulates diameter growth and alters morphogenesis of those roots most important for anchorage. As a tree sways in the wind, leeward and especially windward lateral roots are placed under the most stress. Larger roots or a greater branching density in these areas will counteract wind stresses on the tree. An increase in branching of windward roots may enhance tree stability, because windward roots held in tension are the most important component in resistance to uprooting.

\section{Recommendations: N/A}

* Reprinted from J ournal of Experimental Botany 46(9), A. Stokes, A.H. Fitter, and M.P. Coutts, Responses of young trees to wind and shading: Effects on root architecture, 1139-1146, 1995, Oxford Press, with permission granted through Rightslink, Copyright Clearance Center. 
Title: Growth and functioning of roots and of root systems subjected to soil compaction. Towards a system with multiple signalling?

Author: Tardieu, François

Series/Source: Soil and Tillage Research, 1994. 30:217-243

Peer-reviewed: Yes

Code: RTSYST

Abstract*: The effect of soil mechanical impedance on root growth is discussed on several levels from the apex to the root system. At the individual root level, the balance of pressures on the root apex cannot account for observed reductions in root elongation rate. Furthermore, soil mechanical impedance affects the elongation rate of non-impeded organs, such as leaves or non-impeded roots. A chemical message originating in roots could account for such an effect, probably via changes in cell wall rheological properties in all growing zones of the plant. Changes in carbon allocation could also have a role. At a whole-plant level, indirect effects linked to changes in the plant structure contribute in a major way to the effect of mechanical impedance on root growth. Although only a small proportion of roots of field-grown plants are in contact with compact soil, geometrical characteristics of root systems are considerably affected. In particular, root deepening is delayed and roots tend to have a clumped spatial arrangement. Experimental evidence and modelling suggest that this change in root system architecture could cause water stress, even in relatively wet soil, because of an increase in resistance to the soil-root water flux. As a consequence, root water status and water flux decrease, and stomatal conductance is reduced as a consequence of a chemical message originating in the roots. This secondary message is superimposed onto the direct message linked to mechanical impedance. Under some climatic conditions, whole-plant growth rate, carbon allocation, and phenologic development can then be significantly affected by a compaction in the ploughed layer, while only small changes can be expected under more favourable conditions.

Objective(s): The objective was to discussion physiological characteristics of root growth as a function of soil mechanical impedance based on published experimental results. 


\section{Study Location: N/A}

Method: Literature compilation and data discussions related to soil compaction and root systems.

Vegetation: N/A

\section{Soil Properties: N/A}

Observations/Results: Geometrical characteristics of root systems are considerably affected by soil compaction, although only a small proportion of roots of field-grown plants are in contact with compacted soil. In particular, root deepening is delayed and roots tend to have a clumped spatial arrangement due to compacted soil layers.

\section{Recommendations: N/A}

* Reprinted from Soil and Tillage Research 30. François Tardieu, Growth and functioning of roots and of root systems subjected to soil compaction. Towards a system with multiple signalling? 217-243, 1994, with permission from Elsevier.

Title: Rates of water uptake into the mature root system of maize plants

Author: Varney, G.T., and M.J . Canny

Series/Source: New Phytology, 1993. 123:775-786

Peer-reviewed: Yes

Code: RTSYST

Abstract: Permission to publish abstract was not obtained.

Objective(s): The objective was to test a new experimental study of water uptake in corn seedlings whose roots were vertically grown without surrounding soil inside a mist chamber.

Study Location: Greenhouse at Carleton University, Ottawa, Canada Method: The experimental method centered on the build-up of concentration of dye (sulphorhodamine G) on and in the root surface, when it was fed inside the mist chamber. Water entered the roots rapidly, but the dye was separated from the water by osmotic filtration and penetrated the apoplast only by very slow diffusion. The roots were collected and the dye eluate concentration was measured to quantify water uptake (transpiration) flux rates.

Vegetation: Corn (Zea mays) 


\section{Soil Properties: N/A}

Observations/Results: Heterogeneities in water uptake throughout the root system were noted. The maximum water uptake achieved by a few branches was $40 \mu \mathrm{l} \mathrm{h}^{-1} \mathrm{~cm}^{-2}$ root. On average, flux into axes and branches was the same throughout the root system, at about $5 \mu \mathrm{l} \mathrm{h}^{-1} \mathrm{~cm}^{-2}$.

Recommendations: N/A

Title: Orientation of the lateral roots of trees: 1 . Upward growth of surface roots and deflection near the soil surface

Author: Coutts, M.P., and B.C. Nicoll

Series/Source: New Phytologist, 1991. 119:227-234

Peer-reviewed: Yes

Code: RTSYST

Abstract: Permission to publish abstract was not obtained.

Objective(s): This research describes the origin and behavior of surface roots of Lodgepole pine and Sitka spruce.

Study Location: Britain, UK

Method: Transplanted and seed-germinated tree seedlings were grown in nursery pots. Root development patterns were observed over time.

Vegetation: Lodgepole pine (Pinus contorta Douglas ex Loudon) and Sitka spruce (Picea sitchensis (Bong.) Carr.)

Soil Properties: Moist peat packed in nursery pots

Observations/Results: Discussion of surface root physiology and growth development of the main lateral root.

Recommendations: N/A

Title: Relationships between oak decline and groundwater class in The Netherlands

Author: Oosterbaan, A., and G.J . Nabuurs

Series/Source: Plant and Soil, 1991. 136:87-93

Peer-reviewed: Yes

Code: RTSYST, ECOSYS 
Abstract*: In 1989, the mortality since 1983 and the health class distribution of pedunculate oak (Quercus robur) on soils of different groundwater classes at 11 locations in The Netherlands were compared. It was found that dead and unhealthy oak trees are most prevalent on soils with strongly fluctuating groundwater levels in the rooted zone. On these soils, oaks root less deeply and have more dead roots, especially in the deepest part of the root systems. These findings suggest that unusually dry and wet weather conditions in 1982-1983 led to abnormally low and high groundwater levels in the growing seasons of those years. In addition to other factors such as defoliation by insects and frost damage, this phenomenon probably aggravated oak decline.

Objective(s): This research is a study of groundwater level fluctuation impact on oak tree health.

Study Location: The Netherlands

Method: A Dutch groundwater classification system was used in which assessment of soil profile characteristics provided insight into annual groundwater fluctuations. In selected locations, profile-pit walls were excavated and root mapping was done. Soil samples were analyzed for nutrient chemicals.

Vegetation: Pedunculate oak (Quercus robur)

Soil Properties: Varied across 11 sites (mostly humus podsols)

Observations/Results: It was found that dead and unhealthy oak trees were most prevalent on soils with strongly fluctuating groundwater levels in the rooted zone.

\section{Recommendations: N/A}

* Reprinted from Plant and Soil 136, A. Oosterbaan, and G.J . Nabuurs, Relationships between oak decline and groundwater class in The Netherlands, 87-93, 1991, with permission from Springer.

Title: Study of soil-root interaction

Author: Wu, T.H., R.M. McOmber, T.T. Erb, and P.E. Beal

Series/Source: J ournal of Geotechnical Engineering (ASCE), 1988. 114(12): 1351-1375.

\section{Peer-reviewed: Yes}

Code: RTSYST, RTMODL, SLSTAB 
Abstract*: Soil reinforcement by roots is studied by considering the contribution of the tensile force in a root segment that intersects a potential slip surface in a soil-root system. To evaluate the tensile force when the system is subjected to a shear displacement, the root segment is analyzed as a beam on elastic-plastic support and as a cable for small and large displacements, respectively. Equilibrium and displacement compatibility at a branch point are used to analyze the distribution of forces between two root branches of a root system. Laboratory model tests and in situ root tests were performed to verify the analytical models. The analytical models and in situ root tests are used as means of evaluating the shearing resistance of the reinforced soil.

Objective(s): The objective was to formulate a method for estimating the shearing resistance of a root-reinforced soil by studying the mechanics of soil-root interaction. The roots were modeled by means of analytical methods supplemented by pullout tests and compression tests on roots embedded in soil.

Study Location: Laboratory and in situ (Mapleton, OR)

Method: An analytical study of root-soil reinforcement mechanics was presented. A laboratory shear box test using surrogate roots placed in a 50-50 kaolinite/ sand mixture was designed to analyze assumed parameters such as displacement and yield pressure derived from the derived soil-root interaction model. Lastly, in situ root pull-out tests were done on Western Hemlock roots, and the results were analyzed using the derived soil-root interaction model.

Vegetation: In situ Western Hemlock

Soil Properties: In situ soil was classified as silty sand (SM), with peak shear strength cohesion of $1.64 \mathrm{~N} / \mathrm{cm}^{2}$ and friction angle of $40 \mathrm{deg}$.

Observations/Results: The mechanics of soil-root interaction was studied with analytical methods and model tests. In situ pullout tests and compression tests on roots were conducted. The formulation of a method for estimating the shearing resistance of root-reinforced soil was achieved. The results in general were satisfactory.

\section{Recommendations: N/A}

* Formal permission for abstract publication not required, but bibliographic link is requested. http://cedb.asce.org/cgi/wwwdisplay.cgi? 8803307 


\title{
Title: Developmental processes in tree root systems
}

Author: Coutts, M.P.

Series/Source: Canadian J ournal of Forest Research, 1987. 17:761-767

Peer-reviewed: Yes

Code: RTSYST

\begin{abstract}
Root form can be considered in terms of the simplified threedimensional shape of the system; thus, we have the flat-rooted, heartrooted, and tap-rooted forms of Büsgen et al. (1929) and there is a voluminous literature on the effects of the soil environment on form (see Sutton 1969). Form can also be understood in terms of the number, size, and direction of growth of the component branches. This review covers the development of the system in this sense, although the direction of growth is not included.
\end{abstract}

Although successful soil exploitation for the absorption of water and nutrients requires a finely divided root system, in trees the physical laws governing the strength of beams under bending stress limit the degree of subdivision at the stem-root junction commensurate with the firm platform required for effective anchorage. In beams circular in cross section, stiffness is proportional to the fourth power of the diameter; thus, for effective support the tree requires few but thickened roots at the base. These develop by secondary growth of a limited number of the primary roots (i.e., roots of primary structure) present on the seedling. Root systems with a few thickened members at the base are encountered in most broad-leaved and coniferous trees and are the principal subject of this review. Monocotyledonous trees, which are unable to produce a few thickened members, have vast numbers of thin ones. Oil palms (Elaeis guineensis J acq.) produce many thousands of roots 8 to $10 \mathrm{~mm}$ in diameter (Purvis 1956), and a large coconut palm (Cocos nucifera L.) had more than 8000 primary roots $1 \mathrm{~cm}$ diam radiating from the stem base, scarcely an economical use of material for support.

There are important differences in the primary root skeleton of palms and the "normal type." In palms the roots radiating from the base do not usually produce branches like themselves, but form vertically orientated fans of much finer absorbing roots, whereas in the normal type of tree root system the main axes produce not only the shorter lived, finely divided roots and mycorrhizas of the absorbing system, but in addition give rise to more permanent branches of size and vigour comparable to the mother root. The long roots and their branches facilitate exploration of the soil, and once established provide a longlasting scaffold upon which the 
absorbing roots can proliferate when local conditions are favourable. Functionally it is an adaptable system and occurs in a wide variety of herbaceous species as well as trees. Indeed, the grouth responses of the primary scaffold, in spite of peculiarities in certain species, are so general that much can be deduced about the root behaviour of trees from the work on herbaceous plants.

For purposes of discussion, the development of the seedling radicle and lateral roots of primary structure can be distinguished from a phase of secondary growth, which produces the woody root system; although in practice the phases overlap and appear to be strongly linked physiologically. In both phases there is evidence for strong competition for assimilates between the different parts of the system, as in the shoot.

Objective(s): The objective was to review factors influencing the primary development and secondary development during root growth.

Study Location: N/A

\section{Method: N/A}

Vegetation: Various trees (primarily Sitka spruce)

Soil Properties: N/A

Observations/Results: Root development was discussed from the aspect of plant physiology.

\section{Recommendations: N/A}

* Reprinted from Canadian J ournal of Forest Research 17, M.P. Coutts, Developmental processes in tree root systems, 761-767, 1987, with permission from NRC Research Press.

Title: An overview of the conference Tree root systems and their Mycorrhizas'

Author: J ackson, R.E.

Series/Source: Plant and Soil, 1983. 71:513-515

Peer-reviewed: N/A

Code: RTSYST

Summary*: There has been considerable progress in many areas of study on tree root systems and their mycorrhizas but some important subjects and approaches with respect to both orchard and forest tree roots are very inadequately researched. These include anchorage, root growth and 
emergence of new roots after transplanting, factors controlling nutrient uptake by different parts of mature tree root systems and seasonal variations in nutrient uptake and the use of mathematical models in relation to mycorrhizal infection and its effects on plant growth.

Objective(s): The objective was to present a brief overview of the parts of the subject conference that focused attention on challenges and opportunities as yet largely unmet and unexploited.

Study Location: N/A

Method: An overview

Vegetation: N/A

\title{
Soil Properties: N/A
}

Observations/Results: Some topics that have been inadequately

researched are: anchorage, root growth and emergence of new roots after transplanting, factors controlling nutrient uptake by different parts of mature tree root systems and seasonal variations in nutrient uptake and the use of mathematical models in relation to mycorrhizal infection and its effects on plant growth

\section{Recommendations: N/A}

* Reprinted from Plant and Soil 71, R.E. J ackson, An overview of the conference Tree root systems and their Mycorrhizas', 513-515, 1983, with permission from Springer.

\section{Title: When is the structural root system determined in Sitka} spruce?

Author: Coutts, M.P., and G.J . Lewis

Series/Source: Plant and Soil, 1983. 71:155-160

Peer-reviewed: Yes

Code: RTSYST

\begin{abstract}
Growth ring analysis was carried out on root systems of Sitka spruce trees which had been planted for 8 and 34 years. Retrospective measurements were made on cross-sectional area increment near the root base. Differentiation of the main laterals into roots of widely different radial growth rates took place mainly during the first eight years, resulting in 3 to 11 'major' woody roots and a larger number of small 'minor' ones, with some of intermediate vigour. The major roots established during the
\end{abstract}


first few years constituted the main structural root system at 34 years. Many of the minor roots stopped growing in diameter after a few years, but were still alive and extending at 34 years. The differentiation into major and minor roots is discussed with reference to their origins and the local environment.

Objective(s): The objective was to conduct a study of tree ring growthrate analysis

Study Location: Scotland

Method: Cross-section measurements were made near the root base.

Vegetation: Mature Sitka spruce (Picea sitchensis Bong. Carr)

Soil Properties: Peaty gley soil

Observations/Results: Radial root growth took place mainly within the first 8 years, and constituted the main structural root system in mature trees.

\section{Recommendations: N/A}

* Reprinted from Plant and Soil 71, M.P. Coutts, and G.J . Lewis, When is the structural root system determined in Sitka spruce? 155-160, 1983, with permission from Springer.

Title: Root distribution under some forest types native to West Virginia

Author: Kochenderfer, J .N.

Series/Source: Ecology, 1973. 54(2):445-448

Peer-reviewed: Yes

Code: RTSYST, ECOSYS

Abstract*: Strip-mine high walls and road cuts less than 2 years old were used to observe root distribution in several soil and forest types common to north-central West Virginia. Seventy-seven to $89 \%$ of all the observed root endings were found in the upper $0.6 \mathrm{~m}$ of soil; the highest percentages occurred in the northern hardwood type. The number of roots was greatest in coarse soil and decreased as the soil texture became finer.

Objective(s): The objective was to study excavated tree root systems by visual observations.

Study Location: North-central WV 
Method: Root profiles were examined at exposed high-walled strip mine excavations and road cuts in forested areas that were 40 to 60 years old. Vegetation: Tree roots were observed in mountain forests and mixedhardwood forests including Northern hardwoods, cove hardwoods, and oak-hickory hardwood stands.

Soil Properties: Numerous agricultural soil series descriptions (typically silt loams)

Observations/Results: Root distribution was similar for all hardwood types, and most root systems were contained in the upper $2 \mathrm{ft}(0.6 \mathrm{~m})$ of soil.

\title{
Recommendations: N/A
}

*Reprinted from Ecology 54(2), J .N. Kochenderer, Root distribution under some forest types native to West Virginia, 445-448, 1973, with permission from the Ecological Society of America.

\section{Title: Root distribution of a plantation-grown red pine in an outwash soil}

Author: Leaf, A.L., R. Leonard, and J . Berglund

Series/Source: Ecology, 1971. 52(1):153-158

Peer-reviewed: Yes

\section{Code: RTSYSTS}

\begin{abstract}
Root distribution and mass of a single dominant sample tree (17 m high, $20 \mathrm{~cm}$ diam) in a 39-year-old Pinus resinosa Ait. plantation supported by a deep, stratified, outwash sandy soil were related to soil horizonation characteristics and aboveground tree components (foliage, branches, bolebark, and bolewood). All roots were excavated by hand in the $A_{p}$ and $B$ horizons and by $0.3-\mathrm{m}$ depths in the $C$ strata, were separated into five size classes, cleaned, dried, and weighed. Root-depth penetration terminated in a great number of fine roots in a thick, very fine sandy-silty stratum below the coarser textured solum at $2.7 \mathrm{~m}$. Lateral root distribution was extremely variable; the maximum radial extent was approximately $9 \mathrm{~m}$ from the stump. Total root weight was approximately twice the total needle weight.
\end{abstract}

Objective(s): A study of the root distribution of a mature red pine growing on coarse sand. 
Study Location: Adirondack mountains, NY

Method: Hand excavation of the entire tree root system.

Vegetation: Red pine (Pinus resinosa Ait.)

Soil Properties: Deep, highly stratified outwash Hinckley loamy coarse sand.

Observations/Results: The maximum lateral root radial extension was slightly greater than the live crown length. The maximum rooting depth was about $30 \%$ of the maximum lateral root extension.

Recommendations: N/A

*Reprinted from Ecology 52(1), A.L. Leaf, R. Leonard, and J. Berglund. Root distribution of a plantation-grown red pine in an outwash soil, 153-158, 1971, with permission from Ecological Society of America.

Title: Root extension of trees in surface soils of the North Carolina Piedmont

Author: Brown, J.H., and F.W. Woods

Series/Source: Botanical Gazette, 1968. 129(2):126-132

Peer-reviewed: Yes

Code: RTSYST

Abstract: Permission to publish abstract was not obtained.

Objective(s): The objective was to study surface-root extension of hardwood species.

Study Location: Piedmont region of NC

Method: Radioiodine in a carrier solution was applied to a 0.5 -sq ft soil surface area. After application of I-131, trees were monitored with a portable scintillation probe and scaler for 3 to 5 weeks to detect I-131 presence in tree stems. A total of 703 stems in 18 species were studied. Vegetation: Upland hardwood stands of white, black, and red oak (Quercus sp.)

Soil Properties: Silty loam overlying red clay subsoil

Observations/Results: Evaluation of uptake-distance relationships of species made it possible to obtain comparative data on root distribution patterns. A high percentage of white oaks showed uptake in the zone nearest the application spot, implying an intensive network of roots close to their trunks. Other species had more extensive patterns of development. 
Maximum measured distance of root extension ranged from $31.8 \mathrm{ft}$ for dogwood to $54.6 \mathrm{ft}$ for hickory.

\section{Recommendations: N/A}

\section{Title: Root growth around barriers}

Author: Wilson, Brayton F.

Series/Source: Botanical Gazette, 1967. 128(2):79-82

Peer-reviewed: Yes

Code: RTSYST

Abstract: Permission to publish abstract was not obtained.

Objective(s): This study involved experimental observation of barrierimpeded root growth characteristics.

Study Location: Harvard Forest laboratory, MA

Method: Horizontal roots were severed a few feet from the tree stem, wrapped in moist soil, allowed to grow, and then were laterally impeded by a barrier. Root growth and curvature were noted.

Vegetation: Red maple trees (Acer rubrum L.)

Soil Properties: N/A

Observations/Results: The roots curved back toward their original direction as they grew beyond the barrier. This tendency is called "exotrophy."

Recommendations: N/A

Title: Aspen root studies on three sites in northern Utah Author: Gifford, G.F.

Series/Source: American Midland Naturalist, 1966. 75(1):132-141

Peer-reviewed: Yes

Code: RTSYST

Abstract*: Aspen (Populus tremuloides Michx.) root distribution was studied on the Davis County Experimental Watershed (DCEW) near Farmington, UT, and at the head of Cowley Canyon, a secondary valley that drains into Logan Canyon near Logan, UT. At the DCEW two "clone groups" consisting of 9 and 15 trees, respectively, in sandy loam soil and 
one of five trees in clay were identified by the use of eosin bluish dye as a tracer, and were then excavated to determine rooting habits. A single tree was excavated in Cowley Canyon.

Nine of the 29 trees sampled had no vertical adventitious roots and 12 had no lateral root development. Seven trees had no root development whatsoever other than the parent root from which they originated; six others had only a single adventitious lateral or vertical root. Root development was similar in all soils except that small roots were nearly absent in the clay.

Root depth at the DCEW exceeded 114 in. in sandy loam and 50 in. in the clay. At Cowley Canyon rooting depth in loam with a dense clay B horizon exceeded $60 \mathrm{in}$. for a tree of age $52 \mathrm{yr}$. The majority of roots in all soils were concentrated in the top $4 \mathrm{ft}$ of soil.

The total length of the parent root between terminal ramets was 113.2 and $56.8 \mathrm{ft}$, respectively, in the two clones in sandy loam and $20.5 \mathrm{ft}$ in the clone growing in clay on the DCEW. Parent root depth varied from 0.2 to $3.3 \mathrm{ft}$. Lateral roots (one in Cowley Canyon and four from the two clones in sandy loam on DCEW) extended 26, 26.5, 10, 8, and $6 \mathrm{ft}$, respectively. All ramets appeared to originate at depths ranging from 2 to 12 in.

Objective(s): This research is a study of aspen tree root distributions. Study Location: Farmington, UT

Method: Eosin (blue) dye was injected into the xylem tissue of a donor tree, then the donor tree was cut down and transpiration from other trees on the same root system caused the dye to transport through the root system. Roots were then excavated by hand and visually characterized. Vegetation: Aspen (Populus tremuloides Michx.) trees Soil Properties: Friable sandy loam to sandy clay loam (17\% to $25 \%$ clay)

Observations/Results: The majority of roots were in the top $4 \mathrm{ft}$ of soil. Lateral and vertical root distributions, lengths, and descriptions were noted.

\section{Recommendations: N/A}

* Reprinted from American Midland Naturalist 75(1), G.F. Gifford, Aspen root studies on three sites in northern Utah, 132-141, 1966, with permission from American Midland Naturalist. 


\title{
Title: Root extension of individual trees in surface soils of a natural Longleaf pine-Turkey oak stand
}

Author: Hough, W.A., F.W. Woods, and M.L. MoCormack

Series/Source: Forest Science, 1965. 11(2):223-242

Peer-reviewed: Yes

Code: RTSYST

\begin{abstract}
A study of root extension in surface soils of a natural stand of longleaf pine and turkey oak was carried out in the sandhills of North Carolina. Iodine I-131 was introduced to soil at selected spots, absorbed by roots, and translocated to trees through vascular elements. Trunks of trees in the vicinity were monitored for gamma radiation to determine which trees had root connections with the soil volume containing I-131.

Radioactivity was detected in pine stems as far as $55 \mathrm{ft}$ from plot center and in oak stems out to $49 \mathrm{ft}$. All pine trees monitored within a radius of $17 \mathrm{ft}$ from plot center showed contact with the isotope source, while I-131 was detected in all oaks within $15 \mathrm{ft}$. Factors most closely related to distance of root extension were elevation and tree age.
\end{abstract}

Objective(s): The objective was to determine root lateral extension and depth.

Study Location: North Carolina sandhills (between the Coastal Plain and the Piedmont Upland)

Method: Iodine isotope I-131 was introduced to soil at selected spots, absorbed by roots, and translocated to trees through vascular elements. Trunks of trees in the vicinity were monitored for gamma radiation to determine which trees had root connections with the soil volume containing I-131.

Vegetation: Longleaf pine (Pinus palustris Mill.) and turkey oak (Quercus laevis Walt.)

Soil Properties: Angular, medium to coarse, well-drained sands Observations/Results: Radioactivity was detected in pine stems as far as $55 \mathrm{ft}$ from plot center and in oak stems out to $49 \mathrm{ft}$. All pine trees monitored within a radius of $17 \mathrm{ft}$ from plot center showed contact with the isotope source, while I- 131 was detected in all oaks within $15 \mathrm{ft}$. Factors most closely related to distance of root extension were relative elevation of tree locations, tree height, and tree age.

\section{Recommendations: N/A}


* Reprinted from Forest Science 11(2), W.A. Hough, F.W. Woods, and M.L. McCormack, Root extension of individual trees in surface soils of a natural Longleaf pine-Turkey oak stand, 223-242, 1965, with permission from the Society of American Foresters.

Title: Root spread can be estimated from crown width of Douglas fir, Lodgepole pine, and other British Columbia tree species

Author: Smith, J.H.G

Series/Source: The Forestry Chronicle, 1964. 40:456-473

Peer-reviewed: Yes

Code: RTSYST, BDWFAL

Abstract*: Knowledge of the relationships between lateral root spread and crown width is needed to guide plans for providing optimum space per tree during silvicultural operations. Crown width is a valuable indicator of root spread of open-grown Douglas fir, lodgepole and ponderosa pines, and white, Engelmann, and Sitka spruces. The association between root spread and crown width is less reliable in forest-grown trees but is still useful.

Detailed studies of root systems were made by excavation of roots of trees blown down in the U.B.C. Campus Forest by a typhoon in October, 1962. Roots of 89 Douglas fir, 81 western hemlock, 61 western red cedar, and 33 red alder trees were mapped and analyzed in relation to 18 tree and stand variables. In addition, average and maximum root depth, number of main roots, the ratio of maximum to average root spread, and portion of rooting zone occupied by roots were studied.

Average and maximum radius of roots of Douglas fir and lodgepole pine were analyzed in relation to crown width, diameter-breast-height (dbh), age, and other characteristics. Appropriate regression and correlation analyses were completed for all species and the possible advantages of ratio estimates were noted.

Ratios of root spread to crown width were influenced by species, stand density, and kind of soil. Ratios averaged 1.1 for open- and 0.9 for forestgrown Douglas fir but were 2.4 for both open- and forest-grown lodgepole pine on peat or poorly drained soils. 
Objective(s): The objective was to study the relationships between lateral root spread and crown width for trees common to the Northwest U.S.

Study Location: University of British Columbia Campus and Research Forests

Method: Soil and litter were scraped off the roots of windthrown trees to expose all lateral roots from the upper half of the windfall to the ends of its root system. The root systems were mapped, and soil and tree variables were noted.

Vegetation: Douglas fir (Pseudotsuga menziesii Mirb.), western hemlock (Tsuga heterophylla Raf. Sarg.), western red cedar (Thuja plicata Donn.), red alder (Alnus rubra Bong.), lodgepole pine (Pinus contorta Dougl.), ponderosa pine (Pinus ponderosa Laws.), Engelmann spruce (Picea engelmannii Parry), white spruce (Picea glauca Moench Voss), and Sitka spruce (Picea sitchensis Bong. Carr.)

Soil Properties: Various (soil texture class and moisture regimes were noted)

Observations/Results: Ratios of root spread to crown width were influenced by species, stand density, and kind of soil. Ratios averaged 1.1 for open- and 0.9 for forest-grown Douglas fir but were 2.4 for both openand forest-grown lodgepole pine on peat or poorly drained soils. The ratio (root spread to crown width) is highly variable, but generally decreases with increasing tree age and stand density. It is greatest in species such as spruce and lodgepole pine, which have very wide-spreading lateral roots when they are growing on poorly drained soils.

\section{Recommendations: N/A}

* Reprinted from The Forestry Chronicle 40, J .H.G. Smith, Root spread can be estimated from crown width of Douglas fir, Lodgepole pine, and other British Columbia tree species, 456-473, 1964, with permission from the Canadian Institute of Forestry.

\section{Title: Characteristics of Douglas-fir root systems}

Author: McMinn, R.G.

Series/Source: Canadian J ournal of Botany, 1963. 41:105-122

Peer-reviewed: Yes

Code: RTSYST 
Abstract*: The root systems of 28 Douglas fir (Pseudotsuga menziesii (Mirb.) Franco) in four stands, aged 10, 25, 40, and 55 years, were excavated hydraulically to determine the rooting characteristics of trees in different crown classes at various ages. The extent, depth, configuration, rooting density, and mycorrhizal component of root systems were examined. The significance of the characteristics observed is discussed in relation to silviculture, nursery practice, and forest pathology.

Objective(s): This paper reports characteristics of Douglas fir root systems found by excavating the roots of 28 trees.

Study Location: Vancouver Island, British Columbia Method: Trees were felled and their roots were hydraulically excavated using a 120-gpm (gallons per minute) water pump and nozzle hose delivering 10-psi (pounds per square inch) water pressure to remove root soil and expose the root systems.

Vegetation: Douglas fir (Pseudotsuga menziesii (Mirb.) Franco Soil Properties: Gravelly sandy loams with occasional boulders Observations/Results: Root lengths, depths, and density were catalogued, photographed, and categorized. Douglas fir is more of a deeprooted tree species than are spruce and pine with their superficial lateral and sinker root configurations.

\section{Recommendations: N/A}

*Reprinted from Canadian J ournal of Botany 41, R.G. McMinn, Characteristics of Douglas-fir root systems, 105-122, 1963, with permission from NRC Research Press.

\section{Title: The root system of aspen}

Author: Day, M.W.

Series/Source: American Midland Naturalist, 1944. 32(2):502-509

Peer-reviewed: No

Code: RTSYST

Abstract*: The examination of the root systems of aspen seedlings, saplings, and small trees revealed that:

1. The root system of aspen seedlings on moist sandy soil was usually strongly lateral with fine fibrous roots. The length of the laterals was usually less than 16 in. 
2. By the second year, the main lateral roots had extended themselves from 4 to $6 \mathrm{ft}$ and suckers had appeared.

3. On podsolic soils with a dense hardpan the development of sinker roots was correlated with the presence of old roots and root channels in the soil.

4. An aspen tree 18 years of age and $25 \mathrm{ft}$ in height had a main lateral root $47 \mathrm{ft}$ in length with branch sinker roots reaching a vertical depth of $7-1 / 2 \mathrm{ft}$. This lateral root had eight suckers directly on it and many more on the branch roots.

5. An aspen seedling 8 years of age had a sucker 6 years of age and $6 \mathrm{ft}$ high which had an extensive root system with the longest lateral $30 \mathrm{ft}$ in length. There were eight suckers on this root system. The volume of the root system was $780 \mathrm{cc}$, whereas, the volume of the tops was $412 \mathrm{cc}$.

6 . It is essential to recognize the rooting and suckering ability of aspen when subjecting it to silvicultural treatment.

Objective(s): The objective was to provide a detailed look at aspen tree root systems.

\section{Study Location: Upper MI}

Method: Site 1 tree roots were revealed by hand-digging, and Site 2 tree roots were exposed by water-jetting.

Vegetation: Aspen (Populus tremuloides Michx.)

Soil Properties: Fine sand at site 1, and grey dredged clay at site 2.

Observations/Results: An 8-yr-old tree (6 ft tall) root length was $30 \mathrm{ft}$ $(9.1 \mathrm{~m})$. An 18-yr-old tree ( $25 \mathrm{ft}$ tall) root length was $47 \mathrm{ft}(14.3 \mathrm{~m})$ with vertical root $7.5 \mathrm{ft}(3.4 \mathrm{~m})$ depth. Most of the lateral roots are located within the top $1 \mathrm{ft}(0.3 \mathrm{~m})$ of the soil surface.

\section{Recommendations: N/A}

* Reprinted from American Midland Naturalist. 32(2), M.W. Day, The root system of aspen, 502-509, 1944, with permission from American Midland Naturalist.

Title: The root system of longleaf pine on the deep sands of western Florida

Author: Heyward, F.

Series/Source: J ournal of Ecology, 1933. 14(2):136-148

Peer-reviewed: Yes 


\section{Code: RTSYST}

Abstract: Permission to publish abstract was not obtained.

Objective(s): The objective was to study the root patterns and distribution of the longleaf pine growing in well-drained sand.

Study Location: East of Pensacola, FL

Method: Roots of trees at three sites were excavated, sketched, and examined.

Vegetation: Longleaf pine (Pinus palustris)

Soil Properties: Norfolk sand (98\% silica) with moisture-holding capacity of $5 \%$

Observations/Results: Lateral roots were generally $5 \mathrm{ft}(1.5 \mathrm{~m})$ or less in length; the longest taproot was $14 \mathrm{ft}$ (4.2 m) deep.

\section{Recommendations: N/A}

\section{Title: Hydraulic fracturing in embankment dams}

Author: Sherard, J.L.

Series/Source: J ournal of Geotechnical Engineering. (ASCE), 1986. 112(10):905-927

Peer-reviewed: Yes (prize winning paper)

Code: SLSTAB, SOILER, DMCONST

Abstract*: Examines evidence for concentrated leaks through impervious sections in earth dams and embankments caused by hydraulic fracturing. Hydraulic fracturing is a tensile separation along an internal surface in an earthen embankment or dam. The effective stress on this surface approaches zero; that is, the neutral or pore water pressure equals the total confining stress. These surfaces become the locus for fractures that are jacked open by pore water pressures during hydraulic loading. No preexisting fractures, holes, or other void volume defects are required, and the problem only becomes manifest when water levels rise on one side of an embankment. This hydraulic fracturing is facilitated by differential settlement and internal stress transfer within an earthen structure. Usually these concentrated leaks do not cause erosion either because the velocity is too low or because the leak discharges into an effective filter. Subsequently, the leakage channel is squeezed shut by softening or swelling of the embankment materials forming the walls of the crack. 
Objective(s): The objective was to determine to what extent hydraulic fracturing in earth dams occurs and can cause internal erosion or seepage problems.

Study Location: Multiple sites in the USA

Method: Visual examination and study of earth dams with reported seepage or internal erosion problems.

\section{Vegetation: N/A}

Soil Properties: Earthen dams and embankments with homogeneous, impervious sections

Observations/Results: The study showed there is sufficient evidence to conclude that concentrated leaks occur commonly though impervious sections in earth dams and embankments by hydraulic fracturing without it being observed, even in dams which are not subjected to unusually large differential settlements. This action probably occurs to some degree in most embankment dams. Low, homogeneous embankments or dams (without internal filters or drains) are particularly vulnerable to hydraulic fracturing following the first hydraulic loading. Low embankments tend to have lower vertical (confining) stresses to counter internal pore water pressures. Levees along stream channels fall into this category. One, low earthen (unvegetated) dam that Sherard inspected developed a concentrated leak, and erosion tunnels (pipes) $225 \mathrm{~m}$ long under a 50:1 hydraulic gradient when the reservoir head acting on the upstream (outboard) face of the dam was not more than $4 \mathrm{~m}$. This relatively low head and gradient initiated the hydraulic fracturing.

Recommendations: Hydraulic fracturing is yet another potential cause of internal erosion and through seepage in earthen embankments. Hydraulic fracturing does not require the presence of roots or root holes. This damage mechanism should be investigated as an alternative explanation to alleged piping caused by roots.

* Reprinted from J ournal of Geotechnical Engineering 112(10), J.L. Sherard, Hydraulic fracturing in embankment dams, 905-927, 1986, American Society of Civil Engineers, with permission from Springer.

Title: SLIP4EX - A program for routine slope stability analysis to include the effects of vegetation, reinforcement, and hydrological changes 
Author: Greenwood, J.R.

Series/Source: Geotechnical and Geological Engineering, 2006.

24:449-465

Peer-reviewed: Yes

Code: SLSTAB, RTSTAB

\begin{abstract}
SLIP4EX is a straightforward computer program developed in connection with the European Union (EU) funded ECOSLOPES project for routine stability analysis and the assessment of the contribution of vegetation to slope stability. The slope section is drawn up and dimensions and parameters are fed into the Microsoft Excel-based program for stability calculations and comparisons of Factors of Safety using different methods of analysis. The background and assumptions involved in the derivation of each of the methods is briefly described. The simplicity of the program enables the user to understand the nature of the analysis, explore the parameter assumptions made, and compare the different methods of analysis. Soil reinforcement by geosynthetic layers or anchors, and vegetation effects of enhanced cohesion, changed water pressures, mass of vegetation, wind forces, and root reinforcement forces are readily included in the analysis. The program is freely available on request from the author.
\end{abstract}

Objective(s): The objective was to present a model (SLIP4EX) for determining slope stability including vegetation effects, reinforcement, and hydrological changes.

Study Location: N/A

Method: The stability problem was drawn out with soil layer dimensions and the angles between the base of each layer and the horizontal. Each layer of designated soil type was assigned water parameters. Additional tensile root reinforcing force was assumed to act on the base of each soil layer (in exactly the same way that a geosynthetic layer would contribute to stability). Fine roots were assumed to have no influence on soil cohesion, but the piezometric head was assumed drawn down by $0.1 \mathrm{~m}$ under the influence of vegetation. Root force acting on the base of each layer was calculated based on determined root force per square meter of soil and the length of the slip surface. The changes in factors of safety were calculated. In an example, vegetation increased the calculated Factor of Safety from 1.08 to 1.21 .

Vegetation: N/A

Soil Properties: N/A 
Observations/Results: SLIP4EX is a valuable tool for modeling slope stability of vegetated slopes.

Recommendations: It is recognized by the authors that the next stage is to set up a full slope model and run a search program to find the most critical slip surface.

* With kind permission from Springer Science+Business Media: Geotechnical and Geological Engineering 24(3), J.R. Greenwood, SLIP4EX - A program for routine slope stability analysis to include the effects of vegetation, reinforcement, and hydrological changes, 449-465, 2006.

Title: Modelling effects of forest canopies on slope stability Author: Keim, R.F., and A.E. Skaugset Series/Source: Hydrological Processes, 2003. 317:1457-1467 Peer-reviewed: Yes Code: SLSTAB, TREEMD

Abstract: Permission to publish abstract was not obtained.

Objective(s): The objective was to determine the role and importance of vegetation in affecting the hydrology and stability of natural slopes via the modulating influence on rainfall intensity "smoothing" of tree canopies. Study Location: Data were collected from two forest stands in the Pacific Northwest. One stand was in the Gifford Pinchot National Forest, Cascade Mountains, southwestern WA. The other stand is located in the Dunn Research Forest of the Oregon State University, on the eastern margin of the Oregon Coast.

Method: Rainfall intensity data in and adjacent the two stands were collected. Each stand was equipped with a tipping-bucket rain gauge in a large nearby opening, and multiple through-fall gauges randomly located under the canopy. Pore pressure responses from non-steady infiltrating rainfall were modeled using a one-dimensional solution for pore water pressure using the Richards equation. Slope stability resulting from timevarying pore pressures was calculated using the "infinite slope" equation. Vegetation: The overstory trees in the Washington state stand are oldage Douglas fir, western red cedar, and western hemlock. The canopy at this stand is structurally complex because of its age. The spatial 
relationships between canopies of very large trees and younger individuals of tolerant species result in presence of canopy gaps. The overstory trees in the Oregon state stand are Douglas fir, grand fir, and bigleaf maple. The canopy at this site is spatially quite homogeneous with little or no gaps. Soil Properties: To compare modeled pore pressure and slope stability under rainfall and through-fall, responses of a hypothetical soil were used for which rates of drainage approximated the rates of measured precipitation.

Observations/Results: Results indicated that smoothing of precipitation intensities may translate into overall greater stability of hillslopes under forest canopies. In general, peak intensities of throughfall were damped in intensity and lagged in time relative to peak intensities of rainfall. Damping and lagging of rainfall intensity at both study sites generally increased modeled slope stability relative to openings (areas with no canopy).

Recommendations: Several areas for future investigation were cited: (1) elucidate how infiltrating precipitation causes hydrologic response in various soils, and determine the limits for models of pore pressure propagation; (2) determine the importance of the forest floor (duff and litter layer) in mediating pore pressure response in the underlying soil; and (3) investigate the influence of shrub and herbaceous groundcover canopies.

\title{
Title: Role of tree roots in slope stabilization
}

Author: Nilaweera, N.S., and P. Nutalaya

Series/Source: Bulletin of Engineering Geology and the Environment, 1999. 57:337-342

Peer-reviewed: Yes

Code: SLSTAB, RTSTAB

\begin{abstract}
The mechanical stabilization of soil slopes by means of tree roots depends largely on the strength properties of the roots and their growth pattern within the soil. The selection of indigenous tree species on the basis of their root properties is an essential part of biotechnical slope protection in particular areas. In order to determine the effects of tree roots on slope stabilization in the mountainous area of Khao Luang, southern Thailand, seven tree species were studied. The distribution and penetration of the roots was established and their tensile strength and
\end{abstract}


pull-out resistance determined. The paper evaluates the potential contribution of each of these species to slope stabilization with reference to existing slope conditions.

Objective(s): Roots provide a reinforcing effect in the soil through their tensile resistance and frictional or adhesion properties. Root tensile tests, pull-out resistance and root distributions were studied with respect to slope failures and shear planes.

Study Location: Khao Luang, Thailand Method: A DSCS-5000 Shimadzu Universal Testing device with data processing unit and recorder was used in determining root tensile strengths.

Vegetation: Tropical rain forest trees ( 7 species)

Soil Properties: Thin residual soils developed on a granitic batholith forming the bedrock.

Observations/Results: For all trees tested, the root tensile strength decreased with root diameter and the pull-out resistance of the tree increases with root length distribution and depth of root penetration. With the exception of rubber trees, all the species tested would be advantageous in stabilizing soil slopes, although their effectiveness would depend on the slope steepness, mode of potential failure, thickness of the soil cover and nature of the underlying strata.

Recommendations: N/A

* With kind permission from Springer Science+Business Media: Bulletin of Engineering Geology and the Environment 57, N. S. Nilaweera and P. Nutalaya, Role of tree roots in slope stabilization, 337-342, 1999.

Title: Slope instability caused by small variations in hydraulic conductivity

Author: Reid, M.E.

Series/Source: J ournal of Geotechnical and Geoenvironmental

Engineering (ASCE) 1997. 108(8):717-725

Peer-reviewed: Yes

Code: SLSTAB

Abstract: Permission to publish abstract was not obtained. 
Objective(s): To investigate the influence of small, local variations in hydraulic conductivity on slope stability and to determine the ability of standard geotechnical assumptions to provide conservative or "worst case" slope stability assessments.

Study Location: N/A... theoretical study.

Method: Gravity-driven ground-water flow regimes were modeled in saturated hillslopes with: (a) homogeneous region, (b) slope parallel boundary, (c) horizontal boundary, and (d) vertical boundary. The maximum pore pressure change and slope factor of safety for each of these boundary configurations were determined as a function of the hydraulic conductivity contrast.

Vegetation: Applicable to the extent that a former root ball represents a local zone in a slope with a different hydraulic conductivity. The root ball may have been excavated and backfilled with a compacted soil that has a lower hydraulic conductivity than the surrounding soil.

Soil Properties: In all four cases, uniform elastic and density parameters typical of a granular soil (sand) were used ( $c=0$, phi $=42$ deg, porosity $=30 \%$ )

Observations/Results: Low hydraulic conductivity materials that impede downslope ground-water flow can create unstable areas with locally elevated pore-water pressures. This effect is particularly pronounced for regions with vertical boundaries. The effect increases steadily with increasing hydraulic conductivity contrasts. Heavy compaction of backfilled (former rootball zones) in a slope could be counterproductive if this results in hydraulic conductivity substantially lower than the surrounding soil.

Recommendations: In site characterization work, special attention should be paid to any materials and conditions that might impede down slope groundwater flow and create unstable regions.

Title: The role of plant root distribution and strength in moderating erosion of red clay in the Lake Superior watershed Author: Davidson, D.W., L.A. Kapustka, and R.G. Koch Series/Source: Transactions of the Wisconsin Academy of Sciences, Arts, and Letters, 1989. 77:51-63

Peer-reviewed: N/A

Code: SLSTAB, BKSTAB, SOILER 
Abstract*: Erosion of the glacially derived red clay soils in the western Lake Superior Basin is a serious problem and has been known to be a problem since the settlement of western Lake Superior lands. We investigated the influence of plant root systems on erosion of the red clay soils. Measurements of the rates of surface erosion and of deep-seated slope failure (slumping) were made between August 1975 and J une 1978. Slope failure as monitored along transects was greatest in areas with sparse trees or herbaceous cover. The most stable area had a dense tree cover along with a dense understory of Corylus cornuta and Cornus stolonifers. The estimated soil loss (mton per ha-1) during the period 15 May through 15 October 1977 was stable grassed area, 0.2; grassed areas experiencing slumping, 7.8; stable wood areas, $<0.1$; wooded areas with slumping, 0.4. During the same period, detailed measurements of vertical root distributions, root tensile strength, and vegetation cover along and adjacent to stream banks were obtained. Roots were excavated from 36 quadrant sites adjacent to 8 of 12 transects established to quantify slumping of soils. The excavation of $0.2-\mathrm{m}^{2}$ quadrants was accomplished at $10-\mathrm{cm}$ intervals to a depth of $50 \mathrm{~cm}$. All roots obtained from the excavation were sorted according to 12-diam classes to determine total root mass and calculate total root length. Essentially all roots occurred in the upper $50 \mathrm{~cm}$ of clay soil, and $50 \%$ of the root mass occurred in the 0 - to 10 - $\mathrm{cm}$ zone. The tensile strength of roots less than $2 \mathrm{~mm}$ diameter of selected species was determined for 5-cm segments of roots. The tensile strength of small fresh roots (less than 1-mm diam) was 1.5 to 8.5 times greater in woody species than in herbaceous species. Among woody species, later successional species characteristically had stronger roots than early successional species. Collectively, these data indicate that vegetation comprised of woody, advanced successional species afford the best protection against both surface and deep-seated stream bank erosion.

Objective(s): This study investigates the influence of plant root systems on erosion of the red clay soils.

Study Location: Watershed of western Lake Superior in WI and MN Method: Detailed measurements of vertical root distributions, root tensile strength, and vegetation cover along and adjacent to stream banks were obtained. Roots were excavated from 36 quadrant sites adjacent to 8 of 12 transects established to quantify slumping of soils. The excavation of 0.2-m2 quadrants was accomplished at $10-\mathrm{cm}$ intervals to a depth of $50 \mathrm{~cm}$. All roots obtained from the excavation were sorted according to 
12 diameter classes to determine total root mass and calculate total root length.

Vegetation: Hardwood forests dominated by Aspen (Populus tremuloides Michx.); coniferous forest dominated by Balsam fir (Abies balsamea L.), mixed hardwoods with varying amounts of P. tremuloides, A. balsamea, Betula papyrifera Marsh, Picea glauca (Moench) Voss, and Quercus macrocarpa Michx., and grassed areas dominated by Phleum pretense and Festuca sp.

Soil Properties: Red clays (primarily montmorillonite, with minor illite, chlorite, and kaolinite fractions; glacial-lacustrine), loam upland soil, northern sandy soil, and alluvial soils

Observations/Results: Essentially all roots occur in the upper $50 \mathrm{~cm}$ of clay soil. Areas with tree cover had about twice the root mass per unit volume compared with herbaceous cover. The rooting pattern for wooded sites followed a log-linear relationship for root mass vs. soil depth with $50 \%$ of root mass in the 0 to 10 - $\mathrm{cm}$ zone. In herbaceous areas up to $90 \%$ of root mass was in the 0 to $10 \mathrm{~cm}$ zone. Wooded areas had 15 to $22 \%$ of the total root mass in the 0 to 0.5 - $\mathrm{mm}$ size class with almost all roots less than 2 -mm diam. On herbaceous sites approximately $60 \%$ of the root mass was in the 0 to $0.5-\mathrm{mm}$ size class with all roots in the 2-mm diameter limit. The strength of small roots was 1.5 to 8.5 times stronger in woody species than in herbaceous species. Among woody species latter successional species tended to have stronger roots than early successional species. Vegetation comprised of woody, advances successional species appeared to offer the best protections against both surface and deep-seated erosion. Certain species tended to afford greater protection against deep-seated soil movement than others. P. tremuloides-dominated sites exhibited a wide range of slumping. Mixed conifer hardwood stands were quite stable. On inclined slopes, a comparison of stable to non-stable areas revealed that stable areas had twice as dense a vegetation stand.

Collectively, these data indicated that vegetation comprised of woody, advanced successional species afford the best protection against both surface and deep-seated stream bank erosion.

\section{Recommendations: N/A}

* Formal permission not required. Covered under Fair Use in Title 17 of the US Code. 
Title: Unsteady state phreatic surface in earth dams

Author: Huang, Y.H.

Series/Source: J ournal of Geotechnical Engineering (ASCE), 1986.

112(GT1):93-98

Peer-reviewed: Yes

Code: SLSTAB, DMCONST

Abstract*: In the stability analysis of earth dams (or levees), it is necessary to know the location of the phreatic surface. A simple method was developed for estimating the unsteady state phreatic surface in earth dams as a function of time. The method is useful in the steady state analysis of temporary earth dams (or earthen levees) where the steadystate phreatic surface may not develop during the life span of the dams. In most cases, it is assumed that, after a period of time, a steady state seepage condition will finally develop, so the steady state phreatic surface should be used for the analysis. However, steady state seepage in temporary dams (or river levees) may not be reached during their design life. In the case of river levees, which are usually high and dry most of the time, it would be useful to know how long it takes for the phreatic surface to progress across a levee when the flood stage rises above the levee base. Although the method is based on transient flownets and yields only approximate results, the uncertainty in determining the permeability (hydraulic conductivity) of the earthen structure and effective porosity of soils usually precludes the use of other more refined methods and thus, make this simple method particularly attractive.

Objective(s): The purpose of the paper is to present a simple method for estimating the location of an unsteady state phreatic surface in earth dams as a function of time after hydraulic loading.

Study Location: N/A

Method: Theoretical analysis

Vegetation: N/A

\section{Soil Properties: N/A}

Observations/Results: Upon initial hydraulic loading of an earth dam or levee, the phreatic surface will progress across the dam from the upstream face until it reaches a steady state position near the downstream face. In the case of river levees, this method can be used to estimate the time required for the phreatic surface in a levee to intersect the landward toe. The only information required is the geometry of the dam cross section, the average hydraulic conductivity of the dam, the effective 
porosity, and the height of water level (flood stage height) above the base of the dam. With proper discretion, the method should provide valuable information for the design (and stability assessment) of levees and temporary dams.

\title{
Recommendations: N/A
}

* Reprinted from J ournal of Geotechnical Engineering 112(GT1), Huang, Y.H. 1986. Unsteady state phreatic surface in earth dams, 93-98, American Society of Civil Engineers, with permission from Springer.

\section{Title: The role of woody vegetation in stabilizing slopes in the Cincinnati area, $\mathbf{O H}$}

Author: Riestenberg, M.M., and S. Sovonick-Dunford

Series/Source: Geological Society of America Bulletin, 1983. 94:506518

\section{Peer-reviewed: Yes}

Code: SLSTAB, RTSYST

\begin{abstract}
Tree roots markedly stabilize colluvium on steep hillsides in the Cincinnati area, $\mathrm{OH}$, according to detailed analysis of a landslide complex on the south side of Rapid Run Creek, a tributary of the Ohio River. The shear surface of the slide developed near the interface between bouldery, silty clay colluvium and underlying calcareous Ordovician shale, and it broke woody roots that penetrated through the colluvium and into the underlying bedrock. Tensile strength of the roots was about $5.7 \mathrm{kN} / \mathrm{m}^{2}$. The average strength contributed by residual friction of the soil was about $0.7 \mathrm{kN} / \mathrm{m}^{2}$. The tree roots increased the factor of safety against sliding nine-fold. Root strength allows forested, colluvium-mantled hillslopes in the Cincinnati area to resist sliding at slope angles as high as $35 \mathrm{deg}$, whereas similar slopes devoid of trees are subject to sliding at slope angles of 12 to $14 \mathrm{deg}$. The contributions of tree roots to slope stability should be evaluated before removal of trees for development of hillsides.
\end{abstract}

Objective(s): This research is a study of tree root contributions to slope stability from a detailed analysis of a landslide

Study Location: Rapid Run Creek, a tributary to the Deep Stage Valley of the Ohio River in Western Cincinnati, $\mathrm{OH}$ 
Method: The landslide complex was photographed and mapped in detail by plane-table methods to understand the distribution of slide elements, geometric features of the slip surface, and topography of adjacent stable ground. Roots throughout the head and lateral scarps and in the basal shear zone were mapped, classified to species, and their diameters measured. Tensile strengths of representative samples of the roots were measured in the laboratory. The distribution of trees on the slide was estimated by determining original positions of slide elements on the slope. Vegetation: Sugar maple (Acer saccharum Marsh.) was the dominant tree species. Mature trees (greater than $2.5 \mathrm{~cm}$ at breast height) were less dominant (109 trees/ hectare) on the slide areas than on the adjacent stable slopes (218 trees/ hectare). Small sinker roots and tapered roots penetrated into the bedrock. Ash, Buckeye, and other tree species were also in the area. Maple trees dominated in the slide area (83.6\%). In nonslide areas, the tree population percentages were more even (Maple, 35.5\%; Ash, 25.4\%; and Buckeye, 23.9\%).

Soil Properties: Silty-clay colluvium overlying calcareous shale on steep hillsides

Observations/Results: The tree roots increased the factor of safety against sliding nine-fold. Root strength allows forested, colluviummantled hillslopes in the Cincinnati area to resist sliding at slope angles as high as 35 deg, whereas similar slopes devoid of trees are subject to sliding at slope angles of 12 to $14 \mathrm{deg}$. The average root strength for the entire slide area was $5.7 \mathrm{kN} / \mathrm{m}^{2}$. Tree root diameters were less in the upper reaches of the slides as opposed to the thicker root diameters in the lower portions of the slide area. Slide failures began in the upper reaches. Roots within the slide were broken under tensile forces. An infinite-slope analysis resulted in a factor of safety to be 1.24. However, the slope broke in a series of elements, not as one single slide. Tree root resistance contributed significantly to the slope stability and contributed significant resistance to failure of slide elements with thicknesses up to $2 \mathrm{~m}$. Tree root strength contributed a major portion of the strength of thin colluvium. Estimating root strength for computation of factors of safety was a major problem.

Recommendations: The contributions of tree roots to slope stability should be evaluated before removal of trees on hillsides and steep slopes.

* Formal permission not required. Covered under Fair Use in Title 17 of the US Code. 


\title{
Title: A theoretical model of the effects of timber harvesting on
} slope stability

Author: Sidle, R.C.

Series/Source: Water Resources Research, 1992. 28(7): 1897-1910

Peer-reviewed: Yes

Code: SLSTAB(VR)

\begin{abstract}
An infinite slope stability model is proposed which incorporates changes in root cohesion and vegetation surcharge through several timber management cycles along with the stochastic influence of rainfall on pore water pressure. Simulations of probability of failure indicate that alternate thinnings and clear-cuts alone produce less stable conditions than shelterwood harvesting systems and partial cuts. Repeated harvesting cycles with progressively shorter rotations, reduced regeneration potential of new vegetation, and destruction of understory vegetation during logging or site preparation can all increase the probability of failure. These analyses can provide land managers with options for acceptable vegetation management strategies on potentially unstable hillslopes.
\end{abstract}

Objective(s): The objective was to investigate the effect of alternative timber harvesting practices, viz, clear-cuts, partial cuts, and shelterwood) on slope hydrology and stability

Study Location: Selected hillslopes in coastal Alaska and western USA Method: Recovery of rooting strength and tree surcharge following timber harvest are simulated by a sigmoid relationship. Root deterioration of harvested vegetation, on the other hand, is described by an exponential decay function. The effects of long-term timber management on probability of failure are simulated by overlaying the impacts of a prior vegetation removal on a more recent removal. For each year, the critical pore water pressure $\left(\mathrm{u}_{\text {crit }}\right)$ needed to trigger slope failure is computed. An empirical function relating piezometric level to antecedent rainfall, storm intensity, and total precipitation is presented to assess the probability of occurrence of $u_{\text {crit, }}$ based on historical rainfall records for a site in coastal Alaska.

Vegetation: Coniferous forests

Soil Properties: Simulation studies are based on soil, site, and root strength data from selected sites. 
Observations/Results: Slope stability simulations for various silvicultural systems indicated that clear-cuts and alternate thinnings produced the least stable conditions, largely based on net root strength decline following harvesting. A 75\% partial cut reduced the probability of failure more than five times compared to clear cuts.

Recommendations: The model used in the study applies only to shallow, translational failures overlying a bedrock contact. While actual values of probability of failure calculated by the model should be viewed with caution because of assumptions inherent in the infinite slope model and the spatial variability of site parameters, the model provides a viable relative comparison of silvicultural systems.

* Reprinted from Water Resources Research 28(7), R.C. Sidle, A theoretical model of the effects of timber harvesting on slope stability, 1897-1910, 1992. Copyright [1992] American Geophysical Union. Reproduced/ modified by permission of American Geophysical Union.

Title: Forest vegetation removal and slope stability in the Idaho Batholith

Author: Gray, D.H., and Megahan, W.

Series/Source: USDA Research Paper INT-271, Intermountain Forest \& Range Experiment Station, 1989, Ogden, UT, 23 pp.

Peer-reviewed: Yes

Code: SLSTAB(VR)

Abstract*: Results of field studies and supporting theoretical analyses show that forest vegetation often provides a significant margin of safety to the stability of slopes in the Idaho batholith. Woody vegetation contributes to the stability of these slopes by root reinforcement, by soil moisture depletion from interception and transpiration, and by soil arching restraint between tree stems. Removal of vegetation by logging or fire can increase landslide risks at many locations.

Objective(s): To determine the margin of safety provided to slopes in the Idaho batholith (composed of shallow, coarse-textured granitic soils) by the presence of woody vegetation. To examine the temporal relationship between increased landslide frequency after clear-cutting and the gradual loss of root cohesion with time. To determine the sensitivity of the factor of 
safety of a slope to root cohesion in comparison with other parameters such slope angle, soil friction angle and density, and height of the piezometric surface above the bedrock contact.

Study Location: Pine Creek watershed, Boise National Forest, central Idaho

Methodology: Both soil water piezometry and in situ shear strength measurements were made in the study watershed. Estimates of soil shear strength (required for stability analyses) were obtained from in situ borehole shear tests and from results of laboratory triaxial tests on granitic soils from results of laboratory triaxial tests reported by other investigators. Estimates of both root distribution and rooting contribution to soil shear strength were obtained from results of studies in granitic soils of other watersheds in the the Idaho batholith. The relative importance of various soil-slope-hydrologic parameters on slope stability and the direction of change in slope safety factor that may be produced by altering these parameters were determined by conducting sensitivity analyses or parametric variation studies. These same studies also permitted evaluation of the effect of vegetation removal on slope stability through the influence of removal on the parameters themselves.

Vegetation: Overstory of ponderosa pine (Pinus ponderosa Laws.), Douglas-fir (Pseudo-stuga mensiesii Franco), and Engelmann spruce (Picea engelmannii Parry). Understory of small trees and shrubs.

Soil Properties: The surface horizon is typically a sandy, coarse-textured soil with little or no cohesion. It would be classified as a SW-SM under the Unified Soil Classification. This part of the profile is generally the most prone to both surficial and mass erosion.

Observations/Results: Fires or clear-cutting can result in loss of the stabilizing influences of forest vegetation. Results of the Pine Creek study show that vegetation often provides the margin of safety between a secure and failed slope. The factor of safety against sliding is very sensitive to cohesion; most of which is provided by roots. This cohesion is gradually eliminated as roots rot and decay after clear-cutting.

\section{Recommendations: N/A}

*Permission not required for government document.

Title: Soil pipes and slope stability

Author: Pierson, T.C. 
Series/Source: Quarterly J ournal of Engineering Geology (London). 1983. 16: 1-11

Peer-reviewed: Yes

Code: SLSTAB(VR)

Abstract: Permission to publish abstract was not obtained.

Objective(s): To investigate the influence of soil pipes with different orientations and degrees of drainage (e.g., closed, partially blocked, or open at their downstream end) on the flow regime and phreatic surface, and ultimately on the stability of a slope.

Study Location: N/A (theoretical study)

Methodology: A Hele-Shaw model was constructed to simulate twodimensional, subsurface flow in a shallow soil interrupted by a closed soil pipe, which was parallel to the fall line of the slope and to the perched water table in the slope. The model uses two vertical and parallel, clear perspex plates that enclose a viscous fluid (oil or glycerine) between them. The apparatus represents an idealized vertical slice of an isotropic soil interrupted by a longitudinally bisected soil pipe. All the flow vectors in this plane will be parallel to it in the apparatus and in the soil being modeled. Flow nets could be approximated during the model runs by tracking small bubbles and particles of grit as they moved in the oil between the plates.

Vegetation: N/A

Soil Properties: N/A

Observations/Results: Results of the model runs indicate that closed soil pipes occurring in hillslope soils, when filled with water, will cause large localized increases in soil water pressure. This decreases soil shear strength locally and may increase the chance of slope failure. In shallow soils, pipes do not have to be particularly long for relatively large pore pressures to develop. Often the pressures generated at the end of a pipe can exceed those achieved by total saturation of the soil matrix.

Recommendations: Results of the study are applicable to soil pipes formed by penetrating roots that die and decay, leaving open (or partially open) tubular passage-ways. The orientation of the pipes and extent of drainage (open or closed) also play a role. 
Title: Risk of landsliding in shallow soils and its relation to clear-cutting in Southeastern Alaska

Author: Wu, T.H., and D.N. Swanston

Series/Source: Forest Science, 1980. 26(3):495-410

Peer-reviewed: Yes

Code: SLSTAB(VR)

Abstract*: A probabilistic approach was adopted to the evaluate the risk of landsliding associated with clear-cutting in shallow soils in Southeastern Alaska. The paper summarizes the mechanism of debris avalanche and the environmental factors that control slope stability, including woody vegetation removal or clear-cutting. Procedures are outlined that may be used to evaluate risk of debris avalanches and assess potential damage or loss. Analysis of slopes near Hollis, Alaska, was used as an example. A one-dimensional infiltration-seepage model was used to calculate the response of the piezometric level in a slope to rainfall. The probability of the piezometric height in a slope exceeding the height required for failure was calculated for both an intact (forested) slope and the same slope after clear-cutting.

Objective(s): The objective was to examine the use of a probabilistic risk analysis to evaluate the risk of shallow landsliding (debris slides) associated with clear-cutting.

Study Location: Maybeso Valley, near Hollis, AK

Method: Probabilistic slope stability analyses

Vegetation: Sitka spruce, western hemlock, and Alaska yellow-cedar

Soil Properties: Average soil properties for slopes in Maybeso Valley: $\mathrm{c}^{\prime}$ $=5.3 \mathrm{kPa}, \Phi^{\prime}=34.7 \mathrm{deg}, \mathrm{s}_{\mathrm{r}}=0, \mathrm{a}=39 \mathrm{deg}, \mathrm{h}+\mathrm{h}^{\prime}=1.22 \mathrm{~m}, \mathrm{~W}_{\mathrm{f}}=0, \mathrm{~W}_{\mathrm{t}}=0$ (which represents the slope after clearing)

Observations/Results: The probability of the piezometric height exceeding the height for failure was considerably higher for a clear-cut slope compared to the same slope in a forested condition. The procedure outlined in the paper may be used to assess the risk and cost of landslides due to clear-cutting. It is based on the principles of soil mechanics and seepage. Soil properties needed for the analysis may be determined from standard tests. Uncertainties caused by natural variations in soil properties, slope angles, and precipitation, and inaccuracies in the analytical models may be accounted for in this approach.

Recommendations: N/A 
* Reprinted from Forest Science 26(3), T.H. Wu, and D.N. Swanston, Risk of landsliding in shallow soils and its relation to clear-cutting in Southeastern Alaska, 495-410, 1980, with permission from Society of American Foresters.

Title: The effects of timber removal on the stability of forest soils

Author: O'Loughlin, C.L.

Series/Source: J ournal Hydrology (NZ), 1974. 13(2):121-134. New

Zealand Hydrological Society

Peer-reviewed: Yes

Code: SLSTAB(VR)

Abstract*: The principal ways in which the removal of a forest cover influences the stability of sloping soils is briefly described. Potential destabilizing effects of surcharge are compensated by increased stability provided by root reinforcement. Moreover, in most forested slopes the total weight of the soil overlying a potential failure plane far exceed the weight of the forest layer. Methods by which relevant soil physical data can be obtained for use in stability analyses are outlined.

Objective(s): The objective was to determine how timber harvesting practices, e.g., clear-cutting, affect the stability of slopes

Study Location: New Zealand

Method: Infinite slope type stability analyses under dry and saturated conditions were applied to elucidate cause-and-effect relationships between deforestation and mass soil movements.

Vegetation: Conifers, alders, and birch trees. Root strength (reinforcement) data from previous studies was used. Increased soil strength measured from field tests on root permeated soil pedestals beneath different types of trees (conifers, alders, birch) in different types of soil (till and silt loam) ranged 1 to $10 \mathrm{kPa}$. The large range in strengthening effects is due mainly to very different tree-root network densities in terms of root weight per unit volume of soil.

Soil Properties: In the absence of relevant data from New Zealand, the analyses used soil strength, soil unit weight and pore pressure data collected from a steep, clear-cut slope in southwest British Columbia. 
Observations/Results: Measurements of the decline in tensile strength of small roots in coastal British Columbia after death of the parent tree indicated that over half the strength is lost within 3 to $5 \mathrm{yr}$ after cutting. A forest cover can intercept precipitation, either in the crowns of trees or in the forest litter layers at the soil surface. The combination of transpiration and interception tends to delay or mitigate saturation of a soil mantle on steep slopes. Deterioration of tree roots and the changes which occur in the subsurface hydrological status of soils are the most significant tree-croprelated factors involved in accelerated mass wasting on recently deforested slopes.

\title{
Recommendations: N/A
}

* Reprinted from J ournal Hydrology (NZ) 13(2), C.L. O'Loughlin, The effects of timber removal on the stability of forest soils, 121-134, 1974, with permission from the New Zealand Hydrological Society.

\section{Title: Model for piping-plugging in earthen structures}

Author: Khilar, K.C., H.S. Fogler, and D.H. Gray

Series/Source: J ournal of Geotechnical Engineering (ASCE), 1985. 111(7):833-846

\section{Peer-reviewed: Yes \\ Code: SOILER, SLSTAB}

\begin{abstract}
A capillary model was developed to predict under what conditions piping vs. plugging is likely to occur as a result of clay particle dispersion in soils. In the intermediate size range, i.e., particles too small per se to clog pore constrictions and too large to wash through unimpeded, the outcome depends strongly on the concentration of dispersed particles in the seepage stream. This concentration in turn depends upon the rate at which the particles are eroded from pore walls.
\end{abstract}

Objective(s): The objective was to determine under what conditions piping (particle washout) vs. plugging (particle holdup) is likely to occur as a result of clay particle dispersion (detachment and transport in a seepage stream).

Study Location: N/A (theoretical modeling study)

Method: A capillary model was used to ascertain the relationship between key variables at the onset of piping or seepage erosion. This 
relationship involved the initial permeability (hydraulic conductivity) and porosity of the soil, the critical tractive stress, and the hydraulic gradient. The model was also used to predict under what circumstances clay particle concentrations in a seepage stream will buildup suddenly to very high values - a condition favorable to clogging or particle holdup.

\section{Vegetation: N/A}

Soil Properties: Compacted (or indurated) silty or clayey sands Observations/Results: Internal erosion of soils is a two-step process consisting of particle detachment and particle migration. When clay particles disperse and migrate in porous media, be it earthen structures or reservoir rock (e.g., clayey sandstones), two outcomes are possible, viz., plugging (particle holdup) on the one hand and piping (particle washout) on the other. Either outcome depends strongly upon the size distribution of the migrating particles relative to the pore size distribution of the medium through which the particles are moving. At one extreme movement of very large particles will lead to clogging or plugging whereas at the other extreme very small particles will wash through. In the intermediate size range the outcome depends strongly on the concentration of dispersed particles in the seepage stream which in turn depends upon the rate at which they erode from the pore walls.

A relationship developed from the capillary model predicts that the minimum hydraulic gradient required to cause piping (particle washout) is very high (>200) for soils reported to be non-susceptible to piping or internal erosion, i.e., for critical tractive stresses $>10 \mathrm{dynes} / \mathrm{cm}^{2}$. The capillary model also predicted conditions leading to particle holdup (clogging). Results of analyses showed that very large concentration buildups of particles tend to occur at intrinsic permeabilities less than $10^{-9} \mathrm{~cm}^{2}\left(10^{-4} \mathrm{~cm} / \mathrm{sec}\right.$ for water at $\left.20^{\circ} \mathrm{C}\right)$. This prediction is consistent with previous findings reported in the geotechnical literature.

\section{Recommendations: N/A}

* Reprinted from J ournal of Geotechnical Engineering 111(7), K.C. Khilar, H.S. Fogler, and D.H. Gray, Model for piping-plugging in earthen structures, 833-846, 1985, American Society of Civil Engineers, with permission from Springer.

Title: Strength of tree roots and landslides on Prince of Wales Island, Alaska 
Author: Wu, T.H., W.P. McKinnell III, and D.N. Swanston

Series/Source: Canadian Geotechnical J ournal, 1979. 16:19-33

Peer-reviewed: Yes

Code: RTMODL, RTSTAB, SLSTAB (VR)

\begin{abstract}
The stability of slopes before and after removal of forest cover was investigated. Pore water pressures and shear strengths were measured and the soil properties were determined by laboratory and in situ tests. A model of the soil-root system was developed to evaluate the contribution of tree roots to shear strength. The computed safety factors are in general agreement with observed behaviors of the slopes. Decay of tree roots subsequent to logging was found to cause a reduction in the shear strength of the soil-root system.
\end{abstract}

Objective(s): The objective was to study tree root contribution to slope stability

Study Location: Coastal forests in southeastern AK

Method: To study the effect of clear-cutting on stability, pore water pressures and creep rates were measured at several sites in 1964 through 1966, with additional measurements in 1972 through 1975. Permeability tests, piezometer stand pipes, and test pits were all employed to acquire data and samples of soil. These measurements were accompanied by laboratory investigations of soil strength and the contribution of tree roots to shear strength. Tree root tensile strengths were determined by attaching the upper end of a root to a calibrated spring. The device was pulled up by hand and the tensile force was determined from spring compression. A scale attached to the ground surface was used to measure the displacements of the end or the root. The ultimate load was plotted against root diameter. The number of roots per slip scar was estimated from the results of excavations of roots of representative trees. Tree weights were estimated in study plot areas by conducting tree counts and measuring tree diameters.

Vegetation: Spruce and fir conifer trees

Soil Properties: Soil, weathered soils, glacial till, and weathered bedrock Observations/Results: Landslides that involve the shallow surface soils have been observed to be an important form of mass wastage on steep hillsides of southeastern Alaska. More frequently, landslides occur as a rotational slip located in the upper part of a deforested slope, usually at the head of a small gully or drainage depression. The slip is at the base of the weathered soil zone, 1- to1.5-m depth. Most slides are in the autumn 
rain season. Tree roots extended into unweathered till (glacial deposits) and weathered bedrock. Results indicated that strength contributed by tree roots is important to the stability of steeper slopes. Loss of root strength following clear-cutting can seriously affect slope stability.

\section{Recommendations: N/A}

* Reprinted from Canadian Geotechnical J ournal 16, T.H. Wu, W.P. McKinnell III, and D.N. Swanston, Strength of tree roots and landslides on Prince of Wales Island, Alaska, 19-33, 1979, with permission from NRC Research Press.

Title: Effects of riparian vegetation on stream bank subaerial processes in southwestern Virginia USA

Author: Wynn, T.M., and S. Mostaghimi

Series/Source: Earth Surface Processes and Landforms, 2006. 31:399-

413, published online in Wiley InterScience http://www.interscience.wiley.com

Peer-reviewed: No

Code: SOILER, BKSTAB

Abstract: Permission to publish abstract not granted.

Objective(s): This study compared the impact of woody and herbaceous vegetation on subaerial processes by examining soil temperature and moisture regimes in vegetated stream banks.

Study Location: Near Blacksburg, Virginia Method: Soil temperature using Campbell Scientific 107 probes and water tension using Watermark 200 sensors were measured at six paired field sites in southwestern Virginia for one year. A Campbell Scientific CR10X datalogger recorded the output data from the probes and sensors. Vegetation: Ranged from pastureland to mature riparian forest found in the Appalachian Mountain region.

Soil Properties: Not discussed or detailed

Observations/Results: Streambanks may be subject to more freezethaw cycles (and increased soil erosion) if there are more trees than ground cover.

Recommendations: N/A 
Title: Variation in root density along stream banks

Author: Wynn, Theresa M., Saied Mostaghimi, James A. Burger, Adrian

A. Harpold, Marc B. Henderson, and Leigh-Anne Henry

Series/Source: J ournal of Environmental Quality, 2004. 33:2030-2039

Peer-reviewed: Yes

Code: SOILER, BKSTAB

Abstract*: While it is recognized that vegetation plays a significant role in stream bank stabilization, the effects are not fully quantified. The study goal was to determine the type and density of vegetation that provides the greatest protection against stream bank erosion by determining the density of roots in stream banks. To quantify the density of roots along alluvial stream banks, 25 field sites in the Appalachian Mountains were sampled. The riparian buffers varied from short turf grass to mature riparian forests, representing a range of vegetation types. Root length density (RLD) with depth and aboveground vegetation density were measured. The sites were divided into forested and herbaceous groups and differences in root density were evaluated. At the herbaceous sites, very fine roots (diameter $<0.5 \mathrm{~mm}$ ) were most common and more than $75 \%$ of all roots were concentrated in the upper $30 \mathrm{~cm}$ of the stream bank. Under forested vegetation, fine roots $(0.5 \mathrm{~mm}<$ diameter $<2.0 \mathrm{~mm})$ were more common throughout the bank profile, with $55 \%$ of all roots in the top $30 \mathrm{~cm}$. In the top $30 \mathrm{~cm}$ of the bank, herbaceous sites had significantly greater overall $\mathrm{RLD}$ than forested sites $(\mathrm{a}=0.01)$. While there were no significant differences in total RLD below $30 \mathrm{~cm}$, forested sites had significantly greater concentrations of fine roots, as compared with herbaceous sites $(\mathrm{a}=0.01)$. As research has shown that erosion resistance has a direct relationship with fine root density, forested vegetation may provide better protection against stream bank erosion.

Objective(s): The study goal was to determine the type and density of vegetation that provides the greatest protection against stream bank erosion by determining the density of roots in stream banks.

Study Location: Blacksburg, VA Method: Twenty-five field sites (streams with vegetated riparian buffers) in the Appalachian Mountains were sampled. The riparian buffers varied from short turf grass to mature riparian forests, representing a range of vegetation types. Root length density (RLD) and root volume ratio (RVR) with depth and aboveground vegetation density were measured. 
Vegetation: Ranged from pastureland grasses to mature hardwood forest trees typically found along streambanks in the Appalachian Mountains.

Soil Properties: Ranged from clay loam to loamy sand

Observations/Results: Under forested vegetation, fine roots $(0.5 \mathrm{~mm}$

$<$ diameter $<2.0 \mathrm{~mm}$ ) were more common throughout the streambank profile, with $55 \%$ of all roots in the top $30 \mathrm{~cm}$. Forested sites had significantly greater concentrations of fine roots, as compared with herbaceous sites.

Recommendations: Because bank failure caused by increases in bank height or bank angle is initiated by scour of the bank toe, woody vegetation may be the best choice for riparian vegetation where stream bank erosion and stability is a management concern.

*Reprinted from J ournal of Environmental Quality 33, Theresa M. Wynn, Saied Mostaghimi, J ames A. Burger, Adrian A. Harpold, Marc B. Henderson, and Leigh-Anne Henry. Variation in root density along stream banks, 2030-2039, 2004, Executive Enterprises with permission from American Society of Agronomy, Inc.

Title: The importance of plant root characteristics in controlling concentrated flow erosion rates

Author: Gyssels, G., and J. Poesen

Series/Source: Earth Surface Processes and Landforms, 2003. 28:371384

Peer-reviewed: Yes

Code: SOILER, RTSTAB

Abstract: Permission to publish abstract was not obtained.

Objective(s): The objective was to argue the importance of separating the influence of vegetation on soil erosion rates into two parts: the impact of leaves and stems (above ground biomass) and the influence of roots (below-ground biomass).

Study Location: Belgian Loess Belt near the city of Leuven, Belgium Method: Cross-sectional areas of concentrated flow channels (rills and gullies) were compared.

Vegetation: Agricultural crops (wheat, barley, beets)

Soil Properties: All top soils classified as silt and silt loam (USDA classification). Larger sand and rock fragment contents were also found. 
Observations/Results: An increase in shoot density as well as an increase in root density resulted in an exponential decrease of concentrated flow erosion rates.

Recommendations: Protection of the soil surface is crucial with respect to reducing erosion rate, and increasing plant root density in the topsoil could be a viable erosion control strategy.

Title: LIGNUM: A tree model based on simple structural units Author: Perttunen, J ., R. Sievänen, E. Nikinmaa, H. Salminen, H. Saarenmaa, and J. Väkeva

Series/Source: Annals of Botany, 1996. 77:87-98

Peer-reviewed: Partial

Code: VEGMOD, TREEMD

Abstract*: The model LIGNUM treats a tree as a collection of a large number of simple units which correspond to the organs of the tree. The model describes the three-dimensional structure of the tree crown and defines the growth in terms of the metabolism taking place in these units. The activities of physiological processes can be explicitly related to the tree structures in which they are taking place. The time step is 1 year.

The crown of the model tree consists of tree segments, branching points, and buds. Each pair of tree segments is separated by a branching point. The buds produce new tree segments, branching points, and buds. The tree segments contain wood, bark, and foliage. A model tree consists of simple elements translates conveniently to a list structure: the computer program implementing LIGNUM treats the tree as a collection of lists.

The annual growth of the tree is driven by available photosynthetic products after respiration losses are accounted for. The photosynthetic rate of foliage depends on the amount of light. The amount of photosynthates allocated to the growth of new tree segments is controlled by the light conditions and the amount of foliage on the mother tree segment. In principle, the biomass relationships of the tree parts follow the pipe model hypothesis. The orientation of new tree segments results from the application of constant branching angles. LIGNUM has been parameterized for young Scots pine (Pinus sylvestris L.) trees.

Objective(s): The objective was to model a tree as separate components to describe the physiological processes taking place in each unit. The 
model LIGNUM (the acronym was not spelled out in this paper) was developed.

\section{Study Location: N/A}

Method: N/A

Vegetation: Scots pine (Pinus sylvestris L.) trees

Soil Properties: N/A

Observations/Results: The model LIGNUM was developed to describe the three-dimensional structure of the tree crown, to define the growth in terms of metabolism, and was parameterized for young Scots pine trees.

Recommendations: The model is generic and with a change of parameter values and minor modifications, it can be applied to other species.

* Reprinted from Annals of Botany 77, J. Perttunen, R. Sievänen, E. Nikinmaa, H. Salminen, H. Saarenmaa, and J. Väkeva. LIGNUM: A tree model based on simple structural units, 87-98, 1996, Oxford Press, with permission granted through Rightslink, Copyright Clearance Center, Inc. 


\title{
Government Documents (Federal/ State)
}

\section{Title: Environmental features for streambank protection projects}

Author: Henderson, J.E., and F.D. Shields J r.

Series/Source: Environmental and Water Quality Operational Studies

Technical Report, 1984. E-84-11: 1-150, U.S. Army Corps of Engineers,

Waterways Experiment Station (ERDC), Vicksburg, MS

Peer-reviewed: Yes

Code: BKSTAB, SOILER

\begin{abstract}
The stability of the streambanks of a channel is related to both site-specific and basinwide stream reach factors. Streambank erosion or failure is a natural fluvial process that is often accelerated by changes in geotechnical or hydraulic factors and especially the activities of man, e.g., reservoir construction or land use changes. Streambank protection projects stabilize the streambank, preventing or stopping erosion. Stabilization results in a range of environmental changes.
\end{abstract}

Objective(s): The objective was to provide guidance for incorporating environmental considerations into streambank protection projects.

\section{Study Location: N/A}

Method: An information review was performed to identify environmental features for streambank protection projects.

\section{Vegetation: N/A}

\section{Soil Properties: N/A}

Observations/Results: Each environmental feature is discussed in terms of concept, the purpose of appropriate use of the feature, environmental considerations, limitations to use of the feature, performance history, and cost.

Recommendations: The use of vegetation for streambank protection is beneficial because of its contributions to wildlife habitat and aesthetics. Further research should be conducted to identify plant species and propagation methods suitable for a wider range of erosion conditions. The impact of articulated concrete mattress revetments on fish and benthic habitats should be further investigated to duly quantify habitat changes.

Numerous innovative designs have been used for streambank protection as part of the activities in the Corps and other agencies. Many 
of these designs appear to be successful from an engineering standpoint, but the environmental effects of these designs are not monitored beyond the initial operations inspections. The long-term effects on habitat and aesthetics should be documented.

Bank and channel stabilization projects result in basinwide changes in floodplain habitats. The basinwide (or long reach) implications of bank stabilization for land use and habitat diversity changes should be documented when evaluating the impacts of projects.

\title{
Title: Factors affecting streambank and riverbank stability, with an emphasis on vegetation influences, annotated bibliography Author: Ott, R.A. \\ Series/Source: Region III Forest Practices Riparian Management Committee
}

Peer-reviewed: No

Code: BKSTAB

\begin{abstract}
This literature review focuses on factors affecting streambank and riverbank stability, with an emphasis on vegetation influences. The role of large woody debris (LWD) in fluvial systems is covered in another section of this report. Although a formal definition of bank stability was not encountered in the literature, the context in which the term is used implies that a bank is stable if it does not change appreciably within a defined time frame. Bank stability is influenced by factors such as temperature regimes, composition of the bank materials, hydraulic forces, presence or absence of permafrost, and vegetation. In arctic and subarctic regions where permafrost is present, vegetation not only increases shear strength of the soil, but also provides an insulating mat that helps protect frozen banks from erosion. The ability of vegetation to stabilize streambanks or riverbanks is partly dependent upon scale, with both the size of vegetation relative to the watercourse and absolute size of the vegetation being important.
\end{abstract}

Objective(s): The objective was to present a review of literature on streambank and riverbank stability.

\section{Study Location: N/A}

Method: This literature review was conducted in two phases. First, a search was conducted using the electronic databases at the University of 
Alaska in Fairbanks. Additional references were located using the literature citation sections of the material collected in the database search.

Vegetation: N/A

Soil Properties: Permafrost-influenced slope soils

Observations/Results: In arctic and subarctic regions where permafrost is present, vegetation not only increases shear strength of the soil, but also provides an insulating mat that helps protect frozen banks from erosion.

Recommendations: N/A

Title: Tree growth on and adjacent to dams

Author: New Hampshire Department of Environmental Services

Series/Source: Dam Bureau, Environmental Fact Sheet, WD-DB-8. 2008.

http://www.des.state.nh.us/factsheets/dam/inc/8.html

Peer-reviewed: No

Code: DAMVEG

Abstract: One of the most frequently required repairs that the New Hampshire Department of Environmental Services (DES) Water Division requests dam owners to complete is the removal of trees and woody growth that is on or near their dams. This is because the majority of the active dams in the state are either completely or partially earthen embankment type structures. This is not to say that only earthen dams are susceptible to the detrimental effects that trees and woody growth can cause. The stability of all dams, regardless of construction, can be threatened by the presence of these types of vegetation. Some of the potential problems that trees and other woody growth can lead to are listed and described in this fact sheet.

Objective(s): The objective was to produced a fact sheet that briefly discusses uprooting/ overturning (trees), root spreading/infiltration (trees), vegetation hindering adequate dam inspections, and trees hindering the growth of grasses by shading dam surfaces.

Study Location: $\mathrm{NH}$

Method: N/A

Vegetation: Primarily trees

Soil Properties: N/A 
Observations/ Results: The stability of all dams, regardless of construction, can be threatened by the presence of these types of vegetation. Some of the potential problems that trees and other woody growth can lead to are listed and described in this fact sheet.

Recommendations: The present DES policy regarding trees and other woody vegetation is to restrict them from all sections of the dam structure, from within $15 \mathrm{ft}$ of both abutments, and from within $15 \mathrm{ft}$ of the downstream toe. If adhered to, this policy will, in most cases, protect a dam from detrimental effects that these types of vegetation can cause.

\section{Title: Dam owner's guide to plant impact on earthen dams} Author: FEMA

Series/Source: FEMA L-263, September 2005

Peer-reviewed: No

Code: DAMVEG

Introduction: One would not have to look further than down one's own street to appreciate the benefits of trees. From shade to habitat, urban wilderness to visual interest, communities nationwide are enhanced by the enduring presence of trees. While trees enhance most corners of a community, it is important to understand their limitations, especially relating to earthen embankment dams. Located on dams, trees and other woody vegetation that would otherwise bring charm to a city park could interfere with adequate inspection or safe operation of dams, or even cause dam failure.

Private landowners and state and federal agencies use earthen embankment dams as reservoirs to store water for farm and city water supplies, hydropower, navigation, and recreation. Earthen embankments are also used as wastewater lagoons. Composed of compacted earthen fill and often near water sources, embankment dams are naturally conducive to vegetation growth. As such, a troublesome condition can arise if problem vegetation, such as trees, brush, ivy, and other deep-rooted plants, become established. Out of 48 states, 29 document problem vegetation as the cause of dam failures or unsafe dam operations in their states. The U.S. Army Corps of Engineers, the National Park Service, and the Natural Resources Conservation Service document several similar cases at the federal level. State dam safety officials and other experts agree that trees and woody plants on 
dams are a major concern, one which can cause substantial and costly damage if not properly dealt with.

You, the dam owner, are the first line of defense toward the appropriate maintenance and safe operation of dams nationwide. Toward these goals, this brochure was developed to inform federal, state, and private dam owners on the dangers and identification of problem vegetation on earthen embankment dams. This brochure describes how problem vegetation can adversely affect dams and offers dam owners a quick quiz to determine whether their dam may be at risk for problems related to inappropriate vegetation.

Objective(s): This FEMA brochure was developed to inform federal, state, and private dam owners on the dangers and identification of problem vegetation on earthen embankment dams.

\section{Study Location: N/A}

Method: This brochure described how problem vegetation can adversely affect dams and offers dam owners a quick quiz to determine whether their dam may be at risk for problems related to inappropriate vegetation.

\section{Vegetation: N/A}

\section{Soil Properties: N/A}

Observations/Results: Tree roots do not stabilize soil masses, but instead loosen embankment soils and create seepage paths. Dense, lowgrowing groundcover or tall grasses are not desirable embankment plants, and can actually obscure serious dam problems. Even one tree on any size dam is cause for concern.

Recommendations: "Contact your State Dam Safety Official to determine whether inspection and mitigation is required if you answered "yes" to any question on the quick quiz".

Title: Technical manual for dam owners: Impacts of plants on earthen dams

Author: Federal Emergency Management Agency (FEMA)

Source/Series: FEMA 534, 2005

Peer-reviewed: N/A

Code: DAMVEG, LEVVEG

Abstract: Tree and woody vegetation penetrations of earthen dams and their appurtenances have been demonstrated to be causes of serious 
structural deterioration and distress that can result in failure of earthen dams. Damage to earthen dams resulting from plant and animal penetrations is a significant dam safety issue in the United States. The purpose of this technical manual for Dam Owners is to advance awareness of the characteristics and seriousness of dam safety problems associated with tree and woody vegetation growth impacts on earthen dams, provide a higher level of understanding of dam safety issues by reviewing current damage control policies, provide state-of-practice guidance for remediation design considerations associated with damages associated with tree and woody vegetation growth on earthen dams, and provide rationale and state-of-practice techniques and procedures for management of desirable and undesirable vegetation on earthen dams.

Objective(s): The objective was to convey technology assembled through the workshop by successful completion of the following four objectives:

1. Advance awareness of the characteristics and seriousness of the dam safety problems associated with tree and woody vegetation growth impacts on earthen dams

2. Provide a higher level of understanding of dam safety issues associated with tree and woody vegetation growth impacts on earthen dams by reviewing current damage control polices

3. Provide state of the practice guidance for remediation design considerations associated with tree and woody vegetation growth on earthen dams

4. Provide rationale and state of the practice techniques and procedures for management of desirable and undesirable vegetation on earthen dams.

\section{Study Location: N/A}

Method: Description of problems with trees and woody vegetation growth, problems and failures caused by vegetation, tree growth and tree root development requirements, limiting soil dry densities for root growth in various soil types/textures and typical soil parameters in earth dams.

\section{Vegetation: N/A}

Soil Properties: N/A

Observations/Results: N/A

Recommendations: N/A 
Title: A technical manual on the effects of tree and woody vegetation root penetrations on the safety of earthen dams

Author: Marks, B.D., and B.A. Tschantz

Series/Source: Association of State Dam Safety Officials (ASDSO) contract with Marks Enterprises of NC, PLLC, December 2002

Peer-reviewed: No

Code: DAMVEG

Abstract*: Damage to earthen dams and dam safety issues associated with tree and woody vegetation penetrations of earthen dams is all too often believed to be a routine situation by many dam owners, dam safety regulators, and engineers. Contrary to this belief, tree and woody vegetation penetrations of earthen dams and their appurtenances have been demonstrated to be causes of serious structural deterioration and distress that can result in failure of earthen dams. For the first time in the history of dam safety, a Workshop on Plant and Animal Impacts on Earthen Dams was convened through the joint efforts of the Association of State Dam Safety Officials (ASDSO) and the Federal Emergency Management Agency (FEMA) in November 1999 to bring together technical resources of dam owners, engineers, state and federal regulators, wildlife managers, foresters, and academia having expertise in these areas of technology.

The ASDSO/FEMA Workshop highlighted the realization that damage to earthen dams resulting from plant and animal penetrations was indeed a significant dam safety issue in the United States. The purpose of this Technical Manual on the Effects of Tree and Woody Vegetation Root Penetrations on the Safety of Earthen Dams is to convey technology assembled through the ASDSO/FEMA Workshop by successful completion of four objectives. These objectives are as follows:

1. Advance awareness of the characteristics and seriousness of dam safety problems associated with tree and woody vegetation growth impacts on earthen dams;

2. Provide a higher level of understanding of dam safety issues associated with tree and woody vegetation growth impacts on earthen dams by reviewing current damage control policies;

3. Provide state-of-practice guidance for remediation design considerations associated with damages associated with tree and woody vegetation growth on earthen dams; and

4. Provide rationale and state-of-practice techniques and procedures for management of desirable and undesirable vegetation on earthen dams. 
Objective(s): A Workshop on Plant and Animal Impacts on Earthen Dams was convened through the joint efforts of the Association of State Dam Safety Officials (ASDSO) and the Federal Emergency Management Agency (FEMA) in November 1999 to bring together technical resources of dam owners, engineers, state and federal regulators, wildlife managers, foresters, and academia having expertise in these areas of technology.

The purpose of this Technical Manual on the Effects of Tree and Woody Vegetation Root Penetrations on the Safety of Earthen Dams is to convey technology assembled through the ASDSO/FEMA Workshop by successful completion of four objectives. These objectives are as follows:

1. Advance awareness of the characteristics and seriousness of dam safety problems associated with tree and woody vegetation growth impacts on earthen dams;

2. Provide a higher level of understanding of dam safety issues associated with tree and woody vegetation growth impacts on earthen dams by reviewing current damage control policies;

3. Provide state-of-practice guidance for remediation design considerations associated with damages associated with tree and woody vegetation growth on earthen dams; and

4. Provide rationale and state-of-practice techniques and procedures for management of desirable and undesirable vegetation on earthen dams.

Study Location: N/A

Method: Assemblage of ASDSO/FEMA Workshop topics Vegetation: N/A

Soil Properties: N/A

Observations/Results: Effective, shallow-rooted, vegetative cover is necessary to reduce and prevent embankment slope erosion. Trees and other undesirable deep-rooted vegetation should be prevented from being established. Federal agencies that own, operate, and maintain dams do not allow trees to grow on their structures. Remediation guidelines are given for removing existing undesirable vegetation.

Recommendations: Dam owners should observe these four important rules:

1. Existing trees should be removed and not be allowed to mature on earthen dams, abutment groins, or around water conveyance structures;

2. Trees or shrubbery should never be planted on or around new or existing dams;

3. Existing trees should be watched closely until they are removed; 
4. Grasses and shallow-rooted native vegetation are the most desirable surface covering for an earthen dam.

*Reprinted from Association of State Dam Safety Officials (ASDSO) contract with Marks Enterprises of NC, PLLC, B.D. Marks, and B.A. Tschantz, A technical manual on the effects of tree and woody vegetation root penetrations on the safety of earthen dams, December 2002, with permission from B. A. Tschantz, P.E.

Title: Environmental engineering and local flood control channels

Author: U.S. Army Corps of Engineers

Series/Source: Engineer Manual, EM 1110-2-1205. 15 Nov 1989.

Peer-reviewed: N/A

Code: ECOSYS, LVFLCL, SOILER, BKSTAB

Abstract: This manual pertains to projects that involved modifications of natural stream channels to reduce damages due to flooding, bed scour, or bank erosion.

Objective(s): Provides guidance for including environmental considerations related to flood control levees.

Study Location: N/A

Method: N/A

Vegetation: N/A

Soil Properties: N/A

Observations/Results: N/A

Recommendations: Sample procedures for flood control channel designs are provided.

Title: Environmental features for streamside levee projects Author: Hynson, J.R., P.R. Adamus, J .O. Elmer, T. DeWan, and F.D. Shields

Series/Source: Environmental and Water Quality Operational Studies, Technical Report, E-85-7: U.S. Army Corps of Engineers, Waterways Experiment Station (ERDC), Vicksburg, MS. 1985. pp. 1-297 


\section{Peer-reviewed: Yes}

\section{Code: ECOSYS, LEVVEG}

Abstract: This study provides designers of levee projects with guidance for incorporating environmental enhancement features into the project design and maintenance. Forty-six environmental features were identified by information review as having potential to improve fish and wildlife habitat, recreational use, and aesthetic qualities of lands and water associated with levee projects. Information was obtained from review of scientific literature and planning documents as well as contact with U.S. Army Corps of Engineers personnel and site visits to selected completed levee projects.

Features include general items for design and maintenance, as well as specific measures for fish and wildlife habitat, recreation, and aesthetic development. All features included in the main body of the report were evaluated by an interdisciplinary team consisting of two civil engineers, a wildlife biologist, an aquatic biologist, and a landscape architect.

Objective(s): This study provides designers of levee projects with guidance for incorporating environmental enhancement features into the project design and maintenance. Environmental features have been identified for all phases of levee projects: design, construction, operation, and maintenance.

\section{Study Location: N/A}

Method: Forty-six environmental features were identified by information review as having potential to improve fish and wildlife habitat, recreational use, and aesthetic qualities of lands and water associated with levee projects. Information was obtained from review of scientific literature and planning documents as well as contact with U.S. Army Corps of Engineers personnel and site visits to selected completed levee projects.

Vegetation: N/A

\section{Soil Properties: N/A}

Observations/Results: Numerous techniques can be used to improve fish and wildlife habitat, recreational potential, and aesthetic resources associated with levee projects. In order to obtain maximum benefits from environmental features, interdisciplinary approaches are needed throughout the planning and design processes in order to (a) develop management objectives that are appropriate to specific sites, (b) choose features which can be implemented successfully, (c) avoid compromising 
the basic flood protection objectives of the levee system, and (d) ensure that resource conflicts are minimized. Maximum benefits are also reached when features are integrated with each other to improve environmental quality.

\title{
Recommendations: N/A
}

\section{Title: Incorporation of environmental features in flood control} channel projects

Author: Nunnally, N.R., and F.D. Shields, Jr.

Series/Source: Technical Report E-85-3, May 1985 (reprinted J une 1987). U.S. Army Engineer Waterways Experiment Station, Vicksburg, MS. 1985

\section{Peer-reviewed: Yes}

Code: ECOSYS, LVFLCL

\begin{abstract}
Channels modified for flood control often experience severe environmental degradation due to erosion and sedimentation, loss of vegetative cover, reduction in amount and value of habitat, and decline in aesthetic value. Many environmental problems result from a failure to recognize the nature of the fluvial system and its interactions with the biological system. Many negative environmental impacts can be avoided by designing flood channels that are in harmony with other fluvial components, minimizing disruptions to existing fluvial and biological systems, and incorporating environmental features into flood channel design. Environmental features are defined as any structure or action employed in the planning, design, construction, or maintenance of flood control channels that produce environmental benefits. Environmental features may include modifications of standard techniques such as selective clearing and snagging or single bank construction; modified channel designs such as low flow channels, pools and riffles, and meandering alignments; structures for erosion and sediment control, water level management, and instream habitat; inclusion of recreational features in project design; and special designs and treatments for aesthetic purposes. Procedures are presented for the design of environmental features. These procedures are based largely on prior experience with the use of environmental features on modified channels and on fluvial processes and natural stream geometry. Tables are provided to help select
\end{abstract}


the best environmental features based on environmental objectives and stream and watershed conditions.

Objective(s): The objective was to provide guidance for choosing appropriate environmental features related to flood control channels.

\title{
Study Location: N/A
}

Method: Literature and research project compendium

Vegetation: Riparian species

Soil Properties: N/A

Observations/Results: Procedures are presented for the design of environmental features. These procedures are based largely on prior experience with the use of environmental features on modified channels and on fluvial processes and natural stream geometry. Tables are provided to help select the best environmental features based on environmental objectives and stream and watershed conditions.

Recommendations: Environmental objectives should be given equal consideration with economic objectives during all phases of flood control projects.

\section{Title: Innovative methods for levee repair}

Author: Perry, E.B., and M. Myers

Series/Source: Repair, Evaluation, Maintenance, and Rehabilitation Research Program. REMR 10(3): 6 p. 1993

Peer-reviewed: No

Code: GEOTEX, LVCONS

\begin{abstract}
The Flood of 1993 has caused extensive damage to levees in the Upper Mississippi River and Missouri River Basins. With the recession of the floodwaters, repairs will have to proceed expeditiously for the levee systems to be restored to readiness prior to the spring high-water stages in 1994. A complicating factor is the extremely short "window" for accomplishment of repairs because of the time required for assessment and categorization of damages, low equipment mobility at some sites for an extended period after cessation of flooding, and the possible onset of adverse construction weather in late 1993 or early 1994. For these reasons, the application of innovative methods of levee repair that can contribute to rapid, economical, environmentally acceptable, and permanent restoration of the flood-control system is highly desirable.
\end{abstract}


Objective(s): The objective was to discuss innovative methods of levee repair, that can contribute to rapid, economical, environmentally acceptable, and permanent restoration of the flood-control system.

Study Location: Upper Mississippi River and Missouri River basins Method: To effectively curtain overtopping erosion, inflatable dams/ water structures, geotextile-reinforced grass, geocells, concrete block systems, and soil cement/ roller-compacted concrete systems were constructed and evaluated. To abate current and wave attack, used tires for revetment and fabric forms for grout placement were implemented and evaluated. For through-seepage protection, biopolymer drains and bentonite sealing were tested. Under-seepage tests included the use of slurry trench cutoffs and jet-grouted cutoffs. A variety of materials was tested to improve slope stability including stabilized soil, tiresoil, soil nailing, fly ash, and lime injections.

Vegetation: N/A

\section{Soil Properties: N/A}

Observations/Results: The use of geotextile-reinforced grass embankment enhanced the engineering function of grass while retaining its environmental and economic attributes. Listed innovative techniques that mentioned vegetation were geotextile-reinforced grass and geocells for overtopping and wave attack, geocells (with vegetation) for through seepage and under seepage, and vegetation for slope instability.

\section{Recommendations: N/A}

Title: The Spring 2008 Midwest Flood: Observations of Missouri and Iowa Levee Breaches

Author: Kelley, J .R., N. Vroman, C. Groves, L. Harder, and G. Sills Series/Source: USACE Engineer Research and Development Center, ERDC/GSL SR-091, 59 pp (2009)

\section{Peer-reviewed: YES}

Code: LEVVEG, SOILER, RTSYST, SLSTAB(VR)
Abstract: During spring 2008, the Midwestern portion of the continental United States experienced flooding that led to overtopping and levee breaches along several Midwest levee systems. Post-levee failure condi- tions were observed at the Pin Oak, Cap au Gris Levee, and Birdland Levee systems. Levee distress in the form of heavy seepage and sand boils were 
noted at the East St. Louis Levee system. At the Cap au Gris and Birdland Levee systems, large trees were present in the vicinity of the levee failures. Roots from these large trees were exposed in the scour hole left from the levee failures and extended a considerable distance from the tree trunk to the levee, and even through the levee.

Objective(s): The study documented in this report was conducted to support the levee vegetation impact study being conducted by ERDC. These levee systems were selected due to their potential to provide valuable information on vegetation impacts on levee performance and failure mechanisms for levees.

Study Location: Four levee systems included the East St. Louis Levee, the Pin Oak and Cap au Gris levee system located along the Mississippi River, and the Birdland Levee system along the Des Moines River.

Method: Field reconnaissance, site visits, and interviews with USACE staff.

Vegetation: Sycamores, cottonwoods

Soil Properties: Pin Oak levee systems soil described as moderately erosive, brown silty clay (CL classification). Cap au Gris described as a gray silty clay (CL classification) with moderately rapid erosion rate. The Birdland Levee was constructed with miscellaneous fill materials and contained rubble and debris. Sand seams were also present within the levee cross section

Observations/Results: Based on observations of the inspection, there was no direct evidence that the roots were detrimental to the performance of the levees. The four levee failures inspected during the field visit were a result of the following failure modes: (1) defects in the levee embankment, possibly caused by animal burrows and dens, (2) overtopping erosion, and (3) co-location with an area of previous failure and known weakness. Removing trees and their root balls by bulldozing them over without remediating the disturbed ground and extracting the root system appears to exacerbate a marginal under-seepage condition. Large roots from trees at the two Cap au Gris sites penetrated through the levee from the waterside toe to the landside toe. Much of the existing levee system in the Midwest, if situated near large trees, is possibly embedded with extensive root systems. This represents a considerable challenge in maintaining the integrity of the levee system and requires a flexible approach to managing this issue.

\section{Recommendations: N/A}


Title: Common ground white paper document - Among California and federal agencies - Regarding vegetation management on levees

Author: State of California Reclamation Board

Series/Source: 2007

Peer-reviewed: No

Code: LEVVEG

Abstract: A levee conference was held in Sacramento, CA. At the request of the Reclamation Board, the U.S. Army Corps of Engineers and State of California leadership met to discuss issues related to the Corps draft white paper on vegetation management on levees and the upcoming Vegetation Symposium. During the meeting BG McMahon, Division Commander of the South Pacific Division (SPD), U.S. Corps of Engineers, took the initiative to have SPD document "our common ground" with our federal and state partners.

Objective(s): The document attempts to identify areas of common ground between the federal and state agencies, based on existing policies, regulations, and statutes.

Study Location: N/A

Method: General categories were delineated as follows: Overarching

Principles, Existing Vegetation Standards, and Implementation of Vegetation Standards

Vegetation: N/A

Soil Properties: N/A

Observations/Results: Identifying common ground permits a collaborative process to find solutions to the complex vegetation challenge in the California Central Valley.

Recommendations: N/A

Title: Levee owner's manual

Author:

Series/Source: Code of Federal Regulations, Title 33, Vol. 3, J uly 2006

Revision, Part 203, Sec.203.51

Peer-reviewed: No 


\section{Code: LEVVEG}

Introduction: In accordance with section 202(f) of Public Law 104-303, the Corps will provide a levee owner's manual to the non-Federal sponsor of all flood control works in an Active status in the Rehabilitation and Inspection Program (RIP).

Objective(s): The levee owner's manual will include the standards that must be met to maintain an Active Status in the RIP. Manuals will also be provided to sponsors of Inactive non-Federal projects so that the sponsors may evaluate their projects and prepare for an Initial Eligibility Inspection (IEI) to gain an Active status in the RIP.

\section{Study Location: N/A}

\section{Method: N/A}

Vegetation: N/A

Soil Properties: N/A

Observations/Results: N/A

Recommendations: N/A

\section{Title: Interim guidelines for selective vegetation maintenance on flood control levees}

Author: N/A

Series/Source: U.S. Army Corps of Engineers, Portland District, Operations Division, Emergency Management Branch, NPP 1110-1-1, 1993 Peer-reviewed: No

Code: LEVVEG

Abstract: The challenge is to ensure that the environment becomes an integral part of the engineering ethic. This transition will involve those who say, "Levees were not natural environment areas and in no way should they be allowed through regulatory change to become habitat areas. Allowing more vegetation would encourage the establishment of unwanted pests, like beavers, that can significantly threaten the integrity of our levees." On the other hand, some resource agencies believe that removal of vegetation and trees should be the exception, not the rule. We hope to achieve a balance of these two views.

\section{Objective(s): N/A}




\title{
Study Location: N/A
}

\section{Method: N/A}

\section{Vegetation: N/A}

\section{Soil Properties: N/A}

Observations/Results: Separate guidance will be distributed concerning vegetation maintenance on bank protection (or erosion) projects. Such projects have no back or landward slopes. The levees included in these guidelines are part of the following types of projects:

(1) Flood control projects constructed by the federal government for which a local sponsor has assumed operation and maintenance responsibility. (2) Additions to existing flood control projects, constructed cooperatively with the local sponsor.

\section{Recommendations: N/A}

\section{Title: Levee wave wash protection by trees}

Author: Markel, D.G.

Series/Source: Waterways Experiment Station, U.S. Army Corps of Engineers (WES), 1979. Miscellaneous paper HL-79-1

Peer-reviewed: Yes

Code: LEVVEG, TREEMD

\begin{abstract}
A hydraulic model investigation was conducted at a geometrically undistorted scale of 1.5, model to prototype. The purpose of the study was to test the use of tree stands as a possible method for protecting levee embankments from wave wash caused by wind- and boatgenerated waves. Incident wave heights ranging from 1.0 to $3.0 \mathrm{ft}$ and wave periods of 2.0,2.5, and 3.0 sec were tested on a total of 12 different test plans. The 12 plans covered a range of depths of tree stands using exclusively 4-in.- and 12-in.-diam vertical PVC pipes both with and without defoliated branches (wooden dowels). Wave attenuation did not exceed a maximum of about $15 \%$ and on the average did not exceed about 9\%. Tree stems with branch systems showed a maximum wave attenuation of about $45 \%$, but the average wave attenuation did not exceed $15 \%$.
\end{abstract}

Objective(s): Using arrangements of surrogate trees (vertical PVC pipes with inserted wooden dowels) inside a laboratory wave flume, this study was a general investigation of the use of tree stands to help protect levee embankments along inland waterways from wave wash. The purpose of 
the study was to measure the wave attenuation produced by simulated cottonwood trees (surrogates constructed of PVC pipes and wooden dowels) when the water level passed through the PVC pipe stands and when the water level passed through the wooden dowel surrogate tree branch system. These data could then be used to approximate the amount of wave protection during various river stages that could be expected from a stand of surrogate trees (PVC pipes and wooden dowels) placed between a river channel and levee embankment.

Study Location: Laboratory

Method: A physical model constructed in a horizontal hydraulic flume with spaced vertical PVC pipes and wooden dowels. Wave attenuation through the PVC pipe "forest" was observed.

\section{Vegetation: N/A}

\section{Soil Properties: N/A}

Observations/Results: Wave attenuation by vertical PVC pipes (surrogate tree stems) alone, approximately 9\%, is not very effective and on the average would afford only minimum protection. Surrogate tree stems (PVC pipe) with surrogate branch systems (wooden dowels) showed a maximum wave attenuation of about $45 \%$, but the average wave attenuation did not exceed $15 \%$. No vegetation or modeled levee elements were used in this study.

Recommendations: It is recommended that further insight be gained by conducting additional tests with surrogate foliage that are verified by at least one set of prototype attenuation data, or that a full-scale prototype study be conducted in which sufficient wave attenuation measurements are made to quantify the surrogate tree (PVC pipe and wooden dowels) protection concept under varying conditions.

\section{Title: Maintenance costs of vegetation on levees}

Author: N/A

Series/Source: California Water Code Sections 8450-8457, Chapter 5, Maintenance costs for vegetation on levees

Peer-reviewed: No

Code: LEVVEG

Abstract: The legislature finds and declares as follows:

a. Although the levees of flood control projects in this state have in the past been considered to be single-purpose, flood control features, many of 
these projects receive heavy nonlocal usage for recreation, transportation, and other purposes for which the retention and maintenance of vegetative cover is desirable.

b. Construction and maintenance practices have been developed over the past several decades, which were designed to minimize costs while still furnishing the required degree of flood control. These practices in many instances resulted in "bare" levees, devoid of any vegetative cover, that might interfere with local maintenance, levee inspection, or flood fighting.

c. Flood control project levees are increasingly recognized as valuable wildlife, recreational, scenic, and aesthetic resources, and construction and maintenance standards have been developed by the Army Corps of Engineers and the State of California which minimize vegetation removal and which encourage or require, as a condition of the project work, replanting and controlled vegetation maintenance on such levees as part of the responsibility of local flood control districts.

d. Costs of maintaining vegetation on levees for such non-flood-control purposes as wildlife enhancement, recreation, and scenic beauty are approximately double those of normal flood-control-related maintenance, and no local users are the prime beneficiaries. It is therefore appropriate that the general public participate in meeting such additional maintenance costs.

8451-8456 paragraphs are also stated giving conditions of costs and reimbursements.

8457. State expenditures for the purposes of this chapter shall not exceed the amount of two hundred thousand dollars $(\$ 200,000)$ per year.

Objective(s): Legislation

Study Location: California

Method: State regulations

Vegetation: N/A

Soil Properties: N/A

Observations/Results: N/A

Recommendations: N/A

Title: California water code section 8450: Maintenance costs of vegetation on levees

Author: State of California 
Series/Source: Chapter 5 of the California Water Code Section 8450 Peer-reviewed: N/A

Code: LEVVEG

Abstract: N/A

Objective(s): California Legislative declaration regarding sharing maintenance costs for levee vegetation

Study Location: N/A

Method: N/A

Vegetation: N/A

Soil Properties: N/A

Observations/Results: Costs of maintaining levee vegetation for nonflood-control purposes (i.e., wildlife, etc.) are approximately double those of normal flood-control-related maintenance. It is appropriate that the general public participate in meeting such additional maintenance costs. This law provides that the State shall pay $50 \%$ of the costs attributable to planting or retaining controlled vegetative cover on project levees.

Recommendations: N/A

Title: Documentation and analysis of tree root extent and behavior along and in levees in the New Orleans District Author: U.S. Army Corps of Engineers, 2009.

Series/Source: J esco Environmental and Geotechnical Services, Inc., W912P8-07-D-0040, Task 0002/ Draft Report

Peer-reviewed: No

Code: LEVVEG, RTSYST

Abstract: The root study project was broadly defined as the 1,300 miles of Corps of Engineers levees in the New Orleans District of Southern Louisiana. The study and data collection focused on tree removal project areas in the metropolitan area including but not limited to New Orleans Lakefront Levee, Orleans Avenue Canal Levee/ Floodwall on the City Park side, the London Avenue Canal, and the 17th Street Canal. Additional supplementary data was taken on abandoned levee reaches in South Louisiana. 
Objective(s): The objective was to support the refinement of vegetation management guidelines for Federal and non-Federal levees and floodwalls.

Study Location: 1,300 miles of levees in the New Orleans District of southern Louisiana

Method: Seventy-nine trees were selected for root-profile wall mapping. Exploratory trenches 7 to $8 \mathrm{ft}$ deep and 10 to $20 \mathrm{ft}$ in length were excavated adjacent to selected sample trees, and the root system characteristics were visually measured on the trench walls. The trenches were then backfilled and compacted to minimum $90 \%$ standard proctor. Vegetation: Baldcypress (Taxodium distichium), Drake elm (Ulnus spp.), live oak (Quercus virginiana), pecan (Carya illinoinsis), slash pine (Pinus elliotti), sugarberry (Celtis laevigata), sycamore (Platanus occidentalis), tallow, and water oak (Quercus nigra)

Soil Properties: Typical clay and silty clay homogeneous levee fill was noted for the trench walls. Median force (handheld penetrometer) was $13 \mathrm{lb}$.

Observations/Results: Report indicated several observations and preliminary results. For all species, the number of roots greater than $0.5 \mathrm{in}$. in diameter decreased with distance from the base of the tree. Root frequency and radial extent for different root diameter classes were correlated to these variables: tree diameter, tree height, crown diameter, crown height, and soil strength index (penetrometer readings). Wide ranges of correlation between these variables and the root classes were noted for inter- and intra-species of trees.

\section{Recommendations: N/A}

Title: Regional variances to levee vegetation standards

Author: U.S. Army Corps of Engineers

Series/Source: Appendix E, Engineer Pamphlet EP 500-1-1, 2001.

Peer-reviewed: N/A

Code: LEVVEG

Abstract: A flood control levee's public sponsor may request a variance to allow additional vegetation to grow on a levee, in accordance with ER 5001-1, paragraph 5-22.

\section{Objective(s): N/A}




\title{
Study Location: N/A
}

Method: N/A

Vegetation: N/A

\section{Soil Properties: N/A}

Observations/Results: Blanket regional variances are not permitted, but regional variance agreements are encouraged. This document discusses the development and procedure for regional variance agreements regarding levee vegetation.

Recommendations: N/A

Title: Guidelines for landscape planting and vegetation management at floodwalls, levees, and embankment dams Author: N/A Series/Source: U.S. Army Corps of Engineers, Engineer Manual EM 1110-2-301, January 2000

\section{Peer-reviewed: N/A}

Code: LEVVEG, DAMVEG

\begin{abstract}
Floodwalls, levees, and embankment dams serve a common purpose in that they are designed to contain water and prevent flooding for varying lengths of time. Further, levees and floodwalls are sometimes involved in flood-fighting activities of a nature not found in other project structures. The possibility for long-term saturation of levee materials or levee and floodwall foundations, together with their unusual maintenance requirements, makes it necessary to exercise caution in the design of landscape planting and vegetation management at these structures. This manual describes some characteristics of floodwalls, levees, and embankment dams that are of interest to the design team members in such a design.
\end{abstract}

Objective(s): The objective was to provide criteria for the design of landscape plantings and vegetation maintenance at floodwalls, levees, and embankment dams. It is intended as a guide for uniformly safe design and not as a restriction to the initiative of the designer. This manual encourages close coordination between the design team members, which include a civil engineer, environmental engineer, biologist, and landscape architect.

\section{Study Location: N/A}


Method: Engineer Manual

Vegetation: N/A

Soil Properties: N/A

\section{Observations/Results: N/A}

Recommendations: Vegetation variances for flood-control works such as levees, floodwalls, and dam embankments may be permitted for either federal or non-federal flood-control works. The vegetation variance must ensure the following: safety, structural integrity, and functionality of levees, floodwalls, flood channels, and dam embankments are maintained; accessibility is retained for inspection and flood fighting; periodic clearing of some types of woody (trees) and nonwoody (grass, vines, sand shrubs) vegetation will be performed when required; and the variance will not be a substitute for poor maintenance practices.

The vegetation-free zone is an area adjacent to the landside and/ or riverside toe of the levee, floodwall, or embankment dam and appurtenant structure where no type of vegetation, with the exception of grasses, is permitted. This zone is required for maintenance and flood-fighting activities and must be easily accessible at all times.

The root-free zone provides a margin of safety between the greatest expected extent of plant roots and the beginning face of the basic project structure. Knowledge of the rooting habit of each plant selected is required for use in the landscape planting plan. Some type of barrier such as geomembrane will be required at the limits of the root-free zone where root penetration is possible. This barrier should not retard groundwater or seepage flow.

Title: The effects of vegetation on the structural integrity of sandy levees

Author: Gray, D.H., A. MacDonald, T. Thomann, I. Blatz, and

F.D. Shields, Jr.

Series/Source: Repair, Evaluation, Maintenance, and Rehabilitation Research Program Technical Report, REMR-EI-5:117. 1991

Peer-reviewed: N/A

Code: LEVVEG, SLSTAB

Abstract: Current Corps of Engineers guidelines for levee maintenance and operation limit vegetation on levee embankments to sod forming grasses of 2- to 12-in. height to provide for the structural integrity, 
inspectability, and unhindered flood fight access. These standards allow just enough vegetation on levees to provide soil-holding capacity. Exceptions are made to allow taller woody vegetation on overbuilt levee sections. Such standards are justified by the absence of data, which clearly establish the relationship between properties of vegetation on levees and structural impairment of the levees. In many areas of the country, however, these standards result in a significant loss of riparian habitat and may be impractical due to local climatic conditions. Prior to the revision of these standards, engineering guidance must be developed to account for vegetal components of the geotechnical system.

Objective(s): The objective was to investigate relationships between vegetation and structural integrity of river levees. A specific objective was to determine the distribution of roots within levee embankments and the influence of roots on soil properties of the levee embankments. Information will be used to develop engineering criteria for vegetation (particularly woody) on levee embankments.

Study Location: Channel levees along the Sacramento River Method: Methodology included (1) field data collection (distribution and concentration of roots, voids, and pedotubules along transects both perpendicular and parallel to the crest of a sandy levee; (2) seepage and stability analyses (infinite slope and circular arc stability); and (3) field methods for studying root distribution and architecture; excavation, monolith, auger, profile-wall, and glass-wall.

Vegetation: Mixed, woody species: (1) valley oak (Quercus lobata), (2) cottonwood (Populus fremontiii), (3) California rose (Rosa californica), (4) licorice (Glycyrrhiza sp.), (5) various grasses, (6) various sedges, (7) telegraph weed (Heterotheca grandiflora), (8) lotus (Lotus purshianus), (9) mustard (Sisymbrium officinale), (10) bindweed (Convolulus spp.), (11) willow (Salix hindsiana), (12) elderberry (Sambucus mexicana), (13) blackberry (Ribes spp.), and (14) black locust (Robinia pseudoacacia).

Soil Properties: Uniform, medium to fine sands with little or no fines (silts or clays)

Observations/Results: (1) No evidence in the field study that vegetation affected the hydraulic conductivity or porosity. (2) Roots reinforce the soil and increase the shear strength in a measurable manner. (3) Woody plants are more deeply rooted and more effective in preventing deeper seated sliding. (4) Grasses and herbaceous groundcover provided 
greater amounts of roots at very low depths ( $\varangle 6$ in.) than did woody plants.

Lateral plant roots were restricted to, and modified, mainly in the first few feet between the surfaces of a levee. Root area ratios did not exceed $2 \%$ and generally decreased approximately exponentially with depth. Most of the root biomass was concentrated in the top $2 \mathrm{ft}$. Voids and pedotubules (infilled holes or conduits) were also mapped in the vertical faces of the trenches at each site. No voids clearly attributable to plant roots were observed.

Plant roots reinforce the levee soil and increase shear strength in a measurable manner. A shear strength increase or root cohesion can be estimated from the root biomass per unit volume or alternatively from the root area ratio. Both infinite slope and circular arc stability analyses were performed on the landward and riverward slope for steady seepage and sudden drawdown conditions, respectively. These analyses showed that even low root concentrations as measured along selected transects in the sandy levee sufficed to make the slope more secure under "worst case" scenario conditions.

Recommendations: The authors recommended the following:

(1) Conduct additional full excavations around trees to determine if vertical rooting is predominant orientation in sandy levees. Very few large, lateral roots were exposed in the trench faces at the live oak site.

(2) Conduct gravimetric root biomass assays in conjunction with profile-wall surveys to see if the later adequately accounts for the presence of root fibers less than $1 \mathrm{~mm}$ in diameter. The latter size class is probably underestimated in the profile-wall survey method.

(3) Conduct hydraulic conductivity testing with large, double ring infiltrometers in order to determine if near surface portions of a levee are modified by the presence of vegetation. Permeability/density tests on small volume samples do not adequately reflect macroscopic hydraulic properties of levee soils, i.e., the influence of large void volume defects, such as animal burrows, pedotubules, or root holes.

(4) Develop 3-D seepage analysis technique to model adequately the effects of pipes, holes, or large voids on the seepage regime and the danger of internal erosion.

(5) Conduct similar field studies in levees made of cohesive soils and compare results with those obtained for sandy levees.

(6) Conduct studies in regions where climatic conditions are more humid and the vegetation spectrum is different from the semi-arid conditions of central California. 
Title: A study of vegetation on revetments Sacramento Riverbank protection project

Author: Shields, F.D. Jr., L.T. Ethridge, and T.N. Waller

Series/Source: Phase 1, WES Literature Review and Pilot Study: 138 p. 1990

Peer-reviewed: N/A

Code: LEVVEG

\begin{abstract}
This report describes methods and findings of the first phase (pilot study) of a 2-year study of the effect of volunteer woody vegetation on durability of Sacramento River revetments. The study consisted of literature review, analysis of effects of woody vegetation on revetment performance during the 1986 flood using historical records and aerial photos, and visual inspection of revetments along the Sacramento River between river-mile 84.5 and 119. Federal and Corps of Engineers (CE) regulations specifically address removal of woody vegetation from levee slopes and flood control channels, but vegetation on revetted banks that are not part of a levee is not specifically prohibited. However, current CE maintenance standards as applied to the Sacramento River Flood Control Project prohibit woody vegetation on revetments. Primary reasons that vegetation is undesirable on revetments include potential reduction of channel conveyance, impairment of revetment visibility for inspection, and reduced revetment durability. Only revetment durability was addressed in this study.
\end{abstract}

Objective(s): The objective was to conduct a 2-year study of the effect of volunteer woody vegetation on durability of Sacramento River revetments. Study Location: Sacramento River, CA

Method: Literature review, analysis of effects of woody vegetation on revetment performance during the 1986 flood using historical records and aerial photos, and visual inspection of revetments along the Sacramento River between river-mile 84.5 and 119.

Vegetation: Riparian species

Soil Properties: Sandy

Observations/Results: Current Corps maintenance standards as applied to the Sacramento River Flood Control Project prohibit woody vegetation on revetments. Primary reasons that vegetation is undesirable 
on revetments include potential reduction of channel conveyance, impairment of revetment visibility for inspection, and reduced revetment durability. Only revetment durability was addressed in this study. Recommendations: N/A

\section{Title: Issues regarding vegetation management on levee} embankments

Author: MacDonald, A., D.H. Gray, T.G. Thomann, I.W. Blatz, and F.D. Shields, Jr.

Series/Source: REMR (Repair Evaluation Maintenance Rehabilitation) Technical Note REMR-EI-M-1.4, Supplement 3, 1989. U.S. Army Corps of Engineers, Waterways Experiment Station (Engineer Research and Development Center), Vicksburg, MS

Peer-reviewed: Yes

Code: LEVVEG, ECOSYS

\section{Abstract: N/A}

Objective(s): This Tech Note provides an overview of current issues related to vegetation management and refers to ongoing research regarding levee structural integrity and multiple-purpose use. All project levees constructed by the Corps of Engineers for which PL84-99 emergency repair assistance is requested must be maintained in accordance with Corps guidelines. These standards may preclude levees from functioning as multiple-purpose structures (i.e., wildlife habitat, recreation, etc.). Site-specific relaxation of existing vegetation standards could potentially reduce the frequency, cost, and detrimental environmental effects of required maintenance.

\section{Study Location: N/A}

Method: Discussion of current vegetation practices enhancing multipleuse levee structures including those along the Tenn-Tom waterway, the State of California and the Seattle District.

\section{Vegetation: N/A}

\section{Soil Properties: N/A}

Observations/Results: An ongoing project investigated this issue at selected levees not complying with Corps standards (33 CFR), and preliminary results were provided in REMR Tech Note EI-M-1.3. 
Recommendations: Actively establishing vegetation on levees allows selection of species having the desired growth habits which also benefit the environment (and do not compromise levee integrity).

\title{
Title: Interim guidance for vegetation on flood control levees under Reclamation Board Authority, September 16, 1988
}

Author: N/A

Series/Source: California Reclamation Board, 1988

Peer-reviewed: N/A

Code: LEVVEG

\begin{abstract}
The Reclamation Board's Guide for Vegetation on Project Levees was first prepared and adopted by the Board in 1967 in cooperation with the U.S. Army Corps of Engineers. Subsequent revisions made in 1969, 1974, 1976, and 1981 were adopted by the Board without benefit of the Corps' endorsements. Increasing concerns over environmental issues as they relate to flood project safety have clearly identified the need for the Corps and the Board to be unified in their policies relating to the suitability of vegetation on flood control projects. As a result, an "Interim Guide for Vegetation of Flood Control Levees under Reclamation Board Authority" has been prepared with the intention of providing maintaining agencies and adjacent property owners with the basic standards for inspecting and managing levee, levee toe, and berm vegetation. It is termed "Interim" to coincide with a five-year Demonstration Project to be conducted jointly by the Department of Water Resources and the Corps. The objective of the "Demo Project" is to develop a better understanding of the effects of various types of vegetation on levee stability, and to provide a technical base for a final "guide" which would meet the needs and be endorsed by both the Corps and the Board.
\end{abstract}

Objective(s): The objective was to provide maintaining agencies and adjacent property owners with the basic standards for inspecting and managing levee, levee toe, and berm vegetation. Interim guidance coincides with a five-year demonstration program with CA Department of Water Resources and USACE to develop a better understanding of effects of various types of vegetation on levee stability.

Study Location: California levees under the jurisdiction of the Reclamation Board. 
Method: Guidance was developed from both engineering and environmental perspectives. Reclamation Board policy was to develop sound guidance that would ensure the stability and safety of the flood control systems, while allowing retention of riparian vegetation as long as such vegetation poses no threat to the flood control system.

Vegetation: Variety of trees, shrubs, and ground cover

Soil Properties: Levee material varied from sands to clay Observations/Results: No trees are permitted on the slopes of standard levee sections, but are permitted on the slopes of oversized levee sections, as long as they are spaced to allow visibility of levee toe and slope from the crown. Foliage of trees shall be pruned to minimum 5-ft height above the ground level. Allowable trees shall not exceed $50 \mathrm{ft}$ in height. Dead, decaying or leaning trees will be promptly removed. No trees will be allowed within $20 \mathrm{ft}$ of the levee crown so as not to interfere with flood fight activities. Thick, bushy-type shrubs that cannot be reasonably pruned will not be allowed on slopes. Non-woody ground covers and grasses are encouraged. Heights should be limited to $12 \mathrm{in}$. A 10-ft area at the levee toe is to be kept clear of vegetation for maintenance purposes. Naturally occurring vegetation is allowed on berms with minor restrictions.

Recommendations: N/A

Title: Vegetation and the structural integrity of levees: Results of field investigations

Author: MacDonald, A., D.H. Gray, T.G. Thomann, I.W. Blatz, and F.D. Shields, Jr.

Series/Source: Repair, Evaluation, Maintenance, Rehabilitation (REMR) Technical Note EI-M-1.3, Supplement 3, 1987

Peer-reviewed: Yes

Code: LEVVEG, RTSYST

\section{Abstract: N/A}

Objective(s): The objective was to present the preliminary results of a field study of the effects of vegetation on a Sacramento River levee. Current CE guidelines for levee maintenance and operation limit vegetation on levee embankments to sod-forming grasses, 2 to $12 \mathrm{in.} \mathrm{high,}$ to provide for structural integrity, inspectability, and unhindered floodfight access. These standards allow just enough vegetation on levees to 
provide soil-holding capacity. Such standards are justified by the absence of data that clearly establish the relationship between the properties of vegetation on levees (size of individual plants, plant density, and rooting structure, or the ecology of locally common species assemblages), and the structural impairment of levees.

Study Location: Sacramento area, American and Feather rivers, CA Method: To address the question of the amount and distribution of root material in levees, six 1-m-deep, L-shaped trenches were excavated on a levee along the Sacramento River between the confluences of the Feather and American rivers.

Vegetation: Herbaceous weeds and low shrubs, live and dead valley oaks (Quercus lobata), willow (Salix hindsiana), elderberry (Sambucus mexicana), and black locust (Robinia pseudoacacia)

Soil Properties: Fluvial sediments. Coarse to fine sand, with density range of 80 to $100 \mathrm{lb} / \mathrm{cu} \mathrm{ft}$, an average friction angle of $32 \mathrm{deg}$, and an average cohesion of $1.16 \mathrm{lb} / \mathrm{sq}$ in (psi).

Observations/Results: Data obtained from these excavations generally confirm rooting patterns noted in the horticultural and plant physiology literature. The majority of roots for shrubby species are confined to the top meter of the soil, although isolated roots may be found somewhat lower. Additional excavation around an oak stump showed a taproot of 0.5-m diam at $1.4 \mathrm{~m}$ below the levee surface, with lateral roots of $0.1 \mathrm{~m}$ still intact after more than 20 yr of decay. Numerous root casts were observed where the woody material was replaced with sand while the bark remained intact, suggesting that voids from roots do not generally persist in these sandy levees.

Stability analyses showed that the roots stabilized shallow, critical failure surfaces. Seepage analyses showed that, if the levee skin is less permeable than the core (i.e., if intuitively the permeability is proportional to the root-area ratio, RAR), the seepage discharge zone enlarged and greater exit gradients at the downstream face resulted. However, the actual effect of vegetation on the levee permeability is not known.

Recommendations: Exceptions to the Corps standards allow taller or woody vegetation on overbuilt levee sections only. In many areas of the country, however, these standards cause significant loss of riparian habitat and may be impractical for the local climatic conditions. Before revising the Corps standards, however, additional knowledge must be developed regarding vegetal components of the geotechnical system. 
Title: Pilot levee maintenance study

Author: Davis, L.C., S.I. Ito, and P.T. Zwanch

Series/Source: Bulletin 167. California Department of Water Resources, Sacramento, CA. 1967

Peer-reviewed: No

Code: LEVVEG

Abstract: The Pilot Levee Maintenance Study was conducted as a result of the levee stripping controversy in 1961 to test alternative methods of levee maintenance that could provide for multiple uses of levees, especially in the Sacramento-San J oaquin Delta. It is concluded that with proper vegetative management programs, certain Delta levees can be adapted and maintained to serve the needs of esthetics, recreation, and wildlife, as well as the primary purpose of flood control. Such vegetative management will require new techniques and additional authorization and monies.

The common practice of rock revetting certain Delta levee slopes above normal water levels may not be necessary with appropriate vegetative management for erosion control. The protections of levee slopes against erosion at and below normal water levels must be accomplished by the use of some form of revetment. The portions of newly constructed levees not faced with revetment should be planted to ground cover after construction. Ground cover species showing the best adaptability to the Delta are Tifway and Tifgreen bermuda, coastal bermuda, and creeping wildrye.

Existing ground cover can be preserved and managed to meet the needs of flood control, recreation, and wildlife. Planting programs can be undertaken where native vegetation cannot meet multiple-purpose requirements.

Vegetation need not be controlled on berms where channel capacity is not critical to flood-control needs. Trees and shrubs may be allowed on the levee slope in open patterns where berms do not exist on the waterside of the levee.

Preventive maintenance in the form of berm protection and timely repair of toe erosion of levees and berms can head off major reconstruction work, which involves removal of vegetation.

Present-day annual levee maintenance costs in state maintenance areas range from $\$ 800$ to $\$ 2,500$ per mile, depending on the location, type of section, and condition of the levee. The additional cost of maintaining a structurally sound, revetted levee that is free of major encroachments, if trees and shrubs were retained on the waterward slope, is estimated to be 
\$600 per mile per year, using specialized equipment. Such additional cost to make the levee suitable for other purposes should be borne by interests other than flood control.

Before multiple-purpose levee maintenance techniques are adopted for project levees, a number of problems including cost-sharing among beneficiaries, source of additional funding, authorization, and public access to levees, should receive further consideration by the Legislature.

Objective(s): The objective was to test techniques for vegetation management on levees.

Study Location: Several sites along the Sacramento River

Method: A pilot study was conducted.

Vegetation: Riparian species

Soil Properties: N/A

Observations/Results: The Pilot Levee Maintenance Study developed data and information that showed that native and other vegetation can be maintained compatibly with flood-control functions, and that preventive maintenance can avert periodic total reconstruction of levees.

Recommendations: The portions of newly constructed levees not faced with revetment should be planted to ground cover after construction. Ground cover species showing the best adaptability to the Delta are Tifway and Tifgreen bermuda, coastal bermuda, and creeping wildrye.

The common practice of rock revetting certain Delta levee slopes above normal water levels may not be necessary with appropriate vegetative management for erosion control.

Vegetation need not be controlled on berms where channel capacity is not critical to flood-control needs. Trees and shrubs may be allowed on the levee slope in open patterns where berms do not exist on the waterside of the levee.

\section{Title: Design and construction of levees}

Author: U.S. Army Engineer Research and Development Center, Waterways Experiment Station

Series/Source: Department of the Army, U.S. Army Corps of Engineers, Engineer Manual 1110-2-1913, April 2000 (supersedes EM1110-2-1913, 1978)

Peer-reviewed: N/A

Code: LVCONS 
Abstract: The purpose of this manual is to present basic principles used in the design and construction of earth levees. The term levee as used herein is defined as an embankment whose primary purpose is to furnish flood protection from seasonal high water and which is therefore subject to water loading for periods of only a few days or weeks a year.

Embankments that are subject to water loading for prolonged periods (longer than normal flood protection requirements) or permanently should be designed in accordance with earth dam criteria rather than the levee criteria given in this manual.

\section{Objective(s): N/A}

Study Location: N/A

Method: Engineer Manual

Vegetation: N/A

Soil Properties: N/A

Observations/Results: N/A

Recommendations: N/A

\section{Title: Flood control operations and maintenance policies}

Author: N/A

Series/Source: U.S. Army Corps of Engineers. 1996. ER 1130-2-530

Peer-reviewed: Yes

Code: LVFLCL, LEVVEG

\section{Abstract: N/A}

Objective(s): This regulation, in addition to ER 1130-2-500, establishes the policy for the operation and maintenance (O\&M) of USACE flood control and related structures at civil works water resource projects and of USACE-built flood protection projects operated and maintained by nonFederal sponsors.

\section{Study Location: N/A}

Method: Regulatory policy document

Vegetation: N/A

\section{Soil Properties: N/A}

Observations/Results: Establishes requirements and policy for inspection reporting and other O\&M responsibilities. No mention of levee 
vegetation, and no policy specifically listing inspection accessibility or monitoring requirements that address dam or levee vegetation topics.

Recommendations: N/A

Title: Root strength changes after logging in southeast Alaska Author: Ziemer, R.R., and D.N. Swanston

Series/Source: U.S. Department of Agriculture, Forest Service, Research Note PNW-306, December 1977, Portland, Oregon. 10 pp

Peer-reviewed: Yes

Code: RTSTAB, SLSTAB (VR)

Abstract*: A crucial factor in the stability of steep forested slopes is the role of plant roots in maintaining the shear strength of soil mantles. Roots add strength to the soil by vertically anchoring through the soil mass into failures in the bedrock and by laterally tying the slope together across zones of weakness or instability. Once the covering vegetation is removed, these roots deteriorate and much of the soil strength is lost.

Measurements of change in strength of roots remaining in the soil after logging at Staney Creek on Prince of Wales Island, southeast Alaska, indicate that loss of strength in smaller roots occurs rapidly for all species the first 2 yr. Western hemlock (Tsuga heterophylla (Raf.) Sarg.) roots are more resistant to strength loss than are Sitka spruce (Picea sitchensis (Bong.) Carr.) roots. By $10 \mathrm{yr}$, even the largest roots have lost appreciable strength.

Objective(s): The objective was to conduct a study to measure the strength change of roots remaining in the soil after logging.

Study Location: Staney Creek on Prince of Wales Island, southeast AK Method: Root samples were collected from remaining stumps of various ages and from uncut tree stands. The root samples were shipped to the laboratory for testing in the direct shear apparatus (described in Ziemer 1978).

Vegetation: Western hemlock (Tsuga heterophylla (Raf.) Sarg.) and Sitka spruce (Picea sitchensis (Bong.) Carr.)

\section{Soil Properties: N/A}

Observations/Results: Loss of strength in smaller roots occurs rapidly for all species during the first 2 years. Western hemlock (Tsuga heterophylla (Raf.) Sarg.) roots are more resistant to strength loss than 
are Sitka spruce (Picea sitchensis (Bong.) Carr.) roots. By 10 years, even the largest roots have lost appreciable strength.

\section{Recommendations: N/A}

* Formal permission not required. Covered under Fair Use in Title 17 of the US Code.

Title: Effects of land management on soil mass-movement Author: Sidle, R.C., A.J . Pearce, and C.L. O'Loughlin Series/Source: In Hillslope Stability and Land Use. Water Resources Monograph Series 11, American Geophysical Union, Washington, DC. pp. 140. 1985.

Peer-reviewed: Yes

Code: SLSTAB(VR)

Abstract*: Timber harvesting is a major land management practice that can affect hillslope stability by (1) reducing root reinforcement because of root-wood deterioration, site disturbance, and introduction of different plant species and (2) temporarily increasing water inputs and soil moisture because of reduced evapo-transpiration, changes in volume and rate of snowmelt, and overstory canopy modifications.

Objective(s): The objective was to review findings in the scientific literature with regard to the impact of tree removal on the slope stability and the frequency of landslides.

\section{Study Location: N/A}

Method: Literature review

Vegetation: Trees (non-specific)

Soil Properties: N/A

Observations/Results: Widespread removal (clear-cutting) increases the frequency and extent of slope failures. The paper examines the effect of partial or selective cuts that leave part of the tree canopy intact. Landslide frequency was found to increase only slight as overstory crown cover was reduced from $100 \%$ to $11 \%$; but for crown cover reduced below $11 \%$, a major increase in slope failures occurs. In contrast to these findings, for crown covers less than $80 \%$, landslide occurrence appears to be more sensitive to reductions in shrub cover, which indicates the importance of woody, understory vegetation in stabilizing slopes. 
Recommendations: Greater use should be made of partial or selective cutting (as opposed to clear-cutting) to minimize stability problems and slope failures. Timber harvesting options that preserve the integrity of understory species should be considered on potentially unstable sites.

* Sidle, R.C., A.J . Pearce, and C.L. O'Loughlin. Effects of land management on soil mass-movement. In Hillslope Stability and Land Use. Water Resources Monograph Series 11. Copyright [1985] American Geophysical Union. Reproduced/modified by permission of American Geophysical Union.

Title: Creep movement and soil moisture stress in forested vs. cut-over slopes

Author: Gray, D.H.

Series/Source: Report prepared for the National Science Foundation, Grant No. ENG 74-0247, Dept. Civil Engineering, University of Michigan, 137pp (1977)

Peer-reviewed: No

Code: SLSTAB(VR)

\section{Abstract: N/A}

Objective(s): This report describes the results of 8 years of creep monitoring and soil moisture stress measurements in forested and clearcut slopes. The objective was to examine evidence for a cause and effect relationship between clear-cutting and accelerated mass erosion in terms of indicators such as soil moisture stress and creep movement in forested vs. clear-cut slopes.

Study Location: Instrumented sites on steep mountain slopes of the Cascade Range in Central OR; the Klamath Mountains of Northern CA; and the North Cascade Range of WA

Method: Accelerated creep rates (that can result in increased rates of mass-erosion) are generally associated with wet soil conditions (low soil moisture suctions). The soil moisture regime in turn is affected by the presence or absence of tree cover. Accordingly, two types of creep rate and soil moisture monitoring studies were established at the field sites, viz., (1) "side-side" comparisons of forested and adjacent cutover areas and 
(2) "before and after" comparisons at a single site, initially forested and subsequently clear-cut.

Vegetation: Primarily coniferous (evergreen) trees such as Douglas fir with varying amounts of western hemlock, western red cedar, and sugar pine together with a few hardwood species such as big leaf maple

Soil Properties: Slopes with relatively uniform mantle of residual soil ( 5 to $20 \mathrm{ft}$ thick) overlying an inclined bedrock contact. Soil composition and properties were variable from site to site but had sufficient clay content so that measurable down slope creep movement could be detected and measured.

Observations/Results: Removal of slope vegetation (clear-cutting) tended to produce wetter conditions (lower soil moisture suction) in the slopes that were instrumented with tensiometers and/ or piezometers. The pore water pressure response was plotted as a function of the three-month antecedent rainfall for six sites in a watershed in central Oregon (that was initially forested and then clear-cut). The pore water tension (suction) curve was always higher for the sites in a forested condition except at relatively high antecedent rainfall when the two curves tended to merge. Wetter conditions were consistent with observed increases in creep rate at the Oregon sites. Soil moisture stress measurements were not conducted at the other locations because of access, staffing, and time constraints. Recommendations: Creep movement is also strongly influenced by precipitation patterns, which likewise affect the moisture regime in a slope. Unfortunately, the post clear-cutting monitoring period at the Oregon sites coincided with several years of drought, which tended to subdue or limit antecedent rainfall at different points in time. Accordingly, monitoring of these sites should be continued during wetter years to observe creep response and soil moisture stress when antecedent rainfall is higher.

Title: A study of embankment performance during overtopping Author: Gilbert, P.A., and S.P. Miller

Series/Source: Technical Report GL-91-23. Department of the Army, Waterways Experiment Station, Corps of Engineers: 1-96. 1991

Peer-reviewed: N/A

Code: SOILER

Abstract: N/A 
Objective(s): This study was undertaken to determine how embankments behave when overtopped, to predict overtopping performance of different types of embankments and to recommend defensive measures that would increase the durability of an overtopped embankment. An experience-oriented approach was taken. Pertinent literature was reviewed. Prototype dams subjected to overtopping, centrifuge modeling of overtopping embankments, and numerical modeling techniques are described. The objective was to (a) determine how embankments behave when overtopped and based on this knowledge, predict overtopping performance of embankment types (e.g., earthen, rock fill, etc.) and (b) recommend defensive measures that would increase the durability of an overtopped embankment.

Study Location: Twenty-eight dams in United States; information on overtopping taken from literature.

Method: Literature review

Vegetation: N/A

Soil Properties: N/A

Observations/Results: The damaging effect of overtopping water is directly related to the head (height) of water above the crest of the embankment. Vegetation cover increased the erosion resistance by providing an initial protective cover and increasing the (apparent cohesive) strength of the surface of the downstream slope by root system reinforcement.

Recommendations: N/A

Title: Resistance due to vegetation

Author: Fischenich, C.

Series/Source: ERDC Technical Note TN-EMRRP-SR-07, 2000. 9 pp.

Peer-reviewed: Yes

Code: VEGMOD, LVFLCL

\section{Abstract: N/A}

Objective(s): Drag is generated when fluid moves through vegetation. The drag creates velocity gradients and eddies that cause momentum losses. These losses are significant for a wide range of flow conditions, and 
existing techniques for the prediction of resistance do not take these into account, leading to underpredictions of resistance.

Concepts of drag were employed to formulate two new resistance relations for cases when dense vegetation is present in the floodway for unsubmerged and submerged vegetation.

\section{Study Location: N/A}

Method: Mathematical development of steady-state uniform flow equations for unsubmerged and submerged vegetation.

Vegetation: N/A

Soil Properties: N/A

Observations/Results: Flow resistance (drag) equations were developed that are useful when analyzing flow regimes through unsubmerged vegetation (trees, brush, etc.) and submerged vegetation (trees, brush, etc.). Vegetation area and density are critical elements needed to define the equations' applicability.

\section{Recommendations: N/A}




\section{Books}

\section{Title: Biotechnical slope protection and erosion control}

Author: Gray, D.H., and A.T. Leiser

Publisher: Krieger Publishing Company, 1982. Malabar, FL

Peer-reviewed: No

Code: BKSTAB, SOILER

\section{Abstract: N/A}

Objective(s): This book presents the principles of erosion, engineering, and horticulture to provide the advantages and applications of the interdisciplinary approach to slope protection and control. Biotechnical slope protection entails the implementation of mechanical elements in combination with biological elements to arrest and prevent slope failures and erosion. Both biological and mechanical elements must function together in an integrated and complementary manner. Principles of statics and mechanics are used to analyze and design biotechnical slope protection systems; so too must the principles of horticulture and plant science be employed.

\section{Study Location: N/A}

Method: Principles of statics, mechanics, horticulture, and plant science are used to analyze and design biotechnical slope protection systems.

Vegetation: N/A

\section{Soil Properties: N/A}

Observations/Results: N/A

Recommendations: Biological and mechanical elements must function together in an integrated and complementary manner to prevent and arrest slope failures and erosion.

Title: Bioengineering for land reclamation and conservation Author: Hugo Schiechtl

Series/Source: University of Alberta Press, 1980

Peer-reviewed: No

Code: LEVVEG 
Abstract*: On this earth there are a few places where man has not altered the vegetation natural cycles of growth, destruction and regeneration. Now that they are becoming rare, these wilderness areas are more precious to us and are helping us to see that natural flora (and fauna) in all its complexity and variety is man's best ally if he is not to devastate the planet. Man must learn to protect himself and his environment by calling in nature as his working partner. For instance, when safeguarding engineered earthworks, it is more sensible to plant grasses, shrubs, and trees to hold and protect the soils than to use dead materials, which are not only less effective but ugly. Man must learn how nature maintains her balance and work with her rather than fight against her.

Objective(s): The purpose of this book is to show how the products of scientific and technical research can be integrated with natural materials to obtain effective and economic methods of protecting, restoring, and improving our environment. This book also aims at helping co-operation between the civil engineer and the bioengineer, so that they may attain a greater appreciation of each other's discipline.

\section{Study Location: N/A}

\section{Method: N/A}

\section{Vegetation: N/A}

\section{Soil Properties: N/A}

Observations/Results: It is more sensible to plant grasses, shrubs, and trees to hold and protect the soils than to use dead materials, which are not only less effective but ugly.

\section{Recommendations: N/A}

* Reprinted from Bioengineering for land reclamation and conservation, Hugo Schiechtl, 1980, with permission from University of Alberta Press.

\section{Title: Root properties for design of slope stabilization}

Author: Wu, T.H., M.M. Riestenberg, and A. Flege

Series/Source: 1995. Vegetation and slopes: Stabilization, protection, and ecology. D.H. Barker, ed.

\section{Peer-reviewed: No}

Code: RTSTAB, SLSTAB

\section{Abstract: N/A}


Objective(s): The paper focuses on giving data on root properties which could be used to stabilize slopes and also summarizes criterion for slope stability.

\section{Study Location: Ohio}

Method: The pore pressure and root area of the black locust at critical depth needed to be approximated and the safety factor needed to be computed in order to assess the possibility of using vegetation for slope stabilization. Soil type and the way in which the trees were planted were also taken into effect.

Vegetation: Black locusts (Robinia pseudoacacia) and white ash (Fraxinus Americana)

\section{Soil Properties: N/A}

Observations/Results: Results showed that planting black locust and white ash together produces a favorable slope stability contribution depending on the critical slope stability slip surface depth.

Recommendations: N/A

Title: Roots of forest trees (Die Wurzeln der Waldbaume German publication title)

Author: Kostler, J .N., and E. Bruchner

Series/Source: Blackwell Verlag GmbH, Berlin/ Germany, 1968.

Hamburg and Berlin, pp. 1-740

Peer-reviewed: N/A

Code: RTSTAB, RTSYST

Abstract*: Permission to publish abstract was not obtained.

Objective(s): A large number of books have been written on the trunks and crowns of trees, but the roots have relatively little in the way of understanding. The book is written to describe roots, present necessary background to study roots (digging, pertinent aspects, etc.), use radioisotopes to understand plant functions. The objective is to produce a guide and handbook for researchers to undertake the study of roots.

Study Location: Forests of Germany

Method: A compendium of known information and literature on roots supplemented with the knowledge and research of the authors.

Vegetation: Spruce (Picea abies Mill), fir (Abies alba Mill), pine (Pinus silvestris L.), Weymouth pine (Pinus strobus L.), larch (Larixdecidua 
Mill), J apanese larch (Larix leptolepis Gord.), Douglas fir (Pseudotsuga taxifolia Brit.), and other types of conifer trees and deciduous trees.

\section{Soil Properties: N/A}

\section{Observations/Results:}

- Only a limited number of types of trees were taken into consideration.

- The number of individual trees so far examined and analyzed is sufficient for general conclusion only for a few species.

- All the trees on which research had been carried out were picked up from the economically grown forests.

- All researches are directed to a single tree.

- Almost the entire investigations were limited to the morphology of the roots.

- In connection with the morphological consideration, attention has been mainly directed to the rough and coarse roots and thus the fine roots are necessarily described very briefly.

Recommendations: Continue the study of tree roots.

* Reprinted from Blackwell Verlag GmbH, Berlin/Germany, J .N. Kostler, and E. Bruchner, Roots of forest trees (Die Wurzeln der WaldbaumeGerman publication title), Hamburg and Berlin, 1-740, 1968, with permission from Blackwell Verlag $\mathrm{GmbH}$.

\section{Title: Soil-root interaction and slope stability}

Author: Wu, T.H., A.J . Watson, and M.A. El-Khouly

Series/Source: Ground and Water Bioengineering for Erosion Control and Slope Stabilization, D. H. Barker, A.J . Watson, S. Sombatpanit, B. Northcutt, and A.R. Maglinao, ed., Science Publishers, Inc., Enfield, NH, USA, 2004. 184-192

Peer-reviewed: No

Code: RTSYST, RTMODL, SLSTAB, SOILER

Abstract: Permission to publish abstract was not obtained.

Objective(s): The objective was to review results of several recent studies and show how root morphology may control the failure mode and choice of soil-root interaction model to be used for evaluation of root contribution to shear strength of soils. 


\section{Study Location: N/A}

Method: Pullout tests were performed by applying a tensile force to the end of a root. The force was increased until failure occurred either by shear or tensile modes.

Vegetation: Sugar maple (Acer saccharum), white ash (Fraxinus americana), kanuka (Kunzea ericodes), pine (P. radiate), and Hibiscus macrophyllus.

\section{Soil Properties: N/A}

Observations/Results: Pullout tests were performed on several species whose root system consisted of a large taproot. Most of the failures were due to tensile failure of the taproot at some point below the loaded end. In a few tests, failure occurred in the soil and the entire root system was pulled out. The root systems in the study did not fail by interface shear failure. With plate-shape or heart-shape root systems, many of the roots would not fail in tension as shear displacements up to $40 \mathrm{~cm}$.

Recommendations: Results of effort are tentative, further studies are needed on root morphologies and soil-root interaction.

\section{Title: Methods of studying root systems}

Author: Bohm, W.

Publisher: Ecological Services No. 33, 1979. Berlin; Springer-Verlag

Peer-reviewed: No

Code: RTSYST, RTSTAB

Abstract: Permission to publish abstract was not obtained.

Objective(s): This book gives a survey of existing field methods (1979) in ecological root research and discusses the need to be aware of and study root systems by other disciplines.

Study Location: N/A

Method: This book presents a multitude of field methods to study roots and shoots, from trenching, auguring, profile wall studies, root washing, root measurement, etc. It is written primarily for the botanical sciences (such as agriculture, horticulture, and forestry) for learning and applying proven/ practical methods of root and shoot studies. The author's comments state the broad application of root studies to many disciplines.

Vegetation: N/A

Soil Properties: N/A 


\section{Observations/Results: N/A}

Recommendations: The study of roots using modeling techniques will be a future endeavor of use to agricultural, horticultural, and forestry researchers.

Title: Vetiver grass technology for land stabilization, erosion and sediment control in the Asia-Pacific region

Author: Truong, P.N.V.

Series/Source: Ground and Water Bioengineering for Erosion Control and Slope Stabilization, D. H. Barker, A.J . Watson, S. Sombatpanit, B. Northcutt, and A.R. Maglinao, ed., Science Publishers, Inc., Enfield, NH, USA, 2004. 123-134

Peer-reviewed: N/A

Code: SLSTAB, SOILER, LEVVEG

Abstract: Permission to publish abstract was not obtained.

Objective(s): The objective was to present advantages and characteristics of vetiver grass as a bioengineering tool.

Study Location: Southeast Asian countries

Method: Research compilation

Vegetation: Vetiver grass species (Vetiveria zizanioides L. and V. nigritana)

Soil Properties: Varied soil pH, soil toxic metal concentrations, and dry and drought conditions

Observations/Results: Vetiver characteristics: Extremely deep and massive finely structured root system, capable of reaching a depth of 2 to $3 \mathrm{~m}$ in the first year of growth. This extensive root system binds the soil, is very difficult to dislodge, and is extremely drought tolerant. The stiff and erect stems can withstand relatively deep water flow $(0.6$ to $0.8 \mathrm{~m})$. Individual plants placed close together form dense hedging, which can divert run-off water, reduce flow velocity, and therefore can create a very effective sediment filter. New shoots emerge from the base and thus the grass can withstand traffic and heavy grazing pressure. New roots are developed from nodes when buried by trapped sediments. If trapped sediment is not removed, vetiver will continue to grow with the new ground level, eventually forming terraces. It is tolerant to extreme climatic variations, such as extreme temperatures $\left(-14^{\circ} \mathrm{C}\right.$ to $\left.55^{\circ} \mathrm{C}\right)$, prolonged 
drought, flooding, and submergence. The range tolerance of soil $\mathrm{pH}$ (3.0 to 10.5) is broad. It has high tolerance to soil salinity, sodicity, and acid sulphate. It is also tolerant to toxic levels of aluminum, manganese, arsenic, cadmium, chromium, nickel, copper, mercury, lead, selenium, and zinc.

Recommendations: Vetiver grass is a very effective and low-cost bioengineering tool. To provide an effective support for engineering structures, the success requires quality planting material, correct planting techniques, and application design.

Title: Biotechnical and soil bioengineering slope stabilization Author: Gray, D.H., and R.B. Sotir Publisher: J ohn Wiley and Sons, Inc., NY, 1996

Peer-reviewed: No

Code: SLSTAB

\section{Abstract: N/A}

Objective(s): This book introduces the engineer to some aspects of horticulture, and the plant specialist to some concepts from mechanics. Biotechnical stabilization uses mechanical elements in combination with biological elements to provide slope protection and erosion control, and prevent slope failure. On the other hand, soil bioengineering can be regarded as a specialized area of biotechnical stabilization. Soil bioengineering is somewhat unique in that roots and stems serve as the main structural and mechanical elements in a slope protections system.

\section{Study Location: N/A}

\section{Method: N/A}

\section{Vegetation: N/A}

Soil Properties: N/A

Observations/Results: Soil bioengineering and biotechnical techniques are described.

\section{Recommendations: N/A}

Title: Influence of vegetation on the stability of slopes Author: Gray, D.H. 
Series/Source: Vegetation and slopes: Stabilization, protection, and ecology, 1995. D.H. Barker, ed.

Peer-reviewed: No

Code: LEVVEG, SLSTAB (VR)

\begin{abstract}
Vegetation affects both the surficial and mass stability of slopes in significant and important ways. A number of hydro-mechanical mechanisms can be identified that explain the protective role of vegetation. These range from mechanical reinforcement and restraint by the roots to modification of slope hydrology as a result of rain drop interception by the foliage and soil moisture extraction by the process of evapo-transpiration.

A tight, dense cover of grass or herbaceous vegetation provides one of the best protections against surficial rainfall and wind erosion. Conversely, deep rooted, woody vegetation is more effective for mitigating or preventing shallow, mass stability failures. The loss or removal of slope vegetation can result in either increased rates of erosion or higher frequencies of slope failure. This cause and effect relationship can be demonstrated convincingly as a result of many field and laboratory studies reported in the technical literature.
\end{abstract}

Objective(s): The objective was to give an overview of vegetative slope stabilization (interception, restraint, retardation, and infiltration).

\title{
Study Location: N/A
}

\section{Method: N/A}

Vegetation: N/A

\section{Soil Properties: N/A}

Observations/Results: Slope stability can be improved by shoots bending over and covering the surface and/ or reducing the water velocity adjacent to the soil/ water interface, while below ground roots physically restrain or hold soil particles in place. In the case of slope stability, the influences of vegetation are root reinforcement, soil moisture depletion, buttressing and arching, and surcharge. The primary detrimental influence on mass stability associated with woody vegetation is the external loading and the danger of overturning or uprooting of vegetation in high winds or currents. Interesting approach to mitigate the adverse effects of vegetation on slope stability is the practice of coppicing. Coppicing is timber harvesting or pruning to produce new trees from old stumps and trunks/limbs. The removal of vegetation from slopes can cause up to 100 times the mass wasting devastation of pre-harvesting due 
to slope disturbance during clear cutting. Vegetation affects shallow mass stability mainly by increasing the shear strength of the soil via root reinforcement. Infinite slope modeling is appropriate for analyzing shallow slides in which the failure surface is planar and parallel to the slope over most of its length. Infinite slope modeling is generally applicable to sandy slopes which are subject to shallow sloughing.

Recommendations: Vegetation improves the resistance of slopes to both surficial erosion and mass wasting. Conversely, the removal of slope vegetation tends to accelerate or increase slope failures. A tight, dense cover of grass or herbaceous vegetation provides one of the best protections against surficial rainfall and wind erosion. Conversely, deep rooted, woody vegetation is more effective for mitigating or preventing shallow, mass stability failures.

* Formal permission not required. Covered under Fair Use in Title 17 of the US Code.

Title: Tree species performance and slope stability

Author: Watson, A., M. Marden, and D.R. Rowan

Series/Source: Vegetation and slopes: Stabilization, protection, and ecology. 1995, D.H. Barker, ed.

Peer-reviewed: No

Code: SLSTAB, RTSYST

Abstract*: Root systems of 13 radiata pine (Pinus radiate D. Don) and 15 kanuka (Kunzia ericoides), representing three age classes of trees from the East Coast region, North Island, New Zealand, were hydraulically excavated. Each root system was weighed and measured to obtain comparative information on the changes in root architecture (morphology) and root biomass with time. For both species, rates of decline in root-wood strength were determined and compared, along with tree root performance, against the probability of major storm events.

Annual rate of root production of kanuka (2.2 $\mathrm{t} / \mathrm{ha}$ ) exceeded that of radiata pine ( $1.1 \mathrm{t} / \mathrm{ha}$ ) for the first 9 years of growth. Live kanuka rootwood is approximately twice the strength (34.2 MPa) of that of radiata pine (17.6 MPa), and after felling took twice as long to lose its soil reinforcement properties. It was estimated that if kanuka was replaced by another tree species, there would be a 3-year period of inadequate tree 
root protection, which represented a $60 \%$ chance of a major storm event. Similarly, radiata pine would leave a 5-year period of vulnerability, and an $80 \%$ probability of a major storm.

Objective(s): The objective was to evaluate the changes in root architecture and root biomass with time.

Study Location: New Zealand

Method: The excavated trees were found on steep slopes in which the sluiced material could easily flow away from the site of excavation. A high pressure jet was used to remove the soil from the roots; and roots with diameters less than $2 \mathrm{~mm}$ were not thought to increase slope stability and were not regarded. To make sure that the deepest vertical roots could be seen, the sluicing began downhill from the stump and moved upwards, revealing the roots. As the roots were revealed, they were placed in the correct position and their architecture was measured and mapped. To obtain the radial root distribution, a protractor was fastened to the stump of each uncovered root system and the roots were recorded in each 45-deg segment. The roots were dried and the percent moisture lost was recorded and they were weighed and measured.

Vegetation: Radiata pine (Pinus radiate D. Don) and kanuka (Kunzia ericoides)

Soil Properties: Hard fine-grained sandstones and clay-rich shales Observations/Results: The vertical roots of the kanuka trees were inadequately developed and had taproots, which were powerfully tapered and often branched; and of the radiata pines, the two younger age groups had good vertical root growth. In the early years of the kanuka, it shows a better rate of lateral root growth, but as the trees age, the radiata pine dominates. Although kanuka root systems are individually smaller than radiata pine root systems, the yearly root production rate of kanuka surpasses the radiata pine. Tests also showed that the root-wood of a live kanuka has roughly twice the tensile strength compared to the radiata pine. It was decided that the more constructive tree, in its initial years, would be the kanuka.

\section{Recommendations: N/A}

* Formal permission not required. Covered under Fair Use in Title 17 of the US Code. 


\title{
Title: Use of vegetation in civil engineering
}

Author: Coppin, N.J ., and I.G. Richards

Series/Source: Construction Industry Research and Information

Association (CIRIA). 1990

Peer-reviewed: No

Code: SLSTAB

\begin{abstract}
This outcome of a CIRIA project surveying published information and previous experience of the behaviour and applications of natural vegetation as a means of stabilizing and enhancing the performance and visual appeal of civil engineering works is reported. The various types of vegetation, their selection and establishment in a newly created soil environment are considered, followed by a review of procedures for site preparation and the beneficial effects of vegetation. Typical applications comprise slope stabilization, runoff erosion control, watercourse and shoreline protection, wind erosion control, shelter belts for reduction of noise and wind velocity and the control of runoff volume from small catchments. The presentation combines theoretical and practical aspects of the use of vegetation.
\end{abstract}

Objective(s): The objective was to introduce a range of bioengineering applications relevant to the UK construction industry. Vegetation is widely used in civil engineering as a way of reducing the visual impact of civil engineering works and enhancing the quality of the landscape. It can also perform an important engineering function because of its direct influence on the soil, both at the surface, protecting and restraining the soil, and depth, increasing the strength and competence of the soil mass. Vegetation can also very significantly affect soil moisture. All these effects may be adverse or beneficial, depending on the circumstances, and most have direct engineering relevance.

\section{Study Location: N/A}

Method: N/A

\section{Vegetation: N/A}

Soil Properties: Soil conditions are addressed from a slope stability and water-content perspective.

\section{Observations/Results: N/A}

Recommendations: N/A 
* Reprinted from Construction Industry Research and Information Association (CIRIA), No. B12/C708, N.J . Coppin, and I.G. Richards, Use of vegetation in civil engineering, 1990, with permission from CIRIA.

\section{Title: Vegetation and slope stability}

Author: Greenway, D.R.

Series/Source: Slope stability: Geotechnical engineering and geomorphology, M.G. Anderson and K.S. Richards, ed., J ohn Wiley and Sons, New York. Chapter 6: 187-225. 1987

Peer-reviewed: No

Code: SLSTAB (VR), RTSTAB

Abstract: Permission to publish abstract was not obtained.

Objective(s): An objective was to foster increased cooperation and exchange between agricultural and engineering disciplines when incorporating the effects of vegetation in slope stability analyses

Study Location: A case study is given for So UK Tree Study, Hong Kong Method: N/A

Vegetation: Grass, shrubs, and trees

Soil Properties: N/A

Observations/Results: The traditional assumption that vegetation growing on a slope has an indirect or minor effect on stability is not always correct, and for certain forested slopes with relatively thin soil mantles, it has been shown to be significantly in error.

Recommendations: N/A

Title: The way ahead-continuing and future developments in vegetative slope engineering or ecoengineering

Author: Barker, D.H.

Series/Source: Vegetation and slopes: Stabilization, protection, and ecology. 1995, D.H. Barker, ed.

Peer-reviewed: No

Code: SOILER, SLSTAB

Abstract: Permission to publish abstract was not obtained. 
Objective(s): The objective of this paper was to discuss findings and improvements in the interaction of slope processes and vegetation viewed by a civil-geotechnical engineer.

Study Location: N/A

Method: N/A

Vegetation: N/A

Soil Properties: N/A

Observations/Results: N/A

Recommendations: N/A

Title: Plant materials for river control and bank protection Author: Hathway, R.L.

Series/Source: Plant materials handbook for soil conservation, Volume

1: Principles and practices. Section 5, New Zealand National Water and

Soil Conservation Authority Water and Soil Misc. Publication 93, 1986.

C.W.S. van Kraayenoord and R.L. Hathaway, ed.

Peer-reviewed: Yes

Code: SOILER, BKSTAB

Abstract: Permission to publish abstract was not obtained.

Objective(s): Discussion of different plant types useful for New Zealand river control and bank protection.

Study Location: New Zealand

Method: Compilation of practices regarding different species and their applications on riverbanks

Vegetation: Willow species (Salix), poplars (Populus deltoides), alder (Alnus glutinosa), and tamarisk (Tamarix chinensis)

Soil Properties: N/A

Observations/Results: Applicability for specific species is discussed.

Recommendations: Specific recommended species are listed for applications to "heavy bank protection and channel training," "light bank protection," and "wavelap protection" in both freshwater and saltwater environments. Maintenance recommendations are listed including coppicing and spraying. 


\section{Newspaper/ Internet Articles}

Title: Corps of Engineers: 37 California levees at risk of failing Author: Beverly Lumpkin, Associated Press writer Series/Source: Oakland Tribune, CA. 2/ 1/ 2007

http://cbs5.com/local/local_story_032165541.html

Peer-reviewed: No

Code: LEVVEG

\section{Abstract: N/A}

Objective(s): The objective was to discuss levees across the nation that are unacceptable, pose safety risks, and need repairing. According to a list released Thursday by the U.S. Army Corps of Engineers, thirty-seven levees from Chico to Santa Maria are at risk of failing. The levees have one or more problems and, according to the Corps, California (with 37 suspect levees) and Washington state (with 19) led the list for all states.

\section{Study Location: N/A}

Method: N/A

Vegetation: N/A

Soil Properties: N/A

Observations/Results: N/A

Recommendations: N/A

Title: A way to save the levee habitat? A UC Davis study finds plants benefit flood safety

Author: Weiser, M.

Series/Source: The Sacramento Bee (sacbee.com). 7/ 16/2007. 5 pgs.

Peer-reviewed: No

Code: LEVVEG

Abstract*: This is a newspaper article so there is no abstract.

Objective(s): The objective was to show that trees and shrubs may actually improve flood safety. 
Study Location: University of California (UC), Davis, Amorocho Hydraulics Laboratory

Method: The tests were conducted in a flume that simulated a floodway. Giant pumps were used to move water across a field of willow shrubs anchored under water. Water flow and plant movement were monitored by sensors and cameras.

Vegetation: Willow shrubs

Soil Properties: N/A

Observations/Results: The study found that when the water moves over the willows at high velocity, the shrubs flatten and thereby protect the soil from erosion. The willows also provide a refuge for young Chinook salmon.

\section{Recommendations: N/A}

* Formal permission for publication not required, but bibliographic link is requested. http://www.sacbee.com/101/story/274820.html

\section{Title: Tree-laden levees flunk federal inspection}

Author: Weiser, M.

Series/Source: The Sacramento Bee, April 7, 2007. 3 pages

Peer-reviewed: No

Code: LEVVEG

Abstract*: A national directive by the U.S. Army Corps of Engineers could devastate scenery and wildlife habitat in California by forcing Central Valley flood control officials to chop down virtually all trees and shrubs on their levees. A compromise is being negotiated, but unless the policy changes, tree-lined banks on 1,600 miles of levees in the Valley could be transformed into barren culverts within a year.

It requires levees to be cleared of all vegetation to preserve channel capacity and allow access for inspection and repair. The policy is largely based on conditions on the Mississippi and Missouri rivers, where ample wildlife habitat exists between levees and the water's edge. But in California, levees were built close together after the Gold Rush to create high water velocities to flush mining debris out of rivers. In most areas, there is little space between levees and the water, and vegetation on levees provides the only riverside habitat. California has lost $97 \%$ of its riparian habitat since the arrival of Europeans. 
Congress ordered a levee review after Hurricane Katrina. In February 2007 when the Corps released a national list of levees that failed maintenance standards, the directive first came to light. Riverside habitat is essential to a variety of wildlife. The Corps' maintenance manual for the Sacramento River flood control system actually encourages planting vegetation on levees.

The Corps is drafting a new national standard to allow some vegetation on levees. Mostly very small brush, very small trees in some circumstances, could remain. Rotting roots left behind could provide a path for seepage that could compromise the levee. Until the new standard is released, local Corps officials are telling levee districts not to cut trees.

\section{Objective(s): N/A}

Method: N/A

Vegetation: N/A

Soil Properties: N/A

Observations/Results: N/A

Recommendations: N/A

* Formal permission for abstract publication not required, but bibliographic link is requested.

www.safca.org/documents/Pre-symposiummediacoverage.pdf

\section{Title: Tree removal on Anacostia begins}

Author: Nemeth, S.

Series/Source: Gazette.Net, Maryland Community Newspapers Online, April 12, 2007, 2 pages www.gazette.net/storis/041207/hyatnew184530_32320.shtml

Peer-reviewed: N/A

Code: LEVVEG

\section{Abstract: N/A}

\section{Objective(s): N/A}

Study Location: Prince George County along the Anacostia River, MD

Method: N/A

Vegetation: N/A

Soil Properties: N/A

Observations/Results: The Army Corps of Engineers said that the levees were at risk if the vegetation was not removed. The Army Corps of 
Engineers annually inspects the levees as part of a partnership with the Prince George's County Dept. of Public Works and Transportation. In the past, the levees passed inspections, but now trees and roots must be at least $15 \mathrm{ft}$ from the levee.

\section{Recommendations: N/A}

\section{Title: Fixing levees isn't easy or cheap}

Author: Heath, B., P.O’Driscoll, and E. Bazar

Series/Source: USA Today, J anuary 1, 2007

http://www.usatoday.com/news/nation/2007-02-01-levees_x.htm?csp=34

Peer-reviewed: No

Code: LEVVEG, LVSTAB

Abstract: Permission to publish abstract was not obtained.

Objective(s): The objective was to examine levee reaches for vegetation root invasions and wildlife burrows that pose threats to the integrity of levees.

\section{Study Location: N/A}

Method: N/A

Vegetation: Trees (cottonwoods) and brush

Soil Properties: Often clayey soils to impede the percolation of water into levees

Observations/Results: Communities responsible for maintaining levees publicly identified as substandard by the federal government are racing to fix problems caused by years of neglect. Operators acknowledge that many of the problems stem from lax maintenance. One obstacle might prove more formidable than the levees themselves: money. In Macon, GA, a mile-long levee that protects a water treatment plant is considered substandard by the Corps because of trees and brush that have sprouted from it for years. In Albuquerque, the concerns are vegetation and maintenance of drains, not structural problems. In Erie Township, MI, a quarter-mile levee built after Lake Erie flooded in the 1970s is overgrown with brush and has been undermined by groundhogs. In other places, environmental rules have complicated efforts to clear brush, especially in places where vegetation has grown for a long time, and these areas are now habitats for endangered species. 
Recommendations: Investigate levees with uncontrolled vegetative growth and animal burrows

Title: Levee rules could doom hundreds of trees

Author: Bria, R.

Series/Source: Wilkes-Barre, Pennsylvania Times Leader, Web page

timesleader.com, $18 \mathrm{~J}$ anuary 2008

Peer-reviewed: No

Code: LEVVEG

Summary*: Feds say roots could damage the base of levees if trees are within $15 \mathrm{ft}$ of the levee base. New federal standards will require removal of hundreds of trees along the Susquehanna River levee system. As part of the new Federal levee safety standards, the U.S. Army Corps of Engineers has told the county to cut down all trees within $15 \mathrm{ft}$ of the base of the levee facing the river. The trees must be eliminated because they have the potential to erode the levee. The levee system was constructed in four sections and a major upgrade was completed about four years ago. The trees vary in height, with some in Hanover Township being older and larger trees.

"I don't think there's a major environmental impact cutting $15 \mathrm{ft}$ at the toe of the levee," said Vince Catrone, urban forester at the Penn State Cooperative Extension. "If it was $100 \mathrm{ft}$, I'd say, 'Geeze, we're taking a lot of trees."' "A tree that's probably $25 \mathrm{ft}$ off the levee could still have roots growing off the levee," Catrone said. "I mean, how did they arbitrarily come up with $15 \mathrm{ft?"}$

\section{Objective(s): N/A}

\section{Study Location: PA}

Method: N/A

Vegetation: N/A

Soil Properties: N/A

Observations/Results: N/A

Recommendations: N/A

* Reprinted from Wilkes-Barre, Pennsylvania Times Leader, webpage timesleader.com, R. Bria, Levee rules could doom hundreds of trees, 
18 J anuary 2008, with permission from Wilkes-Barre, Pennsylvania Times Leader.

Title: Botanical problems studied by applied geophysics

Author: Attia, Al Hagrey S., and R. Meissner

Series/Source: Online publication of the Deutschen Geophysikalische

Gesellschaft: http://www.dgg-online.de/mitteilungen/2004_2/

Botanicalproblemsstudiedbyappliedgeophysics.pdf

Peer-reviewed: No

Code: RTSYST, RTMODL

Abstract: Permission to publish abstract was not obtained.

Objective(s): This paper focused on characterizing root zones in the near surface unsaturated vadose zone, imaging internal structures of tree trunks, and studying their moisture by accomplishing experiments in the lab. Research was conducted within the European Union/German research projects WATERUSE/ GeoModel.

\section{Study Location: Germany}

Method: Geoelectric and radar (500 MHz) surveys were conducted on a 5-year-old isolated poplar tree root at Kiel University (Germany) in silty sand and clay soil. Geoelectric surveys were conducted on an oak tree root near Borken Germany in dry sandy soil. Geoelectric surveys were done on tree trunks of olive trees near Canosa, southern Italy, and tree trunks of peach trees in Portugal.

Vegetation: Roots of poplar and oak trees, tree trunks of olive and peach trees

Soil Properties: Various

Observations/Results: Location and variations of roots and their moisture with depth was observed using the geoelectric surveys and inversion modeling techniques. Moisture content of root zones was observed using radar techniques. Comparisons of the methods for root zones and tree trunks were discussed.

Recommendations: A new branch of geophysics called "bio-geophysics" seems to have been created. 


\section{Title: Forestry applications of radar remote sensing with} sensors in situ

Author: Pérez-Gracia, V., H. Lorenzo, and N. Diaz-Peñalver

Series/Source: Online publication of the website Close Range Remote

Sensing \& Photogrammetry Group of the University of Vigo (Spain).

http://webs.uvigo.es/grupotf1/research/forestsat.PDF

Peer-reviewed: No

Code: RTSYST

Abstract: Permission to publish abstract was not obtained.

Objective(s): Selected examples of in-situ radar sensors used in forestry applications are shown, including those that can be used to approximate a map of tree root systems.

Study Location: Barcelona, Spain

Method: Several measurements were performed in order to analyze the capability of the radar to study living tree trunks, detecting internal reflectors caused by humidity, damages, or plagues. These parameters were obtained from the study of anomalies recorded in radar data and from the differences in wave velocity. Measurements were performed in wattle and pine trees. The expected results were constant anomalies obtained while the antenna was moving along the trunk because of the healthy aspect of the trees. Velocities were measured in every studied case to compare the results and to determine the usual parameters of a healthy tree. The $1 \mathrm{GHz}$ and the $900 \mathrm{MHz}$ antennae were used in this study because of their high resolution and capacity suitable to the size of the studied objects.

Several measurements were also performed to analyze the capability of the radar survey to detect roots. Two antennae were used in the study: $1 \mathrm{GHz}$ and $900 \mathrm{MHz}$ center frequency antennae. They were selected because of the required resolution. A mesh of profiles near an isolated small wattle was designed. Radar data were acquired using two different polarization arrays for the transmitter and receiver antennae. The $900 \mathrm{MHz}$ dipoles were both fixed in a plastic box and it was not possible to make cross polarization surveys. The $1 \mathrm{GHz}$ antenna was just one dipole, which was used to transmit and receive the pulse.

Vegetation: Measurements were performed in wattle and pine trees (trunks and roots)

Soil Properties: N/A 
Observations/Results: The $900 \mathrm{MHz}$ antennae provided satisfactory radar records, but the $1 \mathrm{GHz}$ antennae provided more obscure records, possibly due to its low transmitter output.

Recommendations: N/A 


\section{Proceedings/ Briefings}

\section{Title: Factors affecting the stability and integrity of earthen levees - presentation \\ Author: Gray, D.H. \\ Series/Source: Vegetation Challenge Symposium, Sacramento, California, August 28, 2007. http://www.safca.org/LeveeVeg-SpeakerPanel.htm}

Peer-reviewed: No

Code: LEVVEG

Introduction*: Three major categories of levee failure/ damage mechanisms are listed in the Independent Levee Investigation Team final report (mass stability failures, surficial erosion, and hydraulic forces). Some twenty different mechanisms are listed under these categories. Woody vegetation plays little or no role in most of them. Of those potentially affected, vegetation plays a beneficial role in most and an adverse role in only a few. The roots of woody vegetation growing on a levee reinforce the soil mantle and significantly increase the resistance to shallow, sloughing failures. These effects are documented in [USCOE (1991). The Effects of Vegetation on the Structural Integrity of Sandy Levees. Technical Report REMR-EI-5, Dept. of the Army, WES, U.S. Corps of Engineers, $117 \mathrm{pp}$ ]. Modest improvements also occur in the case of deeper seated, rotational failures passing through or near the toe of a levee. The main adverse effect of trees occurs in the case of tall, isolated trees growing on a levee that are susceptible to windthrow or overturning. This problem can be mitigated, however, by coppicing which effectively lowers the crown and reduces the "sail effect" or overturning moment.

Vegetation improves resistance to scour and erosion that can occur during overtopping- see [Gilbert, P.A. and Miller, S.P. (1991). A study of embankment performance during overtopping. Tech Rept GL-91-23, Dept. of the Army, WES, Corps of Engineers, Vicksburg, MS, 96 pp]. Vegetation, particularly thickets of supple, woody stems of young trees like willows that bend over and cover the levee face during high flows, likewise armor and protect the levee against lateral or tangential surface erosion. The main adverse effect of vegetation arises in the case of isolated, tall, rigid trees that can promote turbulence and erosion around their base. 
Objective(s): The objective was a discussion of levee failure mechanisms, including the role of vegetation.

\section{Study Location: N/A}

\section{Method: N/A}

\section{Vegetation: N/A}

\section{Soil Properties: N/A}

Observations/Results: Relict tree root holes provide preferential seepage paths; Low, homogeneous embankments or dams (without internal drains or filters) are particularly vulnerable to hydraulic fracturing following the first hydraulic loading. Low embankments tend to have lower vertical stresses to counteract internal pore water pressures. Levees along stream channels fall into this category; woody plant roots reinforce levee soils and increase shear strength in a measurable manner. A shear strength increase or "root cohesion" can be estimated from the root biomass per unit volume of soil or alternatively from the root area ratio. As observed from the New Orleans levees after Katrina, the presence or absence of trees would have little or no effect in preventing the occurrence of hydraulic gradient-induced seepage failure; however, a hydraulic blowout could cause a tree growing in the vicinity of the inboard toe to topple over. The tree (at the London Canal location) did not cause the problem...the reinforcing effect of the tree roots may even have delayed the onset of the quick condition that was primarily responsible for the levee failure. Surcharge (weight of the tree) can either have a beneficial or adverse influence depending on slope inclination, soil friction angle, position of ground water table, and location of tree on the slope. Root reinforcement probably provides the most important and significant beneficial influence. The results of numerous theoretical, field, and laboratory studies support this conclusion. Numerous research studies have shown that widespread removal (clear cutting) of woody vegetation from slopes increases the rate and extent of slope failures.

Recommendations: The sail effect (tree crown exposure to windinduced overturning moment) can be greatly reduced by a pruning procedure known as coppicing in which the tree is cut at approximately breast height above the ground surface. Multiple, smaller and supple shoots sprout from the cut; the crown is effectively lowered and the overturning moment greatly reduced. Many tree species (including eucalyptus) lend themselves to coppicing.

A whole range of strategies and management techniques can be invoked to maximize the benefits and minimize the limitations of vegetation on levees. Even when removal is selected as a necessary option, 
there are recommended procedures to avoid potential hazards associated with general removal or clear-cutting.

*Permission to publish this information was given by the author.

Title: Role of vegetation in levee slope stability and revetment durability - presentation

Author: Shields, F.D.

Series/Source: Vegetation Challenge Symposium, Sacramento, California, August 28, 2007. http://www.safca.org/LeveeVeg-SpeakerPanel.htm

Peer-reviewed: No

Code: LEVVEG, LVSTAB

\section{Abstract: N/A}

Scope of Talk*: Simulation of effects of vegetation on levee slope stability using The Agricultural Research Service (ARS) bank stability model; Sacramento River levee study and revetment study done by the Corps of Engineers in the 1980s

Objective(s): Report on field data collected in summer 1987

Study Location: West bank riverside embankment slopes of levees located along a $10-\mathrm{km}$ reach of the Sacramento River upstream of the Interstate 5 bridge.

Method: L-shaped trenches, $1.2 \mathrm{~m}$ deep, were excavated at each site at the tree driplines, both parallel and perpendicular to the levee crest. Root architecture (root area ratios and vertical distribution patterns) and other features were visually classified. Flow net seepage and the ARS bank stability model calculations were presented.

Vegetation: Herbaceous vegetation, a dead stump, valley oaks $(0.7 \mathrm{~m}$ diam), willow trees, black locust trees, and elderberry bushes

Soil Properties: Medium to fine sands (SP) with permeability, density, friction angle, and cohesion parameters noted.

Observations/Results: From the ARS model, the levee was unstable if the root reinforcement was removed.

Recommendations: Because mature trees and herbaceous vegetation contributed the most to bank stability, these vegetation types should be favored in the maintenance standards. 
* Permission to publish this information was given by the author.

Title: Scientific basis for streambank stabilization using riparian vegetation

Author: Simon, A., and A. Collison

Series/Source: Proceedings of the Seventh Federal Interagency

Sedimentation Conference, March 25-29, 2001, Reno, NV, 2001

Peer-reviewed: N/A

Code: BKSTAB

\section{Abstract: N/A}

Objective(s): The objective was to understand the mechanical and hydrological effects of riparian vegetation on stabilization of streambanks.

Study Location: Goodwin Creek, MS, loess hill section of MS

Method: To assess the effects of vegetation on streambank stability, data were collected on the hydrologic and mechanical properties of three test plots on an unstable incised streambank in northern Mississippi. Data include intrinsic soil-mechanical properties (cohesion, friction angle, and unit weight), matric suction, and pore-water pressure under three vegetation areas, and root tensile strength and distribution. The three vegetation types were control (short-cropped turf), clump grass (Eastern Gamma Grass) and mature riparian trees (mix of sycamore, river birch, and sweetgum). In situ strength of the bank layers at different depths were obtained using an Iowa Borehole Shear Test device. Bank hydrology was monitored using tensiometers to record positive and negative pore-water pressures every $10 \mathrm{~min}$. A series of trenches were dug along riparian trees of different ages and species outside the monitored plots to parameterize the root-reinforcement factors. Numerical modeling was conducted to characterize bank stability.

Vegetation: Cropped grass, eastern gamma grass, deciduous woody vegetation stand (sycamore, river birch, and sweetgum)

Soil Properties: Inspection of bank profiles and boreholes revealed four stratigraphic layers within the bank materials. A course layer of cemented gravel is at the base. The strata are combined into two units. The upper Holocene layer was strength tested and found to be largely frictional with little or no cohesion. Most cohesion in this layer is due to matric suction. The lower Holocene unit has considerable cohesion, and acts as a semipermeable boundary below the upper layer, contributing to the 
development of higher moisture contents and pore-water pressures in the upper Holocene unit during rainfall events.

Observations/Results: Effects of riparian vegetation on pore-water pressure response and bank-stability are positive and negative. The greatest enhancement to bank stability occurred under the tree plot as the positive effects of evapotranspiration negated the negative effects of preferential flow.

\title{
Recommendations: N/A
}

\section{Title: Role of vegetation in riverbank erosion}

Author: Gray, D.H., and A. MacDonald

Series/Source: Proceedings 1989 National Conference of Hydraulic Engineering, 1989. 218-223

\section{Peer-reviewed: Yes}

Code: BKSTAB, RTSTAB, LVSTAB

\begin{abstract}
Vegetation modifies the interface region between flowing water and the streambank. Hydraulic and mechanical properties near this interface will be modified in ways that affect the resistance of the bank to both surficial erosion and mass wasting. With regard to mass stability, plant roots reinforce a soil and increase its shear strength. Roots tend to mechanically modify only the top surface or "skin" of a riverbank or channel levee. A shear strength increase or "root cohesion" can be estimated from the root biomass per unit volume of soil. The near surface layer or "skin" of sandy riverbanks and levees with little intrinsic cohesion is the most vulnerable to both surficial erosion and shallow face sliding. Stability analyses using both infinite slope and circular arc analyses show that even at low root concentrations the presence of woody roots can greatly increase bank stability.

Vegetation also interacts with flowing water to influence bank erosion through disturbance of the flow field. Two distinct conceptual interpretations of this disturbance are proposed. The first views bank vegetation a "carpet" of roughness elements akin to individual, albeit larger, grains of sediment. Stems are so numerous that eddies formed by flow around the stems interfere so that little or no net downstream movement of water occurs. Where local deposition on vegetated banks is observed, the riverbank site is often stable. The second views vegetation in the form of single, isolated tree trunks, which behave much as bridge
\end{abstract}


pilings. Scour around the trunk, both upstream and downstream, may be sufficient to undermine the trunk and accelerate local bank erosion. Such scour is mitigated to some extent by undetermined root reinforcement mechanisms.

Objective(s): The objective was to describe how streambank vegetation, both roots and shoots, modify the "skin" or surface layer and how this, in turn, affects the mass stability and resistance to surficial erosion.

Study Location: Sacramento River, CA

Method: Root densities were described using the profile wall method. Transects were excavated both parallel and perpendicular to the crest of the levee through dominant woody vegetation typical of riparian areas. The findings described are based in part on a field study of root distribution and architecture in a sandy channel levee. The premise was that levee soil shear strength could be estimated from either root biomass concentrations or root area ratios (RAR). Lab and field tests indicated a shear strength increase per unit of fiber concentration ranges from 7.4 to $8.7 \mathrm{psi} / \mathrm{lb}$ of roots per cubic foot of soil. RAR versus depth curves from an elderberry site were used to estimate the root cohesion $\left(\mathrm{C}_{\mathrm{R}}\right)$ as a function of depth. The root concentrations and root cohesions were used in the stability analyses to investigate the influence of bank vegetation on mass stability of a sandy channel levee. Intrinsic soil cohesion was assumed to be zero, and the friction angle set to either $36 \mathrm{deg}$ (maximum value measured on the levee) or $28 \mathrm{deg}$ (lowest recorded value).The average friction and cohesion measured from in-situ bore hole shear tests was 31.6 and 1.16 psi, respectively. Even a small amount of root cohesion increases the factor of safety substantially.

Vegetation: Common riparian area species were encountered. Elderberry plants were representative of the extremes in root densities.

Soil Properties: Sandy

Observations/Results: In circular arc analyses, the most critical failure circles passed through the toe of the slope. Circular arc analyses corroborated the infinite slope analyses. Critical failure circles were shallow in the un-reinforced case. Root presence completely reversed this trend; here the shallow circles had highest factor of safety, whereas the deeper circles were almost unaffected. Roots displaced the critical shear surface downward. The further downward the critical surface is displaced, the less prone the slope is to surface sloughing and raveling. The benefit of plant roots is less important at depth in sandy riverbanks or slopes. 
Recommendations: Analyses of maximum scour-similar to the analysis of Raudkivi and Ettma (1975) - with soil plus vegetation strength substituted for grain size of the armor layer would be informative.

Raudkivi, A.J., and R. Ettema. 1985, J ournal of Hydraulic Engineering 3(4): 713-731.

* Formal permission for abstract publication not required, but bibliographic link is requested.

http://cedb.asce.org/cgi/WWWdisplay.cgi?8903679

Title: Role of vegetation in hydraulics of channel restoration Author: Garcia, M.H.

Series/Source: North American Water and Environment Congress and Destructive Water, 1996. 2607-2612.

Peer-reviewed: N/A

Code: CHSTAB

Abstract*: Boundary layer theory is used to develop a backwater model for flows through vegetated waterways to approximately estimate flow depth variation in channel restoration projects. The effect of vegetation density on flow stage and regime for normal flow conditions are also analyzed and two simple relations to quantify such effect are obtained.

Objective(s): The objective was to develop a backwater equation for flow through emergent vegetation using boundary-layer theory.

\section{Study Location: N/A}

Method: The method considered open-channel flow through emergent vegetation modeled as cylinders. The author followed the procedure for atmospheric flow through vegetation that introduces spatial as well as traditional temporal (Reynolds) averaging operations to transform the highly three-dimensional governing equations into a more tractable onedimensional frame.

Vegetation: N/A

\section{Soil Properties: N/A}

Observations/Results: It is clear that for a channel with a given bed slope, conveying a certain amount of water will involve an increase in the normal flow depth as the vegetation density is increased. Vegetation can 
provide a useful mean to ensure the existence of subcritical flow conditions by lowering the value of the Froude number (a dimensionless number comparing inertial and gravitational forces). The effect of vegetation density on flow stage and regime for normal flow conditions were analyzed and two simple relations to quantify such effect were obtained.

\section{Recommendations: N/A}

* Formal permission for abstract publication not required, but bibliographic link is requested.

http://cedb.asce.org/cgi/WWWdisplay.cgi?9602421

Title: Erosion control with saltmarsh vegetation

Author: Allen, H.H., and J.W. Webb

Series/Source: Proceedings of Coastal Zone '83, ASCE, 735-748.

http://cedb.asce.org/cgi/WWWdisplay.cgi?39117

Peer-reviewed: N/A

Code: CSSTAB

Abstract: A saltmarsh was established in a moderately high-energy winddriven wave climate for the purpose of stabilizing a dredged material dike. The study site was located on a dredged material island in Mobile Bay, Alabama. About 1.7 ha of smooth cordgrass (Spartina alterniflora) sprigs were planted in May of 1981 without wave protection. Significant washout of the sprigs occurred within 2 months. A second planting of two 0.15-ha areas was initiated in August 1981 with two different breakwater systems installed to protect the plants from wave action: a fixed breakwater made from wooden posts with metal planks bolted to them and with rubber tires strapped to the planks and a floating-tire breakwater (FTB). Plant establishment success behind each breakwater and in an area without breakwater protection are described, as well as marsh planting success behind a second FTB constructed in 1982. Degree of success and construction time and costs are given for each breakwater. Results indicated that saltmarsh can be economically established in some moderately high wave-energy area for erosion control or habitat development purposes if wave protection is provided during initial establishment. 
Objective(s): The objective was to determine if cordgrass could survive as an effective erosion control vegetation on an island with moderately strong waves, with or without protective barriers, in Mobile Bay.

Study Location: Mobile Bay, AL

Method: Sprigs of cordgrass were planted in the intertidal zone from about 0.1 to $0.5 \mathrm{~m}$ above mean sea level. The slope of the dredge material surface was 1 vertical to 30 horizontal. The sprigs were planted at $0.5 \mathrm{~m}$ on-center and were planted in fertilized and non-fertilized areas.

Vegetation: Cordgrass (Spartina alterniflora)

Soil Properties: Sandy

Observations/Results: Sprig spacing and fertilizing had significant results in survival rates and total area revegetation.

\section{Recommendations: N/A}

* Reprinted from Proceedings of Coastal Zone '83, ASCE, 735-748 with permission granted through Rightslink, Copyright Clearance Center, Inc.

Title: Erosion and overtopping of a grass dike large-scale model tests

Author: Smith G.M., J.W.W. Seijffert, and J.W. van der Meer. 1994 Series/Source: Proceedings of the Twenty-Fourth international Conference of Coastal Engineering, 2639- 2652.

Peer-reviewed: N/A

Code: LEVVEG, LVSTAB

Abstract*: A comprehensive test series at full-scale was performed on a grass dike to obtain quantitative information on the wave loading, erosion rate, residual strength and overtopping under design storm conditions. The purpose was to establish design and assessment criteria for this type of dike, which exists in many places in The Netherlands. The tested dike exhibited, in general, a considerable resistance to erosion.

Objective(s): The objective was to establish design and assessment criteria for a grassed coastal dike.

Study Location: Delft, Netherlands

Method: In the Netherlands, interest in grass dikes is growing as a result of increasing environmental, economic, and aesthetic concerns. Grass dikes protect the lower-lying polder agricultural land. A section of a sea 
dike was excavated and transported to the test facility. Sixteen $2.5 \mathrm{~m}$ by $2.5 \mathrm{~m}$ by $1 \mathrm{~m}$ thick blocks were collected. The grass-surfaced blocks were subjected to flume testing. Seven tests were conducted on the grass slopes to obtain data about the behavior of the water motion on the slope before and after breaking and about the erosion resistance of the grass layer itself. Initial tests were of short duration and with regular and irregular waves to provide water motion information without damaging the grass. Overtopping and residual strength tests were conducted.

Vegetation: Grass

Soil Properties: Placed dike soils, consisting of grass and root mass on a 1-m-thick layer of clayey material overlying a sand base.

Observations/Results: General descriptive summaries of the erosion features were given. Data were presented in graphs of wave height vs. wave loading duration, erosion rate vs. wave height, and measured and calculated overtopping discharges.

\section{Recommendations: N/A}

* Formal permission for abstract publication not required, but bibliographic link is requested.

http://cedb.asce.org/cgi/WWWdisplay.cgi?9502460

\section{Title: Vegetation and slopes}

Editor: Barker, D.H.

Series/Source: Proceedings of the International Conference of the Institution of Civil Engineers held at the University Museum, Oxford, 29-30 September 1994

Peer-reviewed: N/A

Code: LEVVEG

\section{Abstract: N/A}

Objective(s): The conference was designed to promote dialogue and exchange ideas for the wide range of disciplines (in particular engineering and plant sciences) involved in vegetation. Further aims of the conference and this document were to clarify the concepts and benefits of the use of vegetation on slopes; to review the state-of-knowledge; to highlight activities that are relevant to slope design and management, often 
undertaken in parallel, but using different methodologies; and to further practical multi-disciplinary co-operation.

\title{
Study Location: N/A
}

Method: Conference Proceedings

Vegetation: N/A

Soil Properties: N/A

Observations/Results: N/A

Recommendations: N/A

\section{Title: Resistance of grassmat to wave attack}

Author: Seijffert, J.W., and L. Philipse

Series/Source: ASCE, Proceedings of the Twenty-Second Coastal

Engineering International Conference held J uly 2-6, 1990, in Delft, The

Netherlands, B.L. Edge, editor, 1991, pp. 1662-1674.

\section{Peer-reviewed: No}

Code: LEVVEG, CSSTAB, SOILER

\begin{abstract}
The Dutch dikes along the North Sea and the tidal inlets need protection against erosion by wave attack. In 1983, two full-scale tests were carried out concerning the resistance of large grass sods taken from Dutch sea dikes, against wave attack. For both tests in two different ways grass sods of 7500 to $9000 \mathrm{~kg}$ were dug from dike slopes, transported and placed in test facilities. In Test 1 , the hydraulic load was performed by irregular waves up to $\mathrm{H}_{\mathrm{s}}=1.85 \mathrm{~m}$; in Test 2, the hydraulic load was a simulated regular wave run-up with velocities until $4 \mathrm{~m} / \mathrm{s}$. Test 1 affirmed the possibility of a grassmat to withstand a design storm surge on a dike slope of 1:8 without severe damage. Test 2 showed the limits of erosion resistance and affirmed that the erosion resistance of a grassmat on sandy clay is concentrated in the upper layer of soil and roots.
\end{abstract}

Objective(s): The objective was to test the resistance of large grass sods to erosion by wave attack.

Study Location: Delft, Netherlands

Method: Lab erosion tests were conducted on large grass sod samples taken from Dutch sea-dikes. Sod blocks were placed in a large wave flume $200 \mathrm{~m}$ in length, $5 \mathrm{~m}$ wide, and $7 \mathrm{~m}$ deep, under a slope angle of 1:8. Irregular waves with a Pierson-Moskowitz spectrum were generated with variable water depths. 
Vegetation: Poa pratensis (smooth-stalked meadow or Kentucky blue grass), Festuca rubra (red fescue), Lolium perenne (perennial ryegreass), other grasses and herbs (including Trifolium - clover).

Soil Properties: Illite clay soils and sandy clays

Observations/Results: Proper quality grass on sea-dikes can have a high resistance against erosion by storm surges. The type of erosion depends on the type of grass, particularly the root structure. Quantitative erosion resistance was determined in two specific cases. A wide and fine root-structure (such as Festuca rubra) leaves a fine root structure behind while eroding, which retards further erosion. Other grasses, such as Lolium perenne, omit this property, which causes a lower erosion resistance. The erosion resistance of a grassed levee was concentrated in the upper layer of soil and roots

Recommendations: N/A

* Formal permission for abstract publication not required, but bibliographic link is requested.

http://cedb.asce.org/cgi/WWWdisplay.cgi?9602421

Title: Treatment of vegetation within local flood damage reduction system

Author: U.S. Army Corps of Engineers. 2007. Presenters: L. Harder, S. Buer, and R. Marshal

Series/Source: Briefing on USACE draft final White paper

Peer-reviewed: N/A

Code: LEVVEG

Abstract: N/A

Objective(s): The objective was to present an overview of levee vegetation protection in various areas of California.

Study Location: CA

Method: N/A

Vegetation: N/A

Soil Properties: N/A

Observations/Results: Many flood control projects completed by the Corps had trees on the levees when the projects were turned over to state/ local authorities for maintenance. Effective vegetation management 
policies were in place for several decades. California code of regulations establishes flexible policy on levee maintenance and vegetation. Major threats to levees and public safety include levee under-seepage, bank erosion, toe scour, and levee overtopping.

Recommendations: Maintain integrity of flood damage reduction systems by removing all woody vegetation greater than 2 in. in diameter on levee slopes and within 15-ft-wide vegetation-free zone on both water and landward sides of levees. Negative impacts of vegetation on leveesroots compromise levee structural integrity, make inspections and flood fighting difficult, may cause levee failure by windthrow of trees with root system embedded in levee structures. Potential impacts of vegetation are often minimal on oversized levees. Concerns for proposed vegetation policy- there is little technical or scientific basis for purposed rigid policy on vegetation removal, unintended consequences (destabilized riverbank, harm levee integrity, cost for limited risk reduction), substantial costs and public controversy, negative impacts to habitat and endangered species, important benefits of vegetation on levee reliability not considered (attenuation of boat waves and wind waves, root cohesion of weak alluvial soils, reduction of near-bank flow velocity), need to address both risks and benefits of levee vegetation on a case-by-case basis.

\section{Title: River engineering and environmental resources}

Author: Shields, F.D. Jr., and J J . Ingram

Series/Source: Hydraulic Engineering - Proceedings of the 1990

National Conference, 1128-1133. 1990

Peer-reviewed: No

Code: LEVVEG

Abstract*: Research and development supporting the Corps' commitment to preserve and enhance environmental quality was provided by the CE Environmental Water Quality Operational Studies (EWQOS) Research Program during the early 1980s.

Related research continues at the Waterways Experiment Station's Environmental Lab (EL). This paper presents an overview of some of these efforts and associated products developed for use by river engineers. 
Objective(s): The objective was to present an overview of projects, research, and development support by EWQOS and EL to preserve and enhance the environmental quality of rivers and riparian floodplains.

\section{Study Location: N/A}

\section{Method: N/A}

\section{Vegetation: N/A}

Soil Properties: N/A

Observations/Results: Vegetation on levee observations: In situ shear strength measurements showed that roots increased soil shear strength, and slope stability analyses indicated larger vegetation made levees more stable.

\section{Recommendations: N/A}

* Formal permission for abstract publication not required.

Title: The role of vegetation in integrated pest management approach to levee management

Author: Daar, S., W Klitz, and W. Olkowski

Series/Source: Proceedings: California Riparian Systems Conference, University of California-Davis: 551-555. 1984

Peer-reviewed: N/A

\section{Code: LEVVEG}

Abstract*: Encouraging appropriate vegetation complexes on levee slopes maximizes levee safety, and improves wildlife habitat, recreational opportunities, and aesthetic amenities. This contrasts with standard levee maintenance practices, which annually destroys vegetation on levees, thereby exacerbating a series of maintenance problems, and reducing environmental quality.

Objective(s): The objective was to discuss the role of vegetation complexes on levee slopes regarding wildlife habitat

\section{Study Location: CA}

\section{Method: N/A}

\section{Vegetation: N/A}

\section{Soil Properties: N/A}

Observations/Results: Vegetation on levee slopes maximizes levee safety and improves wildlife habitat, recreational opportunities, and 
aesthetic amenities. Standard levee maintenance practice destroys vegetation on levees and reduces environmental quality.

\section{Recommendations: N/A}

* Formal permission for abstract publication not required.

\section{Title: Trees on embankment dams}

Author: Fondelier, R.

Series/Source: Proceedings of conference Dam Safety Issues of the 80s. Association of State Dam Safety Officials. 1984

Peer-reviewed: N/A

Code: LEVVEG, DAMVEG

Abstract*: The Corps of Engineers Guidance on trees on embankments is delineated in an engineering manual titled "Landscape Planting At Floodwalls, Levees and Embankment Dams" (EM 1110-2-301). This states that where the safety of the structure is not compromised and effective maintenance of the facility is not seriously affected, appropriate landscape planting (trees, shrubs, vines and grasses) will be incorporated into the design of floodwalls, levees and dam embankments.

Objective(s): The objective was to show that trees should not be permitted on the embankments, either upstream or downstream slopes, as it will compromise the safety of the structure.

Study Location: Ohio River

\section{Method: N/A}

Vegetation: Trees, shrubs, vines, and grasses

Soil Properties: N/A

Observations/Results: There appears to be no defendable logic for not removing vegetation when the presence of the structure represents a potential for loss of life or significant property damage should the dam fail. The potential for the damage to the structure is probably greater on smaller dams where there is generally less freeboard, less massive embankment shells, probably steeper slopes, and no internal drainage features to avoid a phreatic surface through the structure close to the outer slope.

Recommendations: There may be individual situations where the presence of trees is acceptable. 
* Reprinted from Proceedings of conference Dam Safety Issues of the 80s, R. Fondelier, Trees on Embankment Dams, 1984, Association of State Dam Safety Officials, with permission from Association of State Dam Safety Officials.

Title: Riparian surrogates in the Sacramento/San J oaquin Delta and their habitat values

Author: Dennis N.B., D. Ellis, J.R. Arnold, and D.L. Renshaw

Publisher: Proceedings of the California Riparian Systems Conference, University of California - Davis, 1981

Peer-reviewed: Yes

Code: LEVVEG

Abstract*: The distribution and condition of riparian vegetation on the Sacramento/ San J oaquin Delta has been highly modified during 130 years of land reclamation, construction, and maintenance of the present levee system, and conversion of the land to agricultural cultivation. A variety of vegetation complexes with partial riparian attributes exist under a few natural, but primarily induced conditions in the Delta, providing some of the wildlife values associated with historic Delta riparian vegetation. These examples of modified riparian communities suggest that compromises will be necessary to achieve wildlife values that are compatible with flood control requirements and agricultural land use in the Delta.

Objective(s): Many types of structures and features are described in this publication. An informal survey of information regarding the delta and wildlife habitat protection and restoration activities is provided.

Study Location: Sacramento/San J oaquin Delta, CA

Method: A historical overview.

Vegetation: Variations and transitional vegetation is presented in the associated sections.

Soil Properties: Varies from mud to sand to cobbles to organic material Observations/Results: Several Delta habitat-types of vegetation, both on and off the levees, have riparian attributes (terrestrial adjacency to free waters and/ or substrate with high soil moisture). Historic communities of riparian species (cottonwood, white alder, western sycamore, ash, valley oak) are less abundant now, but variations (surrogates) of vegetation demonstrate wildlife habitat value. Previous studies of the role of natural 
and introduced vegetation in retarding levee erosion have been conducted. The studies focused on problems in establishing emergent species at the fluctuating water line. Complete mapping of the delta vegetation was done by the Corps of Engineers. The mapping criteria were based on a hierarchy of habitat variables: morphology, vegetation type, substrate, and salinity regime.

Early landowners planted alfalfa or Bermuda grass on the waterside of levees to reduce wave damage. Willows were used also because they survived prolonged submersion. It was believed that willows would reduce the tendency of peat levees to burst when subjected to prolonged river pressure. Willows however choked out the tule, depriving levee faces of the mass of sod and stems which were thought to break wave energy. Since early times, the areal extent of all types of vegetation has been steadily decreasing, limited now to narrow waterway margins. The Delta contains remnant stands of riparian forest isolated from their original association with fluvial processes and sediments. The Delta can no longer sustain the diversity of vegetation it once had. The four most common riparian-like communities associated with waterways on Delta levees are shrub-brush, brushy riprap, herbaceous banks, and unvegetated riprap.

Uncontrolled vegetation on levees presents a potential hazard to levee stability. Willows provide paths for piping of water, alder are subject to wind throw, and dense foliage or undergrowth obscures the levee face from easy visual inspection for signs of erosion/ failure.

Recommendations: A more detailed structural and floristic analysis of the diverse contemporary manifestations and wildlife use of riparian, or quasi-riparian, vegetation would be useful and may provide guidance with respect to vegetation, given control and agricultural operations. Riprap is the most reliable means of stabilizing eroding or incompetent banks; however, the height of the riprap is critical to the amount of vegetation that can be supported on the waterface of the levee.

* Formal permission for abstract publication not required.

Title: Riparian vegetation on flood control project levees: Constraints and opportunities

Author: Carter, L.W., and G.L. Anderson

Series/Source: Proceedings: California Riparian Systems Conference, University of California-Davis: 548-550. 1981 


\title{
Peer-reviewed: N/A
}

Code: LEVVEG

\begin{abstract}
Efforts are being made to find and evaluate alternative construction methods and maintenance practices that are responsive to environmental and aesthetic considerations in conjunction with flood control needs. Although some constraints on vegetation on levees are necessary, progress is being made to reach a compromise between the environmentalists and the flood control project builders and operators to allow riparian vegetation on and adjacent to flood control project levees.
\end{abstract}

Objective(s): The objective was to answer the questions: Can riparian vegetation on flood control project levees be managed differently in the future than it has been in the past? What constraints on the vegetation are necessary to maintain the integrity of flood control project levees?

Study Location: Central Valley, CA

\section{Method: N/A}

Vegetation: N/A

\section{Soil Properties: N/A}

Observations/Results: Vegetation can be retained on and adjacent to flood control levees if (1) the levee section is designed as a multi-purpose structure, that is, enlarged to provide a zone for roots outside the basic structure required for flood control and (2) if the levee and vegetation are adequately maintained.

\section{Recommendations: N/A}

* Formal permission for abstract publication not required.

Title: Vegetation on Corps of Engineers project levees in Sacramento/San J oaquin Valley, California

Author: Nolan, M.H.

Series/Source: Proceedings: California Riparian Systems Conference, University of California-Davis. 1981

Peer-reviewed: N/A

Code: LEVVEG, LVFLCL

Abstract*: The U.S. Army Corps of Engineers' involvement with levees for flood control in the Sacramento/ San J oaquin Valley is in cooperation 
with local interests. The integrity of a levee involves many factors, including structural stability and adequate maintenance. Trees and shrubs can be detrimental to the integrity of a levee, although there are opportunities for allowing vegetation on levees.

Objective(s): The objective was to address the subject of vegetation on levees in the Sacramento/ San J oaquin Valley, which are part of Congressional-authorized flood control projects constructed by the U.S. Army Corps of Engineers (CE).

Study Location: Sacramento/ San J oaquin Valley, CA

Method: Results of observations made on levees were reported including a historical perspective of the necessity of levee surface protection and maintenance.

Vegetation: Vegetation types were alluded to in descriptions, but not specified by species names, nor presented in detail of specific vegetation type benefits.

\section{Soil Properties: N/A}

Observations/Results: With regard to vegetation, the Corps of Engineers regulations require that measures be taken to promote the growth of sod, exterminate burrowing animals, and provide for routine mowing of the grass and weeds and removal of wild growth and drift deposits. Planting of willows and other suitable growth on the riverside of the levees to retard bank erosion is also recommended. Maintenance standards include that the levees will provide serviceability against floods at all times. Levees will have a good growth of sod with grass height of 2 to 12 in. and be substantially free of weeds. All brush, trees, or other undesirable wild growth will be removed from the levee embankment. Vegetation planted for aesthetics or recreation purposes may remain. Inspection and protection criteria for dealing with trees on levees are provided to emphasize the importance of levee tree maintenance. Other agencies and municipalities are also responsible for maintenance of some levee surface vegetation. Detrimental effects of vegetation are also presented. Guidelines for the use of vegetation in Sacramento/San J oaquin Valley are presented with consideration of the complex multitude of benefits a levee system must include, such as habitat preservation, aesthetics, and flood protection.

\section{Recommendations: N/A}

* Formal permission for abstract publication not required. 
Title: Woody plants on flood protection levees: A contradiction?

Author: Lammeranner, W., and H. Meixner

Series/Source: Published by University of National Resources and Applied Life Sciences, Deptartment of Civil Engineering and National Hazards, Institute of Soil Bioengineering and Landscape Construction, Vienna, Austria (2009). See also: Proceedings $2^{\text {nd }}$ International Conference on Ground Bio- and Eco-Engineering, The Use of Vegetation to Improve Slope Stability, Beijing, China, 14-18 J uly 2008.

Peer-reviewed: No

Code: RTSTAB, LEVVEG, LVSTAB, SLSTAB

\begin{abstract}
This technical article describes the influence of woody structures and plant associations on the stability and maintenance of levees. Paper explores whether a contradiction exists in allowing woody plants to grow on earthen levees because of possible damage to their security and preservation. Investigates interaction between levees and woody plants (e.g., large trees) and examines assumptions that have been cited for excluding woody plants from levees. Argues that many of these assumptions are based on anecdotal evidence, often with problematic and questionable logic.
\end{abstract}

Objective(s): The objective was to determine the influence of woody vegetation on the stability and maintenance of levees and to decide whether there is a rational basis for excluding trees from earthen flood protection levees, and to describe how a flexible and dense cover of woody shrub type vegetation can contribute to increased stability and to reduced maintenance.

Study Location: March River basin, Austria

Method: Review of research work and published articles in the European technical literature

Vegetation: Comparison of benefits/limitations of a grass vs. woody plant cover

Soil Properties: N/A

Observations/Results: Contrary to popular belief and practice about the adverse impacts of woody vegetation on levees, numerous technical articles were cited that demonstrated the positive effects of woody structures on stability and maintenance. The reinforcement of the main body of a dike by a grove of trees is much higher and effective in 
comparison to the reinforcement of the top soil layer by a grass sward. The increase in stability against landslides was found to be at least ten times higher. Levee shorelines with supple trees are less affected by floods; woody plants with supple stems can bend over in a flood against the ground surface and protect the ground surface against erosion. In addition, a frictional surface consisting of tree trunks and branches retards flow velocity and dissipates the energy of floods much better compared to a grass sward. In densely vegetated slopes, areas of root death in a levee are quickly colonized and occupied by a new generation of roots from surrounding trees. Thus, the stability of the dike is not affected by root death of a single tree, because in a dense stand or grove the live roots will intermingle and intersperse with dead roots. Woody structures on dams and dikes can also offer protection against burrowing animals.

Recommendations: To avoid damage by muskrats, a fully shaded shore is recommended, as produced by the emergence of continuous shrub vegetation.

* Reprinted from W. Lammeranner, and H. Meixner. 2009. Woody plants on flood protection levees: A contradiction? Publ. by Univ. of Natl. Resources and Applied Life Sciences, Dept. of Civil Engr. and Natl. Hazards, Institute of Soil Bioengineering and Landscape Construction, Vienna, Austria (2009). See also: Proceedings $2^{\text {nd }}$ Intl. Conf. on Ground Bio- and Eco-Engineering, The Use of Vegetation to Improve Slope Stability, Beijing, China, 14-18 J uly 2008, with permission from W. Lammeranner.

Title: Mechanics of root-pullout from soil: A novel image and stress analysis procedure

Author: Hamza, O., A.B. Bengough, M.F. Bransby, M.C.R. Davies, and P.D. Hallett

Series/Source: Eco- and Ground Bio-Engineering: The Use of Vegetation to Improve Slope Stability, 2007. Proceedings of the First International Conference on Eco-Engineering. Springer Publishing, Dordrecht, The Netherlands. Editors: A. Stokes, I. Spanos, J.E. Norris, and E. Cammeraat. pp. 213-221

Peer-reviewed: N/A

Code: RTSTAB, BDWFAL 


\begin{abstract}
When plants are loaded by external forces, whether they be above ground, e.g., wind or canopy weight, or from within the soil, e.g., soil displacement on slopes, the roots will be mechanically loaded. Exactly how the plant roots carry loads during these events is unknown because of their complex morphology and the heterogeneity of the root properties. To gain greater insight into plant root-soil mechanical interactions, a series of tests have been carried out to investigate the mechanical behavior of roots and rubber root-analogues under tension during pull-out from soil. The results of the mechanical tests are augmented by a novel use of image analysis (specifically Particle Image Velocimetry (PIV)) of sequential digital photographs taken during loading. This allows root and soil movements to be measured during the tests so that more can be learned about the effects of root morphology on the load distribution and deformation behavior. The testing methodology and philosophy are presented here together with preliminary results.
\end{abstract}

Objective(s): The objective was to report a series of tests, which were carried out to gain greater insight into plant root-soil interactions during mechanical loading (pull-out).

\title{
Study Location: Laboratory
}

Method: Anchorage tests were performed in a modified root-box packed with soil, referred to here as a phytoplate apparatus. A digital photograph was taken of the straight analogue after a root head displacement of $4 \mathrm{~mm}$. A number of PIV image patches of 50 by 50 pixels along the root length were selected. The GeoPIV76 program was used to measure the displacements of each of these patches in the vertical and horizontal direction between images. The strains within the root can be calculated from the displacement data.

Vegetation: Pea and maise seedlings

Soil Properties: Soil at a water content of $12 \mathrm{~g} / 100 \mathrm{~g}$

Observations/Results: The mechanical resistance of plant roots to uprooting forces has implications for the stabilization of vegetated slopes as well as for the stabilization of plants to external loadings. However, the response of even a simple root system in soil when a vertical uplift (pullout) force is applied is complex. Extension of the analytical measurement work presented here will lead to identification of strain fields within the soil, measurement of axial and bending strains in the roots as well as identification and quantification of sliding at the interface.

Recommendations: The response of root systems to different loading directions ranging from the pure uplift to the pure transverse load is 
required to allow calculation of the reinforcing contribution to a shear plane in the soil.

* Reprinted from Proceedings of the First International Conference on Eco-Engineering, O. Hamza, A.B. Bengough, M.F. Bransby, M.C.R. Davies, and P.D. Hallett, Mechanics of root-pullout from soil: A novel image and stress analysis procedure, Eco- and Ground Bio-Engineering: The Use of Vegetation to Improve Slope Stability, Springer Publishing, Dordrecht, The Netherlands, Editors: A. Stokes, I. Spanos, J .E. Norris, and E. Cammeraat, 213-221, 2007, with permission from Springer.

\title{
Title: Shear strength of the soil root bond system
}

Author: Tobias, S.

Series/Source: Vegetation and slopes: Stabilisation, protection and ecology. Proceedings of the International Conferenceheld at the University Museum, Oxford, 29-30 September 1994, ed D.H. Barker, (Thomas Telford, for ICE), 1995, pp 280-286.

\section{Peer-reviewed: No}

Code: RTSTAB

\begin{abstract}
The use of living plants is one of the oldest techniques in construction engineering. However, there are no rules to dimension a construction with living plants or to estimate its stability. This paper presents an approach to quantify soil root interaction. Shear tests were carried out in situ to observe the reinforcing effect of naturally developed root systems in grassland. The measured values delivered important results. The limits of classical soil mechanics to judge shear strength near the soil surface are evident.
\end{abstract}

Objective(s): The objective of this paper was to give a method to quantify the interaction between soil and roots.

Study Location: Meadow near Zurich, Switzerland, and a filling in the Alps

Method: Shear tests were performed on a large scale and in situ because the natural orientation and spreading cannot be determined or replicated in a laboratory.

\section{Vegetation: N/A}

Soil Properties: N/A 
Observations/Results: Results showed that the soil, which contained no roots failed earlier and more rapidly than the soil which contained roots. The shear plane did not form suddenly, and the failure was slowed by rising root quantity.

\section{Recommendations: N/A}

* Reprinted from Tobias, S. 1995. Shear strength of the soil root bond system. Vegetation and slopes: Stabilisation, protection and ecology. Proc. conference, Oxford, 1994, ed D.H. Barker, (Thomas Telford, for ICE), 1995, pp 280-286, with permission from Thomas Telford Limited.

\section{Title: Roots and the stability of forested slopes}

Author: Zeimer, R.R.

Series/Source: Proceedings of the International Symposium on Erosion and Sediment Transport in Pacific Rim Steeplands, 1981J anuary 25-31. Timothy R. H. Davies and Andrew J . Pearce, ed. Christchurch, N.Z. International Association of Hydrological Sciences, Publication No. 132: 343-361

Peer-reviewed: Yes

Code: RTSTAB, SLSTAB (VR)

Abstract: Permission to publish abstract was not obtained.

Objective(s): The objective was to determine strength characteristics of root systems.

Study Location: (1) coastal sands in northern California, and

(2) Klamath mountains of northwestern California

Method: The shear box enclosed a soil block, but remained open on two sides. Inside dimensions were $60 \mathrm{~cm}$ wide, $30 \mathrm{~cm}$ long, and $30 \mathrm{~cm}$ high. Shear stress was applied by a mechanical jack extended at a rate of $1.3 \mathrm{~cm} / \mathrm{min}$ for $7 \mathrm{~min}$. Stress was measured using a proving ring between the jack and the shear box. The Klamath site soil core roots were extracted, and roots were also extracted from soil excavations. The direct shear apparatus (described in Ziemer 1978) data were correlated to tensile strength.

Vegetation: Lodgepole pine (Pinus contorta) and white fir (Abies concolor) with several sub-dominant conifer species. Brushfields were mostly Ceanothus velutinus. 
Soil Properties: (1) Coastal sands and (2) gravely fine sandy loam Observations/Results: Soil strength increased linearly as root biomass increased. Forests clear-felled 3 years earlier contained about one-third of the root biomass of oldgrouth forests. Nearly all of the roots $<2 \mathrm{~mm}$ in diameter were gone from 7-year-old logged areas while about 30 percent of the $<17 \mathrm{~mm}$ fraction was found. Individual, live brush roots were twice as strong as conifer roots of the same size. This difference may partially compensate for reduced root biomass in brushfields. Net strength of the soil-root matrix in brushfields was about $70 \%$ of that in uncut forests. If soils are barely stable with a forest cover, the loss of root strength following clear-felling can seriously affect slope stability.

\section{Recommendations: N/A}

Title: Mapping the extent and activity of tree root zones with Self Potential and Misse a la Masse

Author: Kepic, A., T. Campbell, and C. Hinz

Series/Source: Proceedings of the 21st Symposium on the Application of Geophysics to Engineering and Environmental Problems (SAGEEP), 2008. pp 223- 231.

Peer-reviewed: Yes

Code: RTSYST

Introduction*: The most popular method of study is to instrument the tree and its environment with some basic non-invasive sensors (if at all), let it grow to some size, and then dig it up to begin the research. The principal instrument used in these studies is a large backhoe. This approach makes time-lapse studies difficult as the subject of the study is killed and the earth surrounding the tree is disturbed in the process. So the possibility of non-invasive monitoring the rhizosphere via geophysical techniques is very appealing to the scientists who study trees.

Objective(s): The objective was to map the extent of tree roots using the self-potential (SP) and Misse-a-la-Masse geophysical methods.

Study Location: The West Swan site is a small blue gum plantation located in the West Swan area, 40-min drive north of Perth, Australia. A second site (red gum trees) was near the town of Pinjarra about $70 \mathrm{~km}$ south of Perth. 
Method: Misse-a-la-Masse Method: this applied potential method works by placing a current electrode into the tree trunk and measuring the distribution of potentials around the tree with a small dipole. A portable electric drill was used to put a $10-\mathrm{mm}$ diam hole into the tree trunk and a steel stake then was embedded into the tree with a hammer to serve as a current electrode (and later pulled out). A resistivity/ IP transmitter was used to inject a current between 80 and $90 \mathrm{~mA}$ (milliampere) for all measurements, and the surface potential measurements made with a high quality voltmeter. Grids were set with line and station spaced $2 \mathrm{~m}$ apart, and the far current electrode was located several hundred meters from the survey grid. SP Method: current electrodes were placed into the ground, and electrical resistivity was noted.

Vegetation: Blue gum and red gum trees

Soil Properties: The red gum site soil profile consisted of fairly homogenous beach-style sands with a high organic content. The blue gum site had zones of high moisture content on top of the clay layers in the subsurface.

Observations/Results: The self-potential method is clearly difficult to use in a quantitative manner, and in the case of the West Swan area was not even able to provide repeatable measurements. Misse-la-masse shows much promise in doing the near impossible: mapping the active root boundaries. The use of both a ground and a tree trunk electrode is particularly promising in its ability to separate out ground influences within the data. However, interpretation of the results and technique require further refinement.

\section{Recommendations: N/A}

* Reprinted from Kepic, A., Campbell, T., and Hinz, C., 2008, Mapping the extent and activity of tree root zones with self potential and misse a la masse, Proceedings of the Symposium on the Application of Geophysics to Engineering and Environmental Problems (SAGEEP), 223-232, with permission from the Environmental and Engineering Geophysical Society.

Title: A numerical investigation into the influence of soil type and root architecture on tree anchorage

Author: Dupuy, L., T. Fourcaud, and A. Stokes

Series/Source: Eco- and Ground Bio-Engineering: The Use of

Vegetation to Improve Slope Stability, Proceedings of the First 
International Conference on Eco-Engineering, 2007. Springer Publishing, Dordrecht, The Netherlands. Editors: A. Stokes, I. Spanos, J.E. Norris, and E. Cammeraat. pp 175-187

Peer-reviewed: N/A

Code: RTSYST, RTMODL

Abstract: Permission to publish abstract was not obtained.

Objective(s): The objective was to determine the anchorage efficiency of four typical root system architectures in theoretical soils representing a wide range of mechanical characteristics.

Study Location: France

Method: A program, SIMUL3R, was developed which generates typical root structures using data from real root systems as input. Simplified structures were used to represent different types of rooting patterns. Conducting a theoretical and parametric study, the soil mechanical behavior chosen was that of a simple, elastic, perfectly plastic model, i.e., without considering hardening. Root wood was considered as an elastic, brittle, perfectly plastic material considering the von Mises yield surface with associated flow rule.

Vegetation: Maritime pine (Pinus pinaster Ait.), Red oak (Quercus rubra L.) Norway spruce (Picea abies L.), Scots pine (PInus sylvestris L.) Soil Properties: Clay and sandy soils

Observations/Results: Rooting depth was a determinant parameter in sandy-like soils. Overturning resistance was greatest in heart- and tap-root systems whatever the soil type. However, the heart root system was more resistant on clay-like soil whereas the taproot system was more resistant on sandy-like soil. Herringbone and plate root systems were twice as less resistant on clay soils and 1.5 times less resistant on sandy soils when compared to heart and tap-like structures.

Recommendations: In future studies, parameters could be modified to determine the effect of wood strength, root shape, root asymmetry, root slippage through soil, soil type, soil hydrology, on tree root anchorage.

Title: Dendrogeomorphological observations in a landslide on Tymfristos Mountain in Central Greece

Author: Papopoulos, A.M., A. Mertzanis, and A. Pantera 
Series/Source: Eco- and Ground Bio-Engineering: The Use of Vegetation to Improve Slope Stability, Proceedings of the First International Conference on Eco-Engineering, 2007. Springer Publishing, Dordrecht, The Netherlands. Editors: A. Stokes, I. Spanos, J.E. Norris, and E. Cammeraat. pp. 223-238

Peer-reviewed: N/A

Code: SLSTAB

Abstract: Permission to publish abstract was not obtained.

Objective(s): The objective was to observe and date landslide events using dendrochronological techniques and also to explore the existing knowledge on the biological and biotechnical behavior of fir (Abies borisii regis Mattf.) on landslides. The direction and tilting degree of trees as well as the deformation of trunks was compared to trees growing on a neighboring stable surface.

Study Location: Tymfritos Mountain, Kati Stream, Sperchios River, Central Greece

Method: Two core borings (cores) and cross sectional cuts were taken from 119 fir trees greater than $4.5 \mathrm{~m}$ high that were growing on a landslide surface and non-slide control surface.

Vegetation: Broad leaf (deciduous) trees, fir trees

Soil Properties: N/A

Observations/Results: The landslide is active with intense mass movement towards the general slope direction. The landslide commenced at least 100 years ago, via a deep mass movement. Sliding effects on vegetation are, to a higher extent and degree, more evident in broadleaf species. Severely leaning trees were deciduous trees. The presence of old fir individuals in the interior of the landslide indicates locations of stable ground (sandstone substrate). The landslide's negative effect on fir growth ring width increases was obvious at certain time-periods without, however, nullifying it.

Recommendations: N/A

Title: Seepage and piping in dams

Author: Martin, R.E.

Series/Source: Presentation (PPT slide show) to Virginia ASCE Geotechnical Meeting, May 2005 
Peer-reviewed: No

Code: SLSTAB, SOILER, DMCONST

Abstract*: Internal erosion is one of the principal causes of dam failure. The enabling conditions for internal erosion are: (1) sufficiently high gradient to cause soil particles to migrate, (2) unfiltered exit, and (3) susceptible soils, viz., silts and sands. Presentation reviewed different types of internal erosion failures, viz., (1) segregation piping,

(2) continuing erosion, and (3) piping. Piping is the erosion of cohesionless soils to form a "pipe" from downstream to source of seepage. Piping can occur at very low critical gradients, on the order of 0.3 to 0.8 . Discharge of turbid water at outlet or discharge point a good indicator of internal erosion or piping.

Objective(s): The objective was to review types of internal erosion leading to failure in earth dams, and to describe manifestations and examples of dam failure caused by internal erosion.

Study Location: Washington power canal embankment Method: Case study review

Vegetation: N/A

Soil Properties: Silts and fine sands contained within stratum consisting of gravel and cobbles.

Observations/Results: Under favorable conditions (e.g., gap-graded soils or soils with internally unstable gradations), relatively small gradients can produce internal erosion and piping. Unfiltered seepage discharge locations permit continued movement of fines in a seepage stream. In the case of the Washington Power canal embankment, heavy pumping caused internal erosion of silts and sands from stratum containing gravel and cobbles (open graded non-self filtering). This pumping imposed a hydraulic gradient of 0.6. Internal erosion can occur for a long time before it results in a hydraulic blowout or slope failure. Recommendations: N/A

* Reprinted from Presentation (PPT slide show) to Virginia ASCE Geotechnical Meeting, R.E. Martin, Seepage and piping in dams, May 2005, with permission from R. E. Martin.

Title: Effect of tree roots on shallow-seated landslides 
Author: Abe, K., and R.R. Ziemer

Series/Source: Proceedings, Geomorphic Hazards in Managed Forests, XIV IUFRO World Congress, 5-11 August 1990, Montreal, Canada. USDA Forest Service General Technical Report PSW-130, Berkeley, California. pp 11-20.

Peer-reviewed: Yes

Code: SLSTAB, RTSTAB, RTMODL

Abstract*: Forest vegetation, especially tree roots, helps stabilize hillslopes by reinforcing soil shear strength. To evaluate the effect of tree roots on slope stability, information about the amount of roots and their strength should be known. A simulation model for the root distribution of Cryptomeria japonica was proposed where the number of roots in each 0.5-cm-diam class can be calculated at arbitrary depths. The pull-out strength of roots was used to analyze the stability of four different types of forested slopes. Root reinforcement is important on slopes where roots can extend into joints and fractures in bedrock or into a weathered transitional layer between the soil and bedrock. Root reinforcement of soil increases quickly after afforestation for about the first 20 years, then remains about constant thereafter.

Objective(s): The objective was to evaluate the effect of tree roots on slope stability.

Study Location: J apan

Method: A simulation model for the root distribution of Cryptomeria japonica was proposed where the number of roots in each $0.5-\mathrm{cm}$-diam class was calculated at arbitrary depths. The pull-out strength of roots was used to analyze the stability of four different types of forested slopes.

Vegetation: Cryptomeria japonica (J apanese cedar) trees

Soil Properties: Four slopes with differing regolith depths were analyzed. The slopes angled between 15 to $32 \mathrm{deg}$, the soil cohesion was $0.2 \mathrm{ton} /$ square meter, the friction angle was $30 \mathrm{deg}$, and soil density was $1.3 \mathrm{~g} / \mathrm{cc}$ at each of the four sites.

Observations/Results: Numerous equations were presented to address root strength contributions to slope stability analyses. Root reinforcement is important on slopes where roots can extend into joints and fractures in bedrock or into a weathered transitional layer between the soil and bedrock. Root reinforcement of soil increases quickly after afforestation for about the first 20 years, then remains about constant thereafter.

\section{Recommendations: N/A}


* Formal permission not required. Covered under Fair Use in Title 17 of the US Code.

Title: Airborne laser scanning for riverbank erosion assessment

Author: Thoma, D.P., S.C. Gupta, M.E. Bauer, and C.E. Kirchoff

Series/Source: Remote Sensing of Environment 95, 2005. 493-501

Peer-reviewed: N/A

Code: SOILER

\begin{abstract}
Worldwide, rivers and streams are negatively impacted by sedimentation. However, there are few broad scale techniques for quantifying the sources of sediment, i.e., upland vs. riverbank erosion. This research was designed to evaluate the use of airborne LIDAR for characterizing sediment and phosphorus contributions from riverbank erosion. The evaluation was done on the main stem of the Blue Earth in southern Minnesota. Detailed topographic data were collected on an annual basis in April 2001 and 2002 over a $56 \mathrm{~km}$ length of the river with a helicopter mounted Topeye laser system. The raw database included $X$, $\mathrm{Y}, \mathrm{Z}$ coordinates of laser returns sampled from the river valley with a density of 1 to 3.3 elevations per square meter. Uniform 1-m bare earth digital elevation models were constructed by stripping vegetation laser returns and interpolation. The two models were differenced to determine volume change over time, which was then converted to mass wasting by multiplying volume change with bulk density. Mass wasting rates were further converted to sediment load based on percentage of transportable material in the bank strata. The average difference between LIDAR measured elevations and GPS- surveyed elevations on five highway bridge surfaces was 2.5 and $8.8 \mathrm{~cm}$ for 2001 and 2002 scans, respectively. The elevation errors were quasi-normally distributed with standard deviation of 6.7 and $6.1 \mathrm{~cm}$ for 2001 and 2002, respectively. No elevation or planimetric corrections were made to the laser data before calculating mass wasting rates because it was not possible to determine the source of error or if it was uniform within and between scans. The mass wasting estimate from the LIDAR surveys varied from $23 \%$ to $56 \%$ of the sediment mass transported past the downstream gauging station depending on the range of textural material that was entrained in the river. These estimates
\end{abstract}


are in the range of values reported in the literature. Total $\mathrm{P}$ contribution due to bank erosion from the river reach was estimated to be 201 tons/yr.

Objective(s): This research focused on a reach of the Blue Earth River between Amboy, MN, and the confluence of the Glue Earth and the Wantonwan rivers $(56 \mathrm{~km})$ that contained 10 minor, 30 moderate and 15 severely eroded sites. Severely eroded sites were classified as greater than $3 \mathrm{~m}$ high. In this stretch of the river, five county highway bridges were used as ground reference control for the LIDAR scans.

Study Location: Blue Earth River, southern MN

Method: The study used LiDAR surveys of fluvial banks in various stages of failure. Uniform 1-m bare earth digital elevation models were constructed by stripping vegetation laser returns and interpolation. The two models were differenced to determine volume change over time, which was then converted to mass wasting by multiplying volume change with bulk density. Mass wasting rates were further converted to sediment load based on percentage of transportable material in the bank strata.

Vegetation: N/A

Soil Properties: Fluvial and glacial origin materials with highly variable physical and chemical characteristics. Bulk densities were higher, the textures more sandy and the phosphorus levels lower than agricultural surface soils in the area.

Observations/Results: This study demonstrated the potential of LiDAR to partition non-point source sediment pollution from bank erosion. Using two scans made one year apart, estimated bank erosion inputs represented up to $56 \%$ and $20 \%$ of transported sediment and total phosphorus measured at a river gauging station. This does not mean that all sloughed bank material made it to the gauging station in that year. Erosion or deposition below the high waterline could not be quantified because the laser wavelengths used are strongly absorbed by water. Interpretation of mass wasting estimates derived from scanner data must be made considering several accuracy affecting factors including laser altimetry shifts in measurement and river gauging station measurements (rating curve and stage measurements). The vertical errors were within laser manufacturers specifications and no consistent bias was detected in planimetric shift. These are not conventional means of surveying at this level of accuracy for such extensive areas. This study illustrated how scanning laser altimetry could be used in conjunction with river gauging station data to estimate the contribution of eroding bank material to total river suspended load. 
Recommendations: Resource managers at all levels of government could use this technology to determine allocation of resources to projects with the greatest potential for pollution abatement. Isolating steam bank inputs and upland contributions by difference with total sediment load can help determine effectiveness of upland soil erosion control efforts.

* Reprinted from Remote Sensing of Environment 95, D.P. Thoma, S.C. Gupta, M.E. Bauer, and C.E. Kirchoff, Airborne laser scanning for riverbank erosion assessment, 493-501, 2005, with permission from Elsevier.

Title: Levee armoring: woody biotechnical considerations for strengthening Midwest levee systems

Author: Wallace, D., C. Baumer, J . Dwyer, and F. Hershey

Series/Source: Paper presented Symposium on Restoration of Aquatic Ecosystems, St. Paul, MN, J une 20-23, 1994

Peer-reviewed: No

Code: SOILER, SLSTAB, LEVVEG

Abstract*: Secondary levees associated with major rivers and upstream tributary levee systems in Missouri experienced an estimated 2019 levee breaks during the historic 1993 floods. Reviews and interviews indicated that fewer breaks occurred along levees sections with woody corridors or with woody cover on the levees. Levee armoring with properly designed woody material will slow floodwater velocities, dissipate energy, reduce scouring potential, and increase soil shear strengths. These hydraulic changes and biomechanical attributes would increase levee protection, reduce maintenance costs, and reduce flood damage to floodplain fields by trapping sediment.

Objective(s): The objectives were to examine potential woody interactions with levee systems and present some armoring designs that purposely incorporate woody plants, and to determine the effect of woody corridor width (levees with forested buffer zones or with woody cover on the levee) on occurrence of levee failures

Study Location: Main stem and upstream tributary levees, MO Method: Field studies and reviews Vegetation: Not specified 
Soil Properties: Not specified

Observations/Results: Field reviews of levee performance along a portion of Shoal Creek in Caldwell County revealed only a single levee break (internal tile line failure) with woody cover and woody corridors of 20 to $100 \mathrm{~m}$ in width. Conversely, levees with woody corridors completely absent and in grass sod upstream from the wooded corridor site, experienced multiple breaks in a similar length of levee.

Recommendations: Based on hydraulic and biomechanical considerations, the authors believe maximum levee protection should incorporate both woody corridors and levee woody plantings. Instead of excluding woody vegetation, the authors recommended that levee designs should actively incorporate woody materials as corridor plantings between the levee and river and as protective cover on the structure itself as long as inspection and flood fighting capabilities are maintained. They suggest four different designs using combinations of woody materials for trial use and study on Midwest levee systems. All of these designs would be incorporated with a river side woody corridor of appropriate width.

* Reprinted from Wallace, D., C. Baumer, J . Dwyer, and F. Hershey. 1994. Levee armoring: woody biotechnical considerations for strengthening Midwest levee systems. Paper presented Symposium on Restoration of Aquatic Ecosystems, St. Paul, MN, J une 20-23, 1994, with permission from National Agroforestry Center. 


\section{Reviews, Annual Reports, Workshops}

WORKSHOP:

Title: Evaluation and utilization of biotechnical techniques and willow posts for stabilizing eroding streambanks

Author: Bhowmik, N.G.

Series/Source: Preprints International Riprap Workshop 1993. 1:163-

192

Peer-reviewed: No

Code: BKSTAB

Abstract*: Erosion of the streambanks is a natural process. However, in many instances bank erosion could be quite extensive requiring not only an evaluation of the bank erosion processes but also developing and implementing bank stabilization techniques that are expected or assumed to be effective for a long time. Structural treatments such as riprap, stone or concrete revetment, etc. have been and will be utilized extensively to stabilize eroded streambanks. In recent times, application of biotechnical methods for small- to medium-sized streams has been tried quite successfully. Biotechnical streambank stabilization not only affords bank stability, but could also enhance aquatic and in some cases terrestrial habitats. This paper summarizes some of the principles utilized in biotechnical applications and case studies on willows, tree revetments, and others that were applied in the Midwest to stabilize eroded streambanks.

Objective(s): This paper summarized some of the principles used in biotechnical application and case studies on willows, tree revetments, and others that were applied in the Midwest to stabilize eroded streambanks.

Study Location: Midwest U.S.

Method: Overview

Vegetation: Grasses and woody plants; reed clumps, reed rolls, live fascines, live wooden baffles, tree revetments, and willows

\section{Soil Properties: N/A}

Observations/Results: Biotechnical methods alone probably will not stabilize a stream having a very high velocity, but these could be used in combination with other structural means such as riprap, wing dams, piles, and fences. 


\section{Recommendations: N/A}

* Permission granted from TU Delft Library.

\section{Title: Environmental features for flood-control channels}

Author: Shields, F.D. Jr.

Series/Source: Environmental and Water Quality Operational Studies, 1982. Technical Report, Environmental Laboratory, U.S. Army Corps of Engineers, Waterways Experiment Station (ERDC) E-82-7: 1-107

Peer-reviewed: N/A

Code: ECOSYS, CHSTAB

Abstract: This report presents and documents information to develop environmental guidance for flood control projects that involve modification of natural stream channels by clearing, snagging, alignment, enlargement, and lining. The response of the fluvial system to modification sometimes results in unintentional or unforeseen environmental impacts.

In general, channel modification results in a shorter, smoother, more uniform channel with large cross-sectional area and less natural vegetation. Overbank flooding is eliminated or reduced, and depths and velocities are changed at all flows. Because extreme channel instability has adverse effects on ecological and aesthetic resources, channel straightening should be minimized. The channel cross section should be designed for low as well as high flows; the existing velocity-versusdischarge relationship should be preserved as much as possible at low and intermediate flow to maintain the sediment transport characteristics of the existing channel. Environmental features have been found to have limited effectiveness unless the modified channel is reasonably stable, the project area is protected against further modification, and construction and maintenance work is closely supervised and inspected.

The adverse environmental impacts of channel enlargement can be reduced by following the existing channel alignment and excavating from one side only. Floodways may be used to preserve portions of the existing channel and its associated aquatic habitat. Low-flow channels may be constructed inside a larger channel, or the existing channel may be preserved as a low-flow channel. Pools and riffles may be constructed. Water control structures may be placed in the channel to maintain water 
levels for aquatic habitat and aesthetics and to prevent invasion and blockage. Meander loops may be maintained as small ponds or wetlands.

Many of the adverse impacts of channel work can be avoided by preservation of existing valuable vegetation and by prompt revegetating with appropriate species. Aquatic habitat diversity may be restored to a modified channel by placing simple habitat structures in the channel to create vertical relief, non-uniform flow patterns, and stable substrate; these devices should be used with care since they increase hydraulic roughness and tend to offset flood control measures. Biological recovery of some modified streams may be improved by armoring the new channel with biologically desirable coarse bed material. Adverse impacts of channel lining or paving may be addressed by incorporating natural material such as boulders in the lining, by ponding water in the lined channel, and by constructing low-flow channels, fishways, pools, and spawning channels.

Modification of stream channels in urban areas frequently offers many opportunities for recreational development and beautification.

Objective(s): The purpose was to document the preliminary findings of an effort to develop environmental guidelines for flood-control channel projects.

\section{Study Location: MN}

Method: Overview

Vegetation: N/A

\section{Soil Properties: N/A}

Observations/Results: Flood control channel projects should be planned and designed with full consideration of the ecological resources of the project area. Channel modifications are frequently accompanied by severe impacts on aesthetic resources, water quality, fish and wildlife resources, and cultural resources. Modification of stream channels for flood control sometimes results in severe channel instability despite the efforts of channel designers to produce a stable channel.

Recommendations: Planning, design, construction, operation, and maintenance of flood-control channel projects should be done in such a way as to maintain or improve environmental quality. Design of channel modifications should include meticulous attention to detail in an effort to preserve features unique to the site and enhance the environmental quality of the completed project. Future work should include further development of design criteria for environmental features such as low-flow channels, floodways, artificial meanders, channels with natural bottom topography, 
oxbow lakes made from severed meanders, habitat restoration structures, and artificial substrate.

Title: Review of Corps of Engineers design for rehabilitation of the perimeter dikes around Cross Lake, MN

Author: Duncan, J.M., and R. Upton

Series/Source: Report submitted to U.S. Army Corps of Engineers, St. Paul District, J uly 14, 1999

Peer-reviewed: No

Code: LEVVEG, LVCONS

Abstract: Corps of Engineers' plans for rehabilitation of the perimeter dikes around Cross Lake, MN, have met with considerable opposition from citizens in the area, because the plans call for cutting down trees and constructing a filter berm in the wetland below two of the dikes.

Where trees restrict access to the toes of dikes for inspection or emergency repair, they should be removed so that unsafe conditions can be recognized and remedied if they develop. Where trees blowing over could cause serious adverse effects on seepage, and could possibly lead to erosion and piping, they should be removed to eliminate these threats to safety. However, trees blowing over on the upstream slopes of the dikes would not impair the integrity of the dikes, and they can be left there without impairing safety. The possibility that tree roots can have an adverse effect on seepage by modifying permeability is extremely remote, and poses no significant risk.

Objective(s): The objective was to conduct a finite element analysis method used to compute the maximum values of hydraulic gradient where seepage through the dikes finds its exit.

Study Location: MN

Method: Finite element analysis

Vegetation: Trees

Soil Properties: N/A

Observations/Results: Where trees restrict access to the toes of dikes for inspection or emergency repair, they should be removed so that unsafe conditions can be recognized and remedied if they develop. Where trees blowing over could cause serious adverse effects on seepage, and could possibly lead to erosion and piping, they should be removed to eliminate 
these threats to safety. However, trees blowing over on the upstream slopes of the dikes would not impair the integrity of the dikes, and they can be left there without impairing safety. The possibility that tree roots can have an adverse effect on seepage by modifying permeability is extremely remote, and poses no significant risk.

Recommendations: Site-specific piezometer locations are suggested.

\section{Title: Forestry strategies to protect floodplain agricultural systems}

Author: Hershey, F., D. Wallace, and J . Dwyer

Series/Source: Restoration of Aquatic Ecosystems Symposium, 1994.

Association of State Wetland Managers, St. Paul, Minnesota, June 20-23, 1994.

Peer-reviewed: No

Code: LEVVEG, BDWFAL, LVSTAB, ECOSYS

\section{Abstract: N/A}

Objective(s): The objective was to discuss the role of trees in floodplains Study Location: N/A

Method: A short literature review

Vegetation: Riparian trees

Soil Properties: N/A

Observations/Results: Some concerns regarding levee vegetation were listed as:

1. Large trees will windthrow from saturated levees, removing a large soil mass and creating a breach point in the levee.

2. Large tree roots will extend through the levee and cause piping during floods. This is primarily a concern when large old trees die.

3. Woody vegetation attracts burrowing animals to the levee and their activities create breach points in the levee.

Trees in floodplains provide numerous benefits to floodplains by protecting crop production, providing windbreaks, stabilizing sandy soils, enhancing bank stability, protecting water quality, and providing wildlife benefits.

Recommendations: N/A 


\section{Title: Use of vegetation to reduce levee erosion in the} Sacramento/San J oaquin Delta

Author: Whitlow, T.H., R.W. Harris, and A.T. Leiser

Series/Source: Department of Environmental Horticulture, University of California, Davis. Report prepared for the California Department of Water Resources, Sacramento. J une 30, 1979. 46 pages plus 4 appendices.

Peer-reviewed: N/A

Code: SOILER, LEVVEG

Abstract: This report summarizes the efforts to establish and maintain vegetation on multiple-use levees in the Sacramento-San J oaquin Delta, California. Emphasis is placed on the use of vegetation to stabilize levees and retard erosion, especially in the intertidal zone. The report includes studies conducted throughout the Sacramento Valley and above the tidal zone, however.

The geomorphology and reclamation history of the delta are described to create a background for understanding the present levee problems. Poor construction materials, destablized channel bottoms, waves generated by wind and boats, and flood flows contribute to the inherent instability of levees. Rodent burrows, decomposed tree roots, and undercut trees aggravate the chronic instability.

Many methods of bank protection have been developed and tested. Most of these involve armoring the bank with a non-eroding material. Both woody and herbaceous vegetation has been used also, sometimes alone and sometimes in conjunction with mechanical protection. Data indicate that vegetation can be an effective means of erosion control on levees. The cost of using vegetation to control erosion is among the least expensive as well.

New research indicates that it is difficult to re-establish vegetation in the intertidal zone of levees unless the levee toes are stabilized and armored in some fashion. It should be feasible to incorporate vegetation and mechanical protection to create a multi-purpose levee face.

Over 200 plant species have been recommended and/ or tested for their ability to survive on California levees. These species are listed in the appendices along with information pertinent to successful establishment.

The technology exists to revamp Delta levees. Application of the technology on a broad scale will require changes in basic policy.

Objective(s): This publication is a summary of levee stabilization and erosion retardation effects due to levee vegetation. 
Study Location: Sacramento-San J oaquin Delta, CA

Method: A compilation of available information up to the year 1979 (published and oral communication)

Vegetation: Over 200 plant species are described in this report. Soil Properties: N/A

Observations/Results: Numerous observations related to bank protection schemes using native vegetation are discussed.

Recommendations: Vegetation can be an effective means of erosion control on levees. 


\section{Dissertations/Theses}

\section{Title: Wave overtopping and grass cover layer failure on the inner slope of dikes}

Author: Young, M.J .

Series/Source: MSc Thesis WSE-CEPD-05.03, UNESCO-IHE Institute

for Water Education, Delft, The Netherlands. J une 2005.

Peer-reviewed: N/A

Code: CSSTAB, LEVVEG, SOILER

Abstract: Historically, breaching of dikes following erosion of the inner slope after heavy wave overtopping has been a major coastal flood hazard. Over recent years, improvement in understanding of storm surge levels and wave run-up has meant that current design practice for the inner slope still relies on criteria set largely from experience and judgment, for allowable overtopping discharge.

Objective(s): The objectives were to present results of hydraulic research describing flow parameters for overtopping events on coastal dikes, to model root cohesion parameters, and to develop a reliability function for grass (turf) stability based on sliding mechanisms.

Study Location: Netherlands

Method: A compilation and review of current literature was performed, and preliminary theoretical concepts were investigated. Probabilistic modeling of grassed levee response to wave action and overtopping events is detailed.

Vegetation: Various grass species on Dutch dikes Soil Properties: Dutch levee system (clay cap over sandy fill) Observations/Results: Well-managed grass covers provide secure and durable surface protection for all but a fairly extreme combination of hydraulic loading circumstances.

Recommendations: Overtopping depth and velocity parameters should be used instead of average overtopping flowrate. The composite strength of turf is significantly higher than the soil alone, and the soil behavior is dominated by its structure. 


\section{International Guidance}

Title: Windthrow handbook for British Columbia forests

Author: Stathers, R.J ., T.P. Rollerson, and S.J . Mitchell

Series/Source: British Columbia Ministry of Forests Research Program

Working Paper 9401, 1994. 31 pp.

Peer-reviewed: Yes

Code: BDWFAL

Abstract*: Permission to publish abstract was not obtained.

Objective(s): The objective was to provide a comprehensive guide detailing windthrow mechanics, tree factors affecting windthrow potential, and methods to quantify windthrow hazard.

Study Location: British Columbia forests

Method: Primarily a synopsis of windthrow literature related to British Columbia forest trees.

Vegetation: British Columbia forest trees

Soil Properties: N/A

Observations/Results: Windthrow is a natural process in forests. Certain sites are more prone to windthrow either due to greater topographic exposure to damaging winds, poor root anchorage, or susceptible tree stand structure and composition. Losses resulting from windthrow can be significantly reduced by recognizing sites where it is likely to be a problem and using management practices to minimize its impact.

Recommendations: More quantitative approaches to hazard classification should be developed as more information becomes available on the characteristics of tree rooting strength under different soil conditions and through wind tunnel and field studies on the effects of landscape and stand characteristics on wind flow and force on tree canopies.

Title: Guidelines for stabilizing streambanks with riparian vegetation

Author: Abernethy, B., and I.D. Rutherfurd 
Series/Source: Cooperative Research Centre for Catchment Hydrology, 1999. University of Melbourne, Parkville, Victoria, Australia, 1-30

\title{
Peer-reviewed: N/A
}

Code: BKSTAB, SOILER

\begin{abstract}
This report provides guidelines for establishing riparian plantations that will stabilize riverbanks, within acceptable limits. Riparian vegetation interacts with a range of geomorphological, geotechnical, hydrological, and hydraulic factors to affect the type and extent of riverbank erosion. The enhanced lateral channel stability offered by well-vegetated riparian zones can also reduce the need for engineered stabilization and heavy maintenance.

The density and type of riparian vegetation cover strongly influence all aspects of riverbank erosion. Riparian forests are typically composed of overstory, understory, groundcover, and macrophyte species. Vegetation conditions are assessed in terms of the Raine and Gardiner (1995) 'traffic light' classification: green, yellow, red for riparian vegetation in good, intermediate, and poor condition. The main consideration when designing riparian revegetation works for bank stability is continuity of cover.

Different types of vegetation affect different processes, so it is imperative to assess the dominant erosion process correctly so that appropriate species can be selected for stability. All of the erosion processes that act on banks can be grouped together into three erosiondomains. (1) Subaerial erosion (erosion caused by processes external to the stream such as cattle, or rain splash). (2) Scour (removal of individual sediment particles or aggregates by flow). (3) Mass-failure (slumps). An underlying philosophy of these guidelines is that the dominant bank erosion process changes downstream along a river due to changes in channel scale.
\end{abstract}

The guidelines stipulate minimum riparian zone establishment-widths. Minimum riparian zone widths are calculated individually for each site on the basis of the present site conditions (observed or estimated bank erosion rate). The basic allowance for the width of any riparian plantation designed for bank stabilization should not be less than $5 \mathrm{~m}$ measured onto the floodplain from the bank crest. As banks become higher, they become less stable. Hence, in addition to the basic allowance, we recommend that the width of riparian strips also include a height allowance not less than the height of the bank measured vertically from the bank toe to the bank crest. Time must be allowed for the plants to grow before they can begin to stabilize the bank; so, where banks are actively eroding, an establishment 
allowance should also be included in the final riparian zone width. The establishment allowance is determined by multiplying the erosion rate by the time required for the plantation to mature.

The material presented in this document is summarized and collated into a series of tables that can be used to guide and focus the practitioner's approach to planning riverbank stability works with vegetation. The report does not account for ecological, or sediment and nutrient filtering, or other criteria that may dictate specific riparian management regimes beyond those appropriate for bank stabilization. The width and character of plantations designed for other criteria may be quite different than plantations designed for bank erosion control. Thus, these guidelines should be considered in the light of other requirements for riparian zone management.

Objective(s): The objective was to present guidelines that will assist in planning and implementing riparian re-vegetation works specifically designed to retard bank erosion rates to more natural levels.

Study Location: Australia

Method: Guideline development

Vegetation: Riparian vegetation

Soil Properties: N/A

Observations/Results: The guidelines stipulate minimum riparian zone establishment-widths. Minimum riparian zone widths are calculated individually for each site on the basis of the present site conditions (observed or estimated bank erosion rate). The basic allowance for the width of any riparian plantation designed for bank stabilization should not be less than $5 \mathrm{~m}$ measured onto the floodplain from the bank crest. As banks become higher, they become less stable.

Recommendations: In addition to the basic allowance, we recommend that the width of riparian strips also include a height allowance not less than the height of the bank measured vertically from the bank toe to the bank crest. Time must be allowed for the plants to grow before they can begin to stabilize the bank; so, where banks are actively eroding, an establishment allowance should also be included in the final riparian zone width. The establishment allowance is determined by multiplying the erosion rate by the time required for the plantation to mature.

* Reprinted from Abernethy, B., and I.D. Rutherfurd. 1999. Guidelines for stabilizing streambanks with riparian vegetation. Cooperative Research 
Centre for Catchment Hydrology, 1999. University of Melbourne, Parkville, Victoria, Australia, 1-30, with permission from J. Frankenburg.

Title: Environmental guidelines for vegetation management on flood protection works to protect public safety and the environment

Author: N/A

Series/Source: Ministry of Environment, 1999. British Columbia (BC), Canada, 1-19

Peer-reviewed: N/A

Code: LEVVEG, BKSTAB

Abstract*: Vegetation management guidelines for flood protection dikes are determined by the public safety need for inspection visibility, access for efficient operation and maintenance, and minimization of detrimental effects to dike fills and bank protection.

Objective(s): These guidelines were developed to apply to Ministry of Environment, Lands and Parks (MELP), which encompasses the Lower Fraser Valley including Hope, the Squamish-Pemberton corridor and the Sechelt Peninsula. Basic public safety needs are common to all flood protection structures in $\mathrm{BC}$ and this information can be adapted to other areas. It should be noted that habitat protection requirements may vary from region to region.

Study Location: Lower Fraser Valley, the Squamish-Pemberton corridor and the Sechelt Peninsula of British Columbia (Canada)

Method: Guideline development

Vegetation: N/A

Soil Properties: N/A

Observations/Results: Vegetation clumps, which are devoid of potentially large growth and/ or excessive vegetation are acceptable in riprap bank protection or on overwidth dikes. Controlled vegetation clumps may contain shrubs, which do not obstruct inspection visibility, displace riprap, or create holes.

\section{Recommendations: N/A}

* Formal permission not required as per Ministry of Citizens' Services, Province of British Columbia. 
Title: Manual for river works in J apan

Author: Ministry of Construction

Series/Source: J apan River Association, Tokyo. 1997.

Peer-reviewed: N/A

Code: LEVVEG

Abstract: Recognizing that rivers are a natural object, which has facets that are environmental and also some that are societal (cities), these facets need to be recognized and planned prior to construction in river space (river land and space above it). The environmental plan includes the environmental conservation and improvement plan for the river space and the preservation plan of the water quality. The low-flow channel is to facilitate the discharge of floodwaters, and the high-water channel is to be used as green belt and park areas. Sabo environment improvement project plans must not only address their primary function of preventing damages due to sediment avalanches, but also develop the environment of the facility to preserve and nurture the overall environment. Afforestation of crests of excavated waterways and toes of back slopes of dikes shall conform to standards of afforestation of riverbanks. Previously afforestation of dikes and riverbanks was prohibited due to consideration of the adverse effects on river control facilities. Recently afforestation of banks has come to be allowed for the improvement of the river environment, but must not be a detriment of river control measures. Afforestation of the high-water riverbanks is considered socially advantageous for the environment and population. However, once planted, the trees are to be maintained. Planting of trees is under the direction of the river controller, but local planters associated with public entities may also do plantings and are required to do the required maintenance. Standards for riverbanks are presented in schematic diagrams depicting excavation of banks and self-supporting revetments.

Objective(s): The objective was to present standards for riverbanks in schematic diagrams depicting excavation of banks and self-supporting revetments.

Study Location: J apan

Method: N/A

Vegetation: Trees 


\title{
Soil Properties: N/A
}

Observations/Results: Plantings on dikes have stipulations; (1) secure the space of planted trees and depth of root spread outside of the stipulated cross section of the dike, (2) avoid planting trees on the crest of the dike and on small steps and slopes on the river side of the dike, and (3) avoid planting trees along the section of the waterway, which posed problems of dike safety, such as water leaks from the dike body. When trees are planted on the riverbank side, a vehicle passage zone shall be secured; but also trees of the wind-resistant type shall be planted $1.5 \mathrm{~m}$ or more from the shoulder of the revetment and will not disturb the revetment. The slope of the riverbank must have trees of $1 \mathrm{~m}$ or less in height.

Recommendations: The slope of the riverbank must have trees of $1 \mathrm{~m}$ or less in height. Avoid planting trees on the crest of the dike and on small steps and slopes on the river side of the dike, and avoid planting trees along the section of the waterway which posed problems of dike safety such as water leaks from the dike body. When trees are planted on the riverbank side, a vehicle passage zone shall be secured; also, trees of the wind-resistant type shall be planted $1.5 \mathrm{~m}$ or more from the shoulder of the revetment.

\section{Title: Sea defences, Dutch guidelines on dike protection} Author: Pilarczyk, K.W.

Series/Source: Rijkswaterstaat, Dutch Ministry of Transport and Public Works, 1987. Road and Hydraulic Engineering Department, Report WBNO-87110, April 1987, Delft, The Netherlands

\section{Peer-reviewed: N/A}

Code: LVCONS, LEVVEG, SOILER, LVSTAB

\begin{abstract}
The increased demand on reliable design methods for protective structures has resulted in the Netherlands in preparing a set of design guidelines for revetments of the sea-, and river-dikes, and for bank protection. These guidelines are intended for technicians and organizations directly involved in the design and management of protective structures. In this report, a brief review of general design philosophy, different hydraulic and geotechnical aspects, and design criteria for various types of revetments are given. The stability criteria based on small- and large-scale tests are formulated for the following
\end{abstract}


systems: riprap, concrete units, asphalt, and grass-mats. Developments for some other systems are also briefly mentioned.

Objective(s): The document is an engineering manual for designing dike protection.

Study Location: Netherlands

Method: Guideline development

Vegetation: N/A

Soil Properties: N/A

Observations/Results: The guidelines presented will bring designers closer to the solution of the typical problem of the design of dikes and the proper choice of revetments in respect to design hydraulic load, ability of materials and skill, and desired function of construction.

\section{Recommendations: N/A}

* Reprinted from Pilarczyk, K.W. 1987. Sea defences, Dutch guidelines on dike protection. Rijkswaterstaat, Dutch Ministry of Transport and Public Works, 1987. Road and Hydraulic Engineering Department, Report WBNO-87110, April 1987, Delft, The Netherlands with permission from K.W. Pilarczyk.

\section{Title: Roots of forest trees (Die Wurzeln der Waldbaume - German publication title)}

Author: Kostler, J .N., and E. Bruchner

Series/Source: Paul Parey Publisher, 1968. Hamburg and Berlin, pp. 1740

Peer-reviewed: N/A

Code: RTSTAB

Abstract*: The following introduction was written by J.N. Kostler: After taking over charge of the Institute of Forest Cultivation of the Forest Research Establishment of Munich, I became interested, to begin with, in the study of the problem of the roots of silver fir trees.

The taproots of forest trees showed at different places an unexpected driving force whereas minor root performance by them was reported. The second type of the tree was black alder whose root performance was conspicuous during the post-war afforestation period, particularly in hard soil. An intense drive in research took place from J anuary 1955 in the 
tertiary hillyland (about 40 miles north of Munich) and in a private scientific farm, directed by me since 1936. The lifted-up roots of a few thousand spruces and pine trees presented a surprising picture of the conditions of the forest land to the interested observers since their early youth. The stability attributed to the general planning of forest cultivation regarding pine trees in the habitat soil did not exist while some flat-rooted notorious spruce trees showed partly a deep-penetrating root system.

Objective(s): A great deal of books has been written on the trunks and crowns of trees, but the roots have relatively little in the way of understanding. This book is written to describe roots, present necessary background to study roots (digging, pertinent aspects), and use radioisotopes to understand plant functions. The objective is to be a guide and handbook for researchers to undertake the study of roots.

Study Location: Forests of Germany

Method: A compendium of known information and literature on roots supplemented with the knowledge and research of the authors.

Vegetation: Spruce (Picea abies Mill), Fir (Abies alba Mill), Pine (Pinus silvestris L.), Weymouth Pine (Pinus strobus L.), Larch (Larixdecidua Mill), J apanese Larch (Larix leptolepis Gord), Douglas Fir (Pseudotsuga taxifolia Brit), and other types of conifer trees and deciduous trees

\section{Soil Properties: N/A}

Observations/Results: In the foreword of the book, all the shortcomings have been clearly pointed out regarding our duty toward the roots of Central European forest trees. The reasons were shortly mentioned.

It is hoped that the book with a basic improvement would be published after a fewyears. In this sense, only a preliminary work is at hand. The reason for this idea is as follows:

1. Only a limited number of types of trees were taken into consideration.

2. The number of individual trees so far examined and analyzed is sufficient for general conclusion only for a few species.

3. All the trees on which research had been carried out were picked up from the economically grown forests.

4. All researches are directed to a single tree.

5. Almost all investigations fully carried out on our own and those utilized by us were limited to the morphology of the roots. 
6. In connection with the morphological consideration, attention has been mainly directed to the rough and coarse roots and thus the fine roots are necessarily described very briefly.

The list of books on the literature of the subject is quite rich with about 830 titles.

In spite of these failures, extensive bases for judgment of tree roots from foreign and even our own investigations can be put together which, offer for wider research a basis, for forest practice a guide for orientation, and for the students an introduction to the study of the present situation of the knowledge of tree roots.

Recommendations: Continue the study of tree roots.

* Permission to reprint abstract is granted by Blackwell Verlag $\mathrm{GmbH}$. 


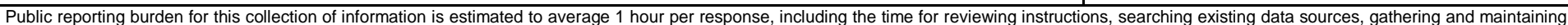

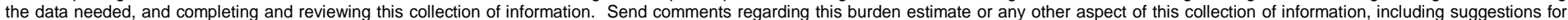

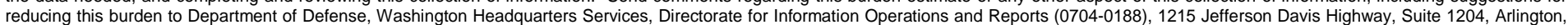

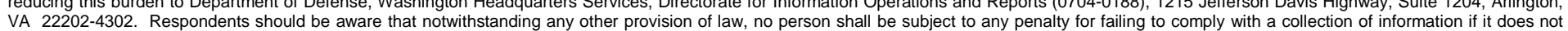
VA 22202-4302. Respondents should be aware that notwithstanding any other provision of law, no person shall be subs
display a currently valid OMB control number. PLEASE DO NOT RETURN YOUR FORM TO THE ABOVE ADDRESS.

\begin{tabular}{l|c}
$\begin{array}{l}\text { 1. REPORT DATE (DD-MM-YYYY) } \\
\text { December } 2010\end{array}$ & $\begin{array}{c}\text { 2. REPORT TYPE } \\
\text { Final report }\end{array}$ \\
\hline
\end{tabular}

4. TITLE AND SUBTITLE

Literature Review - Vegetation on Levees

3. DATES COVERED (From - To)

5a. CONTRACT NUMBER

5b. GRANT NUMBER

5c. PROGRAM ELEMENT NUMBER

6. AUTHOR(S)

Maureen K. Corcoran, Donald H. Gray, David S. Biedenharn, Charlie D. Little,

James R. Leech, Freddie Pinkard, Pamela Bailey, and Landris T. Lee

5d. PROJECT NUMBER

5e. TASK NUMBER

5f. WORK UNIT NUMBER

7. PERFORMING ORGANIZATION NAME(S) AND ADDRESS(ES)

8. PERFORMING ORGANIZATION REPORT NUMBER

U.S. Army Engineer Research and Development Center

Geotechnical and Structures Laboratory

ERDC SR-10-2

3909 Halls Ferry Road

Vicksburg, MS 39180-6199

9. SPONSORING I MONITORING AGENCY NAME(S) AND ADDRESS(ES)

10. SPONSOR/MONITOR'S ACRONYM(S)

Headquarters, U.S. Army Corps of Engineers

Washington, DC 20314-1000

11. SPONSOR/MONITOR'S REPORT NUMBER(S)

\section{DISTRIBUTION / AVAILABILITY STATEMENT}

Approved for public release; distribution is unlimited.

\section{SUPPLEMENTARY NOTES}

\section{ABSTRACT}

The U.S. Army Engineer Research and Development Center conducted an extensive literature review of topics related to vegetation on levees. An objective of this compilation was to better assess if woody vegetation compromises levee integrity. Other objectives were to identify data gaps within the compiled documents on the subject of studying the effects of woody vegetation on levees, and to use this information as a foundation for future research.

In this literature review, vegetation types were identified as woody (i.e., trees, bushes, and shrubbery) and non-woody (brush, shrubs, herbs, and grasses). Vegetation species differ in root system, trunk diameter, and growth pattern. Therefore, the vegetation species documented in the research publications were identified in this literature review. Understanding these differences and the interaction of each vegetation species with the levee soil structure is necessary for interpreting the effects of levee vegetation.

More than 200 documents were reviewed under the following categories: journal articles, federal and state government documents, books, newspaper/Internet articles, proceedings/briefings, reviews/annual reports/ workshops, dissertations/theses, and international guidance. Of these, 61 addressed some aspect of woody vegetation on levees. However, this number includes guidance documents and conference briefings. There are very few research publications that focus specifically on the complex interAction of woody vegetation and a soil matrix within an engineered levee.

\begin{tabular}{|c|c|c|c|c|c|}
\hline \multirow{3}{*}{\multicolumn{2}{|c|}{$\begin{array}{l}\text { 15. SUBJECT TERMS } \\
\text { International guidance on vegetation } \\
\text { Levee vegetation }\end{array}$}} & REMR & \multicolumn{3}{|c|}{ Trees on levees } \\
\hline & & Seepage & \multirow{2}{*}{\multicolumn{3}{|c|}{ USACE vegetation guidance }} \\
\hline & & Slope stability & & & \\
\hline \multicolumn{3}{|c|}{ 16. SECURITY CLASSIFICATION OF: } & $\begin{array}{l}\text { 17. LIMITATION } \\
\text { OF ABSTRACT }\end{array}$ & $\begin{array}{l}\text { 18. NUMBER } \\
\text { OF PAGES }\end{array}$ & $\begin{array}{l}\text { 19a. NAME OF RESPONSIBLE } \\
\text { PERSON }\end{array}$ \\
\hline $\begin{array}{l}\text { a. REPORT } \\
\text { UNCLASSIFIED }\end{array}$ & $\begin{array}{l}\text { b. ABSTRACT } \\
\text { UNCLASSIFIED }\end{array}$ & $\begin{array}{l}\text { c. } \text { THIS PAGE } \\
\text { UNCLASSIFIED }\end{array}$ & & 376 & $\begin{array}{l}\text { 19b. TELEPHONE NUMBER (include } \\
\text { area code) }\end{array}$ \\
\hline
\end{tabular}

